\title{
Estudo dos efeitos de estratégias de manipulação química e estrutural em catalisadores heterogêneos aplicados à hidrogenação de $\mathrm{CO}_{2}$ a metanol
}

Tese apresentada ao Instituto de Química de São Carlos, da Universidade de São Paulo, como parte dos requisitos para a obtenção do título de doutor em ciências

Área de Concentração: Físico-Química

Orientadora: Profa. Dra. Elisabete M. Assaf

São Carlos

2020 
Dedicado à Vó Dinha, Vó Ione, Vô Nelson e Vô Onofre Muito obrigado por tanto, por tudo! Estejam com Deus e Nossa Senhora! Até um dia... Com amor, 


\section{AGRADECIMENTOS}

Gostaria de agradecer à professora Elisabete Assaf pela oportunidade de fazer parte do grupo de pesquisa, por toda a orientação e conselhos ao longo dessa etapa.

Agradeço à Fundação de Amparo à Pesquisa do Estado de São Paulo (FAPESP) por tornar possível que eu realizasse o doutorado por meio da concessão de bolsa e financiamento do meu projeto, com número de processo FAPESP: 2017/10154-6.

Ao Conselho Nacional de Desenvolvimento Científico e Tecnológico (CNPq) pelo financiamento dos meus primeiros cinco meses do doutorado (Número de Processo 140391/2017-7).

À Universidade de São Paulo, em especial ao Instituto de Química de São Carlos por toda a estrutura de excelência concedida e pelas inúmeras oportunidades acadêmicas que certamente foram inestimáveis à minha formação.

Aos funcionários do Instituto de Química de São Carlos da Universidade de São Paulo por toda sua dedicação e solicitude em auxiliar, muitas vezes além do que seria a função de cada um. Em especial, ao Marcelo e ao Luiz pela amizade e boas conversas que ultrapassaram os assuntos profissionais. À Daniele, Gislei e Érica por toda a disponibilidade sempre imediata em ajudar nas incontáveis vezes em que tive dúvidas com os procedimentos burocráticos. Ao Alex e ao Ednelson pela paciência e prontidão com os importunos quase diários causados pelos nossos reatores.

Por fim, eu confesso que havia pensado em agradecer àqueles que foram fundamentais, não somente para a concretização do doutorado, mas para a construção dos meus muitos momentos felicidade e por tudo de bom que possa haver em mim.

Contudo, depois de horas tentando encontrar o texto ideal, percebi que simplesmente não seria possível registrar toda a minha gratidão e o quanto eu devo a vocês em palavras.

Portanto, aos meus avós Dinha, Ione, Nelson e Onofre, aos meus pais Nelson e Hélia, ao meu irmão Fernando, aos meus tios Edson, Edvaldo, Elisângela, Evaldo, José, Mônica, Raquel, Rosa, Sebastião e Valdinéia, aos meus primos Bruno, Camila, Kauan, Mateus, Michele, Miria, Miriane, Rafael, Rodrigo, Vitória e Zelinha e aos meus amigos Adriana Maneira, Alisson Marques, André Salgado, Bruno Rodrigues, Bruno Carvalho, Caroline Cambraia, Cássia Santana, Cássio Lima, Dorotéia dos Anjos, Eliane Campadeli, Elton Francisquini, Felipe Dias, Felipe Ribeiro, Felipe Vilela, Flávio Souza, Guilherme Mattos, Gabriela Ferreira, Grasiele 
Morais, Iara Guimarães, Kassiana Magalhães, Lara Murad, Larissa Lopes, Leandro Luz, Letícia Rasteiro, Luiz Vieira, Marcos Carvalho, Mozarte Santana, Pamelly Leal, Paulo Mendonça, Ricardo Lello, Rodrigo Bernardo, Rangel Shida, João Lucas, Renan Shida, Ronan Carvalho, Ronaldo Mendonça, Ronnie Shida, Rosembergue Gonçalvez, Rosyan Carvalho, Tadeu Silva, Thiago Andrade, Vinícius Avayou, Vivian Thyssen e William Borges apenas me resta assumir o compromisso de tentar ser uma pessoa melhor a cada dia, de tentar me corrigir a cada dia para, ao menos, tentar ser merecedor do privilégio que é/foi conviver e aprender com cada um de vocês.

Mesmo acreditando que, por mais que eu possa progredir, sempre estarei em débito com Deus por permitir que nossos caminhos se cruzassem ao longo da caminhada, pela providência divina que me concedeu o benefício de aprender e encontrar alegria, por meio do exemplo de cada um.

Vocês são luz que me guia. 
"Vocês são a luz do mundo"

Jesus Cristo

"Seja a mudança que você quer ver no mundo." Mahatma Gandhi 


\section{RESUMO}

Atualmente, fatores como o crescimento populacional, o uso indiscriminado da água e a contaminação de suas fontes e reservatórios levam à necessidade de ações que promovam o manejo sustentável desse recurso através do uso consciente, do tratamento e da sua reutilização. Apesar da alta eficiência dos sistemas de tratamento moderno, alguns aspectos ainda podem ser melhorados como a destinação adequada do $\mathrm{CO}_{2}$ gerado na etapa de degradação anaeróbia de contaminantes orgânicos, uma vez que este é o principal gás causador do efeito-estufa, cujas altas concentrações atmosféricas têm levado a mudanças climáticas significativas. Dentre as possibilidades para esse fim, uma das estratégias mais promissoras envolve a conversão desse composto em moléculas de alto valor agregado, como o metanol, através de reações de hidrogenação por meio do uso de catalisadores heterogêneos. Neste contexto, o presente trabalho tem como objetivo a aplicação de estratégias de manipulação da natureza química e estrutural de catalisadores baseados em cobre e zircônia ou céria buscando melhorias no desempenho catalítico por eles apresentados. Na primeira etapa, foram estudados os efeitos da modificação destes materiais com átomos de índio. Como resultado, foi verificado um aumento considerável na seletividade ao metanol devido a atuação dos átomos de índio sobre as energias de adsorção de certas moléculas e de ativação para etapas específicas de hidrogenação de intermediários que são, em geral, muito altas inviabilizando a produção do metanol. Além disso, a maior basicidade desses materiais devido a vacâncias de átomos de oxigênio se mostrou também importante. Na segunda etapa, foram estudados os efeitos da estratégia de encapsulamento dos catalisadores por revestimento poroso de sílica. Foi observado que os materiais do tipo "core-shell" apresentaram desempenho notavelmente superior aos demais catalisadores em virtude da eficiência dos revestimentos de sílica em minimizar a sinterização das partículas durante as etapas de tratamento térmico e etapas reacionais ocorrentes em temperaturas elevadas. Além dos efeitos advindos da presença de átomos de índio, as pequenas dimensões e alta homogeneidade das partículas obtidas possibilitaram uma maior basicidade que se refletiu em alta seletividade ao metanol mesmo nas maiores temperaturas. Além disso, a alta dispersão e área metálica das partículas de cobre levaram a maiores conversões que resultaram em valores significativos de produtividade ao metanol em todas as faixas de temperatura testadas. 


\section{ABSTRACT}

Nowadays, factors such as population growth, indiscriminate use of water, and contamination of its sources and reservoirs created a need for actions capable of promoting sustainable management of this resource through the conscious use, treatment, and reuse of this resource. Despite the high efficiency of modern treatment systems, some aspects can still be improved, such as the proper destination of the $\mathrm{CO}_{2}$ molecules generated in the anaerobic decomposition stage of organic contaminants, considering that this is the main greenhouse gas whose high concentrations in the atmosphere have led to the recent climate issues. Among the possibilities for this purpose, one of the most promising strategies involves the conversion of this compound into molecules of high added value, such as methanol through hydrogenation reactions through the use of heterogeneous catalysts. In this context, the present work aims to apply strategies for manipulating the chemical and structural nature of catalysts based on copper and zirconia or ceria, in an attempt to achieve considerable improvements in the catalytic performance presented by them. In the first stage, the effects of modifying these materials with indium atoms were studied. As a result, it was found that a considerable increase in methanol selectivity occurred due to indium atoms effects involving changes in the intermediate adsorption and activation energy for specific stages of hydrogenation that are, in general, very high, hindering methanol production. Also, the greater basicity of these materials due to oxygen vacancies was important. In the second stage, the effects of the catalysts encapsulation by porous silica coating were studied. It was observed that the core-shell type materials presented a performance remarkably superior to the other catalysts due to the efficiency of the silica coating in minimizing particles sintering during the heat treatment steps in the synthesis procedure and in reaction steps occurring at high temperatures. In addition to the effects arising from the indium atoms presence, the low dimensions and high homogeneity of the particles obtained enabled considerable values of basicity which have led to high selectivity values for methanol. Also, the high copper dispersion and metallic area values have led to higher $\mathrm{CO}_{2}$ conversion, which associated to the high methanol selectivity, resulted in significant molar productivity for methanol in all tested temperature ranges. 


\section{LISTA DE FIGURAS}

Figura 1. Difração de raios $\mathrm{X}$ para os catalisadores pertencentes aos grupos $\mathrm{Cu} / \mathrm{ZrO}_{2}-\mathrm{X} \% \mathrm{In}$ e $\mathrm{Cu} / \mathrm{CeO}_{2}-\mathrm{X} \% \mathrm{In}$.

Figura 2. Refinamento de Rietveld aplicado aos materiais $\mathrm{Cu} / \mathrm{CeO} 2, \mathrm{Cu} / \mathrm{CeO}_{2}-5 \% \mathrm{In}$ e $\mathrm{Cu} / \mathrm{CeO}_{2}-$ $10 \%$ In após calcinação em $873 \mathrm{~K}$ por $2 \mathrm{~h}$

Figura 3. Microscopia eletrônica de transmissão acoplada a espectroscopia de energia dispersiva de raios $\mathrm{X}$ para os materiais $\mathrm{Cu} / \mathrm{ZrO}_{2}-\mathrm{XIn}$.

Figura 4. Microscopia eletrônica de transmissão acoplada a espectroscopia de energia dispersiva de raios $\mathrm{X}$ para os materiais $\mathrm{Cu} / \mathrm{CeO}_{2}-\mathrm{XIn}$.

Figura 5. Redução à temperatura programada para os grupos de catalisadores $\mathrm{Cu} / \mathrm{ZrO}_{2}-\mathrm{XIn} \mathrm{e}$ $\mathrm{Cu} / \mathrm{CeO}_{2} \mathrm{XIn}$.

Figura 6. Cinética de redução do óxido de cobre para os catalisadores pertencentes aos grupos $\mathrm{Cu} / \mathrm{ZrO}_{2}$-XIn e $\mathrm{Cu} / \mathrm{CeO}_{2}$-XIn.

Figura 7. Isotermas de fisissorção de $\mathrm{N}_{2}$ para os materiais dos grupos $\mathrm{Cu} / \mathrm{ZrO}_{2}-\mathrm{XIn}$ e $\mathrm{Cu} / \mathrm{CeO}_{2}-$ XIn.

Figura 8. Distribuição de tamanho de poros para os materiais dos grupos $\mathrm{Cu} / \mathrm{ZrO}_{2}$ - $\mathrm{XIn}$ e $\mathrm{Cu} / \mathrm{CeO}_{2}$-XIn obtidas por fisissorção de $\mathrm{N}_{2}$.

Figura 9. Espectro de fotoelétrons de Raios X correspondentes às emissões do subnível 3d dos átomos de zircônio e índio presentes nos catalisadores do grupo $\mathrm{Cu} / \mathrm{ZrO}_{2}-\mathrm{XIn}$.

Figura 10. Espectro de fotoelétrons de Raios X correspondentes às emissões do subnível 3d dos átomos de cério e índio presentes nos catalisadores do grupo $\mathrm{Cu} / \mathrm{CeO}_{2}-\mathrm{XIn}$.

Figura 11. Conversão e seletividade aos principais produtos obtidos da hidrogenação do $\mathrm{CO}_{2}$ utilizando os materiais pertencentes aos grupos $\mathrm{Cu} / \mathrm{ZrO}_{2}-\mathrm{XIn}$ e $\mathrm{Cu} / \mathrm{CeO}_{2}-\mathrm{XIn}$, sob as condições de pressão, temperatura e velocidade espacial iguais a $3 \mathrm{MPa}, 473 \mathrm{~K}$ e $6 \mathrm{~L} \cdot \mathrm{h}^{-1} \cdot \mathrm{g}^{-1}$.

Figura 12. Rotas mecanísticas pelas quais moléculas de metanol podem ser obtidas a partir de reações de hidrogenação do dióxido de carbono. Os asteriscos representam espécies adsorvidas. 
Figura 13. Frequência de Turnover e produtividade molar de $\mathrm{CH}_{3} \mathrm{OH}$ e $\mathrm{CO}$ utilizando os catalisadores pertencentes aos grupos $\mathrm{Cu} / \mathrm{ZrO}_{2}-\mathrm{XIn}$ e $\mathrm{Cu} / \mathrm{CeO}_{2}-\mathrm{XIn}$ sob as condições de $3 \mathrm{MPa}$, $473 \mathrm{~K}$ e $6 \mathrm{~L}^{-\mathrm{g}^{-1}} \cdot \mathrm{h}^{-1}$.

Figura 14. Diferenças na seletividade a $\mathrm{CH}_{3} \mathrm{OH}$ e $\mathrm{CO}$ entre os catalisadores promovidos com índio e os catalisadores $\mathrm{Cu} / \mathrm{ZrO}_{2}$ e Cu/CeO 2 não modificados. Condições reacionais: $3 \mathrm{MPa}, 473$ $\mathrm{K}$ e $6 \mathrm{~L} \cdot \mathrm{h}^{-1} \cdot \mathrm{g}^{-1}$

Figura 15. Gráfico de Pareto com a significância do efeito principal causado pela variação dos valores de pressão, temperatura e velocidade espacial sobre a seletividade ao metanol assim como os efeitos de interação entre as elas utilizando o catalisador $\mathrm{Cu} / \mathrm{ZrO}_{2}-5 \% \mathrm{In}$. A análise foi realizada com $95 \%$ de confiabilidade estatística. 78

Figura 16. Superfícies de resposta contendo a seletividade ao metanol para diferentes combinações das variáveis pressão, temperatura e velocidade espacial, utilizando o catalisador $\mathrm{Cu} / \mathrm{ZrO}_{2}-5 \%$ In.

Figura 17. Conversão de $\mathrm{CO}_{2}$ e seletividade aos produtos obtidos para os catalisadores $\mathrm{Cu} / \mathrm{ZrO}_{2}$ e $\mathrm{Cu} / \mathrm{ZrO}_{2}-5 \% \mathrm{In}$ sob as condições de $3 \mathrm{MPa}, 456 \mathrm{~K}$ e $14 \mathrm{~L} \cdot \mathrm{g}^{-1} \cdot \mathrm{h}^{-1}$.

Figura 18. Gráfico de Pareto com a significância do efeito principal causado pela variação dos valores de pressão, temperatura e velocidade espacial sobre a seletividade ao metanol assim como os efeitos de interação entre as elas utilizando o catalisador $\mathrm{Cu} / \mathrm{CeO}_{2}-5 \% \mathrm{In}$. A análise foi realizada com $95 \%$ de confiabilidade estatística. 85

Figura 19. Superfícies de resposta contendo a seletividade ao metanol para diferentes combinações das variáveis pressão, temperatura e velocidade espacial, utilizando o catalisador $\mathrm{Cu} / \mathrm{CeO}_{2}-5 \% \mathrm{In}$ 88

Figura 20. Conversão de $\mathrm{CO}_{2}$ e seletividade aos produtos obtidos para os catalisadores $\mathrm{Cu} / \mathrm{CeO}_{2}$ e $\mathrm{Cu} / \mathrm{CeO}_{2}-5 \%$ In sob as condições de $3 \mathrm{MPa}, 456 \mathrm{~K}$ e $14 \mathrm{~L} \cdot \mathrm{g}^{-1} \cdot \mathrm{h}^{-1}$. 89

Figura 21. Gráfico de Arrhenius para o cálculo da energia de ativação para $\mathrm{CH}_{3} \mathrm{OH}$ e $\mathrm{CO}$ utilizando os catalisadores $\mathrm{Cu} / \mathrm{ZrO}_{2}-5 \% \mathrm{In}$ e $\mathrm{Cu} / \mathrm{CeO}_{2}-5 \% \mathrm{In}$. 90

Figura 22. Difratogramas de raios X para os materiais CuZrIn-cs e CuCeIn-cs 92

Figura 23. Microscopia eletrônica de transmissão e distribuição do tamanho de partículas que formam os núcleos dos catalisadores CuZrIn-cs e CuCeIn-cs. 
Figura 24. Isotermas de fisissorção de $\mathrm{N}_{2}$ para os catalisadores CuZrIn-cs e CuCeIn-cs.

Figura 25. Redução à temperatura programada dos catalisadores CuZrIn-cs e CuCeIn-cs utilizando $\mathrm{H}_{2}$ como gás redutor. . .96

Figura 26. Desempenho catalítico dos catalisadores CuZrIn-cs e CuCeIn-cs sob pressão = 3 $\mathrm{MPa}$ e GHSV $=6 \mathrm{~L} \cdot \mathrm{h}^{-1} \cdot \mathrm{g}^{-1}$ 101

Figura 27. Frequência de Turnover utilizando os catalisadores $\mathrm{Cu} / \mathrm{ZrO}_{2}-5 \% \mathrm{In}, \mathrm{Cu} / \mathrm{CeO}_{2}-5 \% \mathrm{In}$, CuZrIn-cs e CuCeIn-cs sob as condições de $3 \mathrm{MPa}, 473 \mathrm{~K}$ e $6 \mathrm{~L} \cdot \mathrm{g}^{-1} \cdot \mathrm{h}^{-1}$. 102

Figura 28. Produtividade molar dos principais produtos obtidos utilizando os catalisadores $\mathrm{Cu} / \mathrm{ZrO}_{2}-5 \% \mathrm{In}, \mathrm{Cu} / \mathrm{CeO}_{2}-5 \% \mathrm{In}, \mathrm{CuZrIn}-\mathrm{cs}$ e $\mathrm{CuCeIn}$-cs em diferentes temperaturas mantendose a pressão e velocidade espacial constantes em $3 \mathrm{MPa}, 6 \mathrm{~L} \cdot \mathrm{g}^{-1} \cdot \mathrm{h}^{-1}$. 103

Figura 29. Diferenças na produtividade molar de $\mathrm{CH}_{3} \mathrm{OH}$ e $\mathrm{CO}$ entre os catalisadores core-shell $\mathrm{CuZrIn}$-cs e $\mathrm{CuCeIn}$-cs e os materiais $\mathrm{Cu} / \mathrm{ZrO}_{2}-5 \% \mathrm{In}$ e $\mathrm{Cu} / \mathrm{CeO}_{2}-5 \%$ In. Condições reacionais: $3 \mathrm{MPa}, 543 \mathrm{~K}$ e $6 \mathrm{~L} \cdot \mathrm{h}^{-1} \cdot \mathrm{g}^{-1}$.

Figura 30. Gráfico de Pareto com a significância do efeito principal causado pela variação dos valores de pressão, temperatura e velocidade espacial sobre a seletividade ao metanol assim como os efeitos de interação entre as elas utilizando o catalisador CuZrIn-cs. A análise foi realizada com $95 \%$ de confiabilidade estatística. 107

Figura 31. Superfícies de resposta contendo a seletividade ao metanol para diferentes combinações das variáveis pressão, temperatura e velocidade espacial, utilizando o catalisador CuZrIn-cs. 110

Figura 32. Gráfico de Pareto com a significância do efeito principal causado pela variação dos valores de pressão, temperatura e velocidade espacial sobre a seletividade ao metanol assim como os efeitos de interação entre as elas utilizando o catalisador CuCeIn-cs. A análise foi realizada com $95 \%$ de confiabilidade estatística.

Figura 33. Superfícies de resposta contendo a seletividade ao metanol para diferentes combinações das variáveis pressão, temperatura e velocidade espacial, utilizando o catalisador CuCeIn-cs. 115

Figura 34. Gráficos de Arrhenius para a produção de $\mathrm{CH}_{3} \mathrm{OH}$ e $\mathrm{CO}$ utilizando os catalisadores $\mathrm{Cu} / \mathrm{ZrO}_{2}-5 \% \mathrm{In}, \mathrm{Cu} / \mathrm{CeO}_{2}-5 \% \mathrm{In}, \mathrm{CuZrIn}-\mathrm{cs}$ e CuCeIn-cs. 


\section{LISTA DE TABELAS}

Tabela 1. Quantidades molares dos sais precursores adicionados em $250 \mathrm{~mL}$ de água destilada na síntese dos catalisadores pertencentes aos grupos $\mathrm{Cu} / \mathrm{ZrO}_{2}-\mathrm{X} \% \mathrm{In}$ e $\mathrm{Cu} / \mathrm{CeO}_{2}-\mathrm{X} \% \mathrm{In}$........35

Tabela 2. Valores definidos para os pontos mínimos, máximos, médios, axiais mínimos e axiais máximos dos parâmetros de pressão, temperatura e velocidade espacial.

Tabela 3. Matriz de experimentos definidos pela metodologia de planejamento experimental do tipo Compósito Central a partir de combinações entre pontos mínimos, máximos, médios e axiais de cada parâmetro.

Tabela 4. Volume de célula unitária e parâmetro de rede (a) para a estrutura da céria calculados através do Refinamento de Rietveld e fatores Rwp e GOF de qualidade do ajuste.

Tabela 5. Composição elementar em porcentagem molar para os catalisadores dos grupos $\mathrm{Cu} / \mathrm{ZrO}_{2}$-XIn e $\mathrm{Cu} / \mathrm{CeO}_{2}$-XIn calculadas por espectroscopia de fluorescência de raios X......51

Tabela 6. Área específica de superfície e perfil de porosidade dos grupos de catalisadores $\mathrm{Cu} / \mathrm{ZrO}_{2}-\mathrm{XIn}$ e $\mathrm{Cu} / \mathrm{CeO}_{2}$-XIn calculado por fisissorção de $\mathrm{N}_{2}$.

Tabela 7. Propriedades químicas e texturais dos materiais pertencentes aos grupos $\mathrm{Cu} / \mathrm{ZrO}_{2}-$

$\mathrm{XIn}$ e $\mathrm{Cu} / \mathrm{ZrO}_{2}-\mathrm{XIn}$.

Tabela 8. Composição elementar de superfície e razão molar mensuradas por espectroscopia fotoeletrônica de Raios $\mathrm{X}$ dos materiais pertencentes aos grupos $\mathrm{Cu} / \mathrm{ZrO}_{2}-\mathrm{XIn}$ e $\mathrm{Cu} / \mathrm{ZrO} 2-\mathrm{XIn}$.

Tabela 9. Energia de ligação dos elétrons presentes na componente $3 \mathrm{~d}^{5 / 2}$ ao núcleo dos átomos de zircônio, cério e índio para os catalisadores pertencentes aos grupos $\mathrm{Cu} / \mathrm{ZrO}_{2}-\mathrm{XIn}$ e $\mathrm{Cu} / \mathrm{CeO}_{2}$-XIn.

Tabela 10. Desempenho catalítico dos materiais pertencentes aos grupos $\mathrm{Cu} / \mathrm{ZrO} 2-\mathrm{XIn}$ e $\mathrm{Cu} / \mathrm{CeO}_{2}$-XIn aplicados à hidrogenação do $\mathrm{CO}_{2}$

Tabela 11. Frequência de Turnover e produtividade molar de $\mathrm{CH}_{3} \mathrm{OH}$ e $\mathrm{CO}$ utilizando os catalisadores pertencentes aos grupos $\mathrm{Cu} / \mathrm{ZrO}_{2}-\mathrm{XIn}$ e $\mathrm{Cu} / \mathrm{CeO}_{2}-\mathrm{XIn}$ sob as condições de $3 \mathrm{MPa}, 473 \mathrm{~K}$ e $6 \mathrm{~L} \cdot \mathrm{g}^{-1} \cdot \mathrm{h}^{-1}$ 
Tabela 12. Matriz experimental gerada pelo planejamento estatístico do tipo compósito central com diferentes condições de pressão $(\mathrm{P})$, temperatura $(\mathrm{T})$ e velocidade espacial $\left(\mathrm{L}^{-1} \cdot \mathrm{g}^{-}\right.$ ${ }^{1} \cdot \mathrm{h}^{-1}$ ) e resultados de conversão (XCO2) e seletividade (S) utilizando o catalisador $\mathrm{Cu} / \mathrm{ZrO}_{2}-$ $5 \%$ In.

Tabela 13. Efeitos principais causados pela alteração de pressão, temperatura e velocidade espacial sobre a seletividade ao metanol e efeitos de interação entre essas variáveis utilizando o catalisador $\mathrm{Cu} / \mathrm{ZrO}_{2}-5 \% \mathrm{In}$.

Tabela 14. Análise de variância (ANOVA) para o modelo quadrático puro utilizando o catalisador $\mathrm{Cu} / \mathrm{ZrO}_{2}-5 \%$ In e as respostas do planejamento tipo compósito central.

Tabela 15. Conversão de $\mathrm{CO}_{2}\left(\mathrm{X}_{\mathrm{CO} 2}\right)$ e seletividade(S) aos produtos obtidos para os catalisadores $\mathrm{Cu} / \mathrm{ZrO}_{2}$ e $\mathrm{Cu} / \mathrm{ZrO}_{2}-5 \% \mathrm{In}$ sob as condições de $3 \mathrm{MPa}, 456 \mathrm{~K}$ e $14 \mathrm{~L} \cdot \mathrm{g}^{-1} \cdot \mathrm{h}^{-1}$.

Tabela 16. Matriz experimental gerada pelo planejamento estatístico do tipo compósito central com diferentes condições de pressão $(\mathrm{P})$, temperatura $(\mathrm{T})$ e velocidade espacial $\left(\mathrm{L}^{-1} \cdot \mathrm{g}^{-}\right.$ ${ }^{1} \cdot \mathrm{h}^{-1}$ ) e resultados de conversão $\left(\mathrm{X}_{\mathrm{CO} 2}\right.$ ) e seletividade $(\mathrm{S})$ utilizando o catalisador $\mathrm{Cu} / \mathrm{CeO}_{2}$ $5 \%$ In.

Tabela 17. Efeitos principais causados pela alteração de pressão, temperatura e velocidade espacial sobre a seletividade ao metanol e efeitos de interação entre essas variáveis utilizando o catalisador $\mathrm{Cu} / \mathrm{CeO}_{2}-5 \% \mathrm{In}$.

Tabela 18. Análise de variância (ANOVA) para o modelo quadrático utilizando o catalisador $\mathrm{Cu} / \mathrm{CeO}_{2}-5 \%$ In e as respostas do planejamento tipo compósito central.

Tabela 19. Conversão de $\mathrm{CO}_{2}\left(\mathrm{X}_{\mathrm{CO} 2}\right)$ e seletividade(S) aos produtos obtidos para os catalisadores $\mathrm{Cu} / \mathrm{CeO}_{2}$ e $\mathrm{Cu} / \mathrm{CeO}_{2}-5 \%$ In sob as condições de $3 \mathrm{MPa}, 456 \mathrm{~K}$ e $14 \mathrm{~L} \mathrm{~g}^{-1} \cdot \mathrm{h}^{-1}$.

Tabela 20. Composição elementar dos materiais CuZrIn-cs e CuCeIn-cs analisadas por espectroscopia de fluorescência de raios X.

Tabela 21. Áreas específicas de superfície e distribuição de volumes de poros obtidas por fisissorção de $\mathrm{N}_{2}$ para os catalisadores CuZrIn-cs e CuCeIn-cs.

Tabela 22. Área metálica de superfície e basicidade para os materiais CuZrIn-cs, CuZrIn-i, 
Tabela 23. Desempenho catalítico dos catalisadores CuZrIn-cs e CuCeIn-cs sob pressão $=3$ $\mathrm{MPa}$ e GHSV $=6 \mathrm{~L} \cdot \mathrm{h}^{-1} \cdot \mathrm{g}^{-1}$

Tabela 24. Frequência de Turnover e produtividade molar de $\mathrm{CH}_{3} \mathrm{OH}$ e $\mathrm{CO}$ utilizando os catalisadores CuZrIn-cs e CuCeIn-cs sob as condições de 3MPa, $473 \mathrm{~K}$ e 6 L.g $\mathrm{g}^{-1} \cdot \mathrm{h}^{-1}$.

Tabela 25. Matriz experimental gerada pelo planejamento estatístico do tipo compósito central com diferentes condições de pressão $(\mathrm{P})$, temperatura $(\mathrm{T})$ e velocidade espacial $\left(\mathrm{L}^{-1} \cdot \mathrm{g}^{-}\right.$ ${ }^{1} \cdot \mathrm{h}^{-1}$ ) e resultados de conversão ( $\mathrm{X}_{\mathrm{CO} 2}$ ) e seletividade (S) utilizando o catalisador CuZrIn-cs

Tabela 26. Efeitos principais causados pela alteração de pressão, temperatura e velocidade espacial sobre a seletividade ao metanol e efeitos de interação entre essas variáveis utilizando o catalisador CuZrIn-cs.

Tabela 27. Análise de variância (ANOVA) para o modelo quadrático utilizando o catalisador CuZrIn-cs e as respostas do planejamento tipo compósito central.

Tabela 28. Matriz experimental gerada pelo planejamento estatístico do tipo compósito central com diferentes condições de pressão $(\mathrm{P})$, temperatura $(\mathrm{T})$ e velocidade espacial $\left(\mathrm{L}^{-1} \cdot \mathrm{g}^{-}\right.$ ${ }^{1} \cdot \mathrm{h}^{-1}$ ) e resultados de conversão (XC2) e seletividade (S) utilizando o catalisador CuCeIn-cs.

Tabela 29. Efeitos principais causados pela alteração de pressão, temperatura e velocidade espacial sobre a seletividade ao metanol e efeitos de interação entre essas variáveis utilizando o catalisador CuCeIn-cs.

Tabela 30. Análise de variância (ANOVA) para o modelo quadrático utilizando o catalisador $\mathrm{CuCeIn-cs} \mathrm{e} \mathrm{as} \mathrm{respostas} \mathrm{do} \mathrm{planejamento} \mathrm{tipo} \mathrm{compósito} \mathrm{central.}$ 


\section{SUMÁRIO}

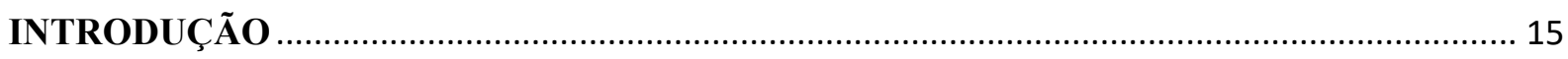

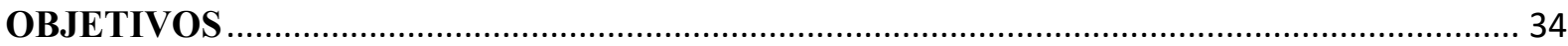

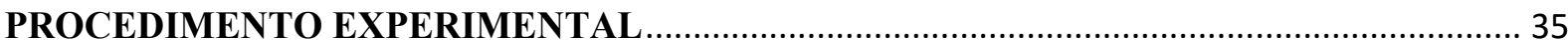

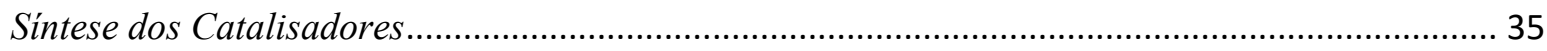

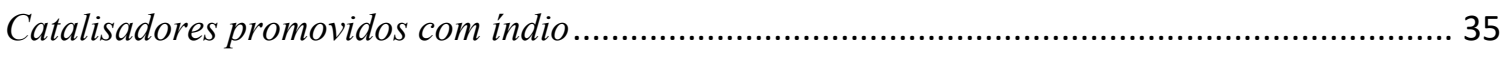

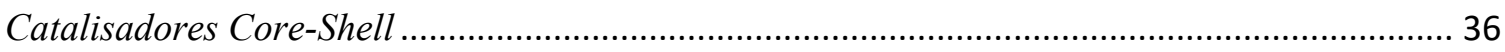

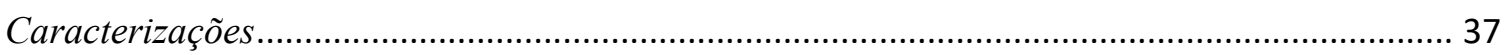

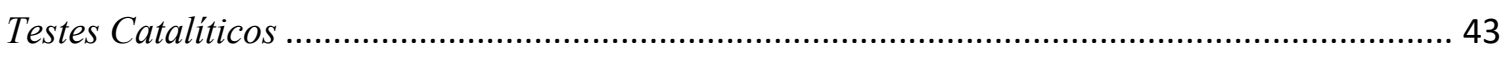

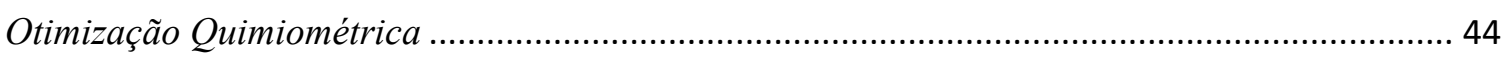

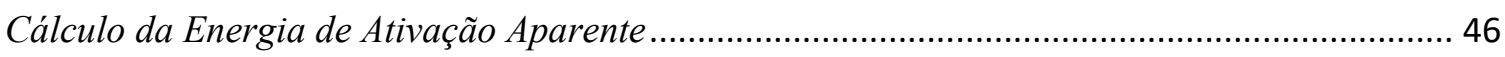

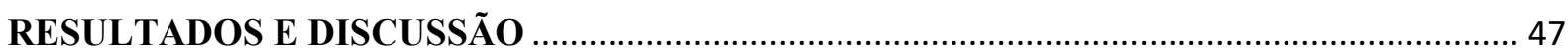

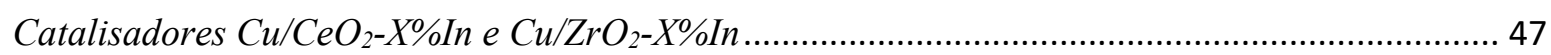

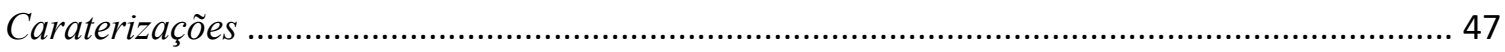

Desempenho Catalítico dos catalisadores $\mathrm{Cu} / \mathrm{ZrO}_{2}-\mathrm{X} \% \mathrm{In}$ e $\mathrm{Cu} / \mathrm{CeO}_{2}-\mathrm{X} \% \mathrm{In}$.................................. 65

Otimização Quimiométrica dos catalisadores $\mathrm{Cu} / \mathrm{ZrO}_{2}-\mathrm{X} \% \mathrm{In}$ e $\mathrm{Cu} / \mathrm{CeO}_{2}-\mathrm{X} \% \mathrm{In}$............................ 76

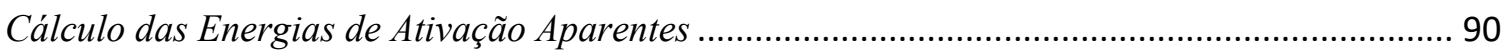

Catalisadores Core-Shell CuZrIn-cs e CuCeIn-cs ...................................................................... 91

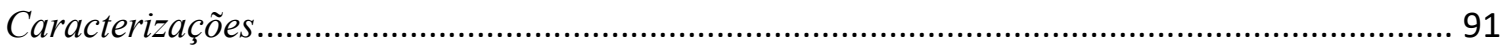

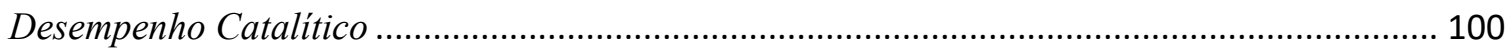

Otimização Quimiométrica dos Catalisadores CuZrIn-cs e CuCeIn-cs ...................................... 105

Cálculo das Energias de Ativação Aparentes ........................................................................ 116

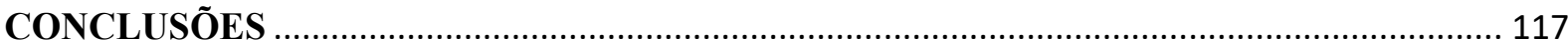

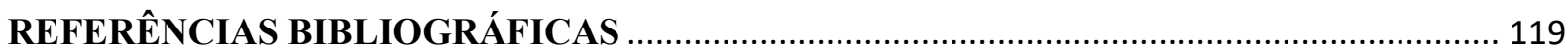




\section{INTRODUÇÃO}

Atualmente, o expressivo crescimento populacional, a contaminação desenfreada dos corpos d'água e a ocorrência de secas cada vez mais severas e duradouras em muitas regiões do planeta que levam à consequente competição acerca do uso dos recursos hídricos disponíveis têm ameaçado a viabilidade do modelo vigente de utilização das fontes de água ao redor do mundo (DIMITRIOU et al., 2015; KAVVADA et al., 2016).

Diante disso, alternativas de manejo sustentável através de ações que envolvam economia e reuso da água ganham destaque. Nesse âmbito, o avanço nas técnicas de tratamento de águas residuárias e esgoto tem importância inegável (DIMITRIOU et al., 2015; KAVVADA et al., 2016).

No entanto, apesar da alta eficiência dos sistemas de tratamento de efluentes atuais, alguns aspectos ainda podem ser ajustados na busca por um processo que, em geral, seja mais alinhado aos princípios de sustentabilidade norteadores da sociedade atual (DIMITRIOU et al., 2015; THOMAS, J. M., 2014).

Dentre esses aspectos, tem-se o exemplo dos processos oxidativos de mineralização da matéria orgânica presente nos efluentes em tratamento que leva a formação de quantidades consideráveis do chamado "biogás", uma mistura de gases contendo, principalmente, $\mathrm{CO}_{2} \mathrm{e}$ $\mathrm{CH}_{4}$, sendo esses os principais gases estufa cujas altas concentrações atmosféricas têm levado a alterações climáticas (DIMITRIOU et al., 2015; KAVVADA et al., 2016; MARAGKAKI et al., 2017; THOMAS, J. M., 2014).

Assim, torna-se crucial que destinações apropriadas, do ponto de vista ambiental e econômico, sejam conferidas aos componentes do biogás gerado a partir de estratégias de captura e utilização que minimizem sua emissão à atmosfera (DIMITRIOU et al., 2015; KAVVADA et al., 2016; MARAGKAKI et al., 2017; THOMAS, J. M., 2014).

No que se refere especificamente ao $\mathrm{CO}_{2}$ advindo do biogás, Wang et al. (2011) e Porosoff et al. (2015) destacaram a necessidade por estratégias eficientes para diminuição da concentração desse poluente na atmosfera através de três práticas principais, sendo elas: a redução das emissões, as técnicas de sequestro e aprisionamento de $\mathrm{CO}_{2}$ e a conversão catalítica de $\mathrm{CO}_{2}$ em produtos de alta demanda e valor agregado (POROSOFF; YAN; CHEN, 2015; WANG, WEI et al., 2011).

Dentre tais técnicas, um grande destaque tem sido dado a pesquisas relacionadas à conversão catalítica de $\mathrm{CO}_{2}$. É relatado que, de modo geral, os estudos de conversão de $\mathrm{CO}_{2}$ 
envolvem duas vias principais mais promissoras: a redução eletroquímica e a redução térmica, realizada por hidrogenação das moléculas de $\mathrm{CO}_{2}$, sendo, essa última, o foco das investigações do presente estudo (POROSOFF; YAN; CHEN, 2015).

Vale ressaltar que a utilização do $\mathrm{CO}_{2}$ como precursor na síntese de diferentes compostos ainda é dificultada em virtude, principalmente, da grande estabilidade termodinâmica do dióxido de carbono (WANG, WEI et al., 2011).

Se por um lado isso se mostra um desafio, por outro acaba por evidenciar as muitas possibilidades de avanço e aprimoramentos que ainda podem ser buscadas nessa área de estudo em particular, especialmente no que diz respeito ao desenvolvimento de novos catalisadores que permitam melhorias nas taxas de conversão e seletividade dos processos (POROSOFF; YAN; CHEN, 2015; WANG, WEI et al., 2011).

A quantidade de moléculas com alto valor agregado que pode ser obtida através da hidrogenação do $\mathrm{CO}_{2}$ é bem vasta contando com variados grupos de compostos como hidrocarbonetos, álcoois, éteres, ácidos carboxílicos e amidas (WANG, WEI et al., 2011).

Dentre estes, o metanol se apresenta com grande destaque, o que pode ser atestado por sua alta demanda anual que gira em torno de milhões de toneladas e, principalmente, pelas suas versáteis possibilidades de aplicação (FIORDALISO et al., 2015).

Especificamente, o metanol pode ser descrito como um líquido primário de importância considerável nas indústrias de síntese de compostos e do setor energético. Atualmente, esse composto é muito utilizado como solvente e como estrutura precursora na produção de compostos importantes para indústrias de vários setores como formaldeído, ácido acético, metacrilato de metila, tereftalato de dimetila, metilaminas e olefinas leves (como etileno e propileno, posteriormente usados na síntese de polímeros) (FIORDALISO et al., 2015; GOEPPERT et al., 2014; JADHAV et al., 2014; LIAO et al., 2011).

Pode, também, ser aplicado como um combustível (tanto em motores a combustão quanto em células a combustível) ou convertido em produtos com maior valor de capacidade calorífica como dimetil éter, etanol e hidrocarbonetos e é utilizado, ainda, como aditivo em muitos combustíveis comerciais (FIORDALISO et al., 2015; GOEPPERT et al., 2014; JADHAV et al., 2014; LIAO et al., 2011).

A reação global da hidrogenação de $\mathrm{CO}_{2}$ a metanol e água é um processo exotérmico conforme evidenciado na reação 1 .

$$
\mathrm{CO}_{2}+3 \mathrm{H}_{2} \longrightarrow \mathrm{CH}_{3} \mathrm{OH}+\mathrm{H}_{2} \mathrm{O} \quad \Delta \mathrm{H}_{298 \mathrm{~K}}=-49,37 \mathrm{kJmol}^{-1}
$$


Esse fato, por si só, traz certas limitações termodinâmicas associadas à síntese do metanol em altas temperaturas. Além disso, em tais condições, a reação reversa de deslocamento gás-água $(R W G S)$, aqui apresentada como reação 2, por ser endotérmica, é priorizada em relação à redução até metanol levando a uma diminuição da seletividade para o produto de interesse e a um aumento da seletividade para o monóxido de carbono (LARMIER et al., 2017; RODRIGUEZ et al., 2015; WOLF; JESS; KERN, 2016).

$$
\mathrm{CO}_{2}+\mathrm{H}_{2} \longrightarrow \mathrm{CO}+\mathrm{H}_{2} \mathrm{O} \quad \Delta \mathrm{H}_{298 \mathrm{~K}}=+41 \mathrm{kJmol}^{-1}
$$

A utilização de altas temperaturas não é, portanto, benéfica para a obtenção do metanol. No entanto, a possibilidade de decréscimo na temperatura reacional levando a condições termodinâmicas favoráveis à obtenção desse álcool é, também, restrita uma vez que, em temperaturas relativamente baixas, há uma limitação cinética associada às conversões de $\mathrm{CO}_{2}$ levando a valores extremamente baixos de conversão (POROSOFF; YAN; CHEN, 2015; RODRIGUEZ et al., 2015).

Paralelo a isso, em condições de temperatura mais baixas, uma competição entre a reação de geração do metanol e a conversão de $\mathrm{CO}_{2}$ em metano, representada pela reação 3, que também é exotérmica, passa a ocorrer a partir da clivagem de ambas as ligações C-O (POROSOFF; YAN; CHEN, 2015; RODRIGUEZ et al., 2015).

$$
\mathrm{CO}_{2}+4 \mathrm{H}_{2} \longrightarrow \quad \mathrm{CH}_{4}+2 \mathrm{H}_{2} \mathrm{O} \quad \Delta \mathrm{H}_{298 \mathrm{~K}}=-39,4 \mathrm{kJmol}^{-1}
$$

Deve-se, ainda, considerar a diminuição na entropia do sistema ao se converter moléculas de dióxido de carbono e hidrogênio em metanol e água por ser uma reação de consumo de quantidade de matéria. Em virtude disso, uma segunda limitação termodinâmica surge relacionada à necessidade de pressurização para que ocorra o favorecimento de reações dessa natureza, por deslocamento de equilíbrio químico, de modo a aumentar a viabilidade do processo de obtenção do metanol (POROSOFF; YAN; CHEN, 2015; RODRIGUEZ et al., 2015).

Assim sendo, a busca por catalisadores com alta atividade e seletividade para a hidrogenação de $\mathrm{CO}_{2}$ a metanol deve focar em materiais que possam operar eficientemente em faixas adequadas de temperatura e pressão, que sejam capazes de adsorver eficientemente as moléculas de dióxido de carbono e interagir apropriadamente com os intermediários formados 
e que, em acréscimo, não levem ao rompimento de ambas as ligações $\mathrm{C}-\mathrm{O}$ da estrutura da molécula nem tenham como produto principal o monóxido de carbono (POROSOFF; YAN; CHEN, 2015; RODRIGUEZ et al., 2015; WANG, WEI et al., 2011).

Considerando que as reações ocorram em condições termodinâmicas e cinéticas favoráveis à hidrogenação do $\mathrm{CO}_{2}$ a metanol, a busca pela elucidação do mecanismo reacional detalhado dessa reação se tornou o objetivo de uma série de estudos recentes que vêm sendo realizados para diversos sistemas distintos de catalisadores (KATTEL et al., 2016; LARMIER et al., 2017; LIU, C.; CUNDARI; WILSON, 2012; RODRIGUEZ et al., 2015; STUDT et al., 2014).

Tais estudos envolvem tanto métodos de simulação teórica, utilizando-se cálculos por teoria do funcional de densidade $(D F T)$ e método cinético Monte Carlo, quanto estudos experimentais através, principalmente, de análises de espectroscopia de reflectância difusa na região do infravermelho com transformada de Fourier, espectroscopia de absorção e reflexão na região do infravermelho, espectroscopia de ressonância magnética nuclear e técnicas de marcação de isótopos (CHENG; LO, 2016; KATTEL et al., 2016; LARMIER et al., 2017; LI, YAWEI; CHAN; SUN, 2015; LIU, C.; CUNDARI; WILSON, 2012; MARTIN et al., 2016; RODRIGUEZ et al., 2015; STUDT et al., 2014; YE et al., 2013; YE; LIU; GE, 2012).

Dentre as muitas classes de catalisadores que podem ser empregados com o objetivo de converter as moléculas de $\mathrm{CO}_{2}$ em uma série de produtos por meio de reações de hidrogenação, há grande destaque para materiais compostos por nanopartículas metálicas suportadas em nanopartículas de óxidos, os quais apresentam, até o momento, os desempenhos catalíticos mais promissores (POROSOFF; YAN; CHEN, 2015; WANG, WEI et al., 2011).

Os trabalhos de Graciani et al. (2014) e Kattel et al. (2016), evidenciam a importância da presença de ambos os sítios (metálicos e óxidos) para a geração de metanol. Segundo esses pesquisadores, os sítios ativos para a hidrogenação do $\mathrm{CO}_{2}$ são as regiões de interface entre essas partículas metálicas e de óxido com a participação de ambas em um mecanismo bifuncional (GRACIANI et al., 2014; KATTEL et al., 2016).

De modo mais detalhado, na região de interface entre os sítios, a molécula de $\mathrm{CO}_{2}$ se adsorve através do seu átomo de carbono e um dos seus átomos de oxigênio na partícula metálica enquanto o outro átomo de oxigênio da molécula se adsorve em um sítios óxidos próximos, preferencialmente nas vacâncias de átomos de oxigênio que atuam como fortes sítios básicos de Lewis com grande afinidade por moléculas ácidas como o $\mathrm{CO}_{2}$ (GRACIANI et al., 2014; KATTEL et al., 2016; MCFARLAND; METIU, 2013). 
Já a adsorção dissociativa das moléculas de $\mathrm{H}_{2}$ ocorre preponderantemente nas partículas metálicas. Por influência de diferenças no potencial químico da superfície, os hidrogênios atômicos gerados sofrem, então, um fenômeno de transferência (spillover) em direção aos sítios óxidos presentes na interface onde se adsorvem como hidroxilas ficando disponíveis para as sucessivas etapas de hidrogenação do $\mathrm{CO}_{2}$ (GRACIANI et al., 2014; KATTEL et al., 2016; RODRIGUEZ et al., 2015).

Ainda segundo esses pesquisadores, após as etapas de adsorção descritas, duas rotas mecanísticas principais podem levar à formação de metanol a partir do $\mathrm{CO}_{2}$.

A primeira delas é a rota da reação reversa de deslocamento gás-água (Reverse watergas shift - RWGS) que gera moléculas de água e monóxido de carbono adsorvidas na superfície do catalisador. Em sequência, contanto que a molécula de CO produzida permaneça adsorvida, ela sofrerá sucessivas hidrogenações até o metanol (GRACIANI et al., 2014; KATTEL et al., 2016; RODRIGUEZ et al., 2015).

Já a segunda rota é conhecida como Rota do Formiato. De acordo com Kattel et al. (2016), após adsorção de $\mathrm{CO}_{2}$ e adsorção dissociativa de $\mathrm{H}_{2}$, uma espécie formiato é produzida e se mantém adsorvida na superfície passando por uma série de etapas subsequentes de hidrogenação que levam à geração de metanol como produto final (KATTEL et al., 2016).

Em ambas as rotas, existem desafios consideráveis à geração de metanol com alta seletividade, principalmente devido a verificação de energias de ativação muito altas para algumas etapas de hidrogenação de certas moléculas intermediárias utilizando a maioria dos catalisadores (GRACIANI et al., 2014; KATTEL et al., 2016; RODRIGUEZ et al., 2015).

Além disso, especificamente na rota da reação reversa do deslocamento gás-água, as moléculas de $\mathrm{CO}$ geradas no processo, geralmente, apresentam energia de adsorção muito baixa, de modo que sua dessorção é favorecida antes que elas possam ser hidrogenadas até metanol, o que leva à geração de grandes quantidades de monóxido de carbono (GRACIANI et al., 2014; KATTEL et al., 2016; RODRIGUEZ et al., 2015).

Diante disso, muitos trabalhos recentes têm como foco o desenvolvimento de novos catalisadores com diferentes composições e estruturas, capazes de minimizar os problemas apresentados de geração de $\mathrm{CO}$ e altas energias de ativação para certas etapas em ambas rotas (AHMADI; MISTRY; ROLDAN CUENYA, 2016; PAN et al., 2017).

A grande maioria se vale da formação de nanocompósitos ou estruturas suportadas constituídos por partículas metálicas e partículas de óxidos que possam atuar eficientemente 
como catalisadores bifuncionais (AHMADI; MISTRY; ROLDAN CUENYA, 2016; PAN et al., 2017).

Dentre o vasto número de metais de transição já avaliados, entre os quais estão paládio, ouro, ródio, níquel, molibdênio e tungstênio, os catalisadores baseados em cobre recebem grande destaque por catalisar a reação de hidrogenação do $\mathrm{CO}_{2}$ a metanol com alta eficiência e seletividade comparativamente a outros elementos testados (BERSANI et al., 2016; POROSOFF; YAN; CHEN, 2015; WANG, WEI et al., 2011).

As energias envolvidas na adsorção e ativação do $\mathrm{CO}_{2}$ em sistemas contendo cobre favorecem a quebra de apenas uma das ligações entre carbono e oxigênio, o que é importante para a formação de compostos oxigenados como o metanol e desfavorece a produção de compostos como o metano (BERSANI et al., 2016; POROSOFF; YAN; CHEN, 2015; WANG, WEI et al., 2011).

Além disso, catalisadores baseados em cobre apresentam custo consideravelmente reduzido em relação a outros catalisadores que envolvem metais nobres como componente ativo além de apresentar temperaturas menores de redução em relação à maioria dos outros sistemas que utilizam elementos não nobres, levando a vantagens inerentes de menor custo do processo em virtude da utilização de condições de síntese mais brandas (BERSANI et al., 2016; POROSOFF; YAN; CHEN, 2015).

Uma boa noção da importância do cobre é gerada ao se considerar o fato de que o atual catalisador utilizado em processos industriais para obtenção de metanol a partir da hidrogenação de uma mistura de $\mathrm{CO}$ e $\mathrm{CO}_{2}$ é constituído por partículas de cobre metálico e óxido de zinco suportados em alumina, tradicionalmente representado como $\mathrm{Cu} / \mathrm{ZnO} / \mathrm{Al}_{2} \mathrm{O}_{3}$ (BERSANI et al., 2016; RODRIGUEZ et al., 2015).

Já em relação aos óxidos, muitos compostos são relatados na literatura. Em comum a todos eles, há a necessidade da presença de vacâncias de oxigênio em sua estrutura conforme já descrito acima pela atuação dessas deficiências estruturais como sítios básicos fortes capazes de adsorverem e ativarem, adequadamente, moléculas de $\mathrm{CO}_{2}$ e muitos dos intermediários principais do processo de geração do metanol que também apresentam caráter ácido em ambas as rotas mecanísticas (KOUVA et al., 2015; POROSOFF; YAN; CHEN, 2015; RODRIGUEZ et al., 2015; SENANAYAKE et al., 2016; WANG, WEI et al., 2011).

Recentemente muito destaque foi conferido ao óxido de cério, inicialmente pela sua capacidade de alterar, com relativa facilidade, o estado de oxidação de alguns de seus átomos nos compostos sólidos através da dinâmica entre os íons de configuração $\mathrm{Ce}^{4+} \mathrm{e} \mathrm{Ce}^{3+}$, o que 
facilita a formação de vacâncias em sua estrutura, como também pela sua basicidade tipicamente verificada em óxidos compostos por lantanídeos (CHENG; LO, 2016; LU et al., 2015).

Além do óxido de cério, há também uma série de estudos dedicados ao óxido de zircônio devido a verificação da existência de fortes interações do tipo metal-suporte (Strong MetalSupport Interactions - SMSI) entre esse óxido e as partículas metálicas como as de cobre. Além disso, características importantes como a alta capacidade de transferência eletrônica na interface e da alta estabilidade térmica e química são apresentadas pelas partículas de $\mathrm{ZrO}_{2}$ (ARENA et al., 2007; BONURA et al., 2011; GUO et al., 2011; LI, L. et al., 2015; PAN et al., 2017; POROSOFF; YAN; CHEN, 2015; WANG, WEI et al., 2011).

É bem estabelecido que a ocorrência dessas fortes interações entre metal e suporte (SMSI) levam a um grau de interação muito maior entre as partículas metálicas e de óxido gerando, como resultado, altos valores de dispersão entre elas (PAN et al., 2017; POROSOFF; YAN; CHEN, 2015).

Como consequência direta dessa dispersão considerável entre as partículas metálicas e as de óxido, haverá uma quantidade muito superior de regiões de interface entre essas partículas quando comparadas a materiais sem forças intensas de interação nos quais as partículas metálicas tendem a se agregar em virtude da pouca interação com as partículas de óxido (PAN et al., 2017; POROSOFF; YAN; CHEN, 2015; WANG, WEI et al., 2011).

Uma vez que os sítios ativos para as reações de hidrogenação de $\mathrm{CO}_{2}$ são justamente as regiões de interface, materiais que apresentem intensas forças de interação como os formados por cobre e zircônia tendem a gerar bons resultados. De fato, em muitos trabalhos publicados, nenhum dos óxidos estudados apresentou melhor atividade que a zircônia combinada ao cobre (MARTIN et al., 2016; PAN et al., 2017; POROSOFF; YAN; CHEN, 2015; WANG, WEI et al., 2011).

Apesar de todo o progresso já realizado no desenvolvimento de catalisadores para a geração de metanol a partir da hidrogenação de $\mathrm{CO}_{2}$ e todo o conhecimento já construído, é crucial que se tenha ciência de que muitas limitações ainda estão presentes no atual estágio de avanço (POROSOFF; YAN; CHEN, 2015; WANG, WEI et al., 2011).

Tais desafios se mostram relacionados à geração de catalisadores que apresentem, ao mesmo tempo, valores apreciáveis de conversão e seletividade para o metanol, características essas que são vitais para a aplicação dos catalisadores desenvolvidos em escala industrial viável (POROSOFF; YAN; CHEN, 2015; WANG, WEI et al., 2011). 
Consequentemente, inúmeras melhorias e aprimoramentos podem ser obtidos em um futuro próximo através de estratégias bem definidas de manipulação de estrutura e de propriedades físico-químicas dos materiais utilizados como catalisadores levando a um bom desempenho catalítico (POROSOFF; YAN; CHEN, 2015).

Uma das principais estratégias que pode ser aplicada envolve o aumento do número de vacâncias de oxigênio na rede iônica do óxido a fim de fornecer mais centros eficientes de adsorção química às moléculas de $\mathrm{CO}_{2}$ e outros intermediários pelos motivos já discutidos (ARENA et al., 2007; BANSODE et al., 2013; BONURA et al., 2011; GUO et al., 2011; LI, L. et al., 2015; POROSOFF; YAN; CHEN, 2015).

Na grande maioria dos trabalhos, é estabelecido que o aumento na temperatura do tratamento térmico sob atmosfera redutora é capaz de realizar essa função, no entanto, altas temperaturas de redução favorecem a agregação das partículas o que se mostra prejudicial aos processos catalíticos de um modo geral (POROSOFF; YAN; CHEN, 2015; WANG, WEI et al., 2011).

Diante disso, busca-se, frequentemente, medidas alternativas para geração de vacâncias que não envolvam aumento das temperaturas nos tratamentos térmicos necessários para a obtenção dos materiais.

Nesse sentido, grande ênfase pode ser conferida à prática de dopagem ou modificação de um óxido principal utilizando elementos de menor valência em relação ao elemento majoritário, chamados, por essa razão, modificadores de baixa valência (MCFARLAND; METIU, 2013).

Segundo McFarland e Metiu (2013), como o oxigênio é eletrofílico, a criação de uma deficiência eletrônica gerada na superfície do material devido a introdução de uma espécie catiônica de menor valência que a valência do cátion principal na rede cristalina leva a uma diminuição na energia de atração elétrica ou das ligações iônicas entre os cátions e as espécies eletrofílicas como os átomos de oxigênio (MCFARLAND; METIU, 2013).

Esse fato acarreta em diminuição da energia de ligação desses átomos de oxigênio à rede iônica que forma o sólido, possibilitando que temperaturas menores sejam necessárias à formação de vacâncias devido à saída de átomos de oxigênio da superfície do material como oxigênio molecular ou reagindo com moléculas da atmosfera (MCFARLAND; METIU, 2013).

Outro desafio considerável se refere à formação de grandes quantidades de CO obtidas com grande parte dos catalisadores utilizados. A proposta de solução para esse problema envolve a busca por modificações no catalisador que levem a um ajuste na energia de adsorção 
de intermediários como o CO e a uma diminuição na energia de ativação para a hidrogenação de intermediários específicos presentes em ambas as rotas que levam ao metanol (GUO et al., 2011; KATTEL et al., 2016; LARMIER et al., 2017; POROSOFF; YAN; CHEN, 2015; ZHU et al., 2017).

Nesse sentido, estudos teóricos de Ye et al. (2012 e 2013) demonstraram que a hidrogenação de $\mathrm{CO}_{2}$ a metanol utilizando o óxido de índio como catalisador apresenta resultados expressivamente promissores (YE et al., 2013; YE; LIU; GE, 2012).

Foi verificado que, em superfícies contendo óxido de índio, o processo de hidrogenação se dá preponderantemente pela rota do formiato e a energia de ativação para as reações de hidrogenação de intermediários, que é muito alta quando se utiliza outros materiais, se torna consideravelmente menor (YE et al., 2013; YE; LIU; GE, 2012).

No que se refere à rota mecanística da reação reversa do deslocamento gás-água que, neste caso, ocorre em menor quantidade utilizando tais materiais, as energias de ativação para hidrogenação dos intermediários também se mostraram menores em catalisadores a base de óxido de índio (YE et al., 2013; YE; LIU; GE, 2012).

Além disso, no que se refere à geração de $\mathrm{CO}$ como produto indesejado por essa última rota, Bielz et al. (2010) e Bielz et al. (2011) evidenciaram que, em catalisadores contendo índio a energia de adsorção das moléculas de monóxido de carbono à superfície é muito maior, desfavorecendo sua dessorção (BIELZ, T et al., 2011; BIELZ, THOMAS et al., 2010).

Essas predições, foram, posteriormente, confirmadas em trabalhos experimentais como o de Martin et al. (2016) que utilizou óxido de índio suportado em zircônia como catalisador obtendo metanol com alta seletividade (MARTIN et al., 2016).

No que se refere à síntese dos materiais, um grande número de métodos para o preparo de catalisadores suportados e compósitos tem sido extensamente explorado, como deposiçãoprecipitação, impregnação e deposição coloidal (HU et al., 2014; POROSOFF; YAN; CHEN, 2015; WANG, WEI et al., 2011).

No entanto, em muitos dos casos, é difícil que se obtenha superfícies com fases bem distribuídas, tamanho e distribuição de partículas uniforme e boa estabilidade térmica. Em geral, são obtidas fases amplamente segregadas com partículas metálicas consideravelmente agregadas e pouco dispersas sobre as partículas de óxido (HU et al., 2014).

Ao se levar em conta o caráter bifuncional do processo catalítico de hidrogenação do $\mathrm{CO}_{2}$ a metanol ocorrente na interface entre os sítios metálicos e básicos, percebe-se, claramente, que procedimentos de síntese que levem a materiais muito segregados, com pouca interação 
entre centros metálicos e óxidos e, portanto, menos regiões de interface, devem ser evitados uma vez que resultarão em desempenho catalítico insatisfatório (POROSOFF; YAN; CHEN, 2015; RODRIGUEZ et al., 2015; WANG, WEI et al., 2011).

Assim, métodos que possibilitem dispersão considerável entre as fases constituintes dos catalisadores e a um maior número de zonas interfaciais têm ganhado cada vez mais espaço no cenário acadêmico e industrial para processos em que a reação de interesse apresente caráter bifuncional (POROSOFF; YAN; CHEN, 2015; RODRIGUEZ et al., 2015; WANG, WEI et al., 2011).

Nesse âmbito, há destaque para um grupo de métodos que recebem a terminologia geral: "métodos de síntese em etapa única" (one-step methods). Nesses procedimentos, a síntese se inicia por uma mistura homogênea dos sais precursores, tanto do óxido quanto das partículas metálicas que irão compor o material final, diferentemente das técnicas tradicionais em duas etapas que geram partículas de um material suportadas em um segundo previamente sintetizado (HU et al., 2014).

Da Silva et al. (2016), por exemplo, sintetizaram catalisadores $\mathrm{Cu} / \mathrm{ZnO}-\mathrm{Al}_{2} \mathrm{O}_{3}$ que foram empregados na hidrogenação do $\mathrm{CO}_{2}$ a metanol por dois métodos distintos, sendo um deles um processo de impregnação convencional e o outro uma coprecipitação em etapa única de uma mistura contendo os sais precursores de todos os metais que iriam compor os materiais finais (DA SILVA et al., 2016).

Como resultado, o catalisador sintetizado em etapa única apresentou melhor desempenho para a geração do metanol comparado ao catalisador suportado sintetizado em duas etapas por impregnação em um suporte pré-sintetizado devido à maior dispersão entre as partículas de cobre metálico e as partículas de óxido presentes na superfície (DA SILVA et al., 2016).

Ainda nesse contexto, Sun et al. (2009) sintetizaram nanopartículas de cobre metálico em uma matriz de $\gamma-\mathrm{Al}_{2} \mathrm{O}_{3}$ por diferentes métodos e destacaram que a síntese em etapa única apresentou maior homogeneidade com relação à porosidade e à distribuição entre as partículas metálicas e de óxido (SUN; TIAN; LIU, 2009).

Um vasto número de métodos de síntese em etapa única tem sido adotado com frequência crescente na atualidade como o método de coprecipitação em pH constante, um dos métodos clássicos mais utilizados no preparo de materiais em geral, apresentando alta viabilidade econômica e também prática, em virtude da simplicidade e baixo custo do aparato 
instrumental necessário para sua utilização (MUNNIK; DE JONGH; DE JONG, 2015; PUSHPARAJ et al., 2015).

Nesse método, uma mistura dos sais precursores dos componentes finais do material a ser gerado são dissolvidos em um solvente apropriado e uma mudança no ambiente químico da solução, induzida por alterações, principalmente no $\mathrm{pH}$, levam à precipitação dos metais em forma de hidróxidos ou mesmo de oxi-hidróxidos (MUNNIK; DE JONGH; DE JONG, 2015; PUSHPARAJ et al., 2015).

Em precipitações convencionais, nas quais é adicionada uma base lentamente a uma solução contendo os sais dissolvidos, há um problema relacionado ao aumento gradual no $\mathrm{pH}$ que leva, na maioria das vezes, a precipitações sequenciais de hidróxidos de cada um dos metais presentes em solução separadamente em virtude das diferenças no produto de solubilidade de seu hidróxido (MUNNIK; DE JONGH; DE JONG, 2015).

Assim, os hidróxidos de cada um dos metais podem precipitar separadamente em valores distintos de $\mathrm{pH}$ resultando em considerável segregação e fraca interação entre as diferentes fases que irão compor os materiais finais (MUNNIK; DE JONGH; DE JONG, 2015).

É nesse contexto que a coprecipitação em pH constante ganha destaque. Diferentemente do método clássico convencional, essa variação propõe que o gotejamento da solução contendo os sais precursores do catalisador seja realizado em uma solução com pH já controlado em um valor de concentração de íons hidroxila que seja, no mínimo, alto o suficiente para a garantir a precipitação do hidróxido metálico que apresente o maior produto de solubilidade da mistura (MUNNIK; DE JONGH; DE JONG, 2015; THOMAS, J. et al., 2017).

Dessa forma, ocorrerá uma precipitação, praticamente simultânea, de todas as espécies metálicas presentes em solução na forma de seus respectivos hidróxidos garantindo que as diferenças de produto de solubilidade não gerem alta segregação entre as partículas dos diferentes elementos (THOMAS, J. et al., 2017).

Apesar dos aspectos positivos mencionados sobre o método de coprecipitação a $\mathrm{pH}$ constante, vale ressaltar que problemas usuais ocorrentes no processo de coprecipitação tradicional também são encontrados no procedimento em $\mathrm{pH}$ constante, como a agregação das partículas obtidas devido a necessidade de tratamentos térmicos posteriores à precipitação (CUSHING; KOLESNICHENKO; O’CONNOR, 2004).

De modo a evitar ou, ao menos, minimizar a sinterização das partículas geradas, uma série de estratégias vem sendo seguidas por diversos pesquisadores. Dentre as quais, se destaca a utilização de surfactantes no processo de preparo dos catalisadores. Extensas revisões são 
documentadas na literatura apresentando uma série de vantagens obtidas em rotas de síntese assistidas por surfactante como a realizada por Liu Yin et al. (2013) (LIU, Y.; GOEBL; YIN, 2013).

Segundo esses autores, a utilização de diferentes moléculas de surfactante gera benefícios pela capacidade dessa classe de materiais em atuar como estruturas de revestimento que protegem e isolam parcialmente as partículas sintetizadas durante faixas variáveis de temperatura no decorrer do tratamento térmico resultando em agregação consideravelmente menor dessas estruturas (CUSHING; KOLESNICHENKO; O’CONNOR, 2004; LIU, Y.; GOEBL; YIN, 2013).

A faixa de temperatura até a qual ocorre o revestimento e proteção depende da estrutura e natureza química de cada surfactante em virtude de sua temperatura característica de decomposição, após a qual o surfactante se degrada deixando de exercer seu papel protetor (LIU, Y.; GOEBL; YIN, 2013).

Dentre o vasto número de surfactantes distintos que podem ser empregados em diferentes sínteses, Li et al. (2015) obtiveram excelentes resultados utilizando o brometo de hexadeciltrimetilamônio (CTAB) para a síntese de catalisadores constituídos por cobre, óxido de zinco e óxido de zircônio aplicados ao processo de hidrogenação do $\mathrm{CO}_{2}$ a metanol (LI, YAWEI; CHAN; SUN, 2015).

Segundo tais autores, além da proteção à agregação, análises de espectroscopia fotoeletrônica de Raios X confirmaram que as composições de superfície dos materiais sintetizados utilizando $\mathrm{CTAB}$ foram as que apresentaram maior equilíbrio entre os elementos que constituíam as partículas metálicas e os elementos que formavam as partículas de óxido, o que é importante para a formação eficiente de regiões de interface (LI, YAWEI; CHAN; SUN, 2015).

Dessa forma, isso se reflete em melhor interação e maximização das zonas interfaciais entre partículas metálicas e centros óxidos gerando melhores resultados catalíticos para a obtenção do metanol.

Tão importantes quanto as estratégias de manipulação química dos catalisadores através da seleção dos elementos mais adequados, são as estratégias de natureza estrutural capazes de manipular a estrutura e arquitetura dos materiais com o objetivo de se obter melhorias no desempenho catalítico por meio da minimização de problemas como agregação da fase ativa durante os tratamentos térmicos e condições reacionais, por vezes, severas (POROSOFF; YAN; CHEN, 2015; WANG, WEI et al., 2011). 
Nesse sentido, técnicas que permitem encapsulamento levando a estruturas conhecidas como "core-shell", se mostram altamente promissoras. Nesses compostos, há um material interno encapsulado por um revestimento constituído por um material distinto daquele que forma o núcleo, podendo esse revestimento ser poroso ou não (CHAUDHURI; PARIA, 2012; GAWANDE et al., 2015).

As vantagens advindas deste tipo de estrutura são muito amplas e extremamente funcionais. É possível, por exemplo, que se crie novos materiais semicondutores, eletrodos mais resistentes à corrosão, materiais com aplicações ópticas e bioquímicas aumentando a biocompatibilidade de um material através de um revestimento inerte que possa encapsular um núcleo ou criando um revestimento que se degrade lentamente ao atingir a região de destino no organismo levando a uma liberação controlada e mais eficiente do fármaco contido em seu interior (CHAUDHURI; PARIA, 2012).

Em catálise, esses materiais têm sido aplicados com muita originalidade apresentando soluções para problemas que persistem a muito tempo na área. Em reações em fase líquida por exemplo, é possível, criar catalisadores com núcleos magnéticos encapsulados pela fase ativa do catalisador de modo que seja possível realizar a recuperação magnética dos catalisadores para sua regeneração após um ciclo reacional (CHAUDHURI; PARIA, 2012; GAWANDE et al., 2015).

Outra possibilidade envolve sintetizar um núcleo constituído por um material que apresente boa capacidade de transferência eletrônica e baixa afinidade eletrônica encapsulado por uma camada de partículas metálicas que formam o catalisador de modo que, à medida que o catalisador sofra desativação devido a oxidação por reações com a atmosfera, o próprio núcleo forneça uma quantidade de elétrons que garanta sua atividade por um período superior de tempo (CHAUDHURI; PARIA, 2012; GAWANDE et al., 2015).

Em situações nas quais os elementos que formam o catalisador sejam caros, é possível também, sintetizar um núcleo formado por um material mais barato como sílica e usar apenas uma pequena quantidade dos elementos de maior custo que formarão a fase ativa como revestimento (CHAUDHURI; PARIA, 2012; GAWANDE et al., 2015).

Por fim, uma das aplicações mais utilizadas de materiais core-shell em catálise tem como objetivo garantir proteção à fase ativa e às propriedades do material, principalmente contra os danos causados pela sinterização que ocorre com as partículas em condições severas como tratamentos térmicos e reações ocorrentes em altos valores de temperatura (CHAUDHURI; PARIA, 2012; GAWANDE et al., 2015). 
Nesses materiais geralmente há um núcleo contendo a fase ativa responsável por atuar como catalisador. Esse núcleo é, então, revestido por uma camada de material inerte e poroso com alta resistência térmica e química, geralmente sílica, com o objetivo de tornar o material mais resistente à agregação em virtude dos efeitos de confinamento que a sílica gera como camada protetora (CHAUDHURI; PARIA, 2012; GAWANDE et al., 2015).

Isso é capaz de garantir que a atividade catalítica não seja prejudicada mesmo após o material ser submetido a altas temperaturas decorrentes de tratamentos térmicos como a calcinação durante a síntese ou durante o processo reacional uma vez que a sílica é capaz de minimizar a sinterização das partículas mantendo propriedades importantes como pequeno tamanho de partícula, alta área específica de superfície e alta dispersão entre as partículas (CHAUDHURI; PARIA, 2012; GAWANDE et al., 2015).

Em geral, a síntese de estruturas do tipo core-shell ocorre em duas etapas, com a construção do núcleo em um primeiro momento e a geração do revestimento em um segundo passo. De todas as técnicas que podem ser utilizadas para esse fim, a síntese solvotérmica se mostra uma das mais promissoras e utilizadas atualmente (CHAUDHURI; PARIA, 2012; GAWANDE et al., 2015).

Esse tipo de síntese, envolve preparar uma solução contendo os elementos que irão compor o catalisador, geralmente usando água, etanol ou uma mistura de ambos como solvente. Tal solução é, então, transferida para uma autoclave e submetida a um processo de aquecimento (CUSHING; KOLESNICHENKO; O’CONNOR, 2004).

A pressão autógena gerada nessa situação permite que o solvente se mantenha líquido em temperaturas superiores a seu ponto de vaporização em pressão ambiente. Dessa forma, é possível obter um solvente com maior capacidade de solvatação e alteração em propriedades como a constante dielétrica, por exemplo. Nesse ambiente químico, os sais solvatados passam, então, por um processo de nucleação e crescimento que levarão à formação de partículas de óxido (CUSHING; KOLESNICHENKO; O’CONNOR, 2004; LI, W. et al., 2008; WANG, X. M.; LORIMER; XIAO, 2005).

Em processos solvotérmicos, em virtude do ambiente de síntese envolver altas pressões e possibilidade de trabalho com o solvente em maiores temperaturas do que seria possível em pressão ambiente, os materiais produzidos, em geral, apresentarão alta área, dispersão e homogeneidade das partículas, além de alta estabilidade térmica e resistência química (CUSHING; KOLESNICHENKO; O’CONNOR, 2004; LI, W. et al., 2008; WANG, X. M.; LORIMER; XIAO, 2005). 
A variação da temperatura e do tempo de síntese são suficientes para gerar grandes alterações na estrutura e morfologia dos materiais obtidos, além disso, as condições utilizadas permitem um controle extremamente alto do tamanho e homogeneidade das nanopartículas levando, em geral, a altos valores de área específica de superfície e controle de porosidade, parâmetros influentes no desempenho catalítico que será obtido com essas estruturas geradas (CUSHING; KOLESNICHENKO; O’CONNOR, 2004; ZABILSKIY et al., 2015).

Nesse procedimento de síntese, é comum que se utilize surfactantes que aumentarão ainda mais a eficiência da resistência à agregação das partículas formadas devido a seus efeitos como agentes protetores e estabilizadores (CUSHING; KOLESNICHENKO; O'CONNOR, 2004).

Dentre os mais utilizados, se encontram o já citado brometo de hexadeciltrimetilamônio (CTAB) e o polivinilpirrolidona (PVP), que no caso de sínteses de partículas core-shell, atuam não somente no controle do tamanho de partículas mas também como agentes direcionadores das espécies de silício que irão ser introduzidas na suspensão, posteriormente, para a geração de um revestimento de sílica mais uniforme e com porosidade maior e mais homogênea (CHAUDHURI; PARIA，2012; CUSHING; KOLESNICHENKO; O’CONNOR，2004; GAWANDE et al., 2015; LIU, Y.; GOEBL; YIN, 2013).

Já a síntese do revestimento de sílica é feita, principalmente, pelo chamado método de Stober modificado. Por esse método, é preparada uma suspensão contendo as partículas que serão revestidas utilizando álcool como solvente, geralmente etanol, e certa quantidade de surfactante direcionador. Nessa suspensão são adicionadas quantidades específicas de água e uma base fraca, geralmente hidróxido de amônio (CHAUDHURI; PARIA, 2012; GAWANDE et al., 2015).

Por fim, é adicionado, de forma consideravelmente lenta, uma solução de um alcóxido de silício como TEOS, que passará por um processo sol-gel de hidrólise levando à formação de sílica na superfície das partículas que formarão o núcleo. O hidróxido de amônio atua como catalisador uma vez que a hidrólise do alcóxido ocorre de forma mais eficiente em meios básicos (CHAUDHURI; PARIA, 2012; GAWANDE et al., 2015).

A variação das quantidades de água, hidróxido de amônio e alcóxido de silício bem como a variação na velocidade de gotejamento do TEOS sobre a suspensão levam a alterações vastas nas propriedades dos materiais finais gerados (CHAUDHURI; PARIA, 2012; GAWANDE et al., 2015). 
Além do foco na composição e estrutura dos catalisadores, a otimização das variáveis reacionais como temperatura, pressão e velocidade espacial são igualmente importantes para que o desempenho catalítico seja satisfatório (POROSOFF; YAN; CHEN, 2015; WANG, WEI et al., 2011).

Conhecer bem os efeitos que alterações nessas variáveis causam no processo reacional pode fazer muita diferença para que o catalisador possa atuar com alta eficiência minimizando as energias de ativação para os produtos de interesse.

Em geral, essas análises de otimização das variáveis são realizadas por metodologias tradicionais baseadas na variação de um parâmetro por vez enquanto os demais se mantêm constantes (BARROS NETO; SCARMINIO; BRUNS, 2010).

Atualmente, no entanto, existem procedimentos estatísticos de otimização, chamados de quimiométricos, que se dividem em planejamentos experimentais e geração de superfícies de resposta apresentando uma série de vantagens em relação aos demais métodos (BARROS NETO; SCARMINIO; BRUNS, 2010).

Para a realização desses procedimentos, são escolhidos valores de interesse para cada parâmetro, que são chamados de níveis. Em geral, são definidos níveis mínimos, máximos, médios e, em alguns casos, axiais, que são valores ligeiramente superiores ao nível máximo e inferiores ao nível mínimo. A definição de níveis axiais segue algumas regras matemáticas definidas pelo planejamento experimental escolhido, não sendo, portanto, aleatória (BARROS NETO; SCARMINIO; BRUNS, 2010).

A variação conjunta dos níveis definidos por uma matriz experimental com alguns ensaios garante, não somente um estudo quantitativo acerca do efeito de cada parâmetro sobre o processo que se deseja otimizar, como também possibilita a geração de uma faixa de estudos, dentro da qual, é possível predizer resultados em diferentes combinações dos níveis sem a necessidade de realização de experimentos adicionais. O resultado que se deseja otimizar é chamado dentro da quimiometria de resposta (BARROS NETO; SCARMINIO; BRUNS, 2010).

A metodologia de planejamento experimental define cada ensaio de forma metódica de modo a garantir todas as combinações possíveis entre os níveis superiores e inferiores de cada parâmetro além da possibilidade de realização de pontos com níveis médios e axiais que garantam maior confiabilidade dos resultados (BARROS NETO; SCARMINIO; BRUNS, 2010). 
As técnicas de experimentação tradicional têm como princípio geral variar um parâmetro por vez mantendo os demais em níveis constantes. Tal prática pode levar a otimizações incompletas ou mesmo equivocadas, se distanciando dos melhores resultados possíveis uma vez que várias combinações de níveis acabam não sendo analisadas (BARROS NETO; SCARMINIO; BRUNS, 2010).

Como exemplo, se, em um primeiro momento da otimização, é verificado que um parâmetro A atinge o melhor resultado em seu nível superior, esse nível será mantido constante e, portanto, será o único analisado para os testes seguintes que serão feitos com os demais parâmetros, B e C. Não haverá, por essa metodologia, nenhuma combinação do nível inferior de $\mathrm{A}$ com os demais níveis de $\mathrm{B}$ e $\mathrm{C}$, e essa combinação poderia gerar resultados até melhores do que os que foram testados (BARROS NETO; SCARMINIO; BRUNS, 2010).

Além disso, há casos nos quais os parâmetros influenciam uns aos outros havendo interação entre eles. Nesse caso, o nível ótimo de um parâmetro A será diferente dependendo do nível do outro parâmetro B, que o influencia. Por exemplo, pode ser que, mantendo B constante em seu nível superior e variando o parâmetro A, a melhor resposta seja obtida com o valor superior de A. No entanto, se B estivesse mantido constante em seu nível inferior, a melhor resposta já seria obtida com o valor médio de A, e não o seu valor superior (BARROS NETO; SCARMINIO; BRUNS, 2010).

Dessa forma, em casos nos quais haja interação entre os parâmetros, não se pode otimizar os parâmetros separadamente, variando os valores de um deles enquanto os demais se mantem constantes (BARROS NETO; SCARMINIO; BRUNS, 2010).

Além disso, o uso da quimiometria possibilita um estudo quantitativo, tanto da influência individual de cada parâmetro sobre os processos, quanto do grau de interação entre cada um deles com os demais. Diante disso, torna-se possível avaliar, inclusive, se os parâmetros apresentam efeito significativo ou não sobre a resposta que se deseja otimizar e, mais ainda, é possível estabelecer qual o parâmetro mais importante e quantas vezes ele influencia a resposta mais que os demais parâmetros (BARROS NETO; SCARMINIO; BRUNS, 2010).

Por fim, ainda é possível que se crie equações de regressão e superfícies de resposta baseadas nos dados experimentais obtidos. Através delas, pode-se predizer, com alto grau de confiabilidade estatística, as respostas que seriam obtidas para uma condição de reação formada por uma combinação qualquer entre os níveis dos parâmetros analisados desde que esteja 
situada dentro da faixa de análise que terá extremos definidos pelo maior e menor nível utilizado (BARROS NETO; SCARMINIO; BRUNS, 2010).

Ou seja, com a equação de regressão é possível criar superfícies de resposta que possam predizer os resultados de reações em condições não testadas, sem que seja necessário realizar testes complementares experimentalmente (BARROS NETO; SCARMINIO; BRUNS, 2010).

Dessa forma, há uma economia considerável de experimentos, uma vez que respostas podem ser obtidas pelas superfícies de resposta geradas pela equação de regressão, em um procedimento de modelagem de processos (BARROS NETO; SCARMINIO; BRUNS, 2010).

O efeito principal de cada parâmetro está relacionado à diferença causada na resposta quando há variação do nível mínimo ao nível máximo definido para o parâmetro analisado. Já o efeito de interação entre parâmetros se relaciona com o quanto a variação no nível de um deles influencia o efeito de outro na resposta (BARROS NETO; SCARMINIO; BRUNS, 2010).

Ambos são obtidos quantitativamente, além disso, quando o efeito sobre a resposta obtidos para um parâmetro qualquer for positivo, também chamado sinérgico, isso implica que a resposta será diretamente proporcional ao valor desse parâmetro, ou seja, a resposta obtida será tanto maior quanto maior for o valor do parâmetro. No entanto, quando o efeito for negativo, também chamado antagônico, isso significa que as maiores respostas serão obtidas quando esse parâmetro estiver em seu nível mínimo, ou seja, valor do parâmetro e resposta serão inversamente proporcionais (BARROS NETO; SCARMINIO; BRUNS, 2010).

Através do planejamento, é possível que se tenha a variação da resposta causada quando se varia um parâmetro A do nível mínimo ao nível máximo enquanto os níveis de parâmetros B e C se mantem constantes em cada configuração possível. Assim, haverá uma diferença quando se varia o parâmetro A de (-1) a (+1) mantendo os níveis B e C em (-1) e (-1), outra diferença quando $\mathrm{B}$ e $\mathrm{C}$ forem mantidos em $(+1)$ e $(+1)$, outra quando $\mathrm{B}$ e $\mathrm{C}$ forem mantidos em $(-1)$ e $(+1)$ e outra ainda quando B e C forem mantidos em $(+1)$ e $(-1)$ (BARROS NETO; SCARMINIO; BRUNS, 2010).

Por definição, a média entre cada uma dessas diferenças na resposta causada pela variação de A será chamada de efeito principal do parâmetro A. Procedimentos análogos são, então, realizados para que possa calcular os efeitos principais dos parâmetros B e C (BARROS NETO; SCARMINIO; BRUNS, 2010).

Caso a variação na resposta causada pela alteração no parâmetro A tenha o mesmo valor em qualquer nível em que B esteja mantido constante, conclui-se que não há interação entre o 
parâmetro A e o parâmetro B e o mesmo pode ser realizado para avaliar a interação entre todos os parâmetros, por exemplo (BARROS NETO; SCARMINIO; BRUNS, 2010).

Se por acaso, a diferença na resposta obtida com o parâmetro A nos níveis mínimo e máximo quando o parâmetro B estiver constante em um nível " $\mathrm{X}$ ", chamada de resposta 1 , for diferente da diferença na resposta variando o nível de A quando B estiver constante em um nível "Y", chamada resposta 2, o efeito dessa dependência entre A e B será chamado de efeito de interação. Matematicamente, o cálculo do efeito de interação estará relacionado à diferença entre a resposta 1 e a resposta 2 (BARROS NETO; SCARMINIO; BRUNS, 2010).

Por fim, é possível calcular os erros dos efeitos se baseando em repetições em cada ensaio ou nas repetições dos chamados pontos médios (também chamados de centrais) e usar esses valores para se calcular matematicamente o chamado efeito crítico (BARROS NETO; SCARMINIO; BRUNS, 2010).

Estatisticamente, o efeito de um parâmetro, seja ele principal ou de interação, será considerado significativo, sempre que seu módulo for superior ao valor do efeito crítico (BARROS NETO; SCARMINIO; BRUNS, 2010).

Após a análise dos efeitos, é possível, através do ajuste de modelos matemáticos aos resultados experimentais da matriz, gerar os coeficientes de uma equação de regressão para cada parâmetro. Os modelos de ajuste mais utilizados geralmente são equações polinomiais de primeira ou segunda ordem, chamados modelos lineares e quadráticos (BARROS NETO; SCARMINIO; BRUNS, 2010).

Com tal equação, pode-se construir as superfícies de resposta, que basicamente permitem predições de máximos e mínimos nas respostas bem como avaliar a tendência da variação em uma resposta quando se avança em uma direção sobre um dos parâmetros. Além disso, pode-se obter respostas que seriam obtidas em qualquer condição situada dentro dos limites máximo e mínimo definidos para cada parâmetro sem que experimentos complementares tenham que ser realizados (BARROS NETO; SCARMINIO; BRUNS, 2010). 


\section{OBJETIVOS}

Diante do exposto, este trabalho teve por objetivo realizar modificações químicas e estruturais em catalisadores baseados em cobre e zircônia ou céria e avaliar os efeitos causados pelas modificações e como eles podem influenciar o processo de hidrogenação do $\mathrm{CO}_{2}$ a metanol.

De forma específica, na primeira etapa, foram utilizados átomos de índio como promotores em catalisadores compostos por cobre e zircônia e outros compostos por cobre e céria com o intuito de se obter melhorias na seletividade ao metanol devido a efeitos individuais e sinérgicos advindos da presença desse promotor.

Já na segunda etapa, sintetizou-se materiais encapsulados do tipo core-shell com revestimento formado por sílica mesoporosa, sendo o núcleo formado pelos teores de cobre, índio e zircônia ou céria que apresentaram os melhores resultados na etapa anterior.

O objetivo foi avaliar a eficiência do revestimento de sílica em minimizar a sinterização das partículas durante as etapas de tratamento térmico envolvidas nos processos de síntese bem como durante os testes reacionais realizados em valores mais altos de temperatura e, dessa forma, atingir melhorias no desempenho catalítico obtido ao se utilizar esses materiais. 


\title{
PROCEDIMENTO EXPERIMENTAL
}

\author{
Sintese dos Catalisadores
}

Catalisadores promovidos com índio

Três catalisadores baseados em cobre e zircônia assim como outros três materiais baseados em cobre e céria contendo diferentes teores de índio em sua composição $(0,5$ e $10 \%$ em teor molar para cada grupo) foram sintetizados pelo método de coprecipitação em $\mathrm{pH}$ constante assistida pelo surfactante CTAB.

Os materiais contendo zircônia e diferentes quantidade de índio foram denominados $\mathrm{Cu} / \mathrm{ZrO}_{2} ; \mathrm{Cu} / \mathrm{ZrO}_{2}-5 \% \mathrm{In}$ e $\mathrm{Cu} / \mathrm{ZrO}_{2}-10 \% \mathrm{In}$, formando um grupo chamado de $\mathrm{Cu} / \mathrm{ZrO}_{2}-\mathrm{X} \% \mathrm{In}$ e os baseados em céria com diferentes teores de índio foram denominados $\mathrm{Cu} / \mathrm{CeO}_{2} ; \mathrm{Cu} / \mathrm{CeO}_{2}-$ $5 \%$ In e $\mathrm{Cu} / \mathrm{CeO}_{2}-10 \%$ In que, juntos, formam o grupo chamado $\mathrm{Cu} / \mathrm{CeO}_{2}-\mathrm{X} \% \mathrm{In}$.

Para a síntese de cada material foi utilizado um béquer de 500mL. Detalhadamente, em um béquer contendo $250 \mathrm{~mL}$ de água destilada foram adicionados $60 \mathrm{mmol}$ de CTAB e quantidades apropriadas de cada um dos nitratos metálicos conforme definido para a síntese de cada material na Tabela 1.

Tabela 1. Quantidades molares dos sais precursores adicionados em $250 \mathrm{~mL}$ de água destilada na síntese dos catalisadores pertencentes aos grupos $\mathrm{Cu} / \mathrm{ZrO} 2-\mathrm{X} \% \mathrm{In}$ e $\mathrm{Cu} / \mathrm{CeO}_{2}-\mathrm{X} \% \mathrm{In}$.

\begin{tabular}{cccccc}
\hline Catalisador & $\begin{array}{c}\mathrm{Cu}\left(\mathrm{NO}_{3}\right)_{2} \\
(\mathrm{~mol})\end{array}$ & $\begin{array}{c}\mathrm{ZrO}\left(\mathrm{NO}_{3}\right)_{2} \\
(\mathrm{~mol})\end{array}$ & $\begin{array}{c}\mathrm{Ce}\left(\mathrm{NO}_{3}\right)_{3} \\
(\mathrm{~mol})\end{array}$ & $\begin{array}{c}\mathrm{In}\left(\mathrm{NO}_{3}\right)_{3} \\
(\mathrm{~mol})\end{array}$ & $\begin{array}{c}\mathrm{CTAB} \\
(\mathrm{mol})\end{array}$ \\
\hline $\mathrm{Cu} / \mathrm{ZrO}_{2}$ & 0,015 & 0,015 & --- & -- & 0,06 \\
$\mathrm{Cu} / \mathrm{ZrO}_{2}-5 \% \mathrm{In}$ & 0,015 & 0,0135 & --- & 0,0015 & 0,06 \\
$\mathrm{Cu} / \mathrm{ZrO}_{2}-10 \% \mathrm{In}$ & 0,015 & 0,012 & --- & 0,003 & 0,06 \\
\hline $\mathrm{Cu} / \mathrm{CeO}_{2}$ & 0,015 & --- & 0,015 & --- & 0,06 \\
$\mathrm{Cu} / \mathrm{CeO}_{2}-5 \% \mathrm{In}$ & 0,015 & --- & 0,0135 & 0,0015 & 0,06 \\
$\mathrm{Cu} / \mathrm{CeO}_{2}-10 \% \mathrm{In}$ & 0,015 & --- & 0,012 & 0,003 & 0,06 \\
\hline
\end{tabular}

Para cada material, a solução preparada foi mantida em agitação por 2 h. Essa solução foi denominada solução A. 
Paralelamente, em outro béquer foi preparada uma solução aquosa de $\mathrm{NaOH}$ na concentração de 0,5 mol.L ${ }^{-1}$, denominada solução B.

Em um terceiro béquer, foram adicionados $300 \mathrm{~mL}$ de água destilada. $\mathrm{O} \mathrm{pH}$ dessa solução foi ajustado para 10 utilizando-se a solução B. Essa terceira solução foi denominada solução C.

Utilizando-se duas buretas, as soluções A e B foram, então, adicionadas à solução C por meio de gotejamento lento de forma controlada para garantir que o $\mathrm{pH}$ se mantivesse em 10 com variação máxima de $\pm 0,3$. Todo o procedimento foi realizado em temperatura ambiente.

A solução resultante foi mantida em agitação por $12 \mathrm{~h}$. Após esse tempo, o precipitado gerado foi obtido por meio de filtração à vácuo e lavagem até $\mathrm{pH}$ neutro, seco em estufa a $60^{\circ} \mathrm{C}$ por $48 \mathrm{~h}$ e finalmente calcinado em mufla a temperatura de $600^{\circ} \mathrm{C}$ por $2 \mathrm{~h}$ sob atmosfera oxidante.

\section{Catalisadores Core-Shell}

Para síntese do material estruturado do tipo core-shell baseado em cobre, índio e zircônia, 0,89 $\mathrm{g}$ do polímero polivinilpirrolidona (PVP10) com massa molar média igual a 10000 g.mol ${ }^{-1}$ foram dissolvidos em $100 \mathrm{~mL}$ de uma solução de água e etanol (50\%/50\%) juntamente como 0,36 g de $\mathrm{Cu}\left(\mathrm{NO}_{3}\right)_{2}, 0,05 \mathrm{~g}$ de $\mathrm{In}_{2}\left(\mathrm{NO}_{3}\right)_{3}$ e 0,31 g de $\mathrm{ZrO}\left(\mathrm{NO}_{3}\right)_{2}$.

A mistura foi deixada em agitação por $4 \mathrm{~h}$ em temperatura ambiente de modo a garantir a total solubilização dos sais e das cadeias do polímero PVP. Após esse tempo, a solução resultante foi transferida para uma autoclave de teflon e aço inox preenchendo $80 \%$ de sua capacidade volumétrica.

A autoclave foi, então, colocada em estufa e mantida a $453 \mathrm{~K}$ por $12 \mathrm{~h}$. Após esse tempo, a suspensão contendo as partículas de óxido foi transferida para um béquer de 1L.

Após isso, foram introduzidos nesse mesmo béquer, 312, $8 \mathrm{~mL}$ de etanol, 93,9 mL de água, 14,5 mL de solução de hidróxido de amônio $27 \%$ v/v e $0,168 \mathrm{~g}$ do surfactante CTAB.

Essa suspensão foi deixada em agitação por $2 \mathrm{~h}$ em temperatura ambiente e, após esse tempo, 2,175 mL de TEOS foram gotejados sobre a mesma de forma muito lenta com um gotejamento de cerca de 1 gota por minuto.

A suspensão resultante foi deixada em agitação vigorosa por $24 \mathrm{~h}$ em temperatura ambiente. Após essa etapa, a suspensão foi centrifugada e o gel obtido foi seco em estufa a 353 K por $24 \mathrm{~h}$. 
Após esse tempo, o sólido resultante foi macerado e calcinado em mufla com atmosfera estática a $923 \mathrm{~K}$ por $6 \mathrm{~h}$.

O procedimento para obtenção do material estruturado do tipo core-shell contendo ceria em sua composição foi realizado da mesma forma com a diferença de que $0,59 \mathrm{~g}$ de $\mathrm{Ce}\left(\mathrm{NO}_{3}\right)_{3}$ foram dissolvidos na solução inicial no lugar dos $0,31 \mathrm{~g}$ de $\mathrm{ZrO}\left(\mathrm{NO}_{3}\right)_{2}$.

Os materiais foram nomeados CuZrIn-cs e CuCeIn-cs, respectivamente.

As proporções molares entre os cátions foi a mesma dos melhores catalisadores obtidos em etapas anteriores. $50 \%$ de cobre, $5 \%$ de índio e $45 \%$ de zircônio ou cério.

O PVP foi utilizado como agente de controle do tamanho e homogeneidade das partículas que seriam formadas e também como agente direcionador, juntamente com o CTAB, para formação do revestimento de sílica em torno das partículas de óxido formadas durante o tratamento solvotérmico.

\section{Caracterizações}

Difração de Raios X

Com o objetivo de se avaliar as fases cristalinas presentes na amostra foram realizadas análises de difração de raios X (DRX) em um equipamento Brucker, modelo Da Vinci D8 Advance, com fonte de radiação de cobre com comprimento de onda igual 1,5418, 40 $\mathrm{kV} / 15 \mathrm{~mA}$, passo de 0,25 , com tempo de radiação de $0,5 \mathrm{~s}$ por passo e varredura de nos valores de $2 \Theta$ indo de 10 a 70

Fluorescência de Raios X

A composição química dos materiais sintetizados foi analisada utilizando um espectrômetro de fluorescência de raios X PANalytical, modelo: MiniPaI4.

Microscopia Eletrônica de Transmissão

Com o objetivo de se avaliar tamanho, morfologia e distribuição dos elementos nos materiais gerados, foram realizadas análises de microscopia eletrônica de transmissão acoplada a espectroscopia de energia dispersiva de raios X. As análises foram realizadas em um 
microscópio eletrônico de transmissão JEOL, modelo 2100, acoplado a um espectrômetro de raios $\mathrm{X}$ dispersivos Thermo Scientific, operando com fonte de hexaborato de lantânio ( $\left.\mathrm{LaB}_{6}\right)$ e uma aceleração de $200 \mathrm{kV}$ de voltagem.

Redução a Temperatura Programada

A análise de redução a temperatura programada dos catalisadores foi realizada com o intuito de se obter informações acerca da redutibilidade dos materiais. Utilizou-se um modelo equipamento Micromeritics, modelo ChemiSorb 2750 com detector de condutividade térmica.

Para a realização da análise, utilizou-se uma massa de $100 \mathrm{mg}$ de amostra depositada em um reator de quartzo com formato em U. O reator contendo a amostra foi, então, introduzido em um forno equipado com controlador que opera com módulos de programação de rampa de aquecimento. Ainda em temperatura ambiente iniciou-se, sobre a amostra, a passagem de um fluxo de $25 \mathrm{~mL} \cdot \mathrm{min}^{-1}$ de uma mistura gasosa composta por $10 \% \mathrm{de}_{2}$ em argônio. Após essa etapa iniciou-se o aquecimento do sistema até $900{ }^{\circ} \mathrm{C}$ a uma taxa de $10^{\circ} \mathrm{C} \cdot \mathrm{min}^{-1}$.

A área dos picos de consumo de $\mathrm{H}_{2}$ gerados pelo detector de condutividade térmica foi convertida em número de mol de moléculas de hidrogênio, por meio do fator de conversão que expressa o número de mol $\mathrm{H}_{2}$ por unidade de área do pico gerado. Esse fator foi obtido realizando-se a redução de uma quantidade de massa conhecida de $\mathrm{Ag}_{2} \mathrm{O}$, utilizado como padrão para essa finalidade.

Para a obtenção do número de mol de cobre reduzido, foi utilizada a estequiometria de um mol de $\mathrm{H}_{2}$ para a redução de $\mathrm{Cu}^{2+} \mathrm{a} \mathrm{Cu}^{0}$.

O número de mol de cobre reduzido foi calculado pela equação:

$N^{\circ}$ mol Cu reduzido

$$
=\left(\text { Área do pico } x\left(\text { Fator de Conversão } \frac{\text { mol H2 }}{\text { Unidade de área }}\right) \times \frac{1 \text { molCu }}{1 \text { molH2 }}\right)
$$

Já a redutibilidade em porcentagem $(\mathrm{R}(\%))$ foi calculada pela equação:

$$
R(\%)=\frac{N^{\circ} \text { mol de Cu reduzido }}{N^{\circ} \text { total de mol de Cu no catalisador }} \times 100 \%
$$


$R(\%)$

$=\frac{\left.\left(\text { Área do pico } x \text { (F.Conversão } \frac{\text { mol H2 }}{\text { Unidade de área }}\right) \times \frac{1 \text { molCu }}{1 \text { molH2 }} \times \text { Massa Molar Cu }\right)}{\text { (Massa de Catalisador x Fração Mássica de Cu no catalisador })} \times 100 \%$

Difração de Raios X in-situ

As análises de difração de raios $\mathrm{X}$ in situ foram realizadas utilizando-se um difratômetro da marca Huber com detector Cyberstar na linha de luz D10B-XPD localizada no Laboratório Nacional de Luz Sincrotron (LNLS) em Campinas, São Paulo, Brasil. O comprimento de onda utilizado foi igual a $1,5406 \AA$. Foi explorada a região de angulação $2 \Theta$ entre $20^{\circ}$ e $55^{\circ}$.

Os materiais foram colocados em porta amostras que foram, então, inseridos em um forno tipo arara equipado com controladores de temperatura. Para o processo de redução dos catalisadores utilizou-se um fluxo de $30 \mathrm{~mL} \cdot \mathrm{min}^{-1}$ de uma mistura gasosa contendo $5 \%$ de $\mathrm{H}_{2}$ diluído em He. A cinética de redução ocorreu sob aquecimento de $5{ }^{\circ} \mathrm{C} \cdot \mathrm{min}^{-1}$ até $230{ }^{\circ} \mathrm{C}$, temperatura essa que foi mantida por 60 min enquanto difratogramas foram sendo coletados.

Fisissorção de $\mathrm{N}_{2}$

A área específica de superfície foi obtida através de isotermas de fisissorção de nitrogênio em um equipamento Quantachrome NOVA 1000 v.10.02. Para isso, foi utilizado o método B.E.T.; a distribuição de tamanho de poros foi obtida pelo modelo BJH e a área de microporos calculada pelo modelo t-plot.

Para tanto, primeiramente a amostra foi aquecida em um porta amostras para degaseificação e limpeza da superfície na temperatura de $250{ }^{\circ} \mathrm{C}$ por $2 \mathrm{~h}$ sob condições de vácuo. Após esse processo, o porta amostra foi colocado em contato com nitrogênio líquido e iniciou-se a passagem de fluxo de $\mathrm{N}_{2}$ sobre as amostras para que se desse o processo de adsorção e posterior dessorção para obtenção das isotermas.

Quimissorção de $\mathrm{N}_{2} \mathrm{O}$

Para que se obtivesse as áreas metálicas de superfície para os materiais sintetizados, foram realizadas análises de quimissorção de $\mathrm{N}_{2} \mathrm{O}$. Utilizou-se um equipamento com sistema analítico multipropósito (SAMP3) equipado com detector de condutividade térmica. 
Para a análise, foram utilizados $100 \mathrm{mg}$ de massa de amostra em um reator de quartzo em forma U. O reator foi, então, introduzido em um forno com sistema de aquecimento controlado com possibilidade de programação de rampa. Inicialmente, a amostra foi aquecida até $250{ }^{\circ} \mathrm{C}$ a uma rampa de $5{ }^{\circ} \mathrm{C} \cdot \mathrm{min}^{-1}$ e mantida nessa temperatura por uma hora sob fluxo de argônio para limpeza de sua superfície.

Após isso, a amostra foi resfriada e iniciou-se a primeira redução com aquecimento de $5{ }^{\circ} \mathrm{C} \cdot \mathrm{min}^{-1}$ até $230{ }^{\circ} \mathrm{C}$ por $1 \mathrm{~h}$ sob fluxo de $1 \%$ de $\mathrm{H}_{2}$ em argônio (RTP1). Após essa etapa, a amostra foi resfriada a temperatura ambiente sob fluxo de $\mathrm{N}_{2}$, o qual foi mantido após o resfriamento por mais 30 min com o objetivo de remover as moléculas de $\mathrm{H}_{2}$ ainda fisissorvidas na superfície.

Após esse procedimento, foi passado pela amostra, à $30{ }^{\circ} \mathrm{C}$, um fluxo de $30 \mathrm{~mL} \cdot \mathrm{min}^{-1}$ de uma mistura gasosa composta por $10 \%$ de $\mathrm{N}_{2} \mathrm{O}$ em hélio para que ocorresse a oxidação apenas dos átomos de cobre superficiais uma vez que o $\mathrm{N}_{2} \mathrm{O}$ é um oxidante fraco. A temperatura ambiente utilizada foi necessária para evitar reduções parciais na superfície da céria que gerariam interferência na análise da área metálica para o cobre. O fluxo dessa mistura gasosa foi mantido por $30 \mathrm{~min}$.

Após essa etapa, a superfície da amostra foi novamente limpa por um fluxo de $\mathrm{N}_{2}$ que se manteve por $1 \mathrm{~h}$, ainda a $30^{\circ} \mathrm{C}$. Após, foi realizado um segundo ciclo de redução com a passagem da mistura gasosa composta por $1 \%$ de $\mathrm{H}_{2}$ em argônio e aquecimento até $230{ }^{\circ} \mathrm{C}$ a uma rampa de $5{ }^{\circ} \mathrm{C} \cdot \mathrm{min}^{-1}$ por mais $1 \mathrm{~h}$ (RTP2). O consumo de hidrogênio nessa última etapa é relativo à redução do cobre presente na superfície do catalisador.

A área dos picos de consumo de $\mathrm{H}_{2}$ gerados pelo detector de condutividade térmica foi convertida em número de mol de moléculas de hidrogênio, por meio do fator de conversão $5,748 \times 10^{-5} \mathrm{~mol} \mathrm{H}_{2}$ por unidade de área do pico gerado. Esse fator foi obtido realizando-se a redução de uma quantidade de massa conhecida de $\mathrm{Ag}_{2} \mathrm{O}$, utilizado como padrão para essa finalidade.

Para a obtenção do número de mol de cobre reduzido, foi utilizada a estequiometria de um mol de $\mathrm{H}_{2}$ para a redução de $\mathrm{Cu}^{2+}$ a $\mathrm{Cu}^{0}$ e de meio mol de $\mathrm{H}_{2}$ para a redução do $\mathrm{Cu}^{+}$em cobre metálico.

A dispersão do cobre, em porcentagem, foi calculada pela equação:

$$
\text { Dispersão Cu }(\%)=\frac{N^{\circ} \text { mol de Cu superfície }}{N^{\circ} \text { mol Cu total do catalsidor }} \times 100 \%
$$




$$
\text { Dispersão Cu(\%) }=\frac{N^{\circ} \text { mol Cu }\left(2^{\circ} \text { redução) } x\right. \text { Massa Molar Cu }}{\text { Massa Catalisador x Fração Molar de Cobre }} \times 100 \%
$$

A área metálica para os catalisadores foi obtida utilizando o fator de conversão que representa o número de átomos de cobre necessários para ocupar $1 \mathrm{~m}^{2}$ de superfície $\left(1,46 \times 10^{19}\right.$ átomos $\mathrm{Cu} / \mathrm{m}^{2}$ ), por meio da equação:

$$
\begin{aligned}
& \text { Área metálica } C u\left(m^{2} \cdot g^{-1}\right)=\frac{N^{\circ} \text { átomos Cu superfície }}{F \cdot \text { Conversão } \frac{\text { átomos } C u}{m^{2}} \times \text { Massa catalisador }(g)} \\
& \text { Área metálica } C u\left(m^{2} \cdot g^{-1}\right)=\frac{N^{\circ} \text { mol Cu }\left(2^{\text {a }} \text { redução }\right) \cdot 6,02 \times 10^{23}\left(\frac{\text { átomos }}{m o l}\right)}{F . \text { Conversão } \frac{\text { átomos } C u}{m^{2}} \cdot \text { Massa catalisador }(g)}
\end{aligned}
$$

Dessorção de $\mathrm{CO}_{2}$ a Temperatura Programada

Para quantificar os sítios básicos na superfície dos catalisadores foram realizadas análises de dessorção à temperatura programada de $\mathrm{CO}_{2}$. Utilizou-se um equipamento Micromeritics, modelo ChemiSorb 2750 com detector de condutividade térmica.

Para a realização da análise, utilizou-se uma massa de $100 \mathrm{mg}$ de amostra depositada em um reator de quartzo com formato em U. O reator contendo a amostra foi, então, introduzido em um forno equipado com controlador que opera com módulos de programação de rampa de aquecimento. Inicialmente, foi realizada a limpeza da superfície da amostra com aquecimento até $250{ }^{\circ} \mathrm{C}$ em rampa de $10{ }^{\circ} \mathrm{C} \cdot \mathrm{min}^{-1}$ sob fluxo de argônio, a temperatura final foi mantida por $1 \mathrm{~h}$.

Após essa etapa, a amostra foi resfriada à temperatura ambiente e realizou-se uma redução com aquecimento até $230^{\circ} \mathrm{C}$ em rampa de $10{ }^{\circ} \mathrm{C} \cdot \mathrm{min}^{-1} \mathrm{com}$ a passagem de fluxo de uma mistura gasosa composta por $10 \%$ de $\mathrm{H}_{2}$ em argônio. A temperatura final foi, novamente, mantida por $1 \mathrm{~h}$.

Após isso, a amostra foi resfriada sob fluxo de $\mathrm{N}_{2}$ e foi mantido por $30 \mathrm{~min}$, após se ter atingido a temperatura ambiente, para remover as moléculas de $\mathrm{H}_{2}$ adsorvidas na superfície das 
amostras. Foi então, passado sobre as amostras um fluxo de $\mathrm{CO}_{2}$ de $30 \mathrm{~mL} \cdot \mathrm{min}^{-1}$ por $30 \mathrm{~min}$ para garantir a saturação da adsorção dessas moléculas na superfície dos catalisadores.

A partir de então, iniciou-se o processo de dessorção com aquecimento da amostra sob fluxo de $\mathrm{N}_{2}$ até $200{ }^{\circ} \mathrm{C}$ em rampa de $10{ }^{\circ} \mathrm{C} \cdot \mathrm{min}^{-1}$. Essa temperatura final foi mantida até que não houvesse mais dessorção de $\mathrm{CO}_{2}$ verificada pela estabilização no sinal gerado pelo detector de condutividade térmica. A temperatura final de $200{ }^{\circ} \mathrm{C}$ foi escolhida por se tratar da temperatura na qual as reações ocorreriam.

A conversão da área dos picos gerados em mol de $\mathrm{CO}_{2}$ foram calculadas utilizando o fator de conversão obtido pela curva de calibração do $\mathrm{CO}_{2}$ ao se relacionar volumes conhecidos de $\mathrm{CO}_{2}$ injetados à área dos picos, por esses volumes gerados, segundo a equação:

$\frac{N^{\circ} \text { mol de CO2 }}{\text { grama de catalisador }}$
$=\frac{\text { Área dos picos } x \text { F.Conversão }\left(\frac{L C O 2}{\text { Unidade de área }}\right) \times \frac{1 \mathrm{~atm}}{0,082\left(\mathrm{~atm} . \mathrm{Lr}_{\mathrm{mol}}^{-1} \cdot \mathrm{K}^{-1}\right) \times T(\mathrm{~K})}}{\text { massa do catalisador }(\mathrm{g})}$

Espectroscopia Fotoeletrônica por Raios X

As análises de espectroscopia eletrônica por raios $\mathrm{X}$ foram realizadas em um equipamento PHOIBOS-150 (SPECS) que opera em UHV (Ultra alto vácuo), usando um espectrômetro eletrônico equipado com um analisador hemisférico PHOIBOS 150, um canhão de Raios X XR-50 de duplo anodo (Mg /Al-1,2-1,4 KeV), com feixe não monocromatizado.

Este equipamento permite identificar e quantificar quaisquer elementos químicos em uma superfície (Exceto $\mathrm{H}_{2}$ e $\mathrm{He}$ ) de espessura nanométrica (até $10 \mathrm{~nm}$ ), além de interações eletrônicas entre estes. As amostras foram analisadas com anodo de Al $\mathrm{K} \alpha$. Foram utilizadas como energia de passagem valores de $50 \mathrm{eV}$, passo de 1 e 15 scans (varreduras), para o espectro de ampla varredura.

Para as regiões de interesse utilizou-se $20 \mathrm{eV}$ como energia de passagem e varreduras acima de 25 scans. O passo foi mantido em $0,08 \mathrm{eV}$ para a obtenção dos espectros das regiões de alta resolução. $\mathrm{O}$ nível eletrônico $\mathrm{C} 1 \mathrm{~s}$ foi tomado como referência para a calibração dos espectros obtidos. Para a quantificação foi utilizado o software CasaXPS 2.3.16. A quantificação da composição elementar de superfície foi realizada pelo espectro survey. 


\section{Testes Catalíticos}

Os testes catalíticos preliminares foram realizados em um reator do tipo leito fixo modelo Microactivity Effi, da marca PID Eng \& Tech. O reator foi alimentado com uma mistura de $\mathrm{H}_{2}\left(15 \mathrm{~mL} \cdot \mathrm{min}^{-1}\right)$ e $\mathrm{CO}_{2}\left(5 \mathrm{~mL} \cdot \mathrm{min}^{-1}\right)$. Foram utilizados os valores de pressão, temperatura e velocidade espacial iguais a $3 \mathrm{MPa}, 473 \mathrm{~K}$ e $6 \mathrm{~L} \cdot \mathrm{g}^{-1} \cdot \mathrm{h}^{-1}$. Foi utilizada a massa de $200 \mathrm{mg}$ de catalisador misturados a $100 \mathrm{mg}$ de carbeto de silício. Anteriormente ao início da reação, os materiais foram reduzidos in situ, com a taxa de aquecimento de $10 \mathrm{~K} \cdot \mathrm{min}^{-1}$, sob fluxo de $\mathrm{H}_{2}$ $\left(30 \mathrm{~mL} \cdot \mathrm{min}^{-1}\right)$ por $1 \mathrm{~h}$. As temperaturas de redução para os catalisadores pertencentes aos grupos $\mathrm{Cu} / \mathrm{ZrO}_{2}-\mathrm{X} \% \mathrm{In}$ e $\mathrm{Cu} / \mathrm{CeO}_{2}-\mathrm{X} \%$ In foram $503 \mathrm{~K}$ e $513 \mathrm{~K}$, respectivamente. Já a temperatura de redução para os catalisadores core-shell CuZrIn-cs e CuCeIn-cs foi $573 \mathrm{~K}$.

A mistura gasosa contendo os produtos gerados no reator durante os testes reacionais foi analisada em linha por cromatografia em fase gasosa, utilizando-se um cromatógrafo a gás Agilent Technologies modelo 7890A, equipado com um detector de condutividade térmica e outro por ionização de chama.

Os valores de conversão e seletividade, em porcentagem, foram calculados segundo as equações:

$$
\begin{gathered}
\text { Conversão }(\%)=\frac{N^{\circ} \text { mol CO2 } 2_{\text {convertido }}}{N^{\circ} \text { mol CO2 } 2_{\text {total }}} \times 100 \% \\
\text { Conversão }(\%)=\frac{\left(N^{\circ} \text { mol CO2 } 2_{\text {entrada reator }}-N^{\circ} \text { molCO2 } 2_{\text {saída reator }}\right)}{N^{\circ} \text { molCO2 } 2_{\text {entrada reator }}} \times 100 \% \\
\text { Seletividade } \text { produto A }(\%)=\frac{N^{\circ} \text { mol formado } \text { produto A }_{\text {A }}}{N^{\circ} \text { mol CO } 2_{\text {convertido }}} \times 100 \%
\end{gathered}
$$

Já os cálculos de turnover frequency (TOF) e produtividade molar foram calculados segundo às equações:

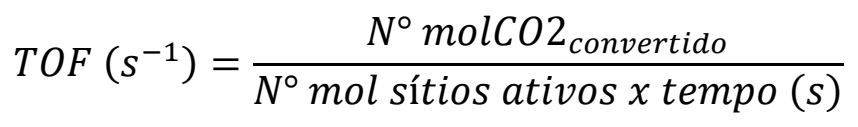




$$
\text { Produtividade Molar }\left(\text { mol. } h^{-1} \cdot g^{-1}\right)=\frac{N^{\circ} \text { mol produto } A_{\text {formado }}}{\text { Massa catalisador }(g) \times \operatorname{Tempo}(h)}
$$

Os cálculos de TOF foram realizados em condições reacionais nas quais a conversão de $\mathrm{CO}_{2}$ foi inferior a $10 \%$. Além disso, diante da impossibilidade de quantificar o número exato de regiões de interface, que são os sítios ativos na superfície do catalisador, muitos pesquisadores fazem uma aproximação utilizando a área metálica como sítios ativos, uma vez que essa propriedade se mostra diretamente proporcional às regiões de interface (CHANG; WANG; CHEN, 2017).

\section{Otimização Quimiométrica}

Os procedimentos de otimização foram realizados utilizando ferramentas quimiométricas. Para todos os catalisadores otimizados, os experimentos foram conduzidos de acordo com que é estabelecido pelo planejamento experimental do tipo Compósito Central contando com pontos mínimos, máximos, médios e axiais que estão detalhados na Tabela 2 (BARROS NETO; SCARMINIO; BRUNS, 2010; NUNES et al., 2012).

Tabela 2. Valores definidos para os pontos mínimos, máximos, médios, axiais mínimos e axiais máximos dos parâmetros de pressão, temperatura e velocidade espacial.

\begin{tabular}{cccccc}
\hline Variável & Ponto & Ponto & Ponto & Ponto Axial & Ponto Axial \\
& Mínimo & Máximo & Médio & Mínimo & Máximo \\
& $(-1)$ & $(+1)$ & $(0)$ & $(-1,68)$ & $(+1,68)$ \\
\hline Pressão $(\mathrm{MPa})$ & 2 & 3 & 2,5 & 1,66 & 3,34 \\
Temperatura $(\mathrm{K})$ & 473 & 523 & 498 & 455,96 & 540,04 \\
V. Espacial $\left(\mathrm{L} \cdot \mathrm{g}^{-1} \cdot \mathrm{h}^{-1}\right)$ & 6 & 12 & 9 & 3,95 & 14,05 \\
\hline
\end{tabular}

A resposta desejada a ser otimizada foi a seletividade ao metanol. Dessa forma, a matriz de experimentos definida pelo planejamento escolhido foi composta por 17 ensaios que se encontram na Tabela 3. 
Tabela 3. Matriz de experimentos definidos pela metodologia de planejamento experimental do tipo Compósito Central a partir de combinações entre pontos mínimos, máximos, médios e axiais de cada parâmetro.

\begin{tabular}{|c|c|c|c|}
\hline Ensaios & $\begin{array}{c}\mathrm{P} \\
(\mathrm{MPa})\end{array}$ & $\begin{array}{c}\mathrm{T} \\
(\mathrm{K})\end{array}$ & $\begin{array}{l}\text { V. Espacial } \\
\left(\mathrm{L} \cdot \mathrm{g}^{-1} \cdot \mathrm{h}^{-1}\right)\end{array}$ \\
\hline 1 & 2 & 473 & 6 \\
\hline 2 & 2 & 473 & 12 \\
\hline 3 & 2 & 523 & 6 \\
\hline 4 & 2 & 523 & 12 \\
\hline 5 & 3 & 473 & 6 \\
\hline 6 & 3 & 473 & 12 \\
\hline 7 & 3 & 523 & 6 \\
\hline 8 & 3 & 523 & 12 \\
\hline 9 & 1,66 & 498 & 9 \\
\hline 10 & 3,34 & 498 & 9 \\
\hline 11 & 2,5 & 455,96 & 9 \\
\hline 12 & 2,5 & 540,04 & 9 \\
\hline 13 & 2,5 & 498 & 3,95 \\
\hline 14 & 2,5 & 498 & 14,05 \\
\hline 15 & 2,5 & 498 & 9 \\
\hline 16 & 2,5 & 498 & 9 \\
\hline 17 & 2,5 & 498 & 9 \\
\hline
\end{tabular}

A partir das seletividades ao metanol obtidas em cada experimento, foram avaliados os efeitos principais de variação de cada parâmetro, bem como os efeitos de interação entre os mesmos sobre o processo de hidrogenação do $\mathrm{CO}_{2}$ ao metanol. Os resultados foram expressos graficamente por gráficos de Pareto. Todas os cálculos foram realizados com 95\% de confiança (BARROS NETO; SCARMINIO; BRUNS, 2010; NUNES et al., 2012).

As superfícies de resposta foram construídas utilizando-se modelos quadráticos e quadráticos puros de ajuste, nos quais os dados experimentais são ajustados a uma equação de regressão do tipo polinomial de segundo grau (BARROS NETO; SCARMINIO; BRUNS, 2010; NUNES et al., 2012). 
Essa equação é capaz realizar predições acerca dos valores de seletividade ao metanol para combinações específicas de pressão, temperatura e velocidade espacial que não foram testadas experimentalmente, desde que se encontrem situadas dentro dos limites da faixa de análise definidos pelos pontos axiais empregados na metodologia de planejamento do tipo Compósito Central. O processamento e tratamento estatístico de todos os dados foi realizado utilizando-se o software livre Chemoface versão 1.6.1. (BARROS NETO; SCARMINIO; BRUNS, 2010; NUNES et al., 2012).

\section{Cálculo da Energia de Ativação Aparente}

Os cálculos das energias de ativação aparente para metanol e monóxido de carbono utilizando os catalisadores $\mathrm{Cu} / \mathrm{CeO}_{2}-5 \% \mathrm{In}, \mathrm{Cu} / \mathrm{ZrO}_{2}-5 \% \mathrm{In}, \mathrm{CuZrIn}$-cs e CuCeIn-cs foram realizadas de acordo com a equação de Arrhenius. Os valores de produtividade molar de metanol e monóxido de carbono em diferentes temperaturas mantendo-se a pressão e a velocidade espacial constantes foram mensurados e tomados como medida da velocidade das reações. A metodologia de escolha e quantificação dos sítios ativos se baseou no que é reportado na literatura em Chang et al., (2017) (CHANG; WANG; CHEN, 2017). 


\section{RESULTADOS E DISCUSSÃO}

Catalisadores $\mathrm{Cu} / \mathrm{CeO}_{2}-\mathrm{X} \%$ In e $\mathrm{Cu} / \mathrm{ZrO}_{2}-\mathrm{X} \% \mathrm{In}$

\section{Caraterizações}

Os difratogramas de raios X para os materiais contendo zircônia bem como para aqueles contendo céria são mostrados na Figura 1.

Figura 1. Difração de raios X para os catalisadores pertencentes aos grupos $\mathrm{Cu} / \mathrm{ZrO} 2-\mathrm{X} \% \mathrm{In}$ e $\mathrm{Cu} / \mathrm{CeO}_{2}-\mathrm{X} \% \mathrm{In}$.
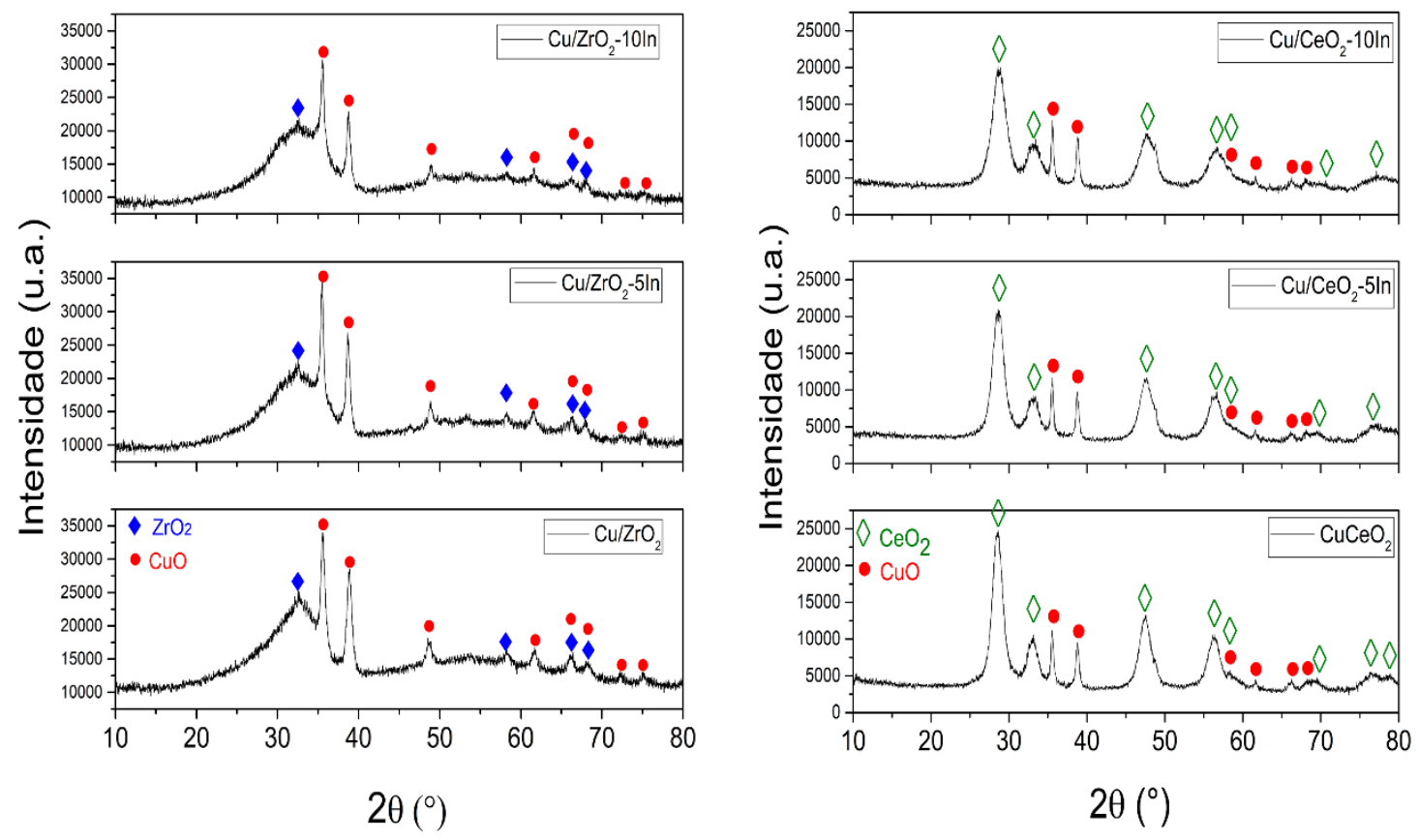

Em todos os materiais contendo zircônia, os picos observados em valores de $2 \theta$ iguais a $35^{\circ}, 38^{\circ}$ e $48^{\circ}$ estão relacionados ao óxido de cobre enquanto os picos em $32^{\circ}$ e $58^{\circ}$ se originam da difração no óxido de zircônio de acordo com os padrões cristalográficos JCPDS n ${ }^{\circ}$ 41-0254 e 81-1551, respectivamente. Os picos em cerca de $62^{\circ}$ e $68^{\circ}$ apresentam contribuições de ambos os óxidos (ÁGUILA et al., 2009; ESPOSITO et al., 2011; GUO et al., 2011; LI, L. et al., 2015; LI, YAWEI; CHAN; SUN, 2015; UD DIN et al., 2015)..

Além disso, a largura de picos como o que se encontra em $32^{\circ}$ e a relação sinal/ruído sugere que parte da zircônia presente nos catalisadores é não-cristalina (ÁGUILA et al., 2009; 
ESPOSITO et al., 2011; GUO et al., 2011; LI, L. et al., 2015; LI, YAWEI; CHAN; SUN, 2015; UD DIN et al., 2015).

Já para os materiais contendo céria, os picos localizados em $28,6^{\circ} ; 33,2^{\circ} ; 47,5^{\circ} ; 56,4^{\circ}$; $56^{\circ} ; 58^{\circ} ; 69,3^{\circ} ; 76,6^{\circ}$ e $78,1^{\circ}$ se referem ao óxido de cério enquanto os picos em $35^{\circ} ; 38^{\circ}$; $61,6^{\circ} ; 66,2$ e $68^{\circ}$ se originam em decorrência do perfil de difração do óxido de cobre de acordo com os padrões cristalográficos JCPDS n 41-0254 e 34-0394 que representam o óxido de cobre e o de cério, respectivamente (GUO et al., 2011; LI, L. et al., 2015; ZABILSKIY et al., 2015).

Em nenhum dos materiais promovidos foram verificados picos referentes ao óxido de índio. De acordo com uma série de autores, a não observância de $\mathrm{In}_{2} \mathrm{O}_{3}$ nos difratogramas sugere duas possibilidades, sendo a primeira a de que átomos de índio podem ter sido incorporados como dopantes nas redes estruturais dos demais óxidos e a segunda que as partículas de óxido de índio formadas se encontram não-cristalinas ou mesmo que as nanopartículas desse óxido estejam altamente dispersas, o que impediria a sua detecção pela técnica de difração de raios X devido à seu pequeno diâmetro (CHUAH et al., 1996; GUO et al., 2011; LI, L. et al., 2015; LOU et al., 2014; NAIK; SALKER, 2018).

Diferentemente do que foi observado para os materiais contendo zircônia, o grau de cristalinidade dos materiais $\mathrm{Cu} / \mathrm{CeO}_{2}-\mathrm{X} \%$ In foi o suficiente para permitir que o refinamento de Rietveld fosse realizado com a devida confiabilidade estatística expressa pelos parâmetros que avaliam a qualidade do ajuste entre o difratogramas experimental e o calculado. Os resultados se encontram na Figura 2 e Tabela 4. 
Figura 2. Refinamento de Rietveld aplicado aos materiais $\mathrm{Cu} / \mathrm{CeO} 2, \mathrm{Cu} / \mathrm{CeO}_{2}-5 \% \mathrm{In}$ e $\mathrm{Cu} / \mathrm{CeO}_{2}-$ $10 \%$ In após calcinação em $873 \mathrm{~K}$ por $2 \mathrm{~h}$.

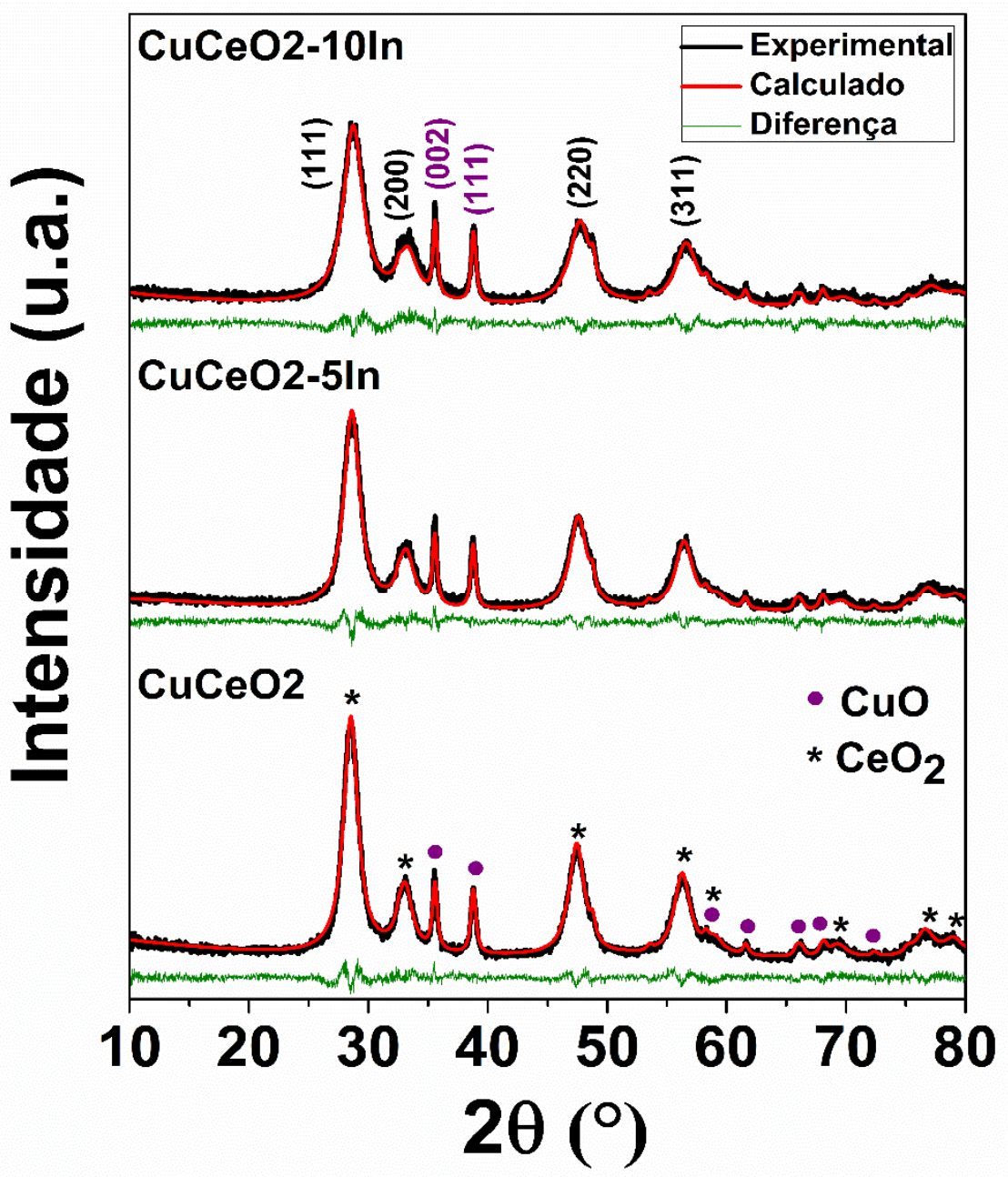

Tabela 4. Volume de célula unitária e parâmetro de rede (a) para a estrutura da céria calculados através do Refinamento de Rietveld e fatores Rwp e GOF de qualidade do ajuste.

\begin{tabular}{ccccc}
\hline Catalisadores & $\mathrm{aCeO} 2(\AA)$ & $\mathrm{V}_{\mathrm{CeO} 2}\left(\AA^{3}\right)$ & $\mathrm{Rwp}$ & GOF \\
\hline $\mathrm{Cu} / \mathrm{CeO}_{2}$ & 5,423 & 159,40 & 5,20 & 3,70 \\
$\mathrm{Cu} / \mathrm{CeO}_{2}-5 \% \mathrm{In}$ & 5,411 & 158,43 & 5,50 & 3,85 \\
$\mathrm{Cu} / \mathrm{CeO}_{2}-10 \% \mathrm{In}$ & 5,401 & 157,59 & 5,46 & 4,01 \\
\hline
\end{tabular}


A partir da análise dos dados presentes na Tabela 4 é possível notar uma diminuição no parâmetro de rede (a) e no volume de célula unitária dos cristalitos de $\mathrm{CeO}_{2}$ à medida que o teor de índio aumenta nos materiais, o que sugere fortemente que átomos de índio estejam localizados como dopantes na estrutura da céria.

Segundo Lou et al., (2014); Ma et al., (2017) e Mcfarland e Metiu, (2013), a introdução de cátions dopantes com raio iônico e número de coordenação distintos dos cátions que formam a rede iônica do óxido principal que está sendo dopado leva a alterações nos parâmetros de rede e volume de célula unitária do óxido principal exatamente como foi observado para os materiais $\mathrm{Cu} / \mathrm{CeO}_{2}-5 \%$ In e $\mathrm{Cu} / \mathrm{CeO}_{2}-10 \%$ In em comparação ao material $\mathrm{Cu} / \mathrm{CeO}_{2}$ (LOU et al., 2014; MA et al., 2017; MCFARLAND; METIU, 2013).

De forma mais específica, o raio iônico das espécies $\operatorname{In}^{3+}(0,94 \AA)$ e seu número de coordenação são menores que o raio iônico das espécies $\mathrm{Ce}^{4+}(1,04 \AA)$. Assim, a dopagem da estrutura da céria com átomos de índio levará a uma contração da célula unitária causando reduções nos valores, tanto do parâmetro de rede (a), quando no volume, conforme foi observado para os catalisadores por meio dos dados presentes na Tabela 4 (NAIK; SALKER, 2018).

Além disso, à medida que o teor de índio aumenta nos materiais, há um deslocamento dos picos de difração referentes à $\mathrm{CeO}_{2}$ para maiores ângulos, o que, de acordo com Lou et al., (2014) e Naik e Salker, (2018), corrobora a dopagem de átomos de índio na estrutura da céria (LOU et al., 2014; NAIK; SALKER, 2018).

No entanto, apesar da verificação da dopagem, é importante ressaltar que não é possível comprovar que, necessariamente, todos os átomos de índio introduzidos nos materiais estejam presentes como dopantes na estrutura da céria (LOU et al., 2014; NAIK; SALKER, 2018).

Parte dos átomos de índio podem ter gerado nanopartículas de óxido de índio segregadas que não poderiam ser detectadas pela técnica da difração de raios $\mathrm{X}$ por serem não-cristalinas ou por estarem altamente dispersas devido ao baixo teor desse elemento gerando perfis de difração com intensidade muito baixa (CHUAH et al., 1996; LOU et al., 2014; NAIK; SALKER, 2018).

Para os materiais contendo zircônia, a porção não cristalina dos materiais inviabilizou que a técnica de Refinamento de Rietveld pudesse ser realizada com alta confiabilidade estatística mensurada pelos parâmetros Rwp e GOF.

Em virtude da impossibilidade da verificação da presença de índio nos catalisadores por meio das difrações de raios $\mathrm{X}$, a composição elementar dos materiais pertencentes aos grupos 
$\mathrm{Cu} / \mathrm{ZrO}_{2}$-XIn e $\mathrm{Cu} / \mathrm{CeO}_{2}$-XIn foi analisada por meio da técnica de espectroscopia de fluorescência de raios $\mathrm{X}$ e os resultados estão expressos na Tabela 5.

Tabela 5. Composição elementar em porcentagem molar para os catalisadores dos grupos $\mathrm{Cu} / \mathrm{ZrO}_{2}-\mathrm{XIn}$ e $\mathrm{Cu} / \mathrm{CeO}_{2}-\mathrm{XIn}$ calculadas por espectroscopia de fluorescência de raios $\mathrm{X}$.

\begin{tabular}{ccccc}
\hline & \multicolumn{4}{c}{ Composição Elementar (\% molar) } \\
\cline { 2 - 5 } Catalisadores & $\mathrm{Zr}$ & $\mathrm{Ce}$ & $\mathrm{Cu}$ & $\mathrm{In}$ \\
\hline $\mathrm{Cu} / \mathrm{ZrO}_{2}$ & 45,7 & 0 & 54,4 & 0 \\
$\mathrm{Cu} / \mathrm{ZrO}_{2}-5 \% \mathrm{In}$ & 40,1 & 0 & 55,5 & 4,4 \\
$\mathrm{Cu} / \mathrm{ZrO}_{2}-10 \% \mathrm{In}$ & 36,0 & 0 & 55,9 & 8,1 \\
\hline $\mathrm{Cu} / \mathrm{CeO}_{2}$ & 0 & 47,5 & 52,5 & 0.0 \\
$\mathrm{Cu} / \mathrm{CeO}_{2}-5 \%$ In & 0 & 40,5 & 54,7 & 4,8 \\
$\mathrm{Cu} / \mathrm{CeO}_{2}-10 \%$ In & 0 & 35,9 & 55,3 & 8,8 \\
\hline
\end{tabular}

Pela Tabela 5 é possível verificar que o teor molar dos cátions se encontra próxima aos teores nominais, em especial no que se refere à concentração de átomos de índio nos materiais promovidos. Além disso, não foram encontradas impurezas ou contaminantes em nenhum dos materiais.

Análises de morfologia, distribuição de tamanho das partículas e mapeamento elementar foram realizadas por microscopia eletrônica de transmissão e os resultados se encontram nas Figuras 3 e 4, referentes aos materiais $\mathrm{Cu} / \mathrm{ZrO}_{2}-\mathrm{XIn}$ e $\mathrm{Cu} / \mathrm{CeO}_{2}-\mathrm{XIn}$, respectivamente. 
Figura 3. Microscopia eletrônica de transmissão acoplada a espectroscopia de energia dispersiva de raios $\mathrm{X}$ para os materiais $\mathrm{Cu} / \mathrm{ZrO}_{2}-\mathrm{XIn}$.
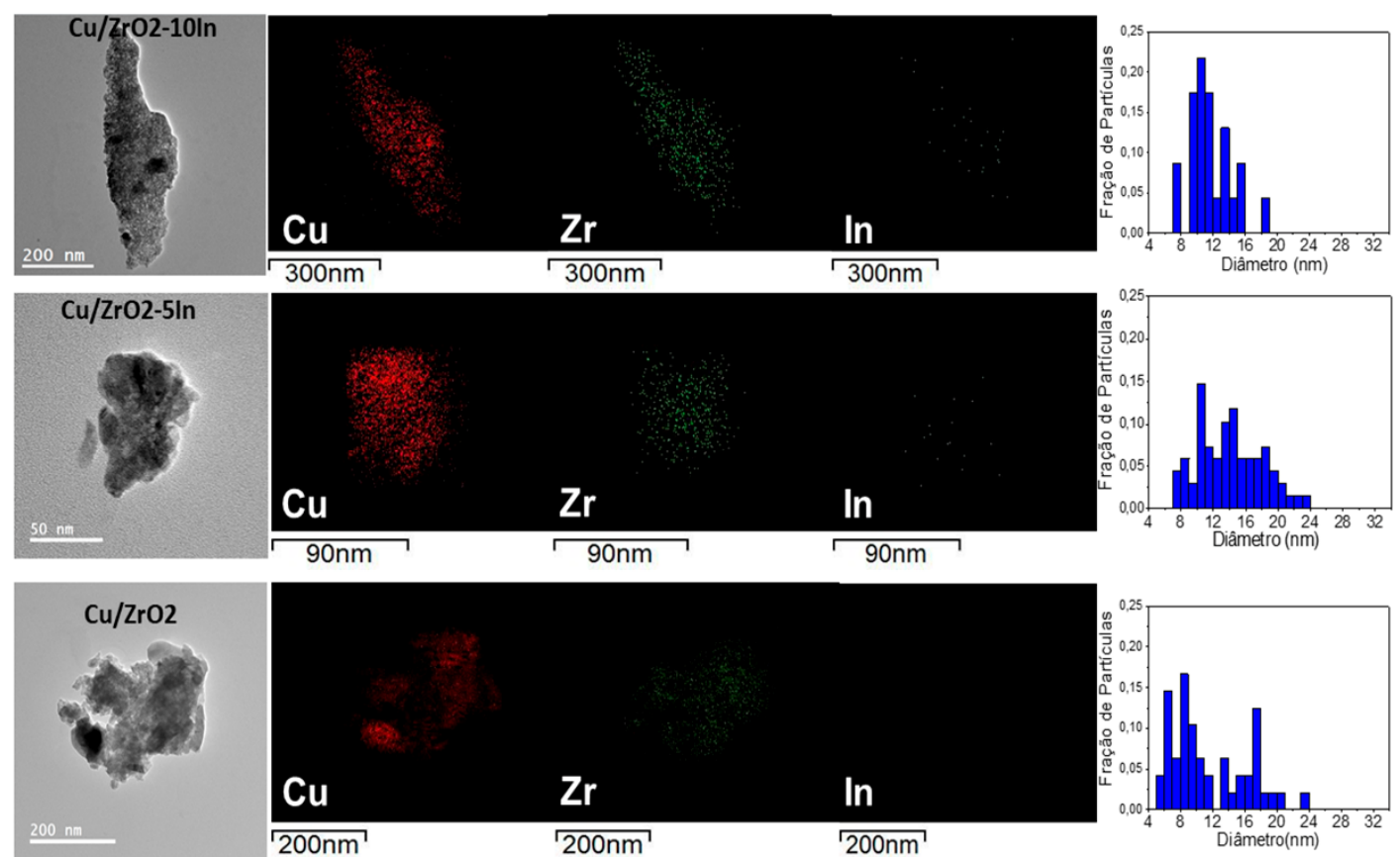

Figura 4. Microscopia eletrônica de transmissão acoplada a espectroscopia de energia dispersiva de raios $\mathrm{X}$ para os materiais $\mathrm{Cu} / \mathrm{CeO}_{2}-\mathrm{XIn}$.
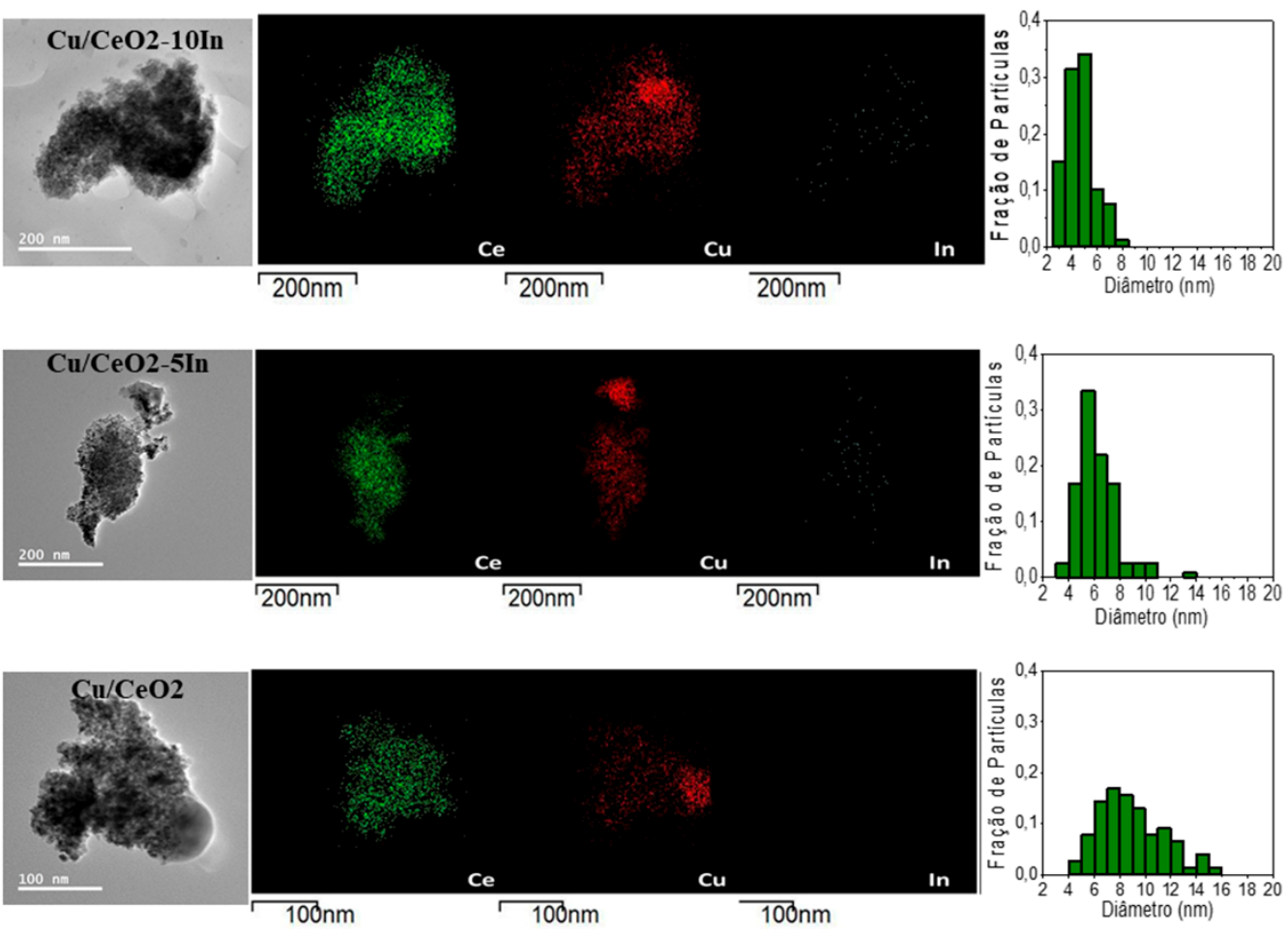
Pelas Figuras 3 e 4 é possível perceber que os catalisadores de ambos os grupos não apresentam morfologias definidas, o que é comumente observado para óxidos mistos sintetizados por métodos de coprecipitação por uma série de autores (DA SILVA et al., 2016; HU et al., 2014; JIANG et al., 2012; LI, YAWEI; CHAN; SUN, 2015).

Isso pode ser explicado pelo fato de que morfologias definidas (cubos, esferas, bastões) são obtidas quando há o crescimento preferencial de um plano cristalográfico específico em detrimento dos demais durante a geração dos cristalitos que se agruparão em partículas (LIU, Y.; GOEBL; YIN, 2013; ZABILSKIY et al., 2015).

Dessa forma, a existência de vários planos cristalográficos criados por cada um dos diferentes cátions e as interações entre eles impedem o crescimento ordenado e preferencial de apenas um dos planos, o que se torna um obstáculo para a obtenção de partículas que apresentem formas específicas e homogêneas entre si (LIU, Y.; GOEBL; YIN, 2013; ZABILSKIY et al., 2015).

Apesar disso, se, por um lado, a utilização de métodos de coprecipitação dificultam morfologias definidas, por outro, se mostra consideravelmente efetiva na geração de materiais com dispersão satisfatória entre os distintos elementos que constituem os catalisadores, o que contribui para a criação de um maior número de zonas interfaciais entre os diferentes domínios que constituem a superfície dos materiais (DA SILVA et al., 2016; GRACIANI et al., 2014; HU et al., 2014; KATTEL et al., 2016; RODRIGUEZ et al., 2015).

As análises de mapeamento elementar permitem verificar que, em todos os materiais, os elementos $\mathrm{Cu}$, In e $\mathrm{Zr}$ ou $\mathrm{Ce}$ se encontram predominantemente bem distribuídos, apesar de algumas poucas regiões nas quais há uma pequena segregação de cobre.

Para ambos os grupos de materiais é possível observar, ainda, uma maior homogeneidade entre o diâmetro das partículas à medida que se aumenta o teor de índio de nos materiais. Além disso, para ambos os grupos de catalisadores, especialmente os materiais contendo céria, é possível observar uma diminuição progressiva do tamanho médio de partícula nos catalisadores modificados com índio.

A redutibilidade dos materiais foi analisada por meio de análises de redução à temperatura programada e os resultados se encontram na Figura 5. 
Figura 5. Redução à temperatura programada para os grupos de catalisadores $\mathrm{Cu} / \mathrm{ZrO}_{2}-\mathrm{XIn} \mathrm{e}$ $\mathrm{Cu} / \mathrm{CeO}_{2} \mathrm{XIn}$.
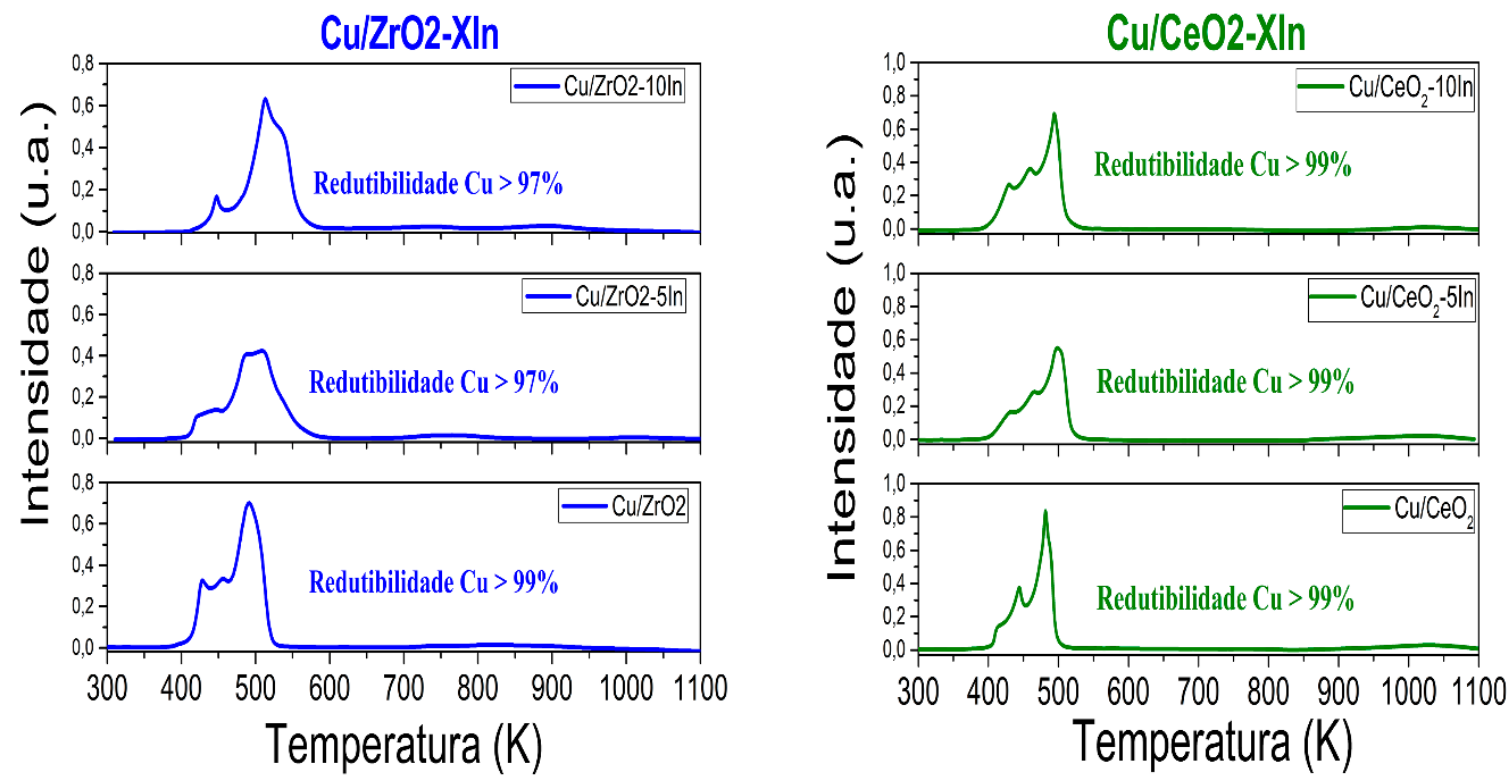

Tanto para os materiais contendo zircônia como para os catalisadores baseados em céria, as curvas de redução apresentam uma série de picos intensos convoluídos na faixa de temperatura entre $400 \mathrm{~K}$ e $600 \mathrm{~K}$ atribuídos à redução de óxido de cobre a cobre metálico (BANSODE et al., 2013; GUO et al., 2011; LARMIER et al., 2017; LI, L. et al., 2015).

De acordo com uma série de autores como Guo et al. (2011) e Maciel et al. (2012) Aguila et al., 2009; Esposito et al. (2011) Din et al. (2015) Chen Xu et al. (2010); Zhang et al. (2017), a ocorrência de mais de um pico de redução para o cobre é explicada pela existência de partículas de óxido de cobre com diferentes propriedades estruturais e físico-químicas devido a fatores como tamanho, morfologia e grau de interação com as partículas dos demais óxidos metálicos presentes nos materiais (ÁGUILA et al., 2009; CHEN et al., 2010; ESPOSITO et al., 2011; GUO et al., 2011; LI, L. et al., 2015; MACIEL et al., 2012; UD DIN et al., 2015; ZHANG, R. et al., 2017).

Os picos formados nos valores mais baixos de temperatura são referentes à redução de partículas de óxido de cobre altamente dispersas devido à interação com os óxidos de zircônio ou cério, enquanto os picos em torno de $500 \mathrm{~K}$ se referem à redução das partículas de óxido de cobre maiores e mais segregadas (GUO et al., 2011; LI, L. et al., 2015; MACIEL et al., 2012).

Além dos picos de cobre, há a formação de outros picos mais alargados e menos intensos que se iniciam em cerca de $700 \mathrm{~K}$ para os materiais contendo zircônia e $900 \mathrm{~K}$ para os 
catalisadores contendo céria. Tais picos são referentes às reduções parciais dos óxidos de zircônia e céria ocasionando a formação de vacâncias de átomos de oxigênio (ÁGUILA et al., 2009; CHEN et al., 2010; ESPOSITO et al., 2011; GUO et al., 2011; LI, L. et al., 2015; LI, YAWEI; CHAN; SUN, 2015; MACIEL et al., 2012; UD DIN et al., 2015; ZHANG, R. et al., 2017).

Vale ressaltar que a redutibilidade calculada dos átomos de cobre se mostrou muito próxima a $100 \%$ para todos os catalisadores.

Diante disso, após definidas as temperaturas nas quais o óxido de cobre nos diferentes catalisadores se reduz a cobre metálico, a cinética de redução foi avaliada por difração de raios $\mathrm{X}$ in-situ e os resultados se encontram na Figura 6.

Figura 6. Cinética de redução do óxido de cobre para os catalisadores pertencentes aos grupos $\mathrm{Cu} / \mathrm{ZrO}_{2}-\mathrm{XIn}$ e $\mathrm{Cu} / \mathrm{CeO}_{2}$-XIn.

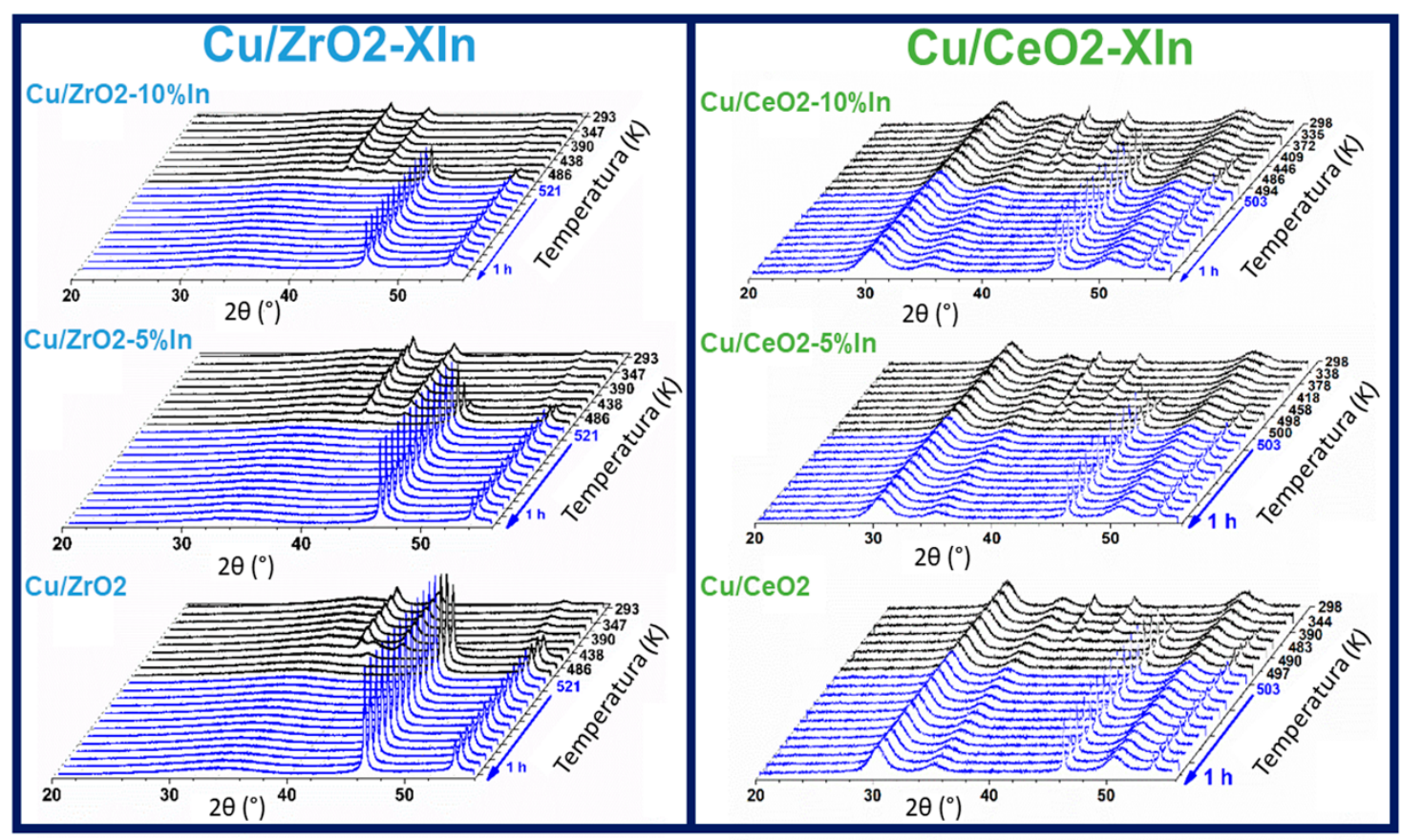

A análise dos difratogramas para os materiais evidencia que, a partir de $462 \mathrm{~K}$ para os materiais contendo zircônio e $483 \mathrm{~K}$ para os materiais baseados em céria, há uma diminuição da intensidade dos picos localizados em $38^{\circ}$ e $41^{\circ}$, relacionados ao óxido de cobre, até que sua detecção não seja mais possível (GUO et al., 2011; LI, L. et al., 2015; MACIEL et al., 2012).

Paralelamente, há o surgimento de picos localizados em $45^{\circ}$ e $55^{\circ}$ relacionados ao cobre metálico. Tais observações sugerem a completa redução das fases de óxido de cobre nos 
materiais, em concordância com os valores de redutibilidade que haviam sido calculados anteriormente (GUO et al., 2011; LI, L. et al., 2015; MACIEL et al., 2012).

Após os estudos estruturais, foram realizadas análises relacionadas à área específica de superfície e ao perfil de porosidade para os catalisadores e os resultados obtidos são apresentados na Tabela 6 e Figuras 7 e 8.

Tabela 6. Área específica de superfície e perfil de porosidade dos grupos de catalisadores $\mathrm{Cu} / \mathrm{ZrO}_{2}-\mathrm{XIn}$ e $\mathrm{Cu} / \mathrm{CeO}_{2}-\mathrm{XIn}$ calculado por fisissorção de $\mathrm{N}_{2}$.

\begin{tabular}{ccccc}
\hline Catalisadores & $\begin{array}{c}\text { Área Específica } \\
\text { de Superfície } \\
\left(\mathrm{m}^{2} \cdot \mathrm{g}^{-1}\right)^{*}\end{array}$ & $\begin{array}{c}\text { Volume Total } \\
\text { de Poros } \\
\left(\mathrm{cm}^{3} \cdot \mathrm{g}^{-1}\right)\end{array}$ & $\begin{array}{c}\text { Volume de } \\
\text { Mesoporos } \\
\left(\mathrm{cm}^{3} \cdot \mathrm{g}^{-1}\right)\end{array}$ & $\begin{array}{c}\text { Volume de } \\
\text { Microporos } \\
\left(\mathrm{cm}^{3} \cdot \mathrm{g}^{-1}\right)\end{array}$ \\
\hline $\mathrm{Cu} / \mathrm{ZrO}_{2}$ & 82,3 & 0,083 & 0,059 & 0,024 \\
$\mathrm{Cu} / \mathrm{ZrO}_{2}-5 \%$ In & 28,5 & 0,026 & 0,019 & 0,007 \\
$\mathrm{Cu} / \mathrm{ZrO}_{2}-10 \%$ In & 35,7 & 0,042 & 0,039 & 0,003 \\
\hline $\mathrm{Cu} / \mathrm{CeO}_{2}$ & 57,1 & 0,060 & 0,055 & 0,005 \\
$\mathrm{Cu} / \mathrm{CeO}_{2}-5 \%$ In & 46,3 & 0,049 & 0,046 & 0,003 \\
$\mathrm{Cu} / \mathrm{CeO}_{2}-10 \%$ In & 54,1 & 0,048 & 0,045 & 0,003 \\
\hline
\end{tabular}

Figura 7. Isotermas de fisissorção de $\mathrm{N}_{2}$ para os materiais dos grupos $\mathrm{Cu} / \mathrm{ZrO}_{2}-\mathrm{XIn}$ e $\mathrm{Cu} / \mathrm{CeO}_{2}$-XIn.
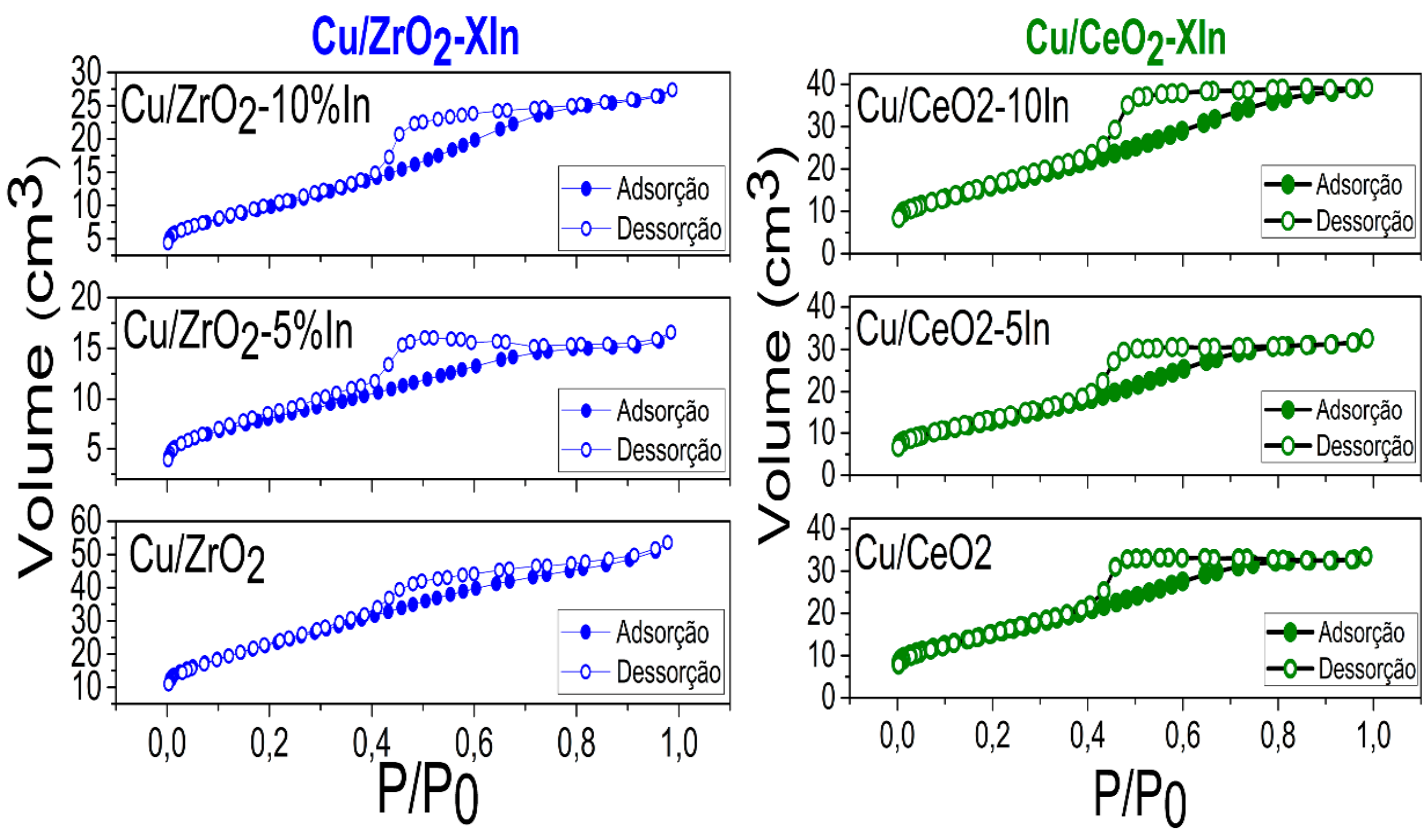
Figura 8. Distribuição de tamanho de poros para os materiais dos grupos $\mathrm{Cu} / \mathrm{ZrO}_{2}-\mathrm{XIn}$ e $\mathrm{Cu} / \mathrm{CeO}_{2}$-XIn obtidas por fisissorção de $\mathrm{N}_{2}$.
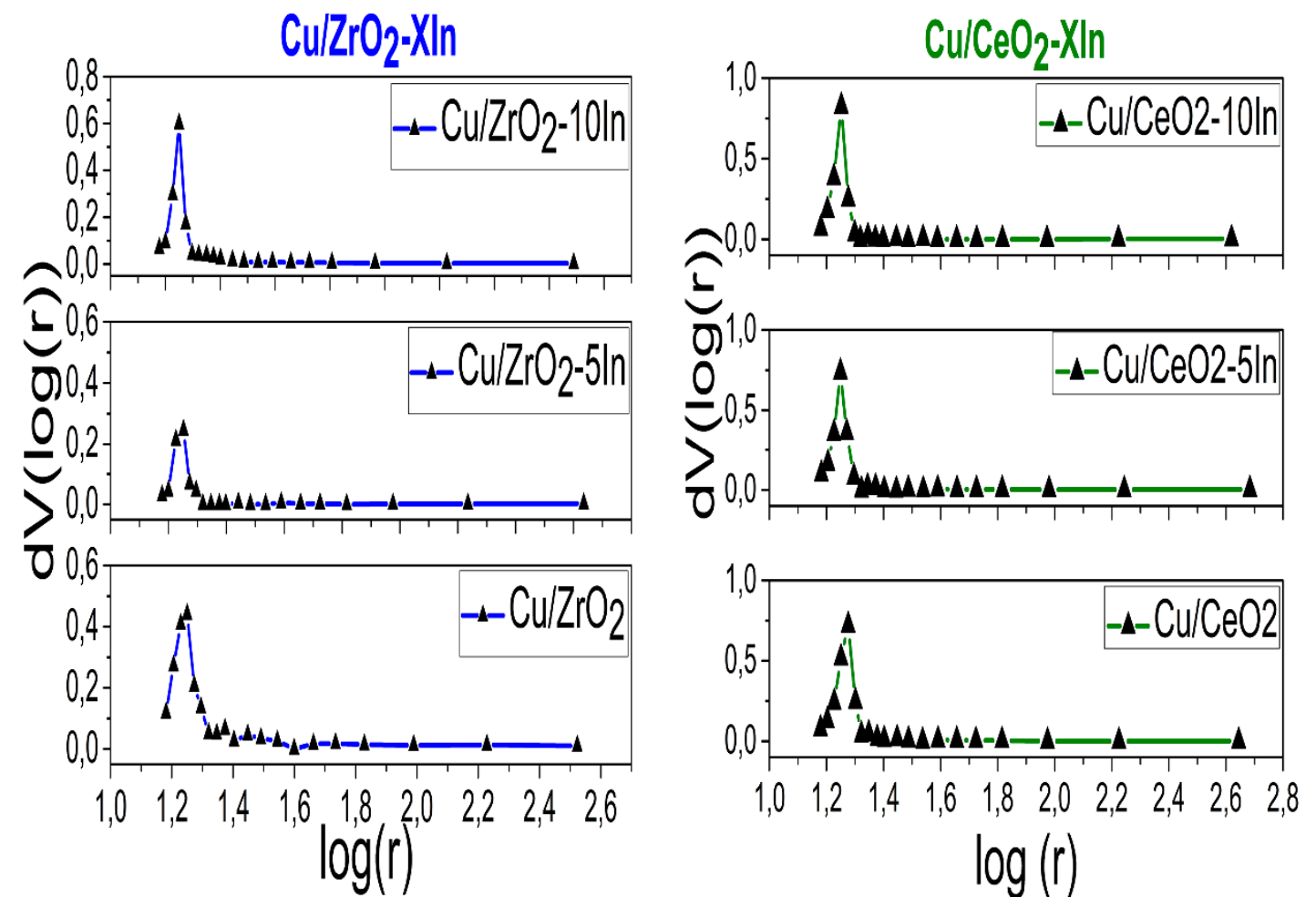

Nos dois grupos de catalisadores observou-se que a área específica de superfície dos materiais promovidos foi menor que a dos materiais não modificados com índio. Essa mesma tendência foi, também, observada em outros trabalhos como os desenvolvidos por Lou et al. (2014) e Amoli et al. (2015) (AMOLI et al., 2015; LOU et al., 2014).

De acordo com esses autores, a diminuição da área específica de superfície em materiais contendo índio ocorreu, principalmente, em virtude das variações na porosidade dos catalisadores de forma que maiores valores de volume de poros levam a maiores áreas específicas de superfície nos catalisadores não modificados (AMOLI et al., 2015; LOU et al., 2014).

Dessa forma, os resultados obtidos presentes na Tabela 6 são condizentes com o observado nos demais trabalhos uma vez que a porosidade dos materiais promovidos com índio é consideravelmente menor que a apresentada pelos materiais $\mathrm{Cu} / \mathrm{ZrO}_{2}$ e $\mathrm{Cu} / \mathrm{CeO}_{2}$ não modificados o que explicaria sua área menor.

Além disso, no caso específico dos materiais contendo céria, é possível perceber que apesar dos catalisadores $\mathrm{Cu} / \mathrm{CeO}_{2}-5 \%$ In e $\mathrm{Cu} / \mathrm{CeO}_{2}-10 \%$ In apresentarem volume de poros 
muito próximos, há uma diferença entre suas áreas específicas de superfície que pode ser explicada pelas diferenças no tamanho de partícula (AMOLI et al., 2015; LOU et al., 2014).

Dessa forma, o catalisador contendo $10 \%$ de índio apresenta área específica de superfície superior em decorrência de seu tamanho de partícula médio inferior conforme constatado na análise de microscopia eletrônica de transmissão (AMOLI et al., 2015; LOU et al., 2014).

Para todos os catalisadores dos grupos $\mathrm{Cu} / \mathrm{ZrO}_{2}-\mathrm{XIn}$ e $\mathrm{Cu} / \mathrm{CeO}_{2}-\mathrm{XIn}$ foram observadas isotermas do tipo IV típicas de materiais mesoporosos que apresentam loops de histerese que surgem devido à condensação capilar do $\mathrm{N}_{2}$ nos mesoporos durante a fisissorção. Essa observação se encontra em acordo com o volume de poros presentes na Tabela 6 e com os gráficos de distribuição de tamanho de poros apresentado na Figura 8 que evidenciam a característica mesoporosa dos catalisadores (AMOLI et al., 2015; GUO et al., 2011; LOU et al., 2014; ROUQUEROL et al., 2014).

A predominância de meso-porosidade observada em todos os catalisadores sugere a eficiência do surfactante $\mathrm{CTAB}$ presente na síntese, com ação estabelecida não somente no controle de tamanho das partículas como também como agente direcionador para a criação de mesoporosos nos materiais (CONTRERAS et al., 2015; LI, YULIN et al., 2018; LIU, Y.; GOEBL; YIN, 2013).

Além das análises de área específica de superfície e volume de poros, outras medidas de caracterização relacionadas às propriedades apresentadas pelas superfícies dos materiais como dispersão do cobre metálico, área metálica e basicidade foram mensuradas e os resultados obtidos são apresentados na Tabela 7.

Tabela 7. Propriedades químicas e texturais dos materiais pertencentes aos grupos $\mathrm{Cu} / \mathrm{ZrO}_{2}-$ $\mathrm{XIn}$ e $\mathrm{Cu} / \mathrm{ZrO}_{2}-\mathrm{XIn}$.

\begin{tabular}{cccc}
\hline Catalisadores & $\begin{array}{c}\text { Dispersão do Cobre } \\
(\%)\end{array}$ & $\begin{array}{c}\text { Área Metálica } \\
\left(\mathrm{m}^{2} \cdot \mathrm{g}^{-1}\right)\end{array}$ & $\begin{array}{c}\text { Basicidade } \\
\left(\mu \mathrm{molCO}_{2} \cdot \mathrm{g}^{-1}\right)\end{array}$ \\
\hline $\mathrm{Cu} / \mathrm{ZrO}_{2}$ & 15,3 & 30,9 & 73,1 \\
$\mathrm{Cu} / \mathrm{ZrO}_{2}-5 \%$ In & 10,0 & 20,3 & 126,4 \\
$\mathrm{Cu} / \mathrm{ZrO}_{2}-10 \%$ In & 10,3 & 20,8 & 117,1 \\
\hline $\mathrm{Cu} / \mathrm{CeO}_{2}$ & 7,01 & 11,39 & 178,2 \\
$\mathrm{Cu} / \mathrm{CeO}_{2}-5 \%$ In & 6,48 & 10,50 & 242,3 \\
$\mathrm{Cu} / \mathrm{CeO}_{2}-10 \%$ In & 6,62 & 11,04 & 237,8 \\
\hline
\end{tabular}


Segundo Arena et al. (2007), Chary et al. (2007) e Sagar et al. (2006), a dispersão do cobre bem como a área metálica de superfície sofrem influência, principalmente, de fatores como o teor de cobre no material, a força de interação entre as partículas de cobre e o óxido que compõem o catalisador, a área específica de superfície e o volume de poros (ARENA et al., 2007; CHARY; SAGAR; SRIKANTH, 2007; SAGAR et al., 2006).

Diante dos resultados presentes na Tabela 7 entre os dois grupos de materiais, é possível verificar que os catalisadores contendo zircônia apresentaram maior área metálica e dispersão do cobre comparados aos seus análogos contendo céria.

Em uma série de trabalhos publicados, observa-se a mesma tendência de maior dispersão do cobre suportado em óxido de zircônio quando comparado a outros óxidos com a céria, por exemplo (MARTIN et al., 2016; PAN et al., 2017; POROSOFF; YAN; CHEN, 2015; WANG, WEI et al., 2011).

Segundo muitos pesquisadores, a ocorrência do fenômeno de fortes interações metalsuporte (SMSI) existentes entre as partículas de cobre e zircônia resultam em alta dispersão das partículas metálicas sobre as de óxido maximizando o contato entre elas e diminuindo, assim, a agregação das partículas de cobre mantendo-as mais dispersas que aquelas suportadas em outras estruturas óxidas (MARTIN et al., 2016; PAN et al., 2017; POROSOFF; YAN; CHEN, 2015; WANG, WEI et al., 2011).

Já ao se comparar os catalisadores pertencentes a um mesmo grupo, é possível perceber que os catalisadores promovidos com índio apresentaram menor dispersão que os materiais $\mathrm{Cu} / \mathrm{ZrO}_{2}$ e $\mathrm{Cu} / \mathrm{CeO}_{2}$, o que pode ser explicado pelas diferenças na área específica de superfície e na porosidade apresentada pelos catalisadores (ARENA et al., 2007; BONURA et al., 2011; CHARY; SAGAR; SRIKANTH, 2007; SAGAR et al., 2006).

Os maiores volumes de poro e área específica de superfície apresentadas pelos catalisadores $\mathrm{Cu} / \mathrm{CeO}_{2}$ e $\mathrm{Cu} / \mathrm{ZrO}_{2}$ implicam, por consequência, em um maior número de átomos de cobre presentes na superfície dos materiais e em uma menor quantidade em seu interior (bulk) devido a maior razão área/volume observada para esses catalisadores e, como consequência, a maior quantidade de átomos de cobre expostos resulta em uma maior área metálica de superfície (ARENA et al., 2007; CHARY; SAGAR; SRIKANTH, 2007; SAGAR et al., 2006).

Já no que se refere à basicidade, os materiais baseados em céria apresentaram valores consideravelmente superiores aos materiais compostos por zircônia o que é condizente com a literatura ao se considerar a acidez inerente da zircônia frente a muitos óxidos e à basicidade 
característica dos óxidos formados por lantanídeos como os átomos de cério (TILLEY, 2004; ZABILSKIY et al., 2015).

É bem estabelecido que a basicidade apresentada por um sólido depende de uma série de fatores envolvendo propriedades químicas e estruturais como a composição elementar, os planos cristalográficos expostos, a área específica de superfície, a energia de superfície, o tamanho de partícula, a morfologia, o grau de cristalinidade e a morfologia (CALLISTER JR.; RETHWISCH, 2009; TILLEY, 2004).

Ao se comparar os valores dentro do mesmo grupo de materiais, verifica-se que os materiais promovidos com índio apresentam basicidade consideravelmente superior aos seus análogos $\mathrm{Cu} / \mathrm{ZrO}_{2}$ e $\mathrm{Cu} / \mathrm{CeO}_{2}$ não modificados o que pode ser explicado em termos do balanço e mobilidade de átomos de oxigênio em suas superfícies.

De acordo com Liang Xu et al. (2008); Hungria et al. (2003) e Xueting et al. (2018), durante a síntese de um óxido misto composto por cátions com estados de oxidação distintos, parte dos átomos de um elemento específico podem se introduzir na rede iônica que está sendo formada pelos outros cátions gerando dopagem estrutural, o que irá gerar vacâncias de átomos de oxigênio, principalmente quando o dopante apresenta menor valência e número de coordenação que o cátion que forma o óxido que está sendo dopado (HUNGRÍA et al., 2003; LIANG et al., 2008; LIN et al., 2018).

De forma mais específica, segundo McFarland e Metiu (2013), a presença de cátions dopantes com menor valência e número de coordenação na estrutura de um óxido formado por um cátion de maior valência causa um desbalanceamento ou déficit eletrônico na estrutura iônica, reduzindo a energia de ligação de espécies eletrofílicas à rede (MCFARLAND; METIU, 2013).

Assim, há uma diminuição da energia de ligação dos ânions $\mathrm{O}^{2-}$ ao sólido, o que facilita a formação de vacâncias de átomos de oxigênio na superfície dos materiais, sendo que tais vacâncias irão atuar como sítios básicos fortes durante as etapas de tratamento térmico (MCFARLAND; METIU, 2013).

Além disso, há também um efeito na basicidade resultante do menor tamanho médio de partículas dos materiais promovidos com índio (principalmente os baseados em céria) em relação aos seus análogos $\mathrm{Cu} / \mathrm{ZrO}_{2}$ e $\mathrm{Cu} / \mathrm{CeO}_{2}$ não modificados, verificado por microscopia eletrônica de transmissão.

É estabelecido por muitos pesquisadores que a diminuição no tamanho das partículas leva a um aumento da energia livre de superfície resultando em menor energia de formação de 
vacâncias de átomos de oxigênio e defeitos em sua superfície resultando em maior reatividade com as moléculas adsorvidas e, portanto, maior basicidade (FUJIWARA et al., 2019; GAO et al., 2013; KUMAR; OJHA, 2015; LI, YEZHOU et al., 2014; STRUNK et al., 2009; TILLEY, 2004; WANG, WEIWEI et al., 2020).

A composição elementar de superfície obtida por meio de espectroscopia fotoeletrônica de Raios X se encontra na Tabela 8.

Tabela 8. Composição elementar de superfície e razão molar mensuradas por espectroscopia fotoeletrônica de Raios $\mathrm{X}$ dos materiais pertencentes aos grupos $\mathrm{Cu} / \mathrm{ZrO}_{2}-\mathrm{XIn}$ e $\mathrm{Cu} / \mathrm{ZrO} 2-\mathrm{XIn}$.

\begin{tabular}{cccccc}
\hline Catalisadores & \multicolumn{3}{c}{ Concentração Relativa (at\%) } & & $\begin{array}{c}\text { Razão Molar } \\
\text { Cu/(Zr ou Ce+In) }\end{array}$ \\
\cline { 2 - 5 } & $\mathrm{Cu}$ & $\mathrm{Zr}$ & $\mathrm{Ce}$ & $\mathrm{In}$ & 0,47 \\
\hline $\mathrm{Cu} / \mathrm{ZrO}_{2}$ & 31,93 & 68,07 & --- & 0,00 & 1,33 \\
$\mathrm{Cu} / \mathrm{ZrO}_{2}-5 \% \mathrm{In}$ & 57,17 & 39,11 & --- & 3,72 & 1,52 \\
$\mathrm{Cu} / \mathrm{ZrO}_{2}-10 \% \mathrm{In}$ & 60,36 & 34,23 & --- & 5,41 & 2,29 \\
\hline $\mathrm{Cu} / \mathrm{CeO}_{2}$ & 69,60 & --- & 30,40 & 0,00 & 2,99 \\
$\mathrm{Cu} / \mathrm{CeO}_{2}-5 \%$ In & 74,92 & --- & 19,12 & 5,96 & 2,62 \\
$\mathrm{Cu} / \mathrm{CeO}_{2}-10 \%$ In & 72,30 & --- & 17,12 & 10,45 & \\
\hline
\end{tabular}

A análise dos dados presentes na Tabela 8 evidencia que, para todos os catalisadores com exceção do material $\mathrm{Cu} / \mathrm{ZrO}_{2}$, as superfícies são predominantemente constituídas por átomos de cobre.

Segundo Tilley (2004), devido a presença de defeitos estruturais e vacâncias de átomos de oxigênio na superfície de um óxido, há um aumento na energia livre de superfície. Com o objetivo de minimização dessa energia livre, durante os tratamentos térmicos, alguns átomos podem se difundir do interior do sólido (bulk) em direção à superfície alterando suas localizações para posições mais estáveis (TILLEY, 2004).

Esse processo gera, assim, uma superfície composta principalmente dos átomos que se difundem de modo que a composição elementar da superfície não corresponda, necessariamente, à composição elementar total do material (TILLEY, 2004).

Vários trabalhos evidenciam esse desbalanceamento elementar na superfície, sendo verificado de forma mais pronunciada em óxidos dopados ou mistos (CHANG; WANG; CHEN, 2017; CHOI et al., 2017; JUNG et al., 2008; MEKKI-BERRADA et al., 2012). 
Os espectros correspondentes aos átomos de zircônio, cério e índio que compõem os catalisadores são mostrados nas Figuras 9 e 10.

Figura 9. Espectro de fotoelétrons de Raios X correspondentes às emissões do subnível 3d dos átomos de zircônio e índio presentes nos catalisadores do grupo $\mathrm{Cu} / \mathrm{ZrO}_{2}-\mathrm{XIn}$.

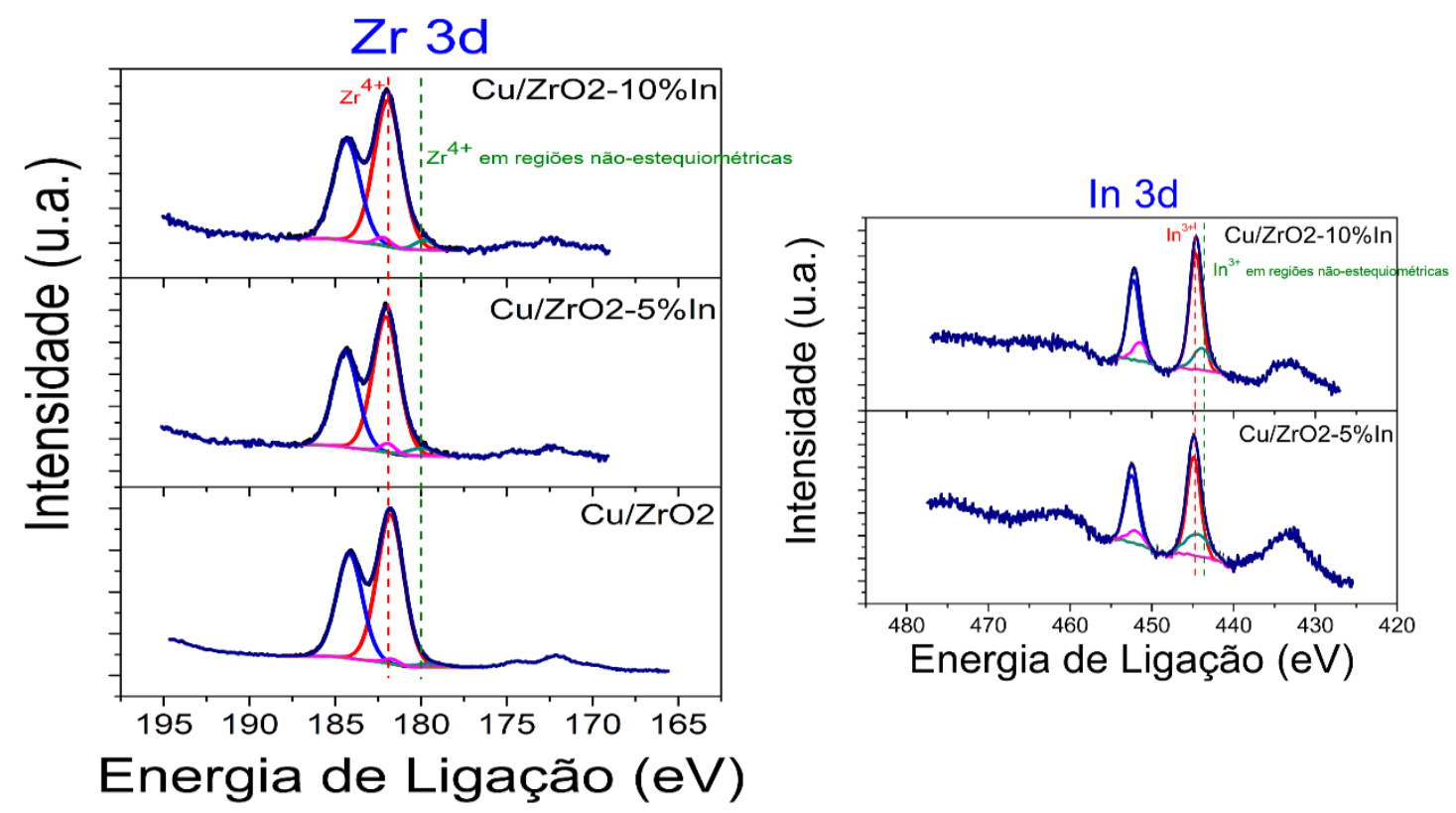

Figura 10. Espectro de fotoelétrons de Raios X correspondentes às emissões do subnível 3d dos átomos de cério e índio presentes nos catalisadores do grupo $\mathrm{Cu} / \mathrm{CeO}_{2}-\mathrm{XIn}$.
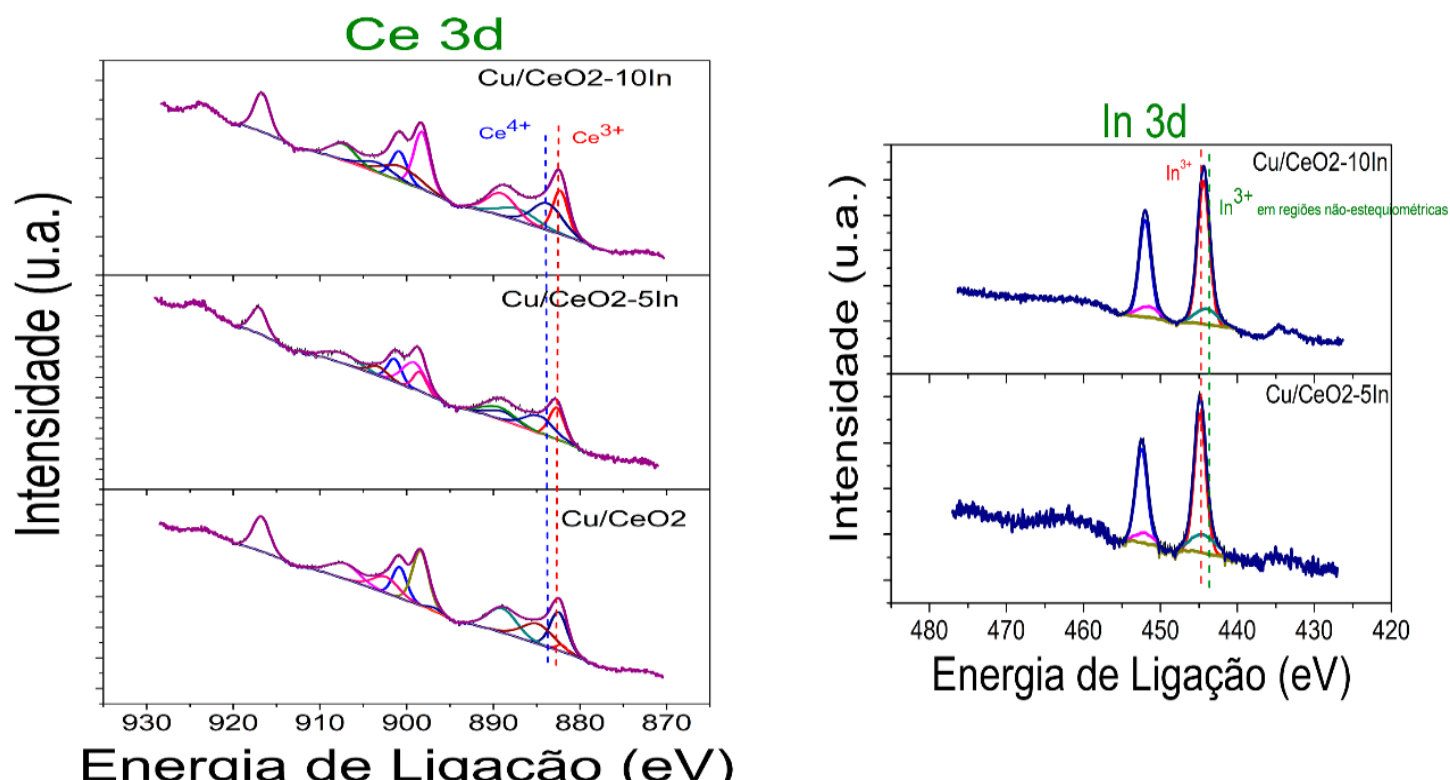
Como pode ser visto na Figura 9, para todos os catalisadores pertencentes ao grupo $\mathrm{Cu} / \mathrm{ZrO}_{2}-\mathrm{XIn}$, os espectros da emissão de elétrons do zircônio são característicos de espécies $\mathrm{Zr}^{4+}$ quando compõem óxidos por apresentar dois picos fotoeletrônicos correspondentes aos componentes $3 \mathrm{~d}^{5 / 2}$ e $3 \mathrm{~d}^{3 / 2}$ resultantes do fenômeno de acoplamento spin-órbita (AZDAD et al., 2018; WANG, L. C. et al., 2007).

A deconvolução dos referidos picos revelam contribuições de duas espécies $\mathrm{Zr}^{4+}$ advindas de dois ambientes químicos distintos, sendo que os picos mais intensos estão relacionados à $\mathrm{Zr}^{4+}$ presentes em ambientes estequiométricos enquanto os picos menos intensos se referem à espécies $\mathrm{Zr}^{4+}$ em regiões não-estequiométricas, nas quais haja vacâncias de átomos de oxigênio de acordo com o que é reportado na literatura (AZDAD et al., 2018; WANG, L. C. et al., 2007).

Analogamente, pela análise da Figura 10, é possível observar que os espectros de emissão de elétrons dos átomos de cério são característicos de espécies catiônicas de cério compondo óxidos. A deconvolução dos picos fotoeletrônicos evidencia contribuições tanto de espécies $\mathrm{Ce}^{4+}$ quanto espécies $\mathrm{Ce}^{3+}$ (AMADINE et al., 2017; SIMS et al., 2019).

De modo mais específico, cátions $\mathrm{Ce}^{4+}$, com configuração eletrônica $3 \mathrm{~d}^{10} 4 \mathrm{f}^{0}$, apresentam 6 picos, sendo dois deles picos fotoeletrônicos correspondentes aos componentes $3 \mathrm{~d}^{5 / 2}$ e $3 \mathrm{~d}^{3 / 2}$ resultantes do acoplamento spin-órbita. Cada um desses picos apresenta dois picos satélites, um shake-up e um shake-down devido a efeitos de múltiplo espalhamento observados (AMADINE et al., 2017; JUNG et al., 2008; RODRIGUEZ et al., 2015; SIMS et al., 2019).

Já espécies $\mathrm{Ce}^{3+}$ com configuração eletrônica de distribuição por subníveis $3 \mathrm{~d}^{10} 4 \mathrm{f}^{1}$, apresentam 4 picos, sendo dois deles picos fotoeletrônicos dos componentes $3 d^{5 / 2}$ e $3 d^{3 / 2}$ resultantes do acoplamento spin-órbita e dois picos satélites (AMADINE et al., 2017; JUNG et al., 2008; RODRIGUEZ et al., 2015; SIMS et al., 2019).

A presença de átomos de céria com dois estados de oxidação distintos pode ser explicada, assim como no caso da zircônia, pela existência de vacâncias de átomos de oxigênio nas partículas do óxido (JUNG et al., 2008; RODRIGUEZ et al., 2015).

Uma vez que, em espécies trivalentes, a interação eletrostática do núcleo ocorre com um número maior de elétrons, a carga nuclear efetiva sobre cada um deles será menor que a observada para os elétrons presentes em espécies tetravalentes do mesmo elemento (AMADINE et al., 2017; BÊCHE et al., 2008; SIMS et al., 2019).

Desse modo, a energia de ligação dos elétrons ao núcleo em espécies trivalentes será, também, menor que a verificada em espécies tetravalentes, o que justifica as energias de ligação 
um pouco menores apresentadas pelos elétrons presentes na componente $3 \mathrm{~d}^{5 / 2}$ de espécies $\mathrm{Ce}^{3+}$ em comparação a energia de ligação dos elétrons presentes na componente $3 \mathrm{~d}^{5 / 2}$ de espécies $\mathrm{Ce}^{4+}$, como foi observado nos espectros mostrados na Figura 10 (AMADINE et al., 2017; BÊCHE et al., 2008; SIMS et al., 2019).

É importante ressaltar que, em todos os materiais promovidos com índio, a razão entre a intensidade dos picos advindos de espécies em regiões contendo vacâncias e a intensidade dos picos advindos de espécies em regiões estequiométricas foi maior que a razão observada para os materiais $\mathrm{Cu} / \mathrm{ZrO}_{2}$ e $\mathrm{Cu} / \mathrm{CeO}_{2}$ não promovidos, o que sugere um aumento da densidade de vacâncias na superfície dos catalisadores contendo índio, corroborando os resultados de basicidade mensurados por dessorção de $\mathrm{CO}_{2}$ discutidos anteriormente.

Para ambos os grupos de materiais, os espectros relacionados aos átomos de índio são característicos de índio compondo óxidos. Em todos eles, há dois picos fotoeletrônicos $3 \mathrm{~d}^{5 / 2} \mathrm{e}$ $3 \mathrm{~d}^{3 / 2}$ resultantes do acoplamento spin-órbita. A deconvolução desses picos evidencia a contribuição principal de espécies $\operatorname{In}^{3+}$ em regiões estequiométricas em conjunto a uma contribuição minoritária de espécies $\operatorname{In}^{3+}$ presentes em regiões não estequiométricas do óxido nas quais haja vacâncias de átomos de oxigênio, de forma similar ao que havia sido observado anteriormente (KYNDIAH et al., 2018).

As informações geradas a partir da deconvolução dos picos foram agrupadas na Tabela 9 com o detalhamento da energia de ligação para cada um deles. 
Tabela 9. Energia de ligação dos elétrons presentes na componente $3 \mathrm{~d}^{5 / 2}$ ao núcleo dos átomos de zircônio, cério e índio para os catalisadores pertencentes aos grupos $\mathrm{Cu} / \mathrm{ZrO}_{2}-\mathrm{XIn}$ e $\mathrm{Cu} / \mathrm{CeO}_{2}$-XIn.

\begin{tabular}{ccccccc}
\hline Catalisadores & \multicolumn{5}{c}{ Energia de Ligação (eV) } \\
\cline { 2 - 7 } & $\mathrm{Zr}^{4+} 3 \mathrm{~d}^{5 / 2}$ & $* \mathrm{Zr}^{4+} 3 \mathrm{~d}^{5 / 2}$ & $\mathrm{Ce}^{4+} 3 \mathrm{~d}^{5 / 2}$ & $\mathrm{Ce}^{3+} 3 \mathrm{~d}^{5 / 2}$ & $\mathrm{In}^{3+} 3 \mathrm{~d}^{5 / 2}$ & $* \mathrm{In}^{3+} 3 \mathrm{~d}^{5 / 2}$ \\
\hline$* *$ Padrão & $\sim 182,30$ & $\sim 182,10$ & $\sim 881,8$ & $\sim 881,0$ & $\sim 444,3$ & $\sim 443,8$ \\
$\mathrm{Cu} / \mathrm{ZrO}_{2}$ & 181,78 & 179,38 & --- & --- & --- & --- \\
$\mathrm{Cu} / \mathrm{ZrO}_{2}-5 \% \mathrm{In}$ & 182,03 & 179,95 & --- & --- & 444,89 & 444,40 \\
$\mathrm{Cu} / \mathrm{ZrO}_{2}-10 \% \mathrm{In}$ & 181,94 & 179,80 & --- & --- & 444,65 & 443,87 \\
$\mathrm{Cu} / \mathrm{CeO}_{2}$ & --- & --- & 882,48 & 882,11 & --- & --- \\
$\mathrm{Cu} / \mathrm{CeO}_{2}-5 \%$ In & --- & --- & 884,77 & 882,67 & 444,85 & 444,43 \\
$\mathrm{Cu} / \mathrm{CeO} 2-10 \%$ In & ---- & --- & 883,76 & 882,27 & 444,40 & 444,00 \\
\hline Zr & & & &
\end{tabular}

É importante ressaltar que, para todos os elementos, as energias de ligação dos elétrons aos respectivos núcleos foram razoavelmente distintas das energias estabelecidas para os mesmos elementos quando eles compõem óxidos puros, de acordo com o Handbook de Espectroscopia Fotoeletrônica de Raios X e com Kyndiah et al. (2018) (KYNDIAH et al., 2018; MOULDER et al., 1995).

Essa observação pode ser explicada pelo fato de a atração coulômbica entre elétrons e núcleos ser influenciada pelo ambiente químico no qual os átomos em questão se encontram inseridos. Uma vez que o ambiente químico para um átomo em um óxido misto ou dopado é diferente do que é verificado em óxidos puros, as energias de ligação dos elétrons, nesse contexto, se mostrarão também relativamente distintas (AMADINE et al., 2017; ANWAR; GHAURI; SIDDIQI, 2007; DONLEY et al., 2002; KYNDIAH et al., 2018; ROMEO; FALLAH; NORMAND, 1993; TETERIN et al., 1998).

Desempenho Catalítico dos catalisadores $\mathrm{Cu} / \mathrm{ZrO} 2-\mathrm{X} \% \mathrm{In}$ e $\mathrm{Cu} / \mathrm{CeO}_{2}-\mathrm{X} \% \mathrm{In}$

Avaliou-se o desempenho catalítico dos catalisadores pertencentes aos grupos $\mathrm{Cu} / \mathrm{ZrO}_{2}-$ $\mathrm{XIn}$ e $\mathrm{Cu} / \mathrm{CeO}_{2}$-XIn quando aplicados à reação de hidrogenação do $\mathrm{CO}_{2}$ sob as condições de 
pressão, temperatura e velocidade espacial iguais a $3 \mathrm{MPa}, 473 \mathrm{~K}$ e $6 \mathrm{~L} \cdot \mathrm{h}^{-1} \cdot \mathrm{g}^{-1}$, respectivamente. Os resultados se encontram na Tabela 10 e Figura 11.

Tabela 10. Desempenho catalítico dos materiais pertencentes aos grupos $\mathrm{Cu} / \mathrm{ZrO}_{2}-\mathrm{XIn}$ e $\mathrm{Cu} / \mathrm{CeO}_{2}$-XIn aplicados à hidrogenação do $\mathrm{CO}_{2}$

\begin{tabular}{cccccc}
\hline Catalisadores & $\begin{array}{c}\mathrm{XCO}_{2} \\
(\%)\end{array}$ & $\begin{array}{c}\mathrm{SCH}_{3} \mathrm{OH} \\
(\%)\end{array}$ & $\begin{array}{c}\mathrm{SCO} \\
(\%)\end{array}$ & $\begin{array}{c}\mathrm{SCH}_{4} \\
(\%)\end{array}$ & $\begin{array}{c}\mathrm{SC}_{2} \mathrm{H}_{6} \\
(\%)\end{array}$ \\
\hline $\mathrm{Cu} / \mathrm{ZrO}_{2}$ & 8,5 & 60,8 & 39,0 & 0,1 & 0,1 \\
$\mathrm{Cu} / \mathrm{ZrO}_{2}-5 \% \mathrm{In}$ & 4,4 & 79,8 & 19,8 & 0,1 & 0,3 \\
$\mathrm{Cu} / \mathrm{ZrO} 2-10 \% \mathrm{In}$ & 4,3 & 82,3 & 17,4 & 0,1 & 0,2 \\
\hline $\mathrm{Cu} / \mathrm{CeO}_{2}$ & 2,6 & 47,3 & 52,1 & 0,3 & 0,3 \\
$\mathrm{Cu} / \mathrm{CeO}_{2}-5 \% \mathrm{In}$ & 1,7 & 78,5 & 20,6 & 0,5 & 0,4 \\
$\mathrm{Cu} / \mathrm{CeO} 2-10 \%$ In & 1,7 & 76,4 & 22,8 & 0,4 & 0,4 \\
\hline
\end{tabular}

Pressão $=3 \mathrm{MPa} ;$ Temperatura $=473 \mathrm{~K} ;$ GHSV $=6 \mathrm{~L} \cdot \mathrm{h}^{-1} \cdot \mathrm{g}^{-1}$ 
Figura 11. Conversão e seletividade aos principais produtos obtidos da hidrogenação do $\mathrm{CO}_{2}$ utilizando os materiais pertencentes aos grupos $\mathrm{Cu} / \mathrm{ZrO}_{2}-\mathrm{XIn}$ e $\mathrm{Cu} / \mathrm{CeO}_{2}-\mathrm{XIn}$, sob as condições de pressão, temperatura e velocidade espacial iguais a $3 \mathrm{MPa}, 473 \mathrm{~K}$ e $6 \mathrm{~L} \cdot \mathrm{h}^{-1} \cdot \mathrm{g}^{-1}$.
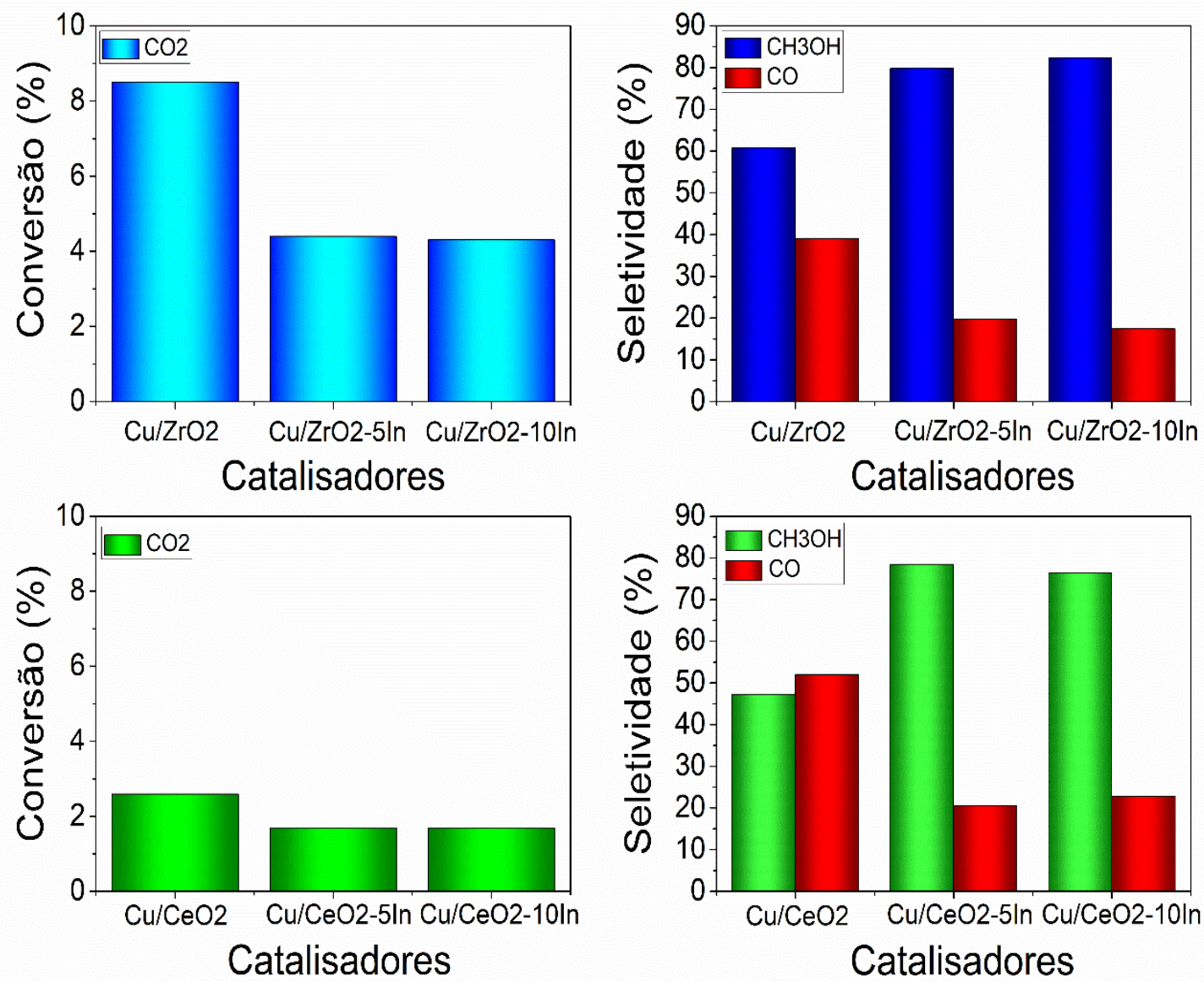

A análise dos resultados catalíticos apresentados permite verificar que a seletividade ao metanol se mostrou consideravelmente superior quando os catalisadores promovidos com índio foram utilizados, muito embora uma menor porcentagem de conversão tenha sido observada para os mesmos materiais quando comparados aos catalisadores $\mathrm{Cu} / \mathrm{ZrO}_{2}$ e $\mathrm{Cu} / \mathrm{CeO}_{2}$.

A menor conversão de $\mathrm{CO}_{2}$ apresentada pelos catalisadores contendo índio pode ser compreendida ao se considerar a natureza bifuncional dos sítios ativos necessários à hidrogenação de $\mathrm{CO}_{2}$ em nanocompósitos (DUYAR; TREVIÑO; FARRAUTO, 2015; GRACIANI et al., 2014; KATTEL et al., 2016).

Especificamente, por meio de estudos teóricos utilizando cálculos baseados na teoria do funcional de densidade (DFT) e estudos espectroscópicos, Kattel et al. (2015) e Graciani et al., (2014) estabelecem que a adsorção inicial das moléculas de $\mathrm{CO}_{2}$ na superfície dos catalisadores ocorre nas chamadas regiões de interface entre as partículas metálicas e as de óxido (GRACIANI et al., 2014; KATTEL et al., 2016). 
Segundo esses autores nas regiões de interface, o átomo de carbono e um dos átomos de oxigênio do $\mathrm{CO}_{2}$ se adsorvem no limite da partícula metálica enquanto o outro átomo de oxigênio da molécula de dióxido de carbono se adsorve em um sítio vicinal presente na partícula de óxido, predominantemente uma vacância de átomos de oxigênio (GRACIANI et al., 2014; KATTEL et al., 2016).

Paralelamente, as moléculas $\mathrm{H}_{2}$ sofrem adsorção dissociativa nas partículas metálicas gerando átomos de hidrogênio adsorvidos. Devido a diferenças no potencial química de superfície, os átomos de hidrogênio gerados sofrem um fenômeno de deslocamento (spillover) se movendo em direção à sítios presentes em uma partícula próxima de óxido na qual eles se ligarão a átomos de oxigênio dando origem a grupos hidroxila que, posteriormente, participarão no processo de redução das moléculas de $\mathrm{CO}_{2}$ (GRACIANI et al., 2014; KATTEL et al., 2016).

Uma série de pesquisadores estabelecem, portanto que, nas regiões de interface entre óxido e metal, tanto partículas de óxido quanto partículas metálicas atuam juntas formando os sítios ativos bifuncionais para os processos de redução do $\mathrm{CO}_{2}$ e que uma dispersão satisfatória entre essas partículas será fundamental e determinante para os valores de conversão que serão obtidos (GRACIANI et al., 2014; KATTEL et al., 2016; POROSOFF; YAN; CHEN, 2015; WANG, WEI et al., 2011).

Atualmente, é bem estabelecido que a quantidade de zonas de interface entre as partículas que compõe superfície dos catalisadores é diretamente proporcional à dispersão e área metálica das partículas metálicas (PAN et al., 2017; POROSOFF; YAN; CHEN, 2015; WANG, WEI et al., 2011).

Além disso, há também uma proporcionalidade direta da conversão de $\mathrm{CO}_{2}$ com o teor de óxido presente na superfície dos catalisadores. Recentemente, Rodriguez et al., (2015) e Graciani et al., (2014) mostraram que em catalisadores nos quais, além de alta dispersão das partículas de cobre, houve também um teor de óxido na superfície mais alto que para os demais, os resultados de conversão obtidos foram superiores (GRACIANI et al., 2014; RODRIGUEZ et al., 2015).

Esses resultados evidenciam que a ocorrência de fortes interações metal-suporte (Strong metal-support interactions $S M S I$ ) são fundamentais para que valores satisfatórios de conversão sejam atingidos (PAN et al., 2017; POROSOFF; YAN; CHEN, 2015; WANG, WEI et al., 2011).

Nesse sentido, os menores valores de conversão para os catalisadores contendo índio estão de acordo com os resultados reportados pelos pesquisadores ao se considerar que, nesses 
materiais promovidos, a dispersão e área metálica das partículas de cobre são menores que as verificadas para os catalisadores $\mathrm{Cu} / \mathrm{ZrO}_{2}$ e $\mathrm{Cu} / \mathrm{CeO}_{2}$.

Em complemento, o teor de óxido presente na superfície dos catalisadores promovidos também foi menor que a dos seus análogos não modificados com índio como pode ser analisado ao se comparar as razões molares $\mathrm{Cu} /[(\mathrm{Zr}$ ou $\mathrm{Ce})+\mathrm{In}]$ calculadas por meio da espectroscopia fotoeletrônica de raios $\mathrm{X}$ e presentes na Tabela 8 .

Além disso, ao se comparar os grupos $\mathrm{Cu} / \mathrm{ZrO}_{2}-\mathrm{XIn}$ e $\mathrm{Cu} / \mathrm{CeO}_{2}-\mathrm{XIn}$, é possível verificar que os melhores resultados de conversão dos materiais baseados em zircônia se justificam, da mesma forma, pela maior dispersão e área metálica das partículas de cobre além de apresentaram um maior teor percentual de óxido em sua superfície (verificados por XPS) quando comparados aos materiais contendo céria (PAN et al., 2017; POROSOFF; YAN; CHEN, 2015; WANG, WEI et al., 2011).

A maior conversão entre todos os materiais foi observada para o catalisador $\mathrm{Cu} / \mathrm{ZrO}{ }_{2}$ que foi justamente o material que apresentou os maiores valores dessas propriedades

Já no que se refere à seletividade apresentada pelos materiais, foi possível verificar que os catalisadores promovidos com índio apresentaram valores consideravelmente maiores para o metanol, com redução significativa na quantidade de monóxido de carbono gerado.

Esse fato pode ser explicado, principalmente, por efeitos advindos da presença dos átomos de índio sobre as moléculas intermediárias geradas nas rotas mecanísticas pelas quais ocorre a geração dos produtos. Além disso, nos materiais promovidos, há também efeitos positivos devido à maior basicidade decorrente de efeitos sinérgicos que levam à geração de vacâncias e também do menor tamanho médio de partículas verificados para esses catalisadores (BANSODE et al., 2013; BIELZ, T et al., 2011; BIELZ, THOMAS et al., 2010; GAO et al., 2013; GUO et al., 2011; KATTEL et al., 2016; KUMAR; OJHA, 2015; LI, L. et al., 2015; LI, YEZHOU et al., 2014; POROSOFF; YAN; CHEN, 2015; STRUNK et al., 2009; WANG, WEI et al., 2011; WANG, WEIWEI et al., 2020; YE et al., 2013; YE; LIU; GE, 2012).

De forma detalhada, após a adsorção de moléculas de $\mathrm{CO}_{2}$ e $\mathrm{H}_{2}$ nas regiões de interface da superfície dos catalisadores, duas rotas mecanísticas são possíveis para a geração do metanol (GRACIANI et al., 2014; KATTEL et al., 2016; RODRIGUEZ et al., 2015).

A primeira delas é a rota reversa do deslocamento gás-água (Reverse water-gas shift $R W G S$ ) seguida pela hidrogenação do CO produzido a metanol. De forma detalhada, após a adsorção de moléculas de dióxido de carbono e hidrogênio, uma espécie carboxilato $\left(\mathrm{CO}_{2}^{-}\right)$é formada. Essa molécula sofre uma primeira hidrogenação gerando a estrutura HOCO, que se 
dissocia gerado espécies $\mathrm{OH}$ e $\mathrm{CO}$ adsorvidas. A hidroxila adsorvida, sofre uma hidrogenação e se dessorve como uma molécula de água enquanto o $\mathrm{CO}$ pode se dessorver como uma molécula de monóxido de carbono ou sofre múltiplas etapas de hidrogenação formando, sequencialmente, espécies $\mathrm{HCO}, \mathrm{H}_{2} \mathrm{CO}$ e $\mathrm{H}_{3} \mathrm{CO}$ adsorvidas até que, em uma última hidrogenação seja formada a molécula de metanol que, então, se dessorve da superfície do catalisador (GRACIANI et al., 2014; KATTEL et al., 2016; RODRIGUEZ et al., 2015).

O maior obstáculo à produção de metanol por essa rota é que a molécula adsorvida de monóxido de carbono formada em uma das etapas apresenta energia de adsorção muito baixa devido a contribuições entrópicas e, desse modo, sua dessorção é altamente favorecida antes que ela possa ser hidrogenada até o metanol (GRACIANI et al., 2014; KATTEL et al., 2016; RODRIGUEZ et al., 2015).

Além disso, vale ressaltar que a molécula de HCO formada apresenta alta energia de ativação para as próximas hidrogenações o que também dificulta a geração de metanol. Esse problema resulta em limitação da seletividade ao metanol e, para a maioria dos catalisadores que seguem predominantemente essa rota, $\mathrm{CO}$ será o produto principal obtido da hidrogenação do $\mathrm{CO}_{2}$ (GRACIANI et al., 2014; KATTEL et al., 2016; RODRIGUEZ et al., 2015).

A segunda rota estabelecida é conhecida como rota do formiato. De acordo com Kattel et al., 2015, após a adsorção das moléculas de $\mathrm{CO}_{2}$ e $\mathrm{H}_{2}$, uma espécie formiato (HCOO) adsorvida é formada. Após isso, ocorrem sucessivas hidrogenações gerando sequencialmente espécies $\mathrm{H}_{2} \mathrm{COO}$ e $\mathrm{H}_{2} \mathrm{COOH}$ (GRACIANI et al., 2014; KATTEL et al., 2016; RODRIGUEZ et al., 2015).

Essa última molécula sofre uma clivagem de uma das ligações $\mathrm{C}-\mathrm{O}$ gerando duas espécies adsorvidas sendo elas $\mathrm{H}_{2} \mathrm{CO}$ e $\mathrm{OH}$. A hidroxila é então hidrogenada formando uma molécula de água que se dessorve enquanto a espécie $\mathrm{H}_{2} \mathrm{CO}$ é hidrogenada gerando uma molécula de metanol que se dessorve da superfície (GRACIANI et al., 2014; KATTEL et al., 2016; RODRIGUEZ et al., 2015).

A maior vantagem dessa rota é o fato de que ela não produz monóxido de carbono em nenhuma das suas etapas, favorecendo fortemente a seletividade ao metanol. O desafio, no entanto, é que a etapa de clivagem da ligação C-O apresenta energia de ativação muito alta quando se utiliza a maioria dos catalisadores já testados limitando a geração do metanol (GRACIANI et al., 2014; KATTEL et al., 2016; RODRIGUEZ et al., 2015).

As duas rotas foram graficamente expressas por Kattel et al. (2016) e os resultados se encontram na Figura 12. 
Figura 12. Rotas mecanísticas pelas quais moléculas de metanol podem ser obtidas a partir de reações de hidrogenação do dióxido de carbono. Os asteriscos representam espécies adsorvidas.

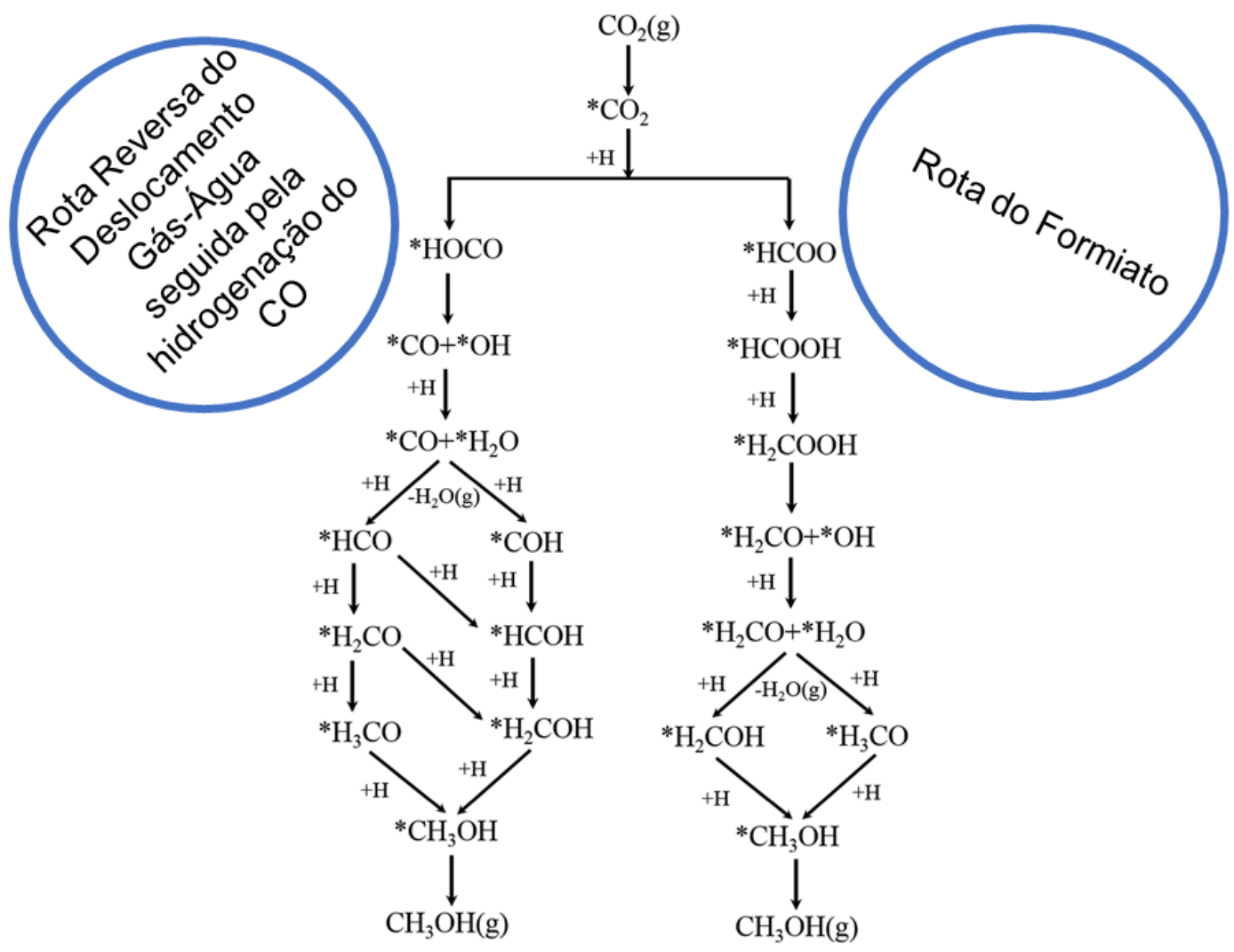

Fonte: KATTEL et al. (2015), modificado.

Nesse sentido, estudos teóricos realizados por Ye e Ge (2011) e Ye e Ge (2012) estabeleceram que, usando óxido de índio como catalisador, uma quantidade reduzida de moléculas de $\mathrm{CO}$ seriam produzidas nas reações de hidrogenação de $\mathrm{CO}_{2}$ (YE et al., 2013; YE; LIU; GE, 2012).

Segundo os pesquisadores, no que se refere à rota $R W G S$, a presença de átomos de índio levaria a um aumento na energia de adsorção do monóxido de carbono à superfície do catalisador, dificultando sua dessorção e permitindo sua hidrogenação até o metanol (BIELZ, T et al., 2011; BIELZ, THOMAS et al., 2010; YE et al., 2013; YE; LIU; GE, 2012).

Além disso, a presença dos átomos de índio nos catalisadores leva a uma diminuição da energia de ativação para a hidrogenação da espécie HCO, o que também contribui de forma importante para a obtenção de alta seletividade ao metanol (BIELZ, T et al., 2011; BIELZ, THOMAS et al., 2010; YE et al., 2013; YE; LIU; GE, 2012). 
Em continuidade, o efeito do índio sobre a rota do formiato também seria significativo uma vez que, em superfícies contendo esse elemento, a energia de ativação para clivagem da ligação C-O das espécies $\mathrm{H}_{2} \mathrm{COOH}$ seria consideravelmente mais baixa favorecendo a produção do metanol (YE et al., 2013; YE; LIU; GE, 2012).

Portanto, parte da alta seletividade apresentada pelos catalisadores promovidos $\mathrm{Cu} / \mathrm{ZrO}_{2}-5 \% \mathrm{In}, \mathrm{Cu} / \mathrm{ZrO}_{2}-10 \% \mathrm{In}, \mathrm{Cu} / \mathrm{CeO}_{2}-5 \%$ In e $\mathrm{Cu} / \mathrm{CeO}_{2}-10 \%$ In se deve a um efeito individual dos átomos de índio ocasionando a alteração das energias de adsorção e ativação de espécies intermediárias favorecendo a produção de metanol.

Além disso, é importante ressaltar a maior basicidade apresentada por esses catalisadores em comparação aos catalisadores $\mathrm{Cu} / \mathrm{ZrO}_{2}$ e $\mathrm{Cu} / \mathrm{CeO}_{2}$ não promovidos. É estabelecido por uma série de pesquisadores que a basicidade é um critério importante para a obtenção de metanol uma vez que ela atua aumentando a interação entre a superfície do catalisador e moléculas ácidas como $\mathrm{CO}_{2}$ e muitas espécies intermediárias presentes em ambas as rotas mecanísticas por meio de interações ácido-base (BANSODE et al., 2013; GUO et al., 2011; LI, L. et al., 2015; POROSOFF; YAN; CHEN, 2015; WANG, WEI et al., 2011).

A maior basicidade apresentada pelos catalisadores modificados com índio pode resultar da maior densidade de vacâncias de átomos de oxigênio verificadas por espectroscopia fotoeletrônica de raios X que atuam como fortes sítios básicos de Lewis (GAO et al., 2013; HU et al., 2014; KUMAR; OJHA, 2015; MCFARLAND; METIU, 2013; STRUNK et al., 2009; WANG, WEIWEI et al., 2020).

Essas vacâncias podem ter surgido tanto em virtude do fenômeno de dopagem com elementos de menor valência quanto pelo menor tamanho médio das partículas de zircônia e céria modificadas com índio que leva a maiores valores de energia livre de superfície, conforme já discutido anteriormente (GAO et al., 2013; KUMAR; OJHA, 2015; MCFARLAND; METIU, 2013; STRUNK et al., 2009).

Foi possível observar ainda, que o aumento na seletividade foi mais expressivo para os catalisadores promovidos com índio pertencentes ao grupo $\mathrm{Cu} / \mathrm{CeO}_{2}-\mathrm{XIn}$ quando comparados aos catalisadores do grupo $\mathrm{Cu} / \mathrm{ZrO}_{2}-\mathrm{XIn}$, o que está de acordo com o que é reportado na literatura uma vez que os materiais contendo céria apresentaram uma maior concentração de átomos de índio em suas superfícies, verificados por espectroscopia fotoeletrônica de Raios X assim como maior basicidade verificada por dessorção de $\mathrm{CO}_{2}$ à temperatura programada. 
A frequência Turnover (Turnover Frequency -TOF) e a produtividade molar para os principais produtos obtidos foram calculados e os resultados se encontram na Tabela 11 e Figura 13.

Diante da impossibilidade de se calcular um número exato que quantificasse as regiões de interface, o cálculo do número de sítios ativos para os catalisadores foi feito tomando-se a área metálica do cobre conforme feito por outros pesquisadores quando se trata de reações de hidrogenação do $\mathrm{CO}_{2}$ em nanocompósitos do tipo metal/óxido (CHANG; WANG; CHEN, 2017; POROSOFF; YAN; CHEN, 2015; WANG, WEI et al., 2011).

Tabela 11. Frequência de Turnover e produtividade molar de $\mathrm{CH}_{3} \mathrm{OH}$ e $\mathrm{CO}$ utilizando os catalisadores pertencentes aos grupos $\mathrm{Cu} / \mathrm{ZrO}_{2}-\mathrm{XIn}$ e $\mathrm{Cu} / \mathrm{CeO}_{2}-\mathrm{XIn}$ sob as condições de $3 \mathrm{MPa}$, $473 \mathrm{~K}$ e $6 \mathrm{~L} \cdot \mathrm{g}^{-1} \cdot \mathrm{h}^{-1}$.

\begin{tabular}{cccc}
\hline Catalisadores & $\begin{array}{c}\text { TOF } \\
\left(\mathrm{s}^{-1}\right)\end{array}$ & $\begin{array}{c}\text { Produtividade Molar } \\
\mathrm{CH}_{3} \mathrm{OH}\left(\mathrm{mol}^{-1} \cdot \mathrm{g}^{-1}\right)\end{array}$ & $\begin{array}{c}\text { Produtividade Molar } \\
\mathrm{CO}\left(\mathrm{mol}^{-1} \cdot \mathrm{h}^{-1}\right)\end{array}$ \\
\hline $\mathrm{Cu} / \mathrm{ZrO}_{2}$ & $1,9 \times 10^{-3}$ & $31,7 \times 10^{-4}$ & $20,2 \times 10^{-4}$ \\
$\mathrm{Cu} / \mathrm{ZrO}_{2}-5 \% \mathrm{In}$ & $1,6 \times 10^{-3}$ & $21,7 \times 10^{-4}$ & $5,3 \times 10^{-4}$ \\
$\mathrm{Cu} / \mathrm{ZrO} 2-10 \% \mathrm{In}$ & $1,4 \times 10^{-3}$ & $21,6 \times 10^{-4}$ & $4,6 \times 10^{-4}$ \\
\hline $\mathrm{Cu} / \mathrm{CeO}_{2}$ & $1,5 \times 10^{-3}$ & $7,5 \times 10^{-4}$ & $8,2 \times 10^{-4}$ \\
$\mathrm{Cu} / \mathrm{CeO}_{2}-5 \% \mathrm{In}$ & $1,1 \times 10^{-3}$ & $8,1 \times 10^{-4}$ & $2,1 \times 10^{-4}$ \\
$\mathrm{Cu} / \mathrm{CeO} 2-10 \% \mathrm{In}$ & $1,1 \times 10^{-3}$ & $8,2 \times 10^{-4}$ & $2,5 \times 10^{-4}$ \\
\hline
\end{tabular}


Figura 13. Frequência de Turnover e produtividade molar de $\mathrm{CH}_{3} \mathrm{OH}$ e $\mathrm{CO}$ utilizando os catalisadores pertencentes aos grupos $\mathrm{Cu} / \mathrm{ZrO}_{2}-\mathrm{XIn}$ e $\mathrm{Cu} / \mathrm{CeO}_{2}-\mathrm{XIn}$ sob as condições de $3 \mathrm{MPa}$, $473 \mathrm{~K}$ e $6 \mathrm{~L} \cdot \mathrm{g}^{-1} \cdot \mathrm{h}^{-1}$.

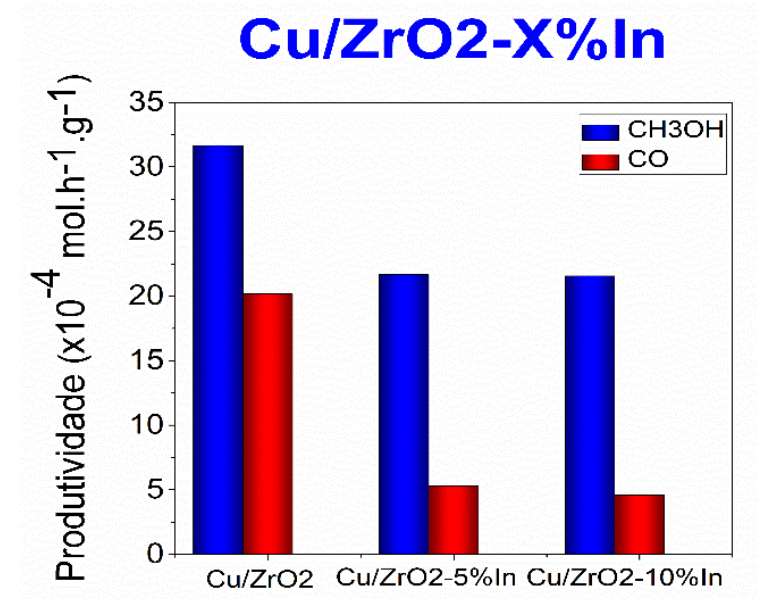

Catalisadores

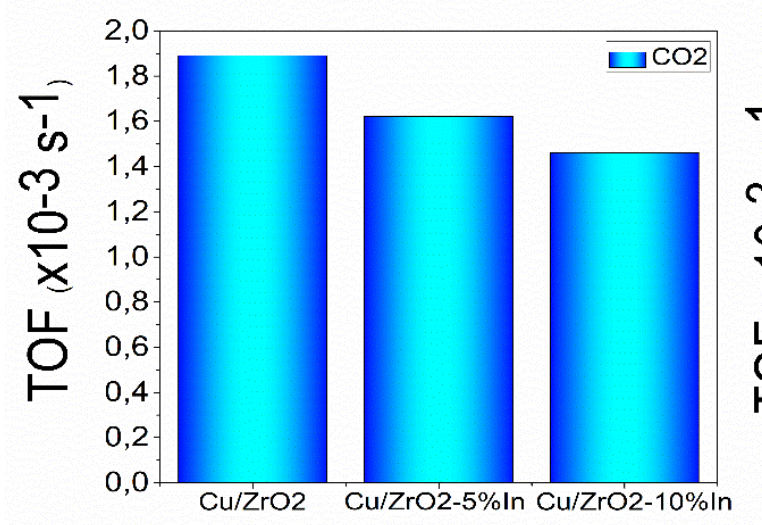

Catalisadores

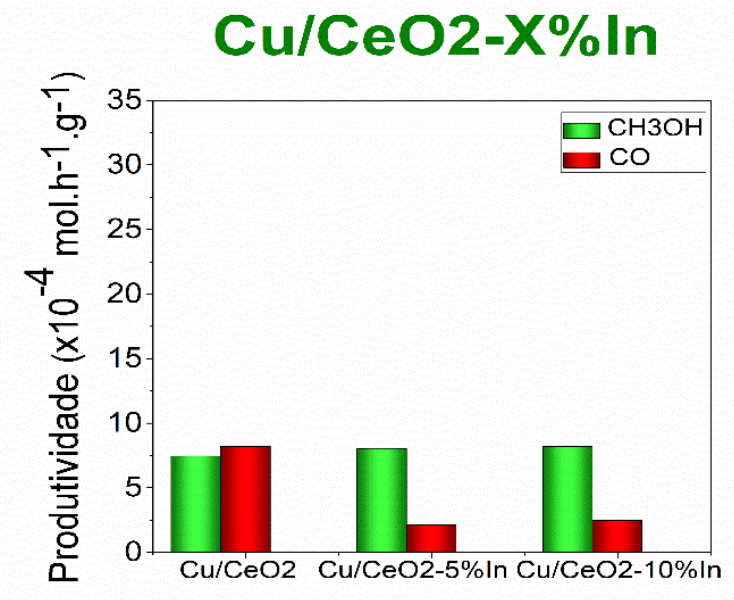

Catalisadores

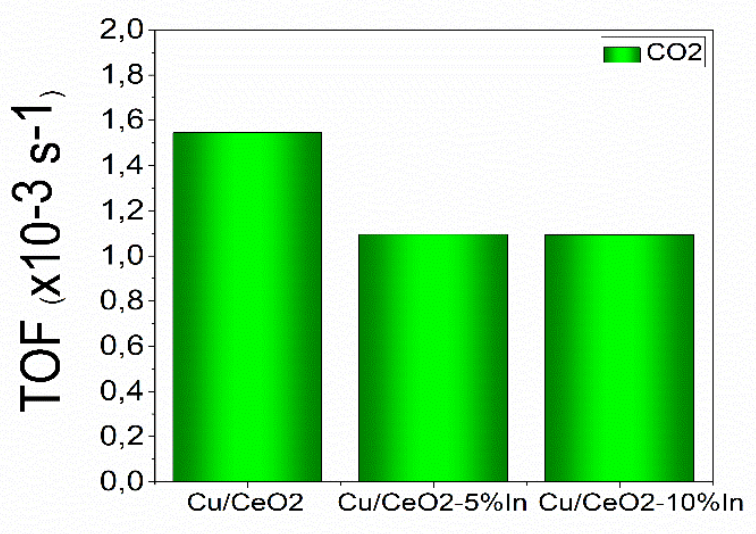

Catalisadores

A análise da Tabela 11 e Figura 13 permite observar que, para os materiais contendo zircônia, a frequência de turnover dos materiais promovidos com índio se mostrou razoavelmente menor do que a apresentada pelo catalisador $\mathrm{Cu} / \mathrm{ZrO}_{2}$ o que é condizente com a conversão de $\mathrm{CO}_{2}$ consideravelmente superior apresentada por esse material.

Além disso, apesar de a produtividade molar de metanol e monóxido de carbono terem se mostrado menores nos catalisadores contendo zircônia promovidos com índio, é muito importante destacar que, enquanto a quantidade de metanol se mostrou cerca de $30 \%$ menor que a observada para o catalisador $\mathrm{Cu} / \mathrm{ZrO}_{2}$, a produção de monóxido de carbono foi cerca de $70 \%$ menor, o que evidencia o caráter consideravelmente mais seletivo dos catalisadores promovidos atestando que a redução da quantidade de $\mathrm{CO}$ gerado foi muito mais pronunciada. 
Já para os materiais baseados em céria, a dopagem com índio levou a efeitos positivos mais evidentes.

Apesar dos catalisadores promovidos também terem apresentado menor frequência de turnover que o catalisador $\mathrm{Cu} / \mathrm{CeO}_{2}$, os valores de produtividade molar do metanol foram razoavelmente superiores aos verificados para catalisador não modificado, o que indica que a maior seletividade dos catalisadores promovidos foi mais significativa que a menor conversão apresentada por eles.

Mais do que isso, foi possível verificar que a quantidade de CO produzida foi consideravelmente menor, cerca de apenas um terço, do que a observada para o material $\mathrm{Cu} / \mathrm{CeO}_{2}$. Dessa forma, apesar da menor conversão dos materiais contendo índio, ainda foi possível obter uma maior quantidade de metanol em um processo mais seletivo.

A comparação entre os grupos evidencia a maior eficiência dos catalisadores baseados em zircônia em termos de conversão e produtividade, o que está de acordo com os valores de área metálica superiores aos catalisadores baseados em céria (PAN et al., 2017; POROSOFF; YAN; CHEN, 2015; WANG, WEI et al., 2011).

No entanto, esse último grupo de catalisadores se mostrou mais eficiente na redução da quantidade de monóxido de carbono formado em virtude da sua maior seletividade ocasionada pela maior quantidade de átomos de índio em sua superfície e pela sua maior basicidade (GUO et al., 2011; LI, L. et al., 2015; YE et al., 2013; YE; LIU; GE, 2012).

Um resumo dos resultados catalíticos devido aos efeitos causados na seletividade aos principais produtos devido à utilização de índio como promotor é mostrado na Figura 14. 
Figura 14. Diferenças na seletividade a $\mathrm{CH}_{3} \mathrm{OH}$ e $\mathrm{CO}$ entre os catalisadores promovidos com índio e os catalisadores $\mathrm{Cu} / \mathrm{ZrO}_{2}$ e $\mathrm{Cu} / \mathrm{CeO}_{2}$ não modificados. Condições reacionais: 3MPa, 473 $\mathrm{K}$ e $6 \mathrm{~L} \cdot \mathrm{h}^{-1} \cdot \mathrm{g}^{-1}$.
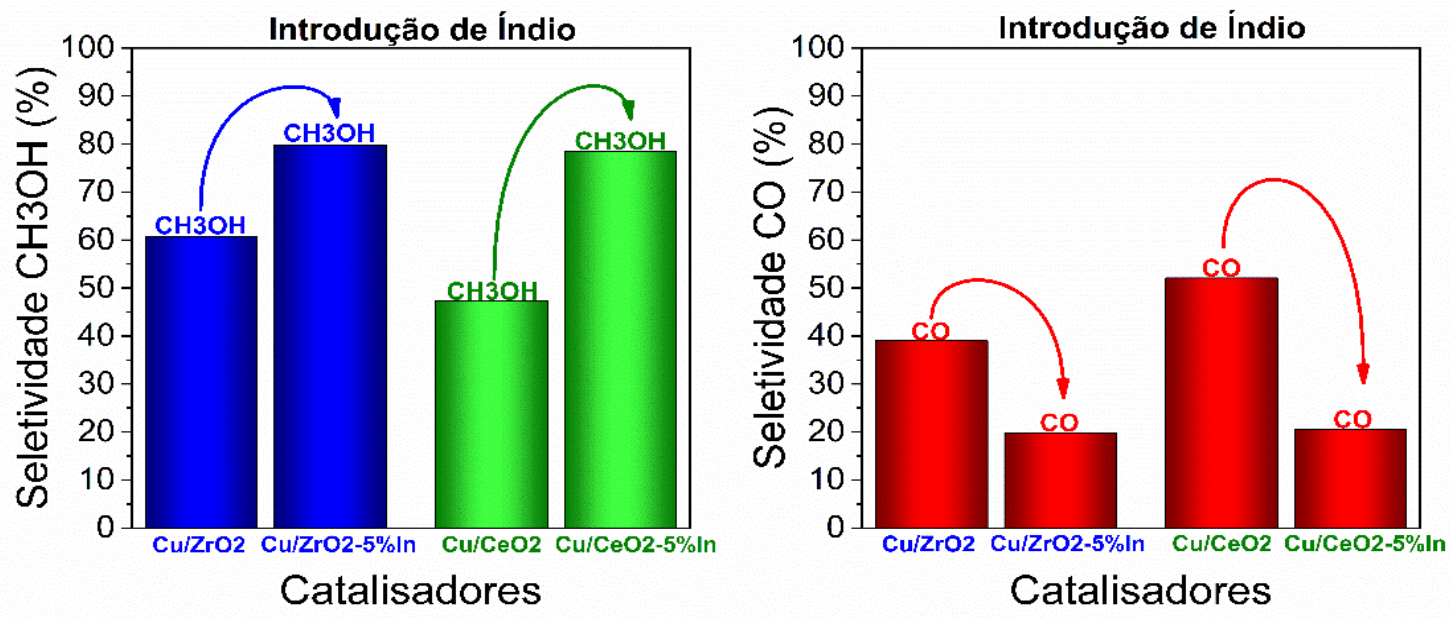

Levando-se em consideração o desempenho catalítico dos materiais associado à economia de utilização de índio em virtude de seu valor mais alto, os catalisadores $\mathrm{Cu} / \mathrm{ZrO}_{2}-$ $5 \%$ In e $\mathrm{Cu} / \mathrm{CeO}_{2} 5 \%$ In foram selecionados como os mais promissores e, portanto, utilizados nas etapas seguintes de otimização dos parâmetros reacionais utilizando ferramentas quimiométricas.

Otimização Quimiométrica dos catalisadores $\mathrm{Cu} / \mathrm{ZrO}_{2}-\mathrm{X} \% \mathrm{In}$ e $\mathrm{Cu} / \mathrm{CeO}$ - $\mathrm{X} \% \mathrm{In}$

A matriz experimental foi criada de acordo com o que é definido no planejamento do tipo Compósito Central (Central Composite Design) e aplicada aos catalisadores $\mathrm{Cu} / \mathrm{ZrO}_{2}-$ 5\%In em diferentes condições de pressão, temperatura e velocidade espacial (BARROS NETO; SCARMINIO; BRUNS, 2010; NUNES et al., 2012). Os resultados utilizando os catalisadores $\mathrm{Cu} / \mathrm{ZrO}_{2}-5 \%$ In se encontram na Tabela 12 . 
Tabela 12. Matriz experimental gerada pelo planejamento estatístico do tipo compósito central com diferentes condições de pressão $(\mathrm{P})$, temperatura $(\mathrm{T})$ e velocidade espacial $\left(\mathrm{L}^{-1} \cdot \mathrm{g}^{-1} \cdot \mathrm{h}^{-1}\right)$ e resultados de conversão $\left(\mathrm{X}_{\mathrm{CO} 2}\right)$ e seletividade $(\mathrm{S})$ utilizando o catalisador $\mathrm{Cu} / \mathrm{ZrO}_{2}-5 \% \mathrm{In}$.

\begin{tabular}{|c|c|c|c|c|c|c|c|c|}
\hline Ensaio & $\begin{array}{c}\mathrm{P} \\
(\mathrm{MPa})\end{array}$ & $\begin{array}{c}\mathrm{T} \\
(\mathrm{K})\end{array}$ & $\begin{array}{c}\text { GHSV } \\
\left(\mathrm{L} \cdot \mathrm{g}^{-1} \cdot \mathrm{h}^{-1}\right)\end{array}$ & $\begin{array}{c}\mathrm{X}_{\mathrm{CO} 2} \\
(\%)\end{array}$ & $\begin{array}{c}\mathrm{S}_{\mathrm{CH} 3 \mathrm{OH}} \\
(\%)\end{array}$ & $\begin{array}{l}\mathrm{S}_{\mathrm{CO}} \\
(\%)\end{array}$ & $\begin{array}{l}\mathrm{S}_{\mathrm{CH} 4} \\
(\%)\end{array}$ & $\begin{array}{c}\mathrm{S}_{\mathrm{C} 2 \mathrm{H} 6} \\
(\%)\end{array}$ \\
\hline 1 & 2 & 473 & 6 & 2,7 & 80,0 & 19,7 & 0,1 & 0,2 \\
\hline 2 & 2 & 473 & 12 & 1,7 & 82,6 & 17,1 & 0,1 & 0,2 \\
\hline 3 & 2 & 523 & 6 & 13,5 & 37,7 & 62,1 & 0,2 & 0,0 \\
\hline 4 & 2 & 523 & 12 & 8,0 & 49,5 & 50,3 & 0,2 & 0,0 \\
\hline 5 & 3 & 473 & 6 & 4,4 & 79,0 & 20,8 & 0,1 & 0,1 \\
\hline 6 & 3 & 473 & 12 & 2,6 & 83,7 & 16,0 & 0,1 & 0,2 \\
\hline 7 & 3 & 523 & 6 & 17,8 & 45,9 & 54,0 & 0,1 & 0,0 \\
\hline 8 & 3 & 523 & 12 & 11,6 & 52,0 & 47,9 & 0,1 & 0,0 \\
\hline 9 & 1,66 & 498 & 9 & 4,2 & 65,7 & 34,1 & 0,1 & 0,1 \\
\hline 10 & 3,34 & 498 & 9 & 6,6 & 69,5 & 30,3 & 0,1 & 0,1 \\
\hline 11 & 2,5 & 455,96 & 9 & 1,3 & 89,5 & 10,2 & 0,0 & 0,3 \\
\hline 12 & 2,5 & 540,04 & 9 & 18,8 & 33,4 & 66,4 & 0,2 & 0,0 \\
\hline 13 & 2,5 & 498 & 3,95 & 12,2 & 57,2 & 42,7 & 0,1 & 0,0 \\
\hline 14 & 2,5 & 498 & 14,05 & 4,0 & 70,4 & 29,4 & 0,1 & 0,1 \\
\hline 15 & 2,5 & 498 & 9 & 5,5 & 67,5 & 32,3 & 0,1 & 0,1 \\
\hline 16 & 2,5 & 498 & 9 & 5,6 & 66,2 & 33,5 & 0,2 & 0,1 \\
\hline 17 & 2,5 & 498 & 9 & 5,3 & 68,5 & 31,3 & 0,1 & 0,1 \\
\hline
\end{tabular}

Usando os resultados presentes na matriz experimental e selecionando a seletividade ao metanol como resposta a ser otimizada, os efeitos principais causados pela variação de pressão, temperatura e velocidade espacial sobre a seletividade ao metanol foram calculados assim como os efeitos de interação entre essas variáveis e sua significância sobre a produção de metanol foi estatisticamente avaliada (BARROS NETO; SCARMINIO; BRUNS, 2010; NUNES et al., 2012).

Os resultados se encontram na Tabela 13 e foram graficamente expressos por meio do Gráfico de Pareto que se encontra na Figura 15. 
Tabela 13. Efeitos principais causados pela alteração de pressão, temperatura e velocidade espacial sobre a seletividade ao metanol e efeitos de interação entre essas variáveis utilizando o catalisador $\mathrm{Cu} / \mathrm{ZrO}_{2}-5 \% \mathrm{In}$.

\begin{tabular}{ccccc}
\hline Variáveis & Efeitos & Erro & Efeito Padronizado (t) & Significância* $^{*}$ \\
\hline Pressão (X1) & 2.5175 & 0.6241 & 4.0336 & Não \\
Temperatura (X2) & -34.3488 & 0.6241 & -55.0341 & Sim \\
V. Espacial (X3) & 6.9415 & 0.6241 & 11.1218 & Sim \\
X1*X2 & 2.6500 & 0.8155 & 3.2496 & Não \\
X1*X3 & -0.9000 & 0.8155 & -1.1037 & Não \\
X2*X3 & 2.6500 & 0.8155 & 3.2496 & Não \\
\hline
\end{tabular}

* Analisada considerando o efeito crítico igual a 3,509 com valor padronizado (t) de 4,303.

Figura 15. Gráfico de Pareto com a significância do efeito principal causado pela variação dos valores de pressão, temperatura e velocidade espacial sobre a seletividade ao metanol assim como os efeitos de interação entre as elas utilizando o catalisador $\mathrm{Cu} / \mathrm{ZrO}_{2}-5 \% \mathrm{In}$. A análise foi realizada com $95 \%$ de confiabilidade estatística.

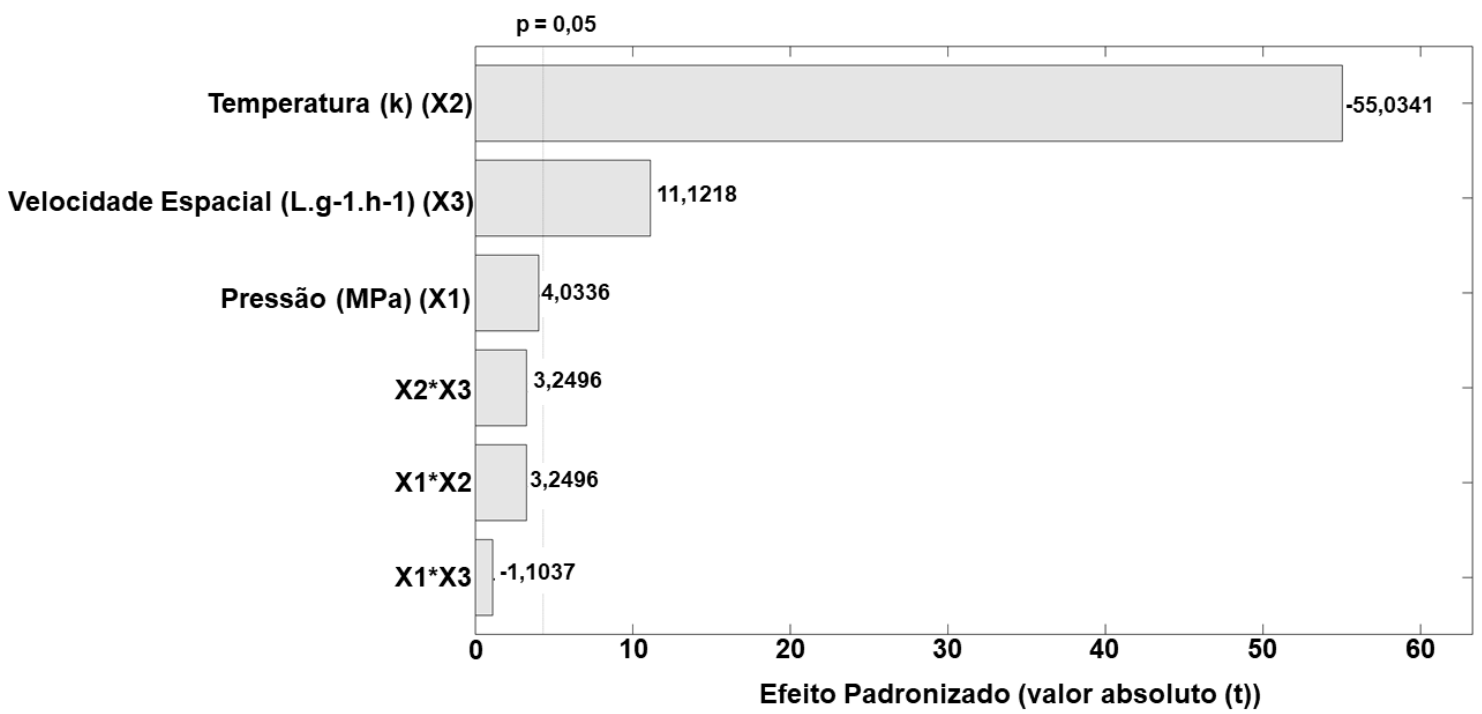

A primeira conclusão importante que emerge da análise da Tabela 13 e Figura 15 é que nenhum dos efeitos de interação entre as variáveis foram significativos.

Na prática, isso significa que a definição de um valor ótimo para uma certa variável, não sofre influência das demais, ou seja, o ponto ótimo encontrado para a temperatura, por exemplo, se manterá o mesmo independente de qual seja o valor de pressão e velocidade espacial 
utilizados. Isso garante que as variáveis possam ser analisadas separadamente (BARROS NETO; SCARMINIO; BRUNS, 2010).

Entre as variáveis, a temperatura mostrou ter o maior efeito sobre a seletividade ao metanol, o que significa que as maiores diferenças nos valores de seletividade ao metanol foram geradas quando se variava a temperatura na qual as reações foram conduzidas (BARROS NETO; SCARMINIO; BRUNS, 2010).

Além disso, o efeito com valor negativo (chamado antagônico) indica que a seletividade ao metanol apresentou os maiores valores em temperaturas mais baixas dentro da faixa analisada.

Essa observação pode ser explicada pelo fato de que a reação de hidrogenação do $\mathrm{CO}_{2}$ ao metanol é um processo exotérmico $\left(\Delta \mathrm{H}^{\circ}=-49,37 \mathrm{~kJ} \cdot \mathrm{mol}^{-1}\right)$ enquanto a reação de hidrogenação do $\mathrm{CO}_{2}$ ao monóxido de carbono é endotérmica $\left(\Delta \mathrm{H}^{\circ}=+41 \mathrm{~kJ} \cdot \mathrm{mol}^{-1}\right)$ (LARMIER et al., 2017; POROSOFF; YAN; CHEN, 2015; RODRIGUEZ et al., 2015; WOLF; JESS; KERN, 2016).

Além disso, assim como a variação da entalpia $\left(\Delta \mathrm{H}^{\circ}\right)$, a variação da entropia $\left(\Delta \mathrm{S}^{\circ}\right)$ é também negativa para a reação de geração do metanol o que implica que valores baixos de temperatura terão maior probabilidade de gerar uma variação da energia livre $\left(\Delta \mathrm{G}^{\circ}\right)$ negativa para a reação de produção do metanol, garantindo sua espontaneidade nas condições utilizadas e favorecendo a geração de metanol enquanto há desfavorecimento da reação de formação do CO (LARMIER et al., 2017; POROSOFF; YAN; CHEN, 2015; RODRIGUEZ et al., 2015; WOLF; JESS; KERN, 2016).

Apesar da vantagem termodinâmica para a seletividade ao metanol em menores valores de temperatura, é importante destacar que, a diminuição do valor dessa variável é limitado a cerca de $453 \mathrm{~K}$ valor abaixo do qual, limitações cinéticas passam a ser consideráveis além da competição entre a produção de metanol e a metanação, reação também exotérmica que passa a ser favorecida juntamente com o metanol em tais condições (POROSOFF; YAN; CHEN, 2015; RODRIGUEZ et al., 2015).

Na sequência, a segunda variável mais importante foi a velocidade espacial. O efeito positivo (chamado sinérgico) sobre a seletividade ao metanol apresentado ao se variar a velocidade espacial evidencia que maiores valores dessa variável levam a maiores seletividades ao metanol.

Essa tendência pode ser explicada pelas limitações cinéticas da reação reversa do deslocamento gás-água que leva à formação de $\mathrm{CO}$, uma vez que essa rota mecanística 
apresenta menor velocidade global do que a rota do formiato, que gera exclusivamente metanol. Considerando que um aumento na velocidade espacial desfavorece reações mais lentas em virtude do menor tempo de contato entre reagentes e a superfície do catalisador, a rota do formiato (mais seletiva ao metanol) será, portanto, favorecida e preponderante sobre a rota de formação do CO (MARTIN et al., 2016; RUI et al., 2017).

Por fim, o efeito positivo (sinérgico) sobre a seletividade ao metanol causado pela variação da pressão esse encontra associado ao fato de que a energia de dessorção de reagentes e intermediários torna-se consideravelmente maior em maiores valores de pressão, o que favorece que as moléculas, incluindo o monóxido de carbono, se mantenham adsorvidas na superfície do catalisador durante as várias etapas de hidrogenação que levarão até o metanol, diminuindo, assim, a dessorção de produtos indesejados (PORTHA et al., 2017).

No entanto, apesar do efeito sinérgico sobre a seletividade ao metanol apresentado pela variação da pressão, é preciso destacar que esse efeito não se mostrou estatisticamente significativo, o que significa que alterações nesta variável não levam a variações consideráveis na seletividade ao metanol dentro da faixa experimental analisada $(1,6 \mathrm{MPa}-3,3 \mathrm{MPa})$ (BARROS NETO; SCARMINIO; BRUNS, 2010).

Essa verificação é muito promissora uma vez que ela implica que a seletividade ao metanol não é significativamente diminuída mesmo em valores consideravelmente mais baixos de pressão (POROSOFF; YAN; CHEN, 2015; WANG, WEI et al., 2011).

É importante ressaltar, no entanto, que embora a pressão não seja significativa para a seletividade dentro da faixa analisada, o mesmo não pode ser dito em relação aos valores de conversão, tornando importante que se mantenha essa variável em valores próximos a $3 \mathrm{MPa}$.

Após a análise inicial quantitativa e de significância dos efeitos, as superfícies de resposta foram construídas de modo a se obter uma análise mais ampla sendo possível obter valores preditos estatisticamente para combinações de pressão, temperatura e velocidade espacial, até então não realizadas nos experimentos práticos. Com a superfície de resposta é possível, inclusive, obter os valores de seletividade ao metanol no ponto otimizado com confiabilidade estatística de 95\% (BARROS NETO; SCARMINIO; BRUNS, 2010).

As superfícies de resposta foram construídas utilizando o modelo polinomial quadrático puro que foi o que apresentou melhor ajuste dentre os modelos testados. Os parâmetros de qualidade de ajuste foram calculados por meio de análise de variância (ANOVA) e os resultados se encontram na Tabela 14. 
Tabela 14. Análise de variância (ANOVA) para o modelo quadrático puro utilizando o catalisador $\mathrm{Cu} / \mathrm{ZrO}_{2}-5 \%$ In e as respostas do planejamento tipo compósito central.

\begin{tabular}{cccccc}
\hline $\begin{array}{c}\text { Fonte de } \\
\text { Variação }\end{array}$ & $\begin{array}{c}\text { Soma } \\
\text { Quadrática }\end{array}$ & $\begin{array}{c}\text { Graus de } \\
\text { Liberdade }\end{array}$ & $\begin{array}{c}\text { Média } \\
\text { Quadrática }\end{array}$ & Valor de F & Valor-p \\
\hline Regressão & $4,2819 \times 10^{3}$ & 6 & 713,6461 & 159,3933 & $2,4491 \times 10^{-9}$ \\
Residual & 44,7727 & 10 & 4,4773 & - & - \\
Falta de Ajuste & 42,1127 & 8 & 5,2641 & 3,9580 & 0,2173 \\
Erro puro & 2,6600 & 2 & 1,3300 & - & - \\
SS $_{\text {Total }}$ & $4,3266 \times 10^{3}$ & 16 & & & \\
$\mathrm{R}^{2}$ & 0,9897 & & & & \\
$\mathrm{R}^{2}$ explicável & 0,9994 & & & & \\
\hline
\end{tabular}

Pela Tabela 14, é possível notar que $98,97 \%$ de toda a variação na resposta foi explicada adequadamente utilizando a equação de regressão gerada pelo modelo quadrático puro, o que é corroborado, não somente pelo $\mathrm{R}^{2}$ obtido, como também pelo alto valor -F obtido $(159,3933)$ consideravelmente superior ao valor- $F$ tabelado $(3,74)$ e pelo valor-p menor que 0,05 , que atesta a confiabilidade estatística e a qualidade do ajuste do modelo gerado aos dados experimentais usados como base (BARROS NETO; SCARMINIO; BRUNS, 2010).

A equação de regressão baseada no modelo quadrático puro, a partir da qual as superfícies de resposta foram geradas e apresentada a seguir com os coeficientes gerados e as variáveis pressão, temperatura e velocidade espacial expressas como $\mathrm{P}, \mathrm{T}$ e $\mathrm{VE}$, respectivamente.

$\mathrm{S}_{\mathrm{CH} 3 \mathrm{OH}}(\%)=\left[-479,7438+2,4099 \mathrm{P}+2,7695 \mathrm{~T}+3,8332 \mathrm{VE}+0,0215(\mathrm{P})^{2}-0,0035(\mathrm{~T})^{2}-0,1487(\mathrm{VE})^{2}\right]$

A partir da equação de regressão gerada pelo modelo polinomial de segundo grau do tipo quadrático puro é possível calcular os valores de seletividade ao metanol para as combinações de pressão, temperatura e velocidade espacial não testadas experimentalmente gerando superfícies gráficas chamadas superfícies de resposta.

As superfícies de resposta geradas por tal equação de regressão se encontram na Figura 16. 
Figura 16. Superfícies de resposta contendo a seletividade ao metanol para diferentes combinações das variáveis pressão, temperatura e velocidade espacial, utilizando o catalisador $\mathrm{Cu} / \mathrm{ZrO}_{2}-5 \%$ In.
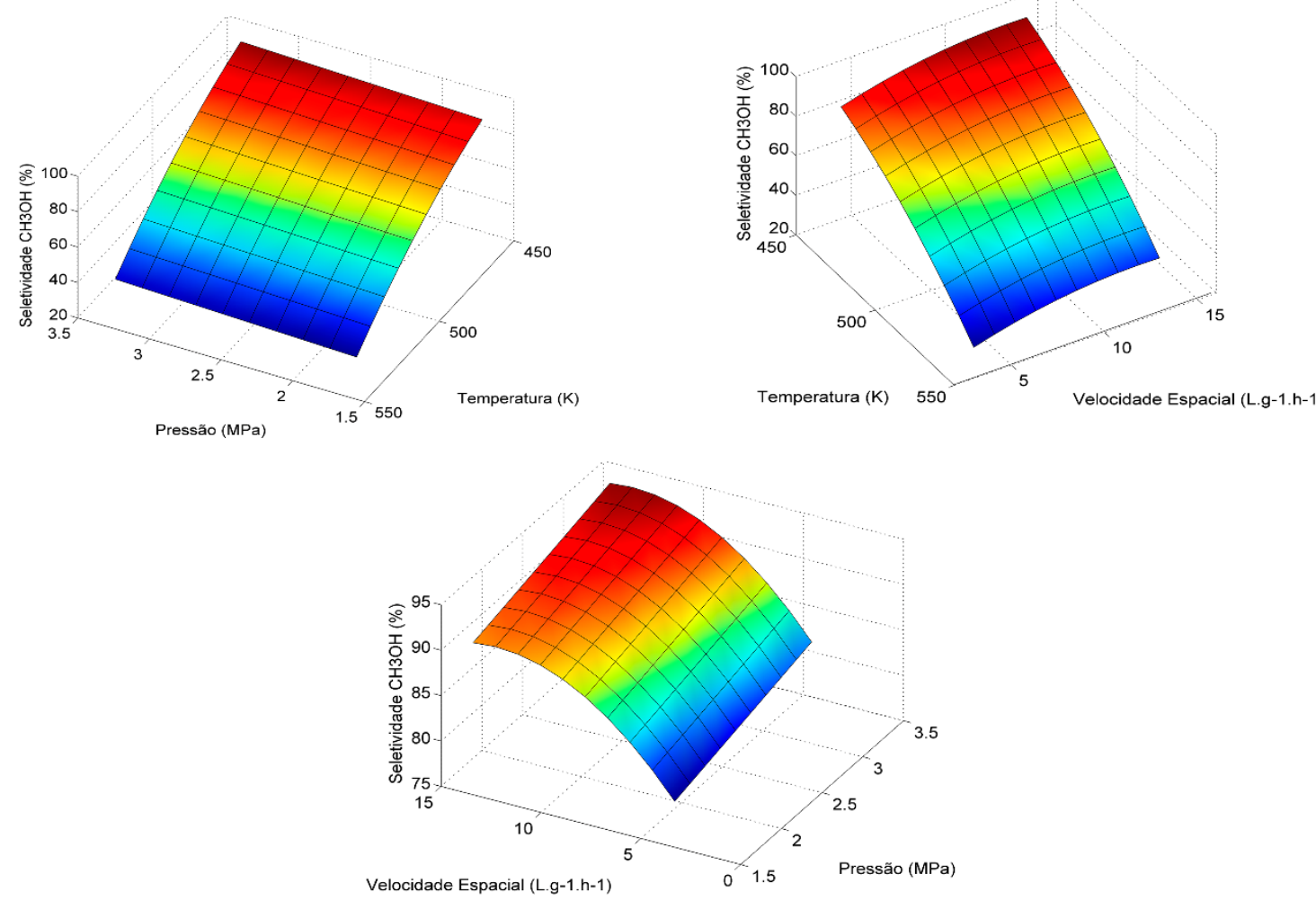

A análise das superfícies permite verificar que, nas condições otimizadas de pressão igual a $3,3 \mathrm{MPa}$, temperatura igual a $456 \mathrm{~K}$ e velocidade espacial igual a $12 \mathrm{~L} \cdot \mathrm{g}^{-1} \cdot \mathrm{h}^{-1}$, foi possível obter cerca de $94 \%$ de seletividade ao metanol.

Além disso, uma vez que a variável pressão não se mostrou significativa, a seletividade ao metanol diminuiu apenas cerca de $4 \%$ ao se variar a pressão de $3,3 \mathrm{MPa}$ para $1,7 \mathrm{MPa}$ mantendo-se a temperatura e velocidade espacial em $456 \mathrm{~K}$ e $12 \mathrm{~L} \cdot \mathrm{g}^{-1} \cdot \mathrm{h}^{-1}$, respectivamente, indo de cerca de $94 \%$ para cerca de $90 \%$, muito embora nessas condições, a conversão tenha sido menor, o que ainda justifica o uso pressão em valores próximos a 3MPa.

Como forma de verificação dos valores preditos pelo modelo, um experimento reacional foi realizado nas condições de $3,3 \mathrm{MPa}, 456 \mathrm{~K}$ e $14 \mathrm{~L} \cdot \mathrm{g}^{-1} \cdot \mathrm{h}^{-1}$ com o objetivo de comparar os catalisadores $\mathrm{Cu} / \mathrm{ZrO}_{2}$ e $\mathrm{Cu} / \mathrm{ZrO}_{2}-5 \%$ In e os valores se encontram na Tabela 15 e expressos graficamente na Figura 17. 
Tabela 15. Conversão de $\mathrm{CO}_{2}\left(\mathrm{X}_{\mathrm{CO} 2}\right)$ e seletividade(S) aos produtos obtidos para os catalisadores $\mathrm{Cu} / \mathrm{ZrO}_{2}$ e $\mathrm{Cu} / \mathrm{ZrO}_{2}-5 \% \mathrm{In}$ sob as condições de $3 \mathrm{MPa}, 456 \mathrm{~K}$ e $14 \mathrm{~L} \cdot \mathrm{g}^{-1} \cdot \mathrm{h}^{-1}$.

\begin{tabular}{cccccc}
\hline Catalisadores & $\mathrm{XCO}_{2}$ & $\mathrm{SCH}_{3} \mathrm{OH}$ & $\mathrm{SCO}$ & $\mathrm{SCH}_{4}$ & $\mathrm{SC}_{2} \mathrm{H}_{6}$ \\
& $(\%)$ & $(\%)$ & $(\%)$ & $(\%)$ & $(\%)$ \\
\hline $\mathrm{Cu} / \mathrm{ZrO}_{2}$ & 2,3 & 69,8 & 29,8 & 0,3 & 0,1 \\
$\mathrm{Cu} / \mathrm{ZrO}_{2}-5 \% \mathrm{In}$ & 1,8 & 93,2 & 6,3 & 0,1 & 0,4 \\
\hline
\end{tabular}

Figura 17. Conversão de $\mathrm{CO}_{2}$ e seletividade aos produtos obtidos para os catalisadores $\mathrm{Cu} / \mathrm{ZrO}_{2}$ e $\mathrm{Cu} / \mathrm{ZrO}_{2}-5 \%$ In sob as condições de $3 \mathrm{MPa}, 456 \mathrm{~K}$ e $14 \mathrm{~L} \cdot \mathrm{g}^{-1} \cdot \mathrm{h}^{-1}$.
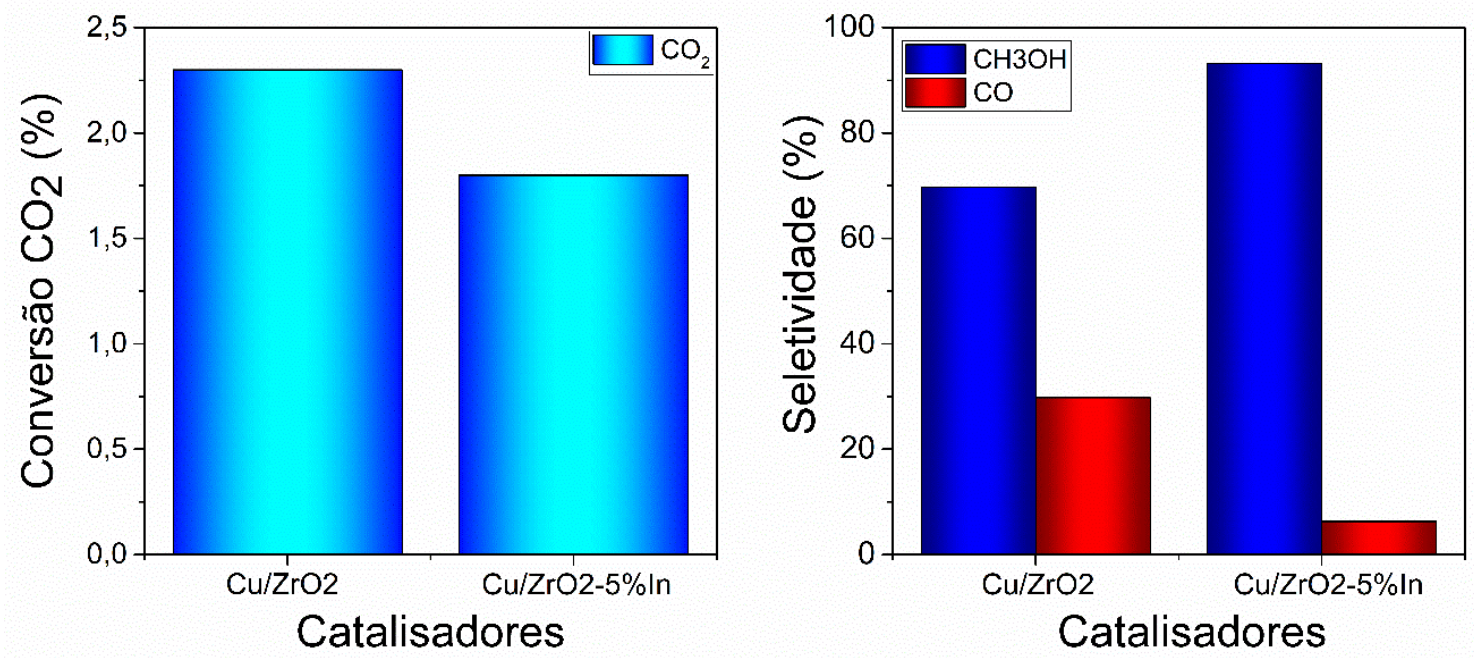

O desempenho catalítico evidenciado pela Tabela 15 e Figura 17 comprovam a alta seletividade obtida pelo catalisador promovido com índio em comparação ao catalisador $\mathrm{Cu} / \mathrm{ZrO}_{2}$.

Após a otimização do catalisador baseado em zircônia, a matriz experimental contendo os resultados utilizando o catalisador $\mathrm{Cu} / \mathrm{CeO}_{2}-5 \%$ In se encontra na Tabela 16 com os respectivos resultados de conversão e seletividade aos produtos obtidos. 
Tabela 16. Matriz experimental gerada pelo planejamento estatístico do tipo compósito central com diferentes condições de pressão $(\mathrm{P})$, temperatura $(\mathrm{T})$ e velocidade espacial $\left(\mathrm{L}^{-1} \cdot \mathrm{g}^{-1} \cdot \mathrm{h}^{-1}\right)$ e resultados de conversão $\left(\mathrm{X}_{\mathrm{CO} 2}\right.$ ) e seletividade $(\mathrm{S})$ utilizando o catalisador $\mathrm{Cu} / \mathrm{CeO}_{2}-5 \% \mathrm{In}$.

\begin{tabular}{|c|c|c|c|c|c|c|c|c|}
\hline Ensaio & $\begin{array}{c}\mathrm{P} \\
(\mathrm{MPa})\end{array}$ & $\begin{array}{c}\mathrm{T} \\
(\mathrm{K})\end{array}$ & $\begin{array}{l}\text { V. Espacial } \\
\left(\mathrm{L} \cdot \mathrm{g}^{-1} \cdot \mathrm{h}^{-1}\right)\end{array}$ & $\begin{array}{c}\mathrm{X}_{\mathrm{CO} 2} \\
(\%)\end{array}$ & $\begin{array}{c}\mathrm{S}_{\mathrm{CH} 3 \mathrm{OH}} \\
(\%)\end{array}$ & $\begin{array}{l}\mathrm{S}_{\mathrm{CO}} \\
(\%)\end{array}$ & $\begin{array}{l}\mathrm{S}_{\mathrm{CH} 4} \\
(\%)\end{array}$ & $\begin{array}{c}\mathrm{S}_{\mathrm{C} 2 \mathrm{H} 6} \\
(\%)\end{array}$ \\
\hline 1 & 2 & 473 & 6 & 0,9 & 72,7 & 26,5 & 0,5 & 0,3 \\
\hline 2 & 2 & 473 & 12 & 0,6 & 73,8 & 25,3 & 0,4 & 0,5 \\
\hline 3 & 2 & 523 & 6 & 6,0 & 32,6 & 66,8 & 0,5 & 0,1 \\
\hline 4 & 2 & 523 & 12 & 3,7 & 34,8 & 64,7 & 0,4 & 0,1 \\
\hline 5 & 3 & 473 & 6 & 1,7 & 78,5 & 20,6 & 0,5 & 0,4 \\
\hline 6 & 3 & 473 & 12 & 1,0 & 80,1 & 19,2 & 0,3 & 0,4 \\
\hline 7 & 3 & 523 & 6 & 7,7 & 37,5 & 61,9 & 0,5 & 0,1 \\
\hline 8 & 3 & 523 & 12 & 4,7 & 42,2 & 57,3 & 0,4 & 0,1 \\
\hline 9 & 1,66 & 498 & 9 & 1,5 & 50,9 & 48,5 & 0,5 & 0,1 \\
\hline 10 & 3,34 & 498 & 9 & 3,0 & 62,4 & 37,1 & 0,4 & 0,1 \\
\hline 11 & 2,5 & 455,96 & 9 & 0,3 & 98,8 & 0,0 & 0,2 & 1,0 \\
\hline 12 & 2,5 & 540,04 & 9 & 7,9 & 30,1 & 69,2 & 0,7 & 0,0 \\
\hline 13 & 2,5 & 498 & 3,95 & 3,3 & 55,4 & 44,0 & 0,5 & 0,1 \\
\hline 14 & 2,5 & 498 & 14,05 & 1,4 & 61,4 & 37,9 & 0,5 & 0,2 \\
\hline 15 & 2,5 & 498 & 9 & 1,8 & 60,3 & 39,0 & 0,5 & 0,2 \\
\hline 16 & 2,5 & 498 & 9 & 1,9 & 59,4 & 40,0 & 0,4 & 0,2 \\
\hline 17 & 2,5 & 498 & 9 & 1,8 & 59,8 & 39,6 & 0,4 & 0,2 \\
\hline
\end{tabular}

De forma análoga ao que foi realizado para o catalisador contendo zircônia, os resultados presentes na matriz experimental foram utilizados tendo a seletividade ao metanol como resposta a ser otimizada.

Assim, o efeito principal causado pela variação no valor de cada variável sobre a seletividade ao metanol e os efeitos de interação entre essas variáveis foram calculados e sua significância foi avaliada estatisticamente (BARROS NETO; SCARMINIO; BRUNS, 2010).

Os resultados se encontram na Tabela 17 e foram graficamente expressos por meio do Gráfico de Pareto que se encontra na Figura 18. 
Tabela 17. Efeitos principais causados pela alteração de pressão, temperatura e velocidade espacial sobre a seletividade ao metanol e efeitos de interação entre essas variáveis utilizando o catalisador $\mathrm{Cu} / \mathrm{CeO}_{2}-5 \% \mathrm{In}$.

\begin{tabular}{ccccc}
\hline Variáveis & Efeitos & Erro & Efeito Padronizado (t) & Significância* \\
\hline Pressão (X1) & 6,4057 & 0,2440 & 26,2485 & Sim \\
Temperatura (X2) & $-40,0589$ & 0,2440 & $-164,1496$ & Sim \\
V. Espacial (X3) & 2,8836 & 0,2440 & 11,8163 & Sim \\
X1*X2 & 0,0500 & 0,3189 & 0,1568 & Não \\
X1*X3 & 0,7500 & 0,3189 & 2,3522 & Não \\
X2*X3 & 1,0500 & 0,3189 & 3,2931 & Não \\
\hline
\end{tabular}

* Analisada considerando o efeito crítico igual a 1,37 com valor padronizado (t) de 4,303.

Figura 18. Gráfico de Pareto com a significância do efeito principal causado pela variação dos valores de pressão, temperatura e velocidade espacial sobre a seletividade ao metanol assim como os efeitos de interação entre as elas utilizando o catalisador $\mathrm{Cu} / \mathrm{CeO}_{2}-5 \% \mathrm{In}$. A análise foi realizada com $95 \%$ de confiabilidade estatística.

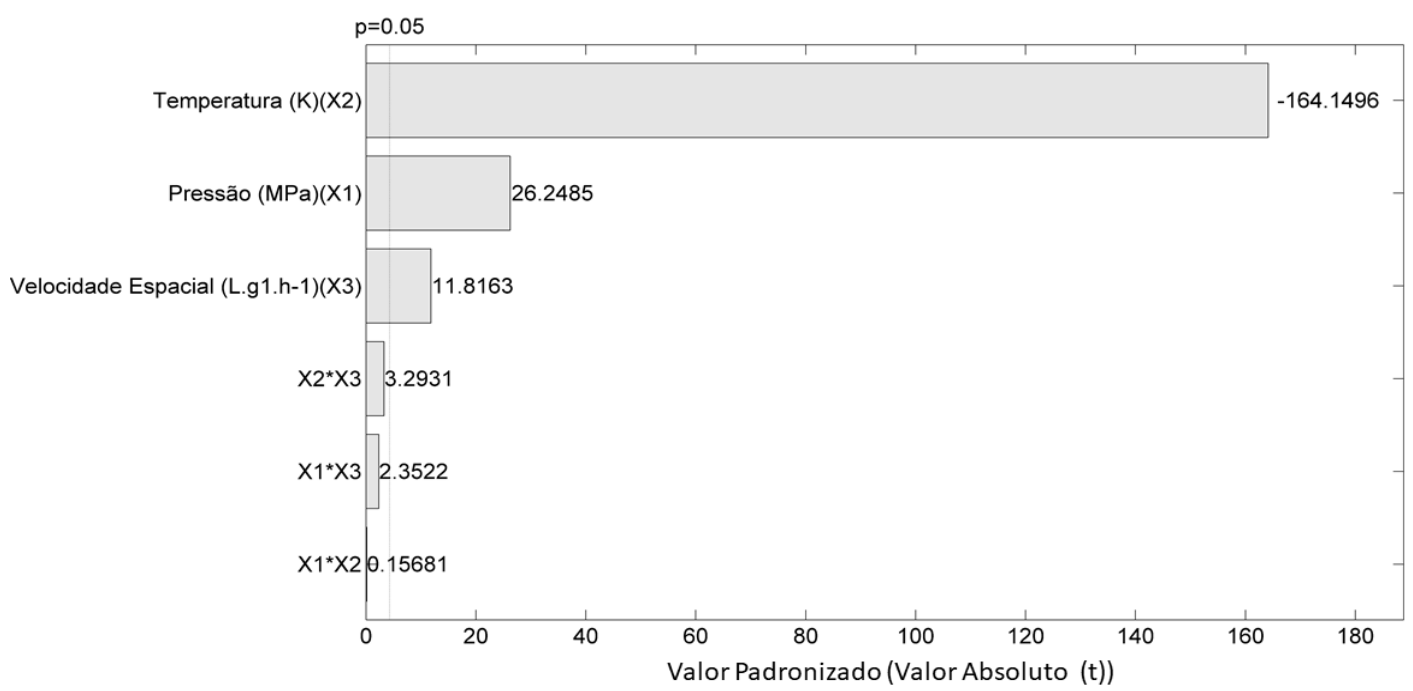

Assim como ocorreu para o material promovido contendo zircônia, os efeitos de interação entre as variáveis não foram significativos para o catalisador $\mathrm{Cu} / \mathrm{CeO}_{2}-5 \% \mathrm{In}$, de modo que o valor ótimo de cada uma delas não mudará independentemente do valor das demais variáveis nos ensaios reacionais. 
Além disso, a temperatura se mostrou a variável que, quando tem seus valores modificados, causa o maior efeito sobre a seletividade ao metanol, apresentando efeito antagônico.

Após a temperatura, a pressão e a velocidade espacial apresentaram efeitos sinérgicos, sendo a pressão a segunda variável cujo efeito da variação é mais considerável sobre a seletividade ao metanol.

As origens para os efeitos causados pela modificação do valor de cada uma das variáveis sobre a seletividade ao metanol são os mesmos já discutidos para o catalisador contendo zircônia (LARMIER et al., 2017; MARTIN et al., 2016; POROSOFF; YAN; CHEN, 2015; PORTHA et al., 2017; RODRIGUEZ et al., 2015; RUI et al., 2017; WOLF; JESS; KERN, 2016).

Diferentemente do que havia sido observado para o catalisador $\mathrm{Cu} / \mathrm{ZrO}_{2}-5 \% \mathrm{In}$, todas as variáveis apresentaram efeitos significativos sobre a seletividade ao metanol quando seus valores foram alterados, de forma que se torna ainda mais importante que a otimização das variáveis seja realizada buscando as melhores condições nas quais o metanol seja produzido em quantidade preponderante sobre os demais produtos que podem ser obtidos pela hidrogenação do $\mathrm{CO}_{2}$ a metanol.

Sendo assim, as superfícies de resposta foram construídas buscando os valores preditos de seletividade nas condições otimizadas para o catalisador $\mathrm{Cu} / \mathrm{CeO}_{2}-5 \% \mathrm{In}$. Para esse catalisador o modelo que apresentou o melhor ajuste entre todos os testados foi polinomial de segundo grau do tipo quadrático.

Utilizando esse modelo, a equação de regressão foi construída, a partir da qual as superfícies foram geradas. Os parâmetros de qualidade de ajuste foram calculados por meio de análise de variância (ANOVA) e os resultados se encontram na Tabela 18. Todos os cálculos foram realizados com confiabilidade estatística de $95 \%$. 
Tabela 18. Análise de variância (ANOVA) para o modelo quadrático utilizando o catalisador $\mathrm{Cu} / \mathrm{CeO}_{2}-5 \%$ In e as respostas do planejamento tipo compósito central.

\begin{tabular}{cccccc}
\hline $\begin{array}{c}\text { Fonte de } \\
\text { Variação }\end{array}$ & $\begin{array}{c}\text { Soma } \\
\text { Quadrática }\end{array}$ & $\begin{array}{c}\text { Graus de } \\
\text { Liberdade }\end{array}$ & $\begin{array}{c}\text { Média } \\
\text { Quadrática }\end{array}$ & Valor de F & Valor-p \\
\hline Regressão & $5,7291 \times 10^{3}$ & 9 & 636,5698 & 114,6009 & $9,1983 \times 10^{-7}$ \\
Residual & 38,8827 & 7 & 5,5547 & - & - \\
Falta de Ajuste & 38,476 & 5 & 7,6952 & 37,8453 & 0,0259 \\
Erro puro & 0,4067 & 2 & 0,2033 & - & - \\
SS $_{\text {Total }}$ & $5,768 \times 10^{3}$ & 16 & & & \\
$\mathrm{R}^{2}$ & 0,9933 & & & & \\
$\mathrm{R}^{2}$ explicável & 0,9999 & & & & \\
\hline
\end{tabular}

A análise de variância, expressa na Tabela 18, permite notar que $99,33 \%$ de toda a variação na resposta foi explicada adequadamente utilizando a equação de regressão gerada pelo modelo quadrático, o que pode ser confirmado pelo $\mathrm{R}^{2}$ obtido, pelo alto valor $-\mathrm{F}(114,6009)$ consideravelmente superior ao valor- $F$ tabelado $(3,74)$ e pelo valor-p menor que 0,05 , que atesta a confiabilidade estatística e a qualidade do ajuste do modelo gerado aos dados experimentais (BARROS NETO; SCARMINIO; BRUNS, 2010).

A equação de regressão baseada no modelo quadrático, a partir da qual as superfícies de resposta foram geradas é apresentada a seguir com os coeficientes gerados e as variáveis pressão, temperatura e velocidade espacial expressas como $\mathrm{P}, \mathrm{T}$ e VE, respectivamente.

$$
\begin{array}{r}
\mathrm{S}_{\mathrm{CH} 3 \mathrm{OH}}(\%)=\left[776,7542+40,3586 \mathrm{P}-2,2999 \mathrm{~T}-1,1479 \mathrm{VE}-7.4398(\mathrm{P})^{2}+0,0014(\mathrm{~T})^{2}\right. \\
\left.-0,1379(\mathrm{VE})^{2}+0,0020(\mathrm{P} . \mathrm{T})+0,2500(\mathrm{P} . \mathrm{VE})+0,0070(\mathrm{~T} . \mathrm{VE})\right]
\end{array}
$$

Por meio da superfície de resposta, valores de seletividade ao metanol foram calculados para as combinações de pressão, temperatura e velocidade espacial não testadas experimentalmente gerando superfícies gráficas chamadas superfícies de resposta.

As superfícies de resposta geradas se encontram na Figura 19. 
Figura 19. Superfícies de resposta contendo a seletividade ao metanol para diferentes combinações das variáveis pressão, temperatura e velocidade espacial, utilizando o catalisador $\mathrm{Cu} / \mathrm{CeO}_{2}-5 \%$ In.
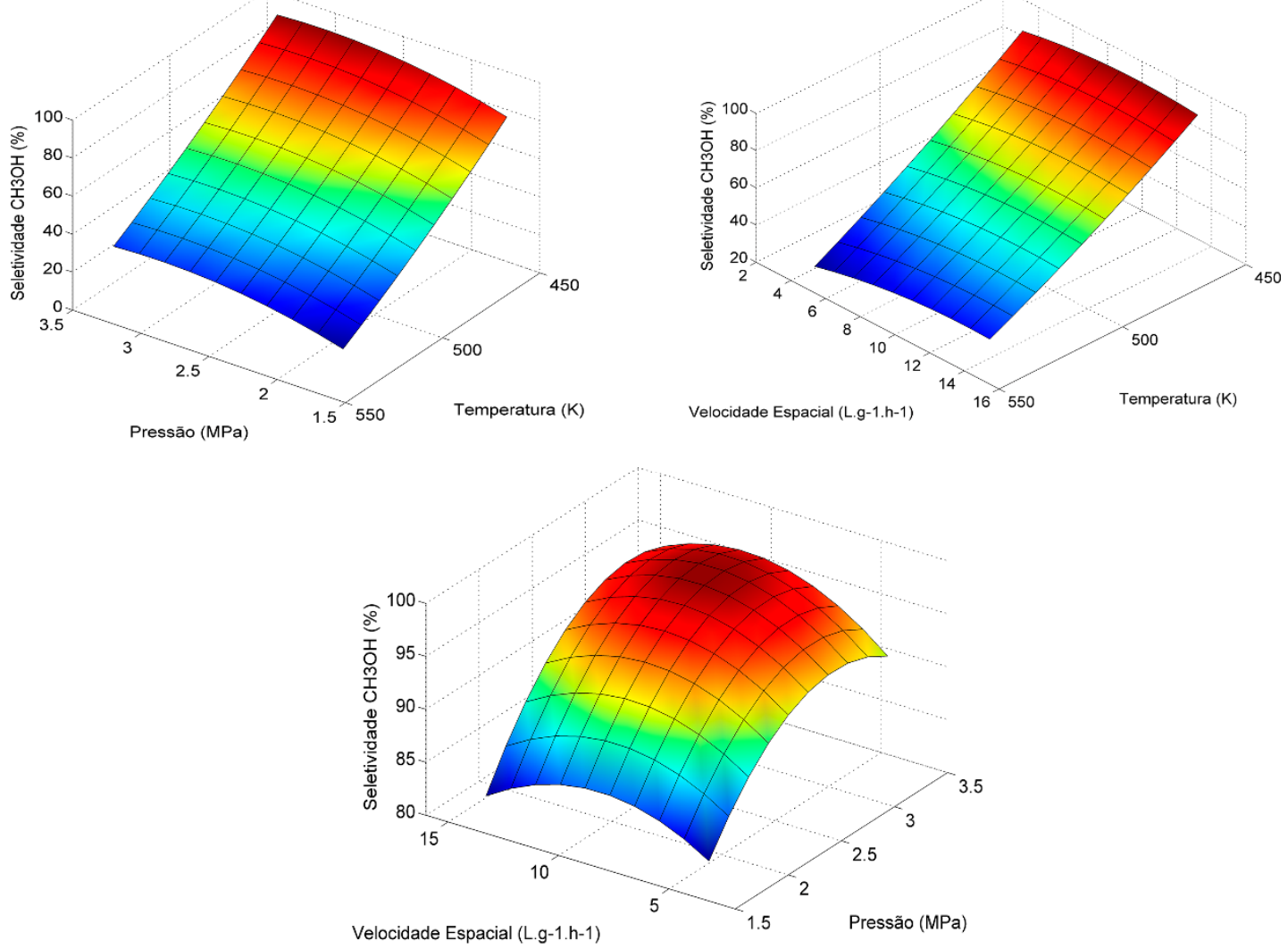

Através da otimização realizada, foi possível obter cerca de $99 \%$ de seletividade ao metanol sob 3,3MPa, $456 \mathrm{~K}$ e velocidade espacial $14 \mathrm{~L} \cdot \mathrm{g}^{-1} \cdot \mathrm{h}^{-1}$, muito embora a conversão tenha sido relativamente baixa nessas condições.

Vale ressaltar, porém, que mesmo em condições distintas, a seletividade ao metanol se mostrou consideravelmente alta juntamente com valores de conversão maiores. Sob 3,3MPa, $473 \mathrm{~K}$ e $14 \mathrm{~L} \cdot \mathrm{g}^{-1} \cdot \mathrm{h}^{-1}$, foi possível obter cerca de $80 \%$ de seletividade a metanol com uma conversão de $1,6 \%$.

Com o objetivo de se comparar os resultados dos catalisadores $\mathrm{Cu} / \mathrm{CeO}_{2}-5 \% \mathrm{In}$ e $\mathrm{Cu} / \mathrm{CeO}_{2}$, nas condições ótimas, foram realizadas dois testes reacionais e os resultados se encontram na Tabela 19 e Figura 20. 
Tabela 19. Conversão de $\mathrm{CO}_{2}\left(\mathrm{X}_{\mathrm{CO} 2}\right)$ e seletividade(S) aos produtos obtidos para os catalisadores $\mathrm{Cu} / \mathrm{CeO}_{2}$ e $\mathrm{Cu} / \mathrm{CeO}_{2}-5 \% \mathrm{In}$ sob as condições de $3 \mathrm{MPa}, 456 \mathrm{~K}$ e $14 \mathrm{~L} \mathrm{~g}^{-1} \cdot \mathrm{h}^{-1}$.

\begin{tabular}{cccccc}
\hline Catalisadores & $\mathrm{XCO}_{2}$ & $\mathrm{SCH}_{3} \mathrm{OH}$ & $\mathrm{SCO}$ & $\mathrm{SCH}_{4}$ & $\mathrm{SC}_{2} \mathrm{H}_{6}$ \\
& $(\%)$ & $(\%)$ & $(\%)$ & $(\%)$ & $(\%)$ \\
\hline $\mathrm{Cu} / \mathrm{CeO}_{2}$ & 1,2 & 65,1 & 33,2 & 0,6 & 1,1 \\
$\mathrm{Cu} / \mathrm{CeO}_{2}-5 \% \mathrm{In}$ & 0,7 & 99,3 & 0,0 & 0,3 & 0,4 \\
\hline
\end{tabular}

Figura 20. Conversão de $\mathrm{CO}_{2}$ e seletividade aos produtos obtidos para os catalisadores $\mathrm{Cu} / \mathrm{CeO}_{2}$ e $\mathrm{Cu} / \mathrm{CeO}_{2}-5 \%$ In sob as condições de $3 \mathrm{MPa}, 456 \mathrm{~K}$ e $14 \mathrm{~L} \cdot \mathrm{g}^{-1} \cdot \mathrm{h}^{-1}$.
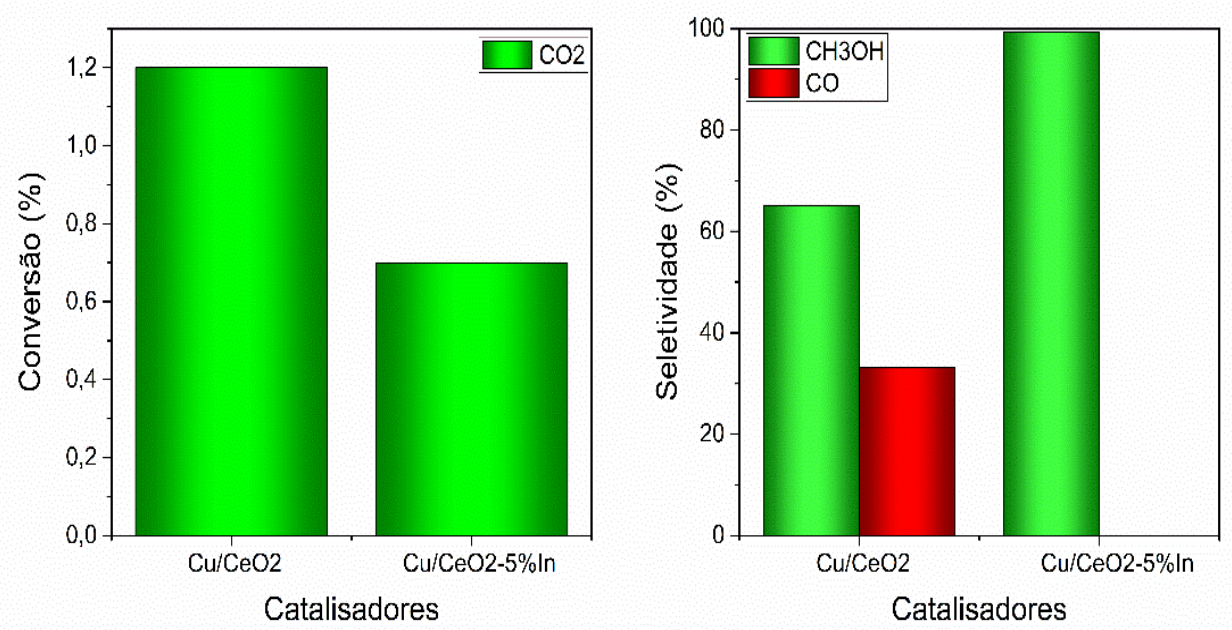

O desempenho catalítico evidenciado pela Tabela 19 e Figura 20 demonstram a alta seletividade ao metanol ao se utilizar o catalisador $\mathrm{Cu} / \mathrm{CeO}_{2}-5 \%$ In nas condições otimizadas, não sendo observada a produção de monóxido de carbono.

É importante ressaltar que, apesar da baixa conversão em tais condições, foi possível obter uma alta seletividade ao metanol e valores maiores de conversão na grande maioria das demais condições, com exceção dos testes reacionais realizados em altas temperaturas que apresentaram alta seletividade ao CO.

Após realizado todo o processo de otimização e da análise do efeito de cada variável sobre o processo reacional, as energias de ativação aparentes para a geração de metanol e monóxido de carbono utilizando os catalisadores $\mathrm{Cu} / \mathrm{ZrO}_{2}-5 \% \mathrm{In}$ e $\mathrm{Cu} / \mathrm{CeO}_{2}-5 \% \mathrm{In}$ foram obtidas. 
Os cálculos foram feitos por meio da equação de Arrhenius considerando a atividade catalítica em várias temperaturas distintas sempre mantendo as variáveis pressão e velocidade espacial constantes em 3MPa e $6 \mathrm{~L} \cdot \mathrm{g}^{-1} \cdot \mathrm{h}^{-1}$. Os resultados são evidenciados na Figura 21.

Figura 21. Gráfico de Arrhenius para o cálculo da energia de ativação para $\mathrm{CH}_{3} \mathrm{OH}$ e $\mathrm{CO}$ utilizando os catalisadores $\mathrm{Cu} / \mathrm{ZrO}_{2}-5 \% \mathrm{In}$ e $\mathrm{Cu} / \mathrm{CeO}_{2}-5 \% \mathrm{In}$.
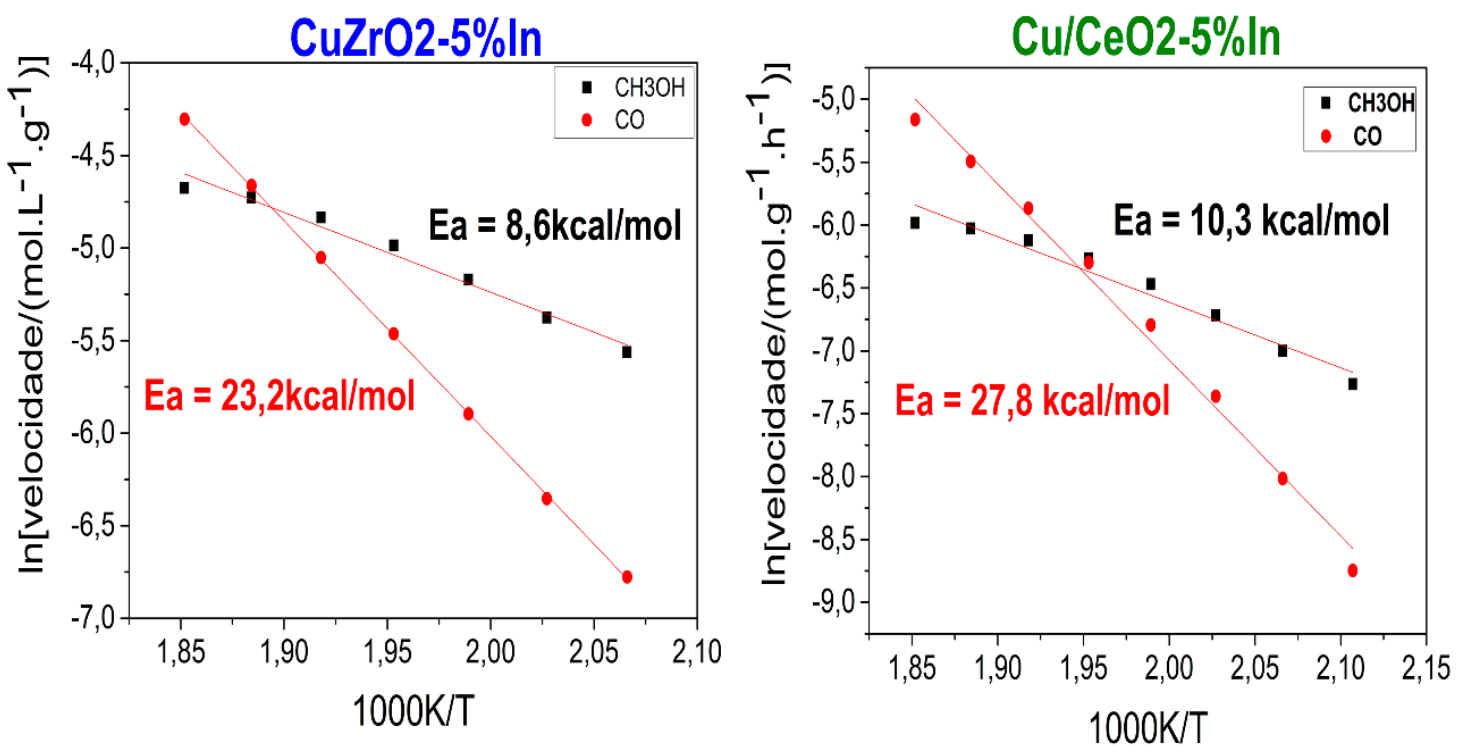

A composição dos catalisadores, o tamanho das partículas, os planos cristalográficos expostos, a dispersão e área metálica são algumas das variáveis que podem influenciar os valores de energia de ativação para a obtenção de um composto específico (CHANG; WANG; CHEN, 2017; WANG, WEI et al., 2011).

Para a maioria dos catalisadores aplicados à hidrogenação do $\mathrm{CO}_{2}$ a metanol presentes na literatura, a energia de ativação para a formação de metanol é maior que $15 \mathrm{kcal}^{\mathrm{mol}}{ }^{-1} \mathrm{e}$, nesses materiais, a energia de ativação para geração de monóxido de carbono é, em geral, um pouco menor que a observada para o metanol (CHANG; WANG; CHEN, 2017; WANG, WEI et al., 2011).

Nos catalisadores $\mathrm{Cu} / \mathrm{ZrO}_{2}-5 \% \mathrm{In}$ e $\mathrm{Cu} / \mathrm{CeO}_{2}-5 \%$ In, no entanto, o oposto foi observado, o que está de acordo com um grupo menor de catalisadores reportados nos quais a energia de ativação para o metanol é menor e, em geral, esse composto é obtido com alta seletividade sendo o produto principal (MA et al., 2017; WANG, WEI et al., 2011). 


\section{Catalisadores Core-Shell CuZrIn-cs e CuCeIn-cs}

\section{Caracterizações}

Apesar da alta seletividade ao metanol obtida com os catalisadores promovidos com índio, é possível verificar, especialmente para os materiais baseados em céria, que o aumento dos valores de conversão do $\mathrm{CO}_{2}$ se mostra muito importante.

Diante disso, algumas estratégias de melhoria de certas propriedades físico-químicas fundamentais como a área metálica, a homogeneidade do tamanho de partículas e a resistência à sinterização do cobre podem ser determinantes para que se obtenha maiores conversões aliadas a alta seletividade ao metanol, mesmo em condições de temperatura mais altas (CHAUDHURI; PARIA, 2012; GAWANDE et al., 2015; POROSOFF; YAN; CHEN, 2015; WANG, WEI et al., 2011).

Em valores mais altos de temperatura, já ocorre o desfavorecimento termodinâmico do metanol que resultará em monóxido de carbono sendo produzido em maior quantidade do que em temperaturas menores (KATTEL et al., 2016; POROSOFF; YAN; CHEN, 2015; WANG, WEI et al., 2011).

Além disso, a agregação das partículas de cobre e do óxido que geralmente ocorre nessas condições, pode levar a uma diminuição da região de interfaces e da quantidade de vacâncias de átomos de oxigênio presente na superfície. Uma vez que essas propriedades afetadas são cruciais para a síntese do metanol, isso fará com o que o catalisador seja ainda menos efetivo para a geração desse produto (KATTEL et al., 2016; POROSOFF; YAN; CHEN, 2015; WANG, WEI et al., 2011).

Diante disso, estratégias de manipulação estrutural como a síntese dos catalisadores em arquitetura core-shell contendo um revestimento poroso de sílica se mostra muito promissora ao funcionar como uma barreira que impeça a agregação das partículas durante tratamentos térmicos na etapa de síntese e em condições reacionais em que temperaturas mais altas sejam utilizadas (CHAUDHURI; PARIA, 2012; GAWANDE et al., 2015).

Tendo esse objetivo em foco, foram sintetizados dois catalisadores em arquitetura coreshell. O primeiro contém um núcleo formado por cobre, zircônia e índio na mesma composição do catalisador $\mathrm{Cu} / \mathrm{ZrO}_{2}-5 \%$ In enquanto o núcleo do segundo é formado por cobre, céria e índio na mesma proporção do catalisador $\mathrm{Cu} / \mathrm{CeO}_{2}-5 \% \mathrm{In}$. Ambos os núcleos foram encapsulados em revestimentos mesoporosos de sílica. Os dois catalisadores foram chamados CuZrIn-cs e CuCeIn-cs. 
As caracterizações e testes catalíticos para esses novos materiais bem como uma comparação entre o desempenho catalítico entre eles e os melhores catalisadores da etapa anterior se encontra a seguir.

Os difratogramas de raios X para os materiais se encontram na Figura 22.

Figura 22. Difratogramas de raios X para os materiais CuZrIn-cs e CuCeIn-cs.
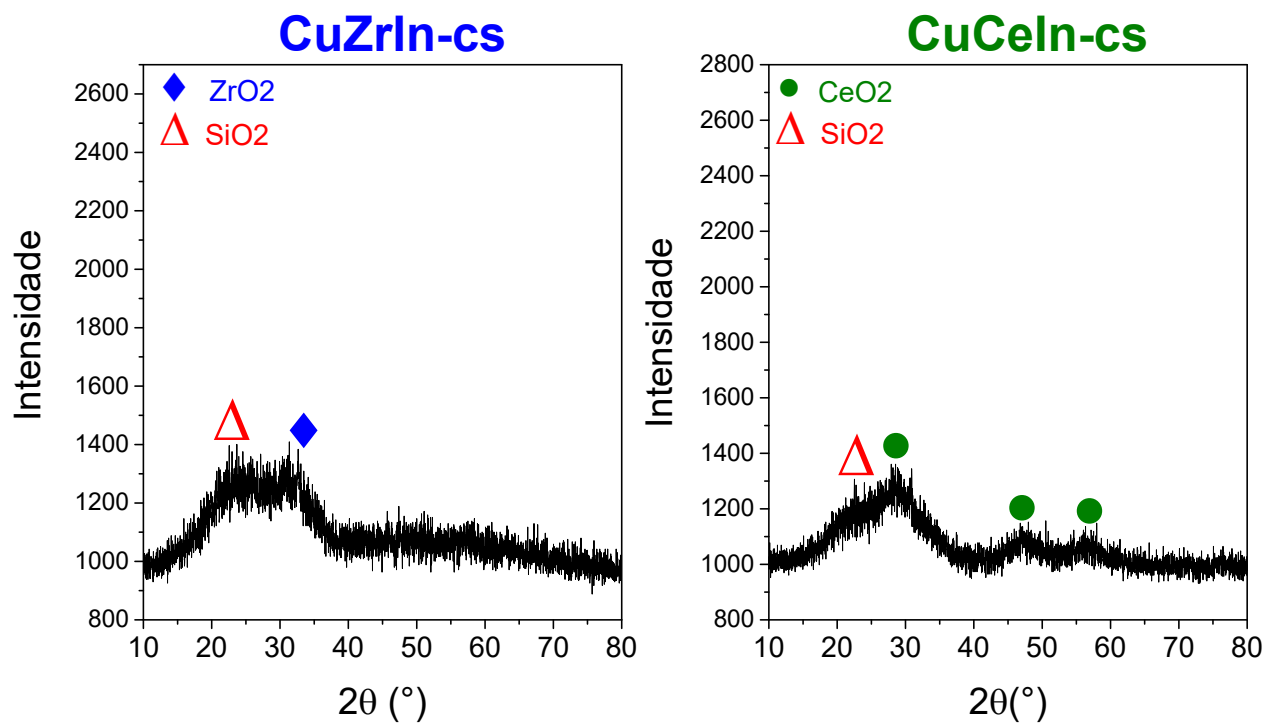

Pela análise dos difratogramas é possível observar a baixa cristalinidade de ambos os catalisadores $\mathrm{CuZrIn}$-cs e CuCeIn-cs, com picos pouco intensos e muito alargados.

Para os dois materiais CuZrIn-cs e CuCeIn-cs, foi observado um pico largo entre 20$30^{\circ}$ característico de sílica amorfa presente como suporte ou revestimento de acordo com o padrão cristalográfico JCPDS $n^{\circ}$ 29-0085 (MUSIĆ; FILIPOVIĆ-VINCEKOVIĆ; SEKOVANIĆ, 2011).

O mesmo perfil foi observado nos trabalhos de Xie et al., 2014; Bai et al., 2016; Yang et al., 2016 e Shi et al., 2018 nos quais os materiais do tipo core-shell sintetizados apresentaram os difratogramas com picos de baixa cristalinidade exibindo um perfil muito próximo ao observado para os materiais deste estudo (BAI et al., 2016; SHI; TAN; WU, 2018; XIE et al., 2014; YANG et al., 2016).

Segundo esses autores, há uma relação diretamente proporcional entre as dimensões das partículas e a intensidade dos picos de difração. Esse fato pode ser explicado pela menor agregação das partículas confinadas no núcleo das estruturas revestidas por sílica durante as 
etapas de tratamento térmico gerando picos pouco definidos (BAI et al., 2016; SHI; TAN; WU, 2018; XIE et al., 2014; YANG et al., 2016).

Para o catalisador contendo zircônia, além do pico alargado atribuído à sílica amorfa, $\mathrm{o}$ pico verificado em torno de $33,5^{\circ}$ se refere ao óxido de zircônio de acordo com o padrão cristalográfico JCPDS n 81-1551 relacionado à estrutura cúbica da $\mathrm{ZrO}_{2}(\mathrm{ARENA}$ et al., 2007; BONURA et al., 2011; GUO et al., 2011; LI, L. et al., 2015).

Já para o catalisador contendo céria, os picos localizados em $28^{\circ} ; 47,5^{\circ}$ e $56,3^{\circ}$ se relacionam à estrutura do óxido de cério estando de acordo com os picos do padrão cristalográfico JCPDS $\mathrm{n}^{\circ}$ 34-0394 referente à estrutura $\mathrm{CeO}_{2}$ cúbica de face centrada (BONURA et al., 2011; GUO et al., 2011; LI, L. et al., 2015; ZABILSKIY et al., 2015).

Com o objetivo de se analisar a composição dos catalisadores em termos da fase ativa, ou seja, desconsiderando a sílica que se encontra apenas como revestimento inerte, análises de espectroscopia de fluorescência de raios $\mathrm{X}$ foram realizadas e os resultados se encontram na Tabela 20.

Tabela 20. Composição elementar dos materiais CuZrIn-cs e CuCeIn-cs analisadas por espectroscopia de fluorescência de raios X.

\begin{tabular}{ccccc}
\hline & \multicolumn{4}{c}{ Composição Elementar (\% molar) } \\
\cline { 2 - 5 } Catalisadores & $\mathrm{Ce}$ & $\mathrm{Zr}$ & $\mathrm{Cu}$ & $\mathrm{In}$ \\
\hline CuZrIn-cs & 0 & 43,1 & 52,3 & 4,6 \\
CuCeIn-cs & 42,5 & 0 & 53,1 & 4,4 \\
\hline
\end{tabular}

* Para as análises elementares, os percentuais de sílica encontrados foram desconsiderados.

As análises de fluorescência de raios $\mathrm{X}$ evidenciaram que as composições elementares se encontram muito próximas aos teores nominais dos materiais sintetizados. Além disso, impurezas não foram encontradas.

Com o objetivo de se analisar as morfologias dos catalisadores, análises de microscopia eletrônica de transmissão foram realizadas e se encontram na Figura 23. 
Figura 23. Microscopia eletrônica de transmissão e distribuição do tamanho de partículas que formam os núcleos dos catalisadores CuZrIn-cs e CuCeIn-cs.

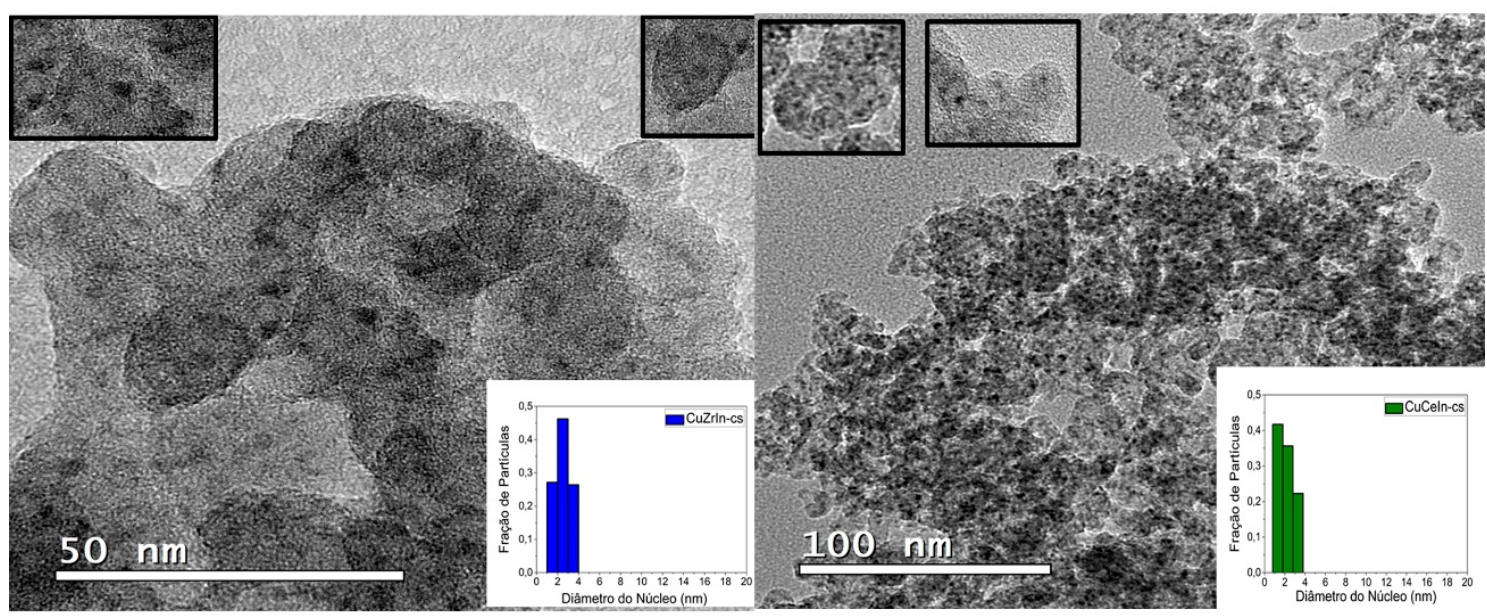

Pelas imagens é possível verificar que os materiais CuZrIn-cs e CuCeIn-cs apresentam núcleos revestidos por sílica em decorrência da diferença de contraste entre os óxidos. A espessura das cascas de sílica medidas apresentou-se relativamente uniforme variando entre 4$6 \mathrm{~nm}$ para o material contendo zircônia e 3-4 nm para o material CuCeIn-cs. As estruturas obtidas apresentam grande semelhança com os materiais core-shell obtidos por Yang et al., 2016 e Shi et al., 2018 (SHI; TAN; WU, 2018; YANG et al., 2016).

Com o objetivo de avaliar as dimensões das partículas que formam a fase ativa para as reações de hidrogenação (desconsiderando a sílica que está presente apenas como revestimento), foi medida a distribuição de tamanho das partículas formadas por cobre, índio e zircônio ou cério que se encontram confinadas no núcleo revestido por sílica mesoporosa.

A distribuição do tamanho de partículas dos materiais evidencia a eficiência das estruturas core-shell em minimizar a agregação entre as partículas devido aos efeitos de confinamento dos núcleos revestidos. Além disso, há a eficiência do método solvotérmico em gerar as partículas do núcleo com alto grau de homogeneidade como já apresentado por vários autores (BAI et al., 2016; SHI; TAN; WU, 2018; WANG, X. M.; LORIMER; XIAO, 2005; XIE et al., 2014; YANG et al., 2016).

As partículas que formam os núcleos dos dois catalisadores revestidos apresentaram dimensões médias menores e têm distribuição de tamanho consideravelmente mais homogênea quando comparadas aos aglomerados presentes nos materiais $\mathrm{Cu} / \mathrm{ZrO}_{2}-5 \%$ in e $\mathrm{Cu} / \mathrm{CeO}_{2}-5 \% \mathrm{In}$ sintetizados na etapa anterior deste trabalho. 
Análises de fisissorção de $\mathrm{N}_{2}$ foram realizadas com o objetivo de se obter as áreas específicas de superfície e o perfil dos poros para os materiais e os resultados se encontram na Tabela 21.

Tabela 21. Áreas específicas de superfície e distribuição de volumes de poros obtidas por fisissorção de $\mathrm{N}_{2}$ para os catalisadores CuZrIn-cs e CuCeIn-cs.

\begin{tabular}{ccccc}
\hline Catalisadores & $\begin{array}{c}\text { Área Específica } \\
\text { de Superfície } \\
\left(\mathrm{m}^{2} \cdot \mathrm{g}^{-1}\right)^{*}\end{array}$ & $\begin{array}{c}\text { Volume Total } \\
\text { de Poros } \\
\left(\mathrm{cm}^{3} \cdot \mathrm{g}^{-1}\right)\end{array}$ & $\begin{array}{c}\text { Volume de } \\
\text { mesoporos } \\
\left(\mathrm{cm}^{3} \cdot \mathrm{g}^{-1}\right)^{* *}\end{array}$ & $\begin{array}{c}\text { Volume de microporos } \\
\left(\mathrm{cm}^{3} \cdot \mathrm{g}^{-1}\right)^{* * *}\end{array}$ \\
\hline CuZrIn-cs & 235,3 & 0,954 & 0,948 & 0,006 \\
CuCeIn-cs & 191,9 & 0,589 & 0,587 & 0,002 \\
\hline
\end{tabular}

* Valores obtidos utilizando-se o modelo de isoterma B.E.T.

** Valores obtidos utilizando o modelo de isoterma BJH

*** Valores obtidos utilizando o modelo T-plot

Os catalisadores CuZrIn-cs e CuCeIn-cs, apresentaram alta área específica de superfície quando comparados a todos os materiais sintetizados anteriormente, além disso, o volume de poros se mostrou substancialmente maior sendo majoritariamente formado por mesoporos. Tais observações podem ser explicadas em termos da influência do método de síntese.

Os materiais do tipo "core-shell” foram obtidos pelo método solvotérmico que, por si só, garante alto grau de controle sobre a distribuição de tamanho das partículas. Já na segunda etapa, a geração do revestimento de sílica se mostrou eficiente na diminuição da agregação das partículas durante as etapas posteriores de tratamento térmico como é bem estabelecido por uma série de pesquisadores (CHAUDHURI; PARIA, 2012; GAWANDE et al., 2015; LIU, Y.; GOEBL; YIN, 2013; SHI; TAN; WU, 2018; WANG, X. M.; LORIMER; XIAO, 2005; YANG et al., 2016).

Por fim, os agentes estabilizadores PVP e CTAB utilizados também atuam tanto no controle de crescimento das partículas quanto na geração de mesoporosidade conforme ficou evidenciado nas análises de microscopia eletrônica de transmissão (LIU, Y.; GOEBL; YIN, 2013; SHI; TAN; WU, 2018; WANG, X. M.; LORIMER; XIAO, 2005; YANG et al., 2016).

As isotermas de adsorção de $\mathrm{N}_{2}$ para os catalisadores foram plotadas e se encontram na Figura 24. 
Figura 24. Isotermas de fisissorção de $\mathrm{N}_{2}$ para os catalisadores CuZrIn-cs e CuCeIn-cs.
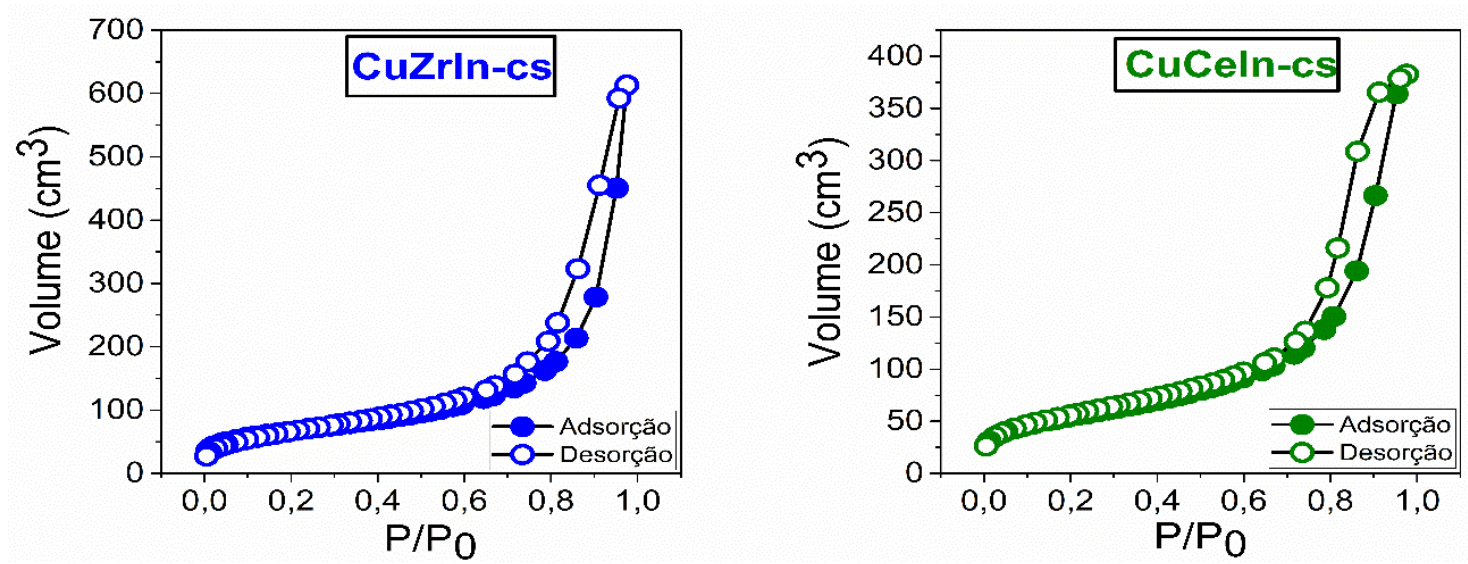

Para os dois catalisadores, foram verificadas isotermas do tipo IV características de materiais mesoporosos apresentando um perfil de histerese decorrente da condensação capilar das moléculas de $\mathrm{N}_{2}$ nos mesoporos durante o processo de fisissorção, sendo a preponderância dos mesoporos condizente com os surfactantes utilizados na síntese, conforme já discutido anteriormente (CONTRERAS et al., 2015; LIU, Y.; GOEBL; YIN, 2013; ROUQUEROL et al., 2014).

Para se obter informações sobre a redutibilidade dos catalisadores, foram realizadas análises de redução à temperatura programada e os resultados se encontram na Figura 25.

Figura 25. Redução à temperatura programada dos catalisadores CuZrIn-cs e CuCeIn-cs utilizando $\mathrm{H}_{2}$ como gás redutor.
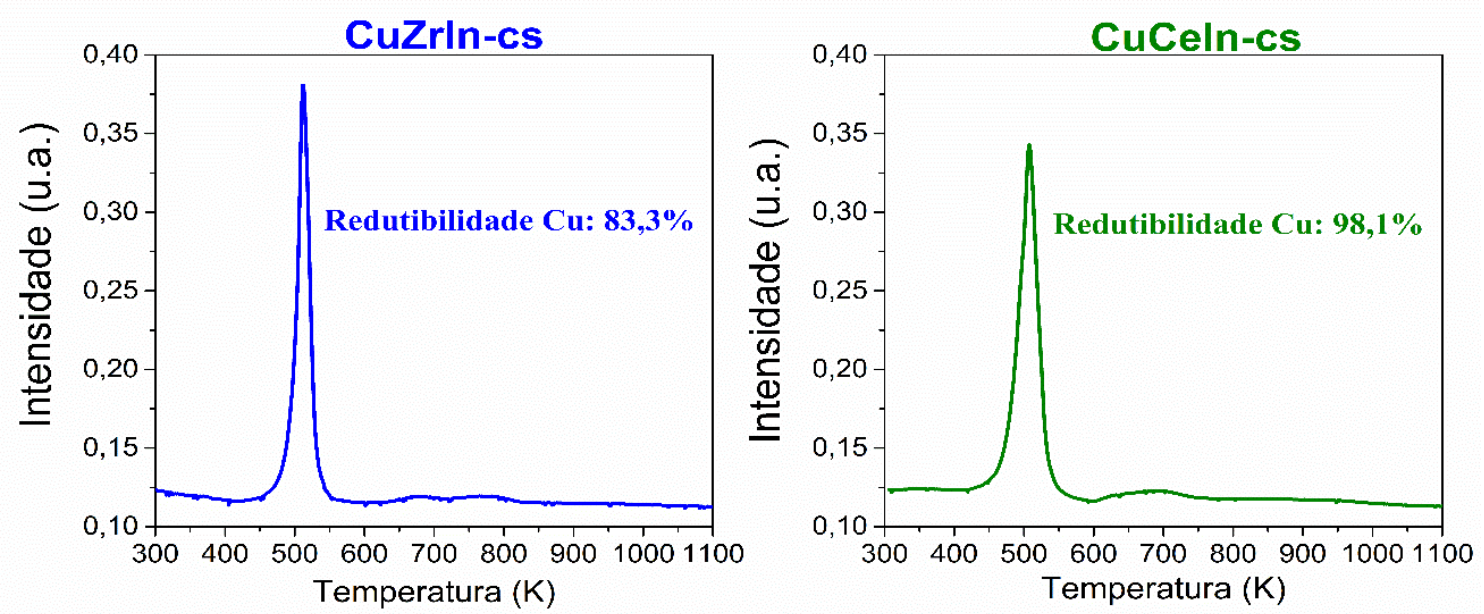
Para todos os materiais foram verificados picos intensos entre $420 \mathrm{~K}$ e $560 \mathrm{~K}$, faixa de temperatura característica da redução do óxido de cobre a $\mathrm{Cu}^{0}$ (BANSODE et al., 2013; MACIEL et al., 2012).

Além disso, foi possível verificar que apenas um pico é gerado. Vale ressaltar que, para os materiais sintetizados na etapa anterior, os picos de cobre sempre se apresentavam com cerca de três picos convoluídos (ombros), o que foi atribuído à existência de partículas de cobre com diferentes propriedades físico-químicas, portanto menos homogêneas (BANSODE et al., 2013; GUO et al., 2011; LI, L. et al., 2015; MACIEL et al., 2012). Já a existência de apenas um pico para os materiais CuZrIn-cs e CuCeIn-cs corrobora a alta homogeneidade das partículas observada pela análise de microscopia eletrônica de transmissão.

Além do pico mais intenso, um segundo pico de redução bem largo foi verificado para os materiais após $620 \mathrm{~K}$. É estabelecido que é nessas regiões que ocorrem reduções parciais tanto no óxido de zircônio quanto no de cério, levando ao surgimento de vacâncias de oxigênio em suas estruturas além da redução do óxido de índio (CHEN et al., 2010; MARTIN et al., 2016).

No que se refere à redutibilidade do cobre presente nos materiais, foi possível perceber que a quase totalidade dos átomos de cobre se reduz no material CuCeIn-cs enquanto para o catalisador CuZrIn-cs apenas cerca de $83 \%$ se converte de $\mathrm{Cu}^{2+} \mathrm{a} \mathrm{Cu}^{0}$.

Essa redutibilidade mais baixa pode ser explicada em termos da interação entre cobre e os demais constituintes do catalisador como zircônia e a sílica que atua como revestimento (CHAUDHURI; PARIA, 2012; GAWANDE et al., 2015).

A sílica, por exemplo, pode interagir com parte dos átomos de cobre presentes nas partículas de óxido que foram recobertas pelo revestimento poroso utilizado diminuindo sua reatividade de forma que eles não se mostram suscetíveis à redução nas condições utilizadas, se mantendo na forma óxida e não metálica (CHAUDHURI; PARIA, 2012; GAWANDE et al., 2015).

As áreas metálicas de superfície bem como a basicidade dos catalisadores foram mensuradas por quimissorção de $\mathrm{N}_{2} \mathrm{O}$ e dessorção de $\mathrm{CO}_{2}$ à temperatura programada, respectivamente, e os resultados se encontram na Tabela 22.

Pelos dados presentes na Tabela 22, é possível verificar que que a dispersão dos átomos de cobre nos dois catalisadores core-shell, CuZrIn-cs e CuCeIn-cs, se mostrou consideravelmente superior à dispersão que foi observada para os catalisadores $\mathrm{Cu} / \mathrm{ZrO} 2-5 \% \mathrm{In}$ e $\mathrm{Cu} / \mathrm{CeO}_{2}-5 \%$ In sintetizados na etapa anterior o que pode ser explicado em termos da eficiência 
do método solvotérmico em gerar partículas bem dispersas além da funcionalidade do revestimento de sílica em evitar agregação das partículas durante as etapas de síntese que envolveram tratamentos térmicos (CHAUDHURI; PARIA, 2012; GAWANDE et al., 2015).

Tabela 22. Área metálica de superfície e basicidade para os materiais CuZrIn-cs, CuZrIn-i, CuCeIn-cs e CuCeIn-i.

\begin{tabular}{cccc}
\hline Catalisadores & Cu Dispersion (\%) & $\begin{array}{c}\text { Área metálica de } \\
\text { superfície }\left(\mathrm{m}^{2} \cdot \mathrm{g}^{-1}\right)\end{array}$ & $\begin{array}{c}\text { Basicidade } \\
\left(\mu \mathrm{molCO}_{2} \cdot \mathrm{g}^{-1}\right)\end{array}$ \\
\hline CuZrIn-cs & 29,6 & 21,0 & 164,3 \\
CuCeIn-cs & 22,7 & 14,6 & 279,1 \\
\hline
\end{tabular}

É bem estabelecido que um menor diâmetro médio de partículas, verificado pelas análises de microscopia eletrônica de transmissão, associado à maior porosidade e área específica de superfície, verificados por fisissorção de $\mathrm{N}_{2}$, levam a uma maior razão área de superfície/volume o que consequentemente irá aumentar a proporção de átomos na superfície em relação ao bulk do catalisador (LIU, Y.; GOEBL; YIN, 2013; TILLEY, 2004).

No entanto, especialmente para o catalisador CuZrIn-cs, o valor expressivamente maior da dispersão do cobre comparado aos catalisadores contendo zircônia da etapa anterior não foi acompanhado por resultados de área metálica maiores na mesma proporção.

Apesar da dispersão ser um dos principais fatores que influenciam nos valores de área metálica observados, é muito importante destacar que ele não é o único. Fatores como o teor de metal por grama do catalisador são igualmente importantes de modo que, um material que apresente maior concentração de átomos de cobre por unidade de massa pode apresentar maior área metálica que um segundo material mesmo que a dispersão do primeiro seja menor (ARENA et al., 2007; CHARY; SAGAR; SRIKANTH, 2007; GUO et al., 2011; LI, L. et al., 2015; SAGAR et al., 2006).

Devido ao fato de que, nos materiais em arquitetura core-shell, a sílica é o composto presente em maior quantidade, o teor de cobre no material CuZrIn-cs é apenas uma pequena fração do teor de cobre presente no catalisador $\mathrm{Cu} / \mathrm{ZrO}_{2}-5 \% \mathrm{In}$.

Além disso, como já discutido, a interação com a sílica pode diminuir a reatividade de parte dos átomos de cobre presentes nas partículas de óxido de cobre que foram recobertas pelo revestimento poroso utilizado, de forma que eles não se mostram disponíveis à reação com hidrogênio se mantendo na forma óxida e não metálica, o que é corroborado pela menor 
redutibilidade observada para esse catalisador quando comparado aos demais (CHAUDHURI; PARIA, 2012; GAWANDE et al., 2015).

Outro ponto a ser discutido é a ocorrência de fortes interações metal-suporte entre cobre e zircônia que podem garantir altos valores de área metálica mesmo em catalisadores não revestidos, como foi observado na etapa anterior que evidenciou que os catalisadores contendo zircônia apresentaram valores de dispersão e área metálica maiores que os catalisadores do grupo contendo céria (PAN et al., 2017).

Essas observações (menor teor mássico de cobre e menor redutibilidade) podem ter feito com que a área metálica apresentada pelo catalisador $\mathrm{Cu} / \mathrm{ZrO}_{2}-5 \% \mathrm{In}$ e $\mathrm{CuZrIn}$-cs tenham se mostrado próximas apesar da dispersão do catalisador core-shell ter sido substancialmente maior.

Já para catalisadores como os contendo céria, que não apresentam forças tão intensas de interação metal-suporte e que, portanto, apresentarão valores mais baixos de dispersão e área metálica; estratégias como o revestimento passam a ser muito importantes e podem levar a melhorias consideráveis em suas propriedades como pôde ser verificado ao se comparar o material $\mathrm{CuCeIn-cs}$ ao $\mathrm{Cu} / \mathrm{CeO}_{2}-5 \%$ In sintetizado na etapa anterior. $\mathrm{O}$ catalisador $\mathrm{CuCeIn-cs}$ apresentou valores expressivamente superiores de área metálica e dispersão em comparação ao catalisador $\mathrm{Cu} / \mathrm{CeO}_{2} 5 \% \mathrm{In}$.

No que se refere a basicidade, os valores obtidos para os materiais os materiais core-shell se mostraram superiores aos verificados para os catalisadores da etapa anterior, o que pode estar relacionado a uma série de fatores como a área específica de superfície superior, além do menor tamanho médio de partículas que pode garantir uma maior densidade de vacâncias de oxigênio devido à maior energia livre de superfície já discutida anteriormente, atuando como fortes sítios básicos de Lewis capazes de adsorver moléculas ácidas como o $\mathrm{CO}_{2}$ (FUJIWARA et al., 2019; GAO et al., 2013; GUO et al., 2011; KUMAR; OJHA, 2015; LI, L. et al., 2015; LI, YEZHOU et al., 2014; STRUNK et al., 2009; TILLEY, 2004; WANG, WEIWEI et al., 2020). Além disso, os maiores valores dessa propriedade verificados para o catalisador CuCeIn-cs quando comparado ao material CuZrIn-cs são esperados pela alta basicidade característica dos lantanídeos em virtude de sua facilidade de doação de elétrons agindo como sítios básicos de Lewis (ZABILSKIY et al., 2015). 


\section{Desempenho Catalítico}

A utilização de estruturas com arquitetura do tipo core-shell é mais vantajosa justamente em condições reacionais de alta temperatura, nas quais a agregação das partículas se torna mais intensa nos catalisadores convencionais (CHAUDHURI; PARIA, 2012; GAWANDE et al., 2015).

Assim, os ensaios reacionais para a produção de metanol a partir do $\mathrm{CO}_{2}$ foram realizados sob pressão de $3 \mathrm{MPa}$, velocidade espacial de $6 \mathrm{~L} \cdot \mathrm{h}^{-1} \cdot \mathrm{g}^{-1}$ e nas temperaturas de 473 , 523 e 540 K. Os resultados se encontram na Tabela 23 e Figura 26.

Tabela 23. Desempenho catalítico dos catalisadores CuZrIn-cs e CuCeIn-cs sob pressão $=3$ $\mathrm{MPa}$ e GHSV $=6 \mathrm{~L} \cdot \mathrm{h}^{-1} \cdot \mathrm{g}^{-1}$.

\begin{tabular}{lcccccc}
\hline Catalisador & $\mathrm{T}(\mathrm{K})$ & $\mathrm{X}_{\mathrm{CO} 2}(\%)$ & $\mathrm{S}_{\mathrm{CH} 3 \mathrm{OH}}(\%)$ & $\mathrm{S}_{\mathrm{CO}}(\%)$ & $\mathrm{S}_{\mathrm{CH} 4}(\%)$ & $\mathrm{S}_{\mathrm{C} 2 \mathrm{H} 6}(\%)$ \\
\hline CuZrIn-cs & 473 & 4,5 & 91,2 & 3,7 & 4,2 & 0,9 \\
& 523 & 16,1 & 80,4 & 15,0 & 2,7 & 1,9 \\
& 543 & 18,0 & 73,3 & 19,8 & 4,2 & 2,7 \\
\hline CuCeIn-cs & 473 & 3,4 & 90,2 & 3,8 & 5,3 & 0,7 \\
& 523 & 12,2 & 87,3 & 10,4 & 2,2 & 0,1 \\
& 543 & 13,9 & 80,7 & 15,9 & 3,4 & 0,0 \\
\hline
\end{tabular}

Os valores apresentados na Tabela 23 evidenciam que, especialmente na temperatura mais alta $(543 \mathrm{~K})$, os catalisadores do tipo core-shell geraram altos valores de conversão de $\mathrm{CO}_{2}$ e seletividade ao metanol sugerindo a eficácia do revestimento de sílica em minimizar a agregação progressiva das partículas na superfície, especialmente em valores mais altos de temperatura (BAI et al., 2016; SHI; TAN; WU, 2018; XIE et al., 2014; YANG et al., 2016).

Ambas as observações com relação à conversão e à seletividade são condizentes com o que é reportado por muitos pesquisadores em trabalhos que estudaram o desempenho das estruturas revestidas, não somente para a reação de hidrogenação de $\mathrm{CO}_{2}$ a metanol como para outras, nas quais o aumento gradual de temperatura favorece a agregação das partículas reduzindo a quantidade de sítios ativos efetivamente disponíveis para a ocorrência do processo reacional desejado (BAI et al., 2016; CHAUDHURI; PARIA, 2012; GAWANDE et al., 2015; SHI; TAN; WU, 2018; XIE et al., 2014; YANG et al., 2016). 
Figura 26. Desempenho catalítico dos catalisadores CuZrIn-cs e CuCeIn-cs sob pressão $=3$ $\mathrm{MPa}$ e GHSV $=6 \mathrm{~L} \cdot \mathrm{h}^{-1} \cdot \mathrm{g}^{-1}$.
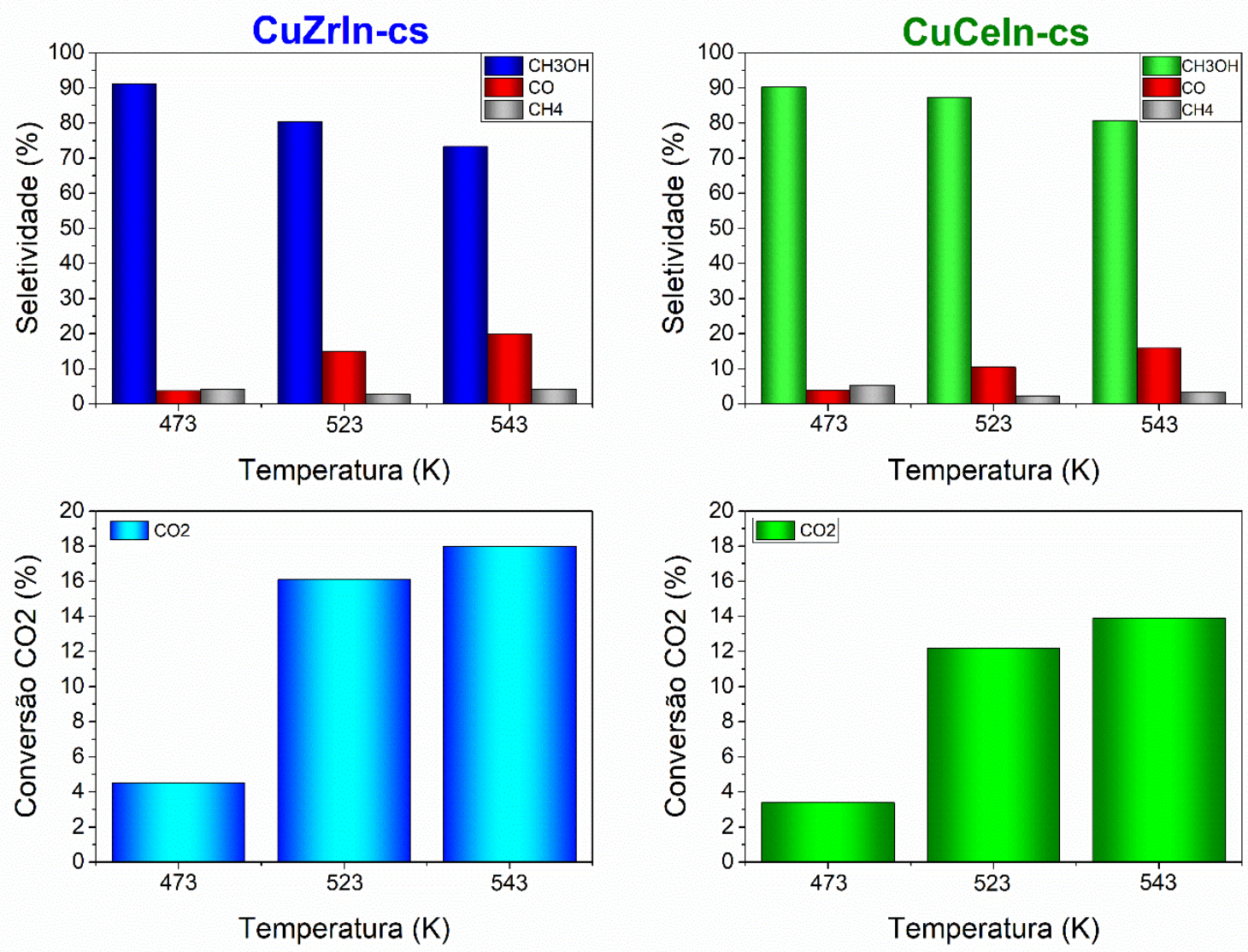

Assim como foi observado para os catalisadores da etapa anterior, o material CuZrIncs, que apresentou a maior dispersão e área metálica do cobre, apresentou os maiores valores de conversão do dióxido de carbono.

No que se refere à seletividade ao metanol, os maiores valores foram obtidos utilizandose o catalisador CuCeIn-cs, atingindo mais de $80 \%$ mesmo quando o processo reacional foi conduzido a $543 \mathrm{~K}$. De forma análoga aos catalisadores da etapa anterior, foi esse o material a apresentar o menor diâmetro médio de partícula assim como maior basicidade.

O desempenho em termos de produtividade molar dos principais produtos foram avaliados sob as condições reacionais de $3 \mathrm{MPa}$, GHSV $6 \mathrm{~L} \cdot \mathrm{h}^{-1} \cdot \mathrm{g}^{-1}$ e $543 \mathrm{~K}$ e comparados aos melhores catalisadores da etapa anterior. Os resultados se encontram na Tabela 24 e Figuras 27 e 28. 
Tabela 24. Frequência de Turnover e produtividade molar de $\mathrm{CH}_{3} \mathrm{OH}$ e $\mathrm{CO}$ utilizando os catalisadores CuZrIn-cs e CuCeIn-cs sob as condições de 3MPa, $473 \mathrm{~K}$ e $6 \mathrm{~L} \cdot \mathrm{g}^{-1} \cdot \mathrm{h}^{-1}$.

\begin{tabular}{cccc}
\hline Catalisadores & $\begin{array}{c}\text { TOF } \\
\left(\mathrm{s}^{-1}\right)\end{array}$ & $\begin{array}{c}\text { Produtividade Molar } \\
\mathrm{CH}_{3} \mathrm{OH}\left(\mathrm{mol}^{-1} \cdot \mathrm{g}^{-1}\right)\end{array}$ & $\begin{array}{c}\text { Produtividade Molar } \\
\mathrm{CO}\left(\mathrm{mol} \cdot \mathrm{h}^{-1} \cdot \mathrm{g}^{-1}\right)\end{array}$ \\
\hline $\mathrm{CuZrIn}-\mathrm{cs}$ & $1,5 \times 10^{-3}$ & $25,3 \times 10^{-4}$ & $1,0 \times 10^{-4}$ \\
$\mathrm{Cu} / \mathrm{ZrO}_{2}-5 \% \mathrm{In}$ & $1,6 \times 10^{-3}$ & $21,7 \times 10^{-4}$ & $5,3 \times 10^{-4}$ \\
\hline $\mathrm{CuCeIn-cs}$ & $1,6 \times 10^{-3}$ & $18,9 \times 10^{-4}$ & $0,8 \times 10^{-4}$ \\
$\mathrm{Cu} / \mathrm{CeO}_{2} 5 \% \mathrm{In}$ & $1,1 \times 10^{-3}$ & $8,1 \times 10^{-4}$ & $2,1 \times 10^{-4}$ \\
\hline
\end{tabular}

Figura 27. Frequência de Turnover utilizando os catalisadores $\mathrm{Cu} / \mathrm{ZrO}_{2}-5 \% \mathrm{In}, \mathrm{Cu} / \mathrm{CeO}_{2}-5 \% \mathrm{In}$, CuZrIn-cs e CuCeIn-cs sob as condições de 3MPa, $473 \mathrm{~K}$ e $6 \mathrm{~L} \cdot \mathrm{g}^{-1} \cdot \mathrm{h}^{-1}$.
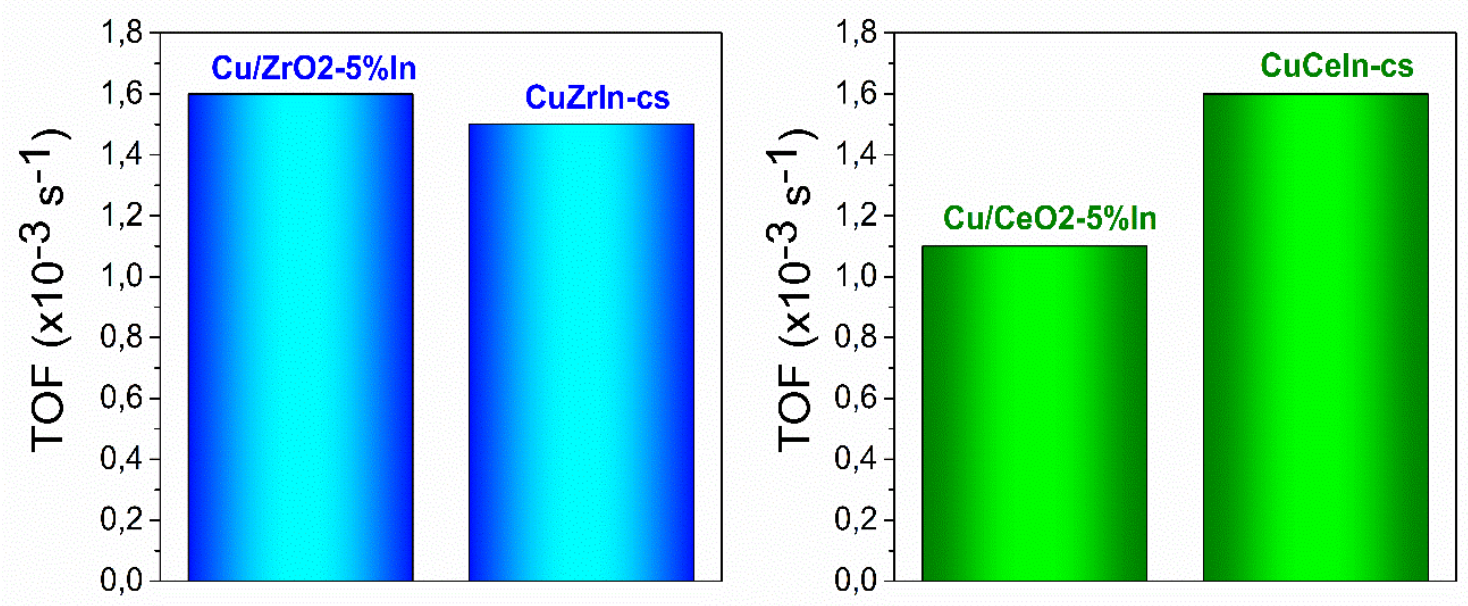

Os valores da Tabela 24 e Figura 27 demonstram que os valores de TOF para os catalisadores contendo zircônia foram muito próximos, sendo apenas um pouco inferior para o catalisador core-shell CuZrIn-cs, o que é condizente com os valores de área metálica e conversão de $\mathrm{CO}_{2}$ muito similares apresentados por ambos.

Já para os catalisadores contendo céria, a maior área metálica e consequente maior conversão de $\mathrm{CO}_{2}$ apresentadas pelo catalisador core-shell CuCeIn-cs levaram a uma melhoria mais significativa do valor de TOF comparado ao valor obtido anteriormente para o material $\mathrm{Cu} / \mathrm{CeO}_{2}-5 \%$ In (GRACIANI et al., 2014; RODRIGUEZ et al., 2015). 
Figura 28. Produtividade molar dos principais produtos obtidos utilizando os catalisadores $\mathrm{Cu} / \mathrm{ZrO}_{2}-5 \% \mathrm{In}, \mathrm{Cu} / \mathrm{CeO}_{2}-5 \% \mathrm{In}, \mathrm{CuZrIn}$-cs e $\mathrm{CuCeIn}$-cs em diferentes temperaturas mantendose a pressão e velocidade espacial constantes em $3 \mathrm{MPa}, 6 \mathrm{~L} \cdot \mathrm{g}^{-1} \cdot \mathrm{h}^{-1}$.
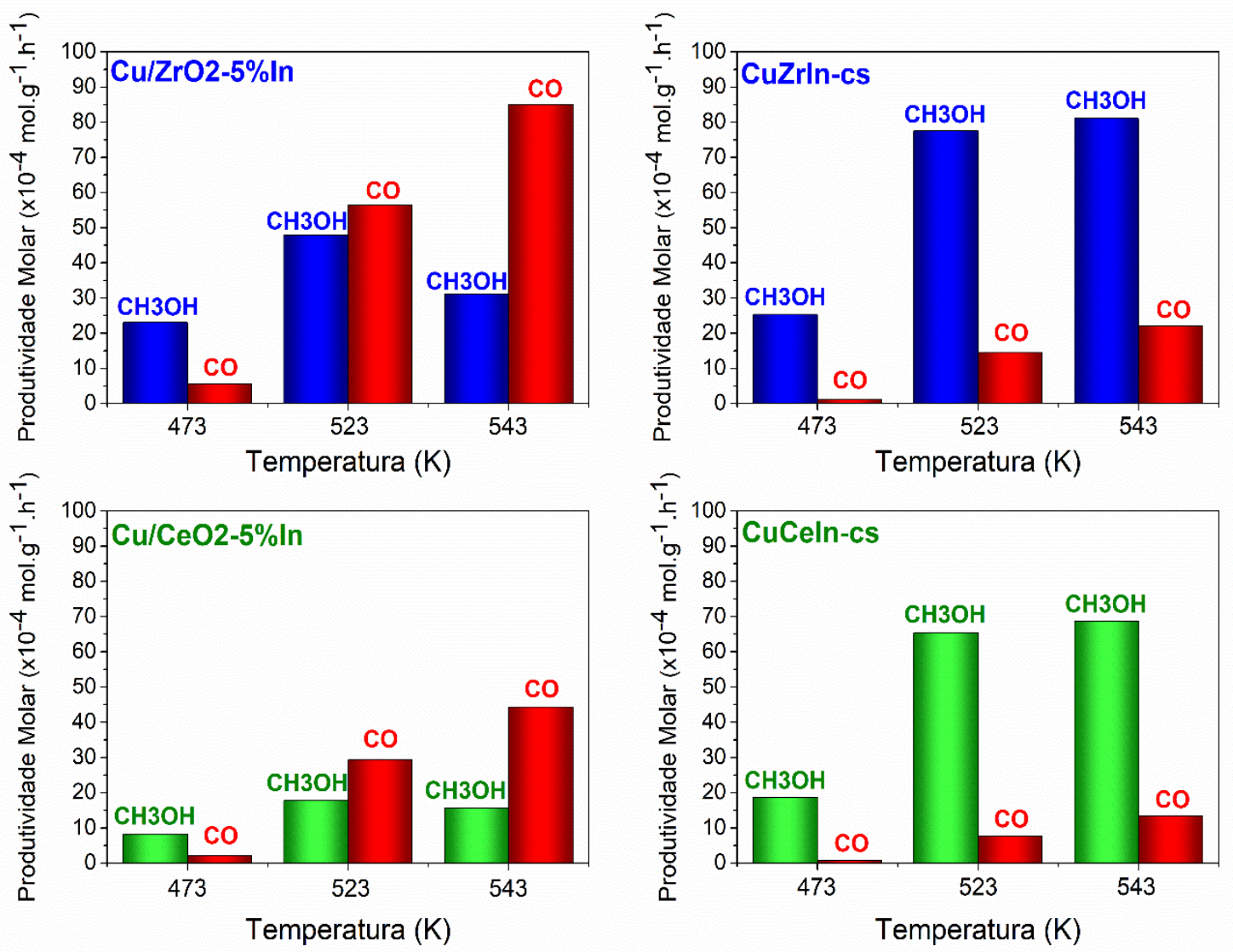

No que se refere aos dados de produtividade molar apresentados nas Figura 28 e Tabela 24 é possível verificar um desempenho reacional consideravelmente superior para ambos os catalisadores do tipo core-shell em relação aos seus análogos $\mathrm{Cu} / \mathrm{ZrO}_{2}-5 \% \mathrm{In}$ e $\mathrm{Cu} / \mathrm{CeO}_{2}-5 \% \mathrm{In}$.

Os melhores valores em certas propriedades físico-químicas como o tamanho médio de partícula, à eficiência do revestimento de sílica em minimizar a agregação das partículas geradas e à maior basicidade levaram a seletividades muito altas ao metanol mesmo em temperaturas mais elevadas, condição na qual foi verificada a maior diferença de desempenho entre os catalisadores revestidos e não revestidos (CHAUDHURI; PARIA, 2012; GAWANDE et al., 2015; GUO et al., 2011; LI, L. et al., 2015).

Além disso, as vantagens de se utilizar o revestimento poroso de sílica foram ainda mais evidentes para os catalisadores contendo céria, que apresentaram um aumento também na área metálica levando a maiores valores de conversão que, aliado à alta seletividade, gerou uma 
produtividade de metanol mais próxima dos valores obtidos ao se utilizar materiais contendo zircônia que, até então, vinham se mostrando muito superiores nesse quesito.

Nos materiais das etapas anteriores a taxa de conversão muito mais baixa observada para os materiais contendo céria em comparação com os de zircônia sempre impediu valores de produtividade próximos por mais que a seletividade sempre tenha sido alta.

Esse fato evidencia a eficácia da estratégia de síntese de catalisadores em arquitetura core-shell principalmente para materiais nos quais a força de interação entre a fase metálica e as partículas do óxido não sejam tão intensas (CHAUDHURI; PARIA, 2012; GAWANDE et al., 2015; PAN et al., 2017; WANG, WEI et al., 2011).

Para os materiais $\mathrm{Cu} / \mathrm{ZrO}_{2}-5 \% \mathrm{In}$ e $\mathrm{Cu} / \mathrm{CeO}_{2}-5 \% \mathrm{In}$, apenas na temperatura de $473 \mathrm{~K}$ foi possível obter metanol como o produto principal. Já para os catalisadores core-shell CuZrIn-cs e CuCeIn-cs, o metanol foi produzido em alta quantidade em todas as temperaturas testadas sendo que, mesmo no valor mais alto dessa variável (543 K), ainda foi possível obter mais de $80 \%$ de seletividade ao metanol utilizando o catalisador CuZrIn-cs e mais de $70 \%$ utilizando o material CuCeIn-cs.

O desempenho apresentado pelos catalisadores core-shell foi o melhor quando comparado a todos os catalisadores análogos testados anteriormente, especialmente em condições reacionais mais propícias à queda da produção de metanol.

Por fim, há um ponto importante para o qual deve-se atentar. Nos catalisadores do tipo "core-shell" CuZrIn-cs e CuCeIn-cs, devido à presença da sílica como componente majoritário, a quantidade de átomos de cobre, índio e zircônio ou céria por unidade de massa do catalisador é de apenas um quinto da quantidade presente nos materiais $\mathrm{Cu} / \mathrm{ZrO}_{2}-5 \% \mathrm{In}$ e $\mathrm{Cu} / \mathrm{CeO}_{5} \% \mathrm{In}$.

Isso se torna importante ao se considerar que o índio é o elemento mais caro presente nos materiais e a utilização de menor teor desse elemento é importante do ponto de vista econômico.

Analisando-se os resultados por essa ótica, é possível perceber que os catalisadores "core-shell" apresentaram desempenho superior aos observados para os melhores catalisadores das etapas anteriores mesmo apresentando uma fração menor dos elementos mais caros, como o índio, em sua composição, o que é documentado para uma série de outras estruturas revestidas em comparação à seus análogos convencionais não encapsulados (CHAUDHURI; PARIA, 2012; GAWANDE et al., 2015).

Além disso, por mais que a geração do revestimento poroso de sílica ainda seja relativamente cara, novos processos vêm sendo desenvolvidos e é possível que, num futuro 
próximo, tornem-se muito mais baratos, estendendo as vantagens de se utilizar esse tipo de arquitetura em catálise também para o âmbito econômico (CHAUDHURI; PARIA, 2012; GAWANDE et al., 2015; ZHANG, Q. et al., 2010).

O resumo gráfico dos efeitos advindos da utilização dos catalisadores em arquitetura core-shell é mostrado na Figura 29.

Figura 29. Diferenças na produtividade molar de $\mathrm{CH}_{3} \mathrm{OH}$ e $\mathrm{CO}$ entre os catalisadores core-shell $\mathrm{CuZrIn}$-cs e $\mathrm{CuCeIn}$-cs e os materiais $\mathrm{Cu} / \mathrm{ZrO}_{2}-5 \% \mathrm{In}$ e $\mathrm{Cu} / \mathrm{CeO}_{2}-5 \% \mathrm{In}$. Condições reacionais: $3 \mathrm{MPa}, 543 \mathrm{~K}$ e $6 \mathrm{~L} \cdot \mathrm{h}^{-1} \cdot \mathrm{g}^{-1}$.
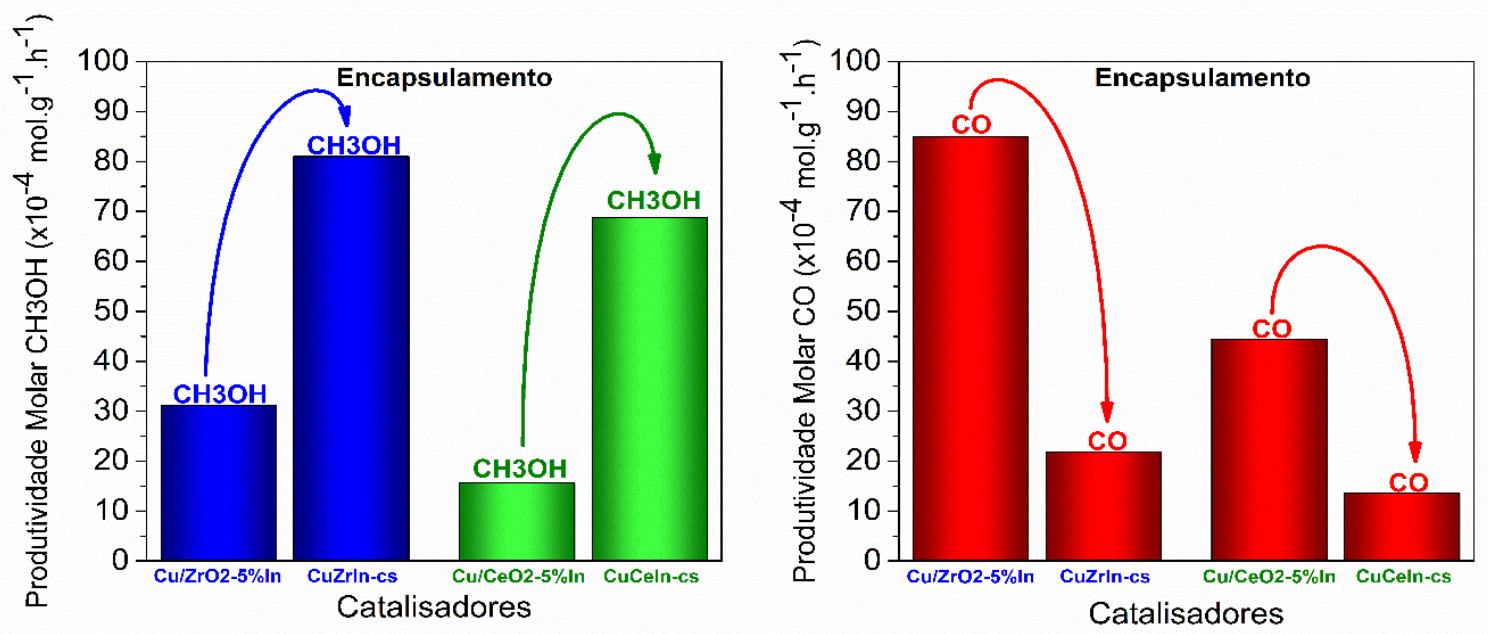

Diante disso, prosseguiu-se com os estudos de otimização quimiométrica das variáveis reacionais utilizando os catalisadores CuZrIn-cs e CuCeIn-cs.

\section{Otimização Quimiométrica dos Catalisadores CuZrIn-cs e CuCeIn-cs}

A matriz experimental com diferentes combinações entre as variáveis pressão, temperatura e velocidade espacial definidas para o catalisador CuZrIn-cs bem como os resultados de conversão de $\mathrm{CO}_{2}$ e seletividade aos principais produtos se encontram na Tabela 25. 
Tabela 25. Matriz experimental gerada pelo planejamento estatístico do tipo compósito central com diferentes condições de pressão $(\mathrm{P})$, temperatura $(\mathrm{T})$ e velocidade espacial $\left(\mathrm{L}^{-1} \cdot \mathrm{g}^{-1} \cdot \mathrm{h}^{-1}\right)$ e resultados de conversão ( $\mathrm{X}_{\mathrm{CO} 2}$ ) e seletividade $(\mathrm{S})$ utilizando o catalisador $\mathrm{CuZrIn-cs}$

\begin{tabular}{|c|c|c|c|c|c|c|c|c|}
\hline Assay & $\begin{array}{c}\mathrm{P} \\
(\mathrm{MPa})\end{array}$ & $\begin{array}{c}\mathrm{T} \\
(\mathrm{K})\end{array}$ & $\begin{array}{c}\text { GHSV } \\
\left(\mathrm{L} \cdot \mathrm{g}^{-1} \cdot \mathrm{h}^{-1}\right)\end{array}$ & $\begin{array}{c}\mathrm{X}_{\mathrm{CO} 2} \\
(\%)\end{array}$ & $\begin{array}{c}\mathrm{S}_{\mathrm{CH} 3 \mathrm{OH}} \\
(\%)\end{array}$ & $\begin{array}{l}\mathrm{S}_{\mathrm{CO}} \\
(\%)\end{array}$ & $\begin{array}{l}\mathrm{S}_{\mathrm{CH} 4} \\
(\%)\end{array}$ & $\begin{array}{c}\mathrm{S}_{\mathrm{C} 2 \mathrm{H} 6} \\
(\%)\end{array}$ \\
\hline 1 & 2 & 473 & 6 & 2,2 & 87,2 & 4,8 & 7,4 & 0,6 \\
\hline 2 & 2 & 473 & 12 & 1,4 & 89,2 & 3,8 & 6,6 & 0,4 \\
\hline 3 & 2 & 523 & 6 & 8,3 & 78,9 & 9,8 & 9,5 & 1,8 \\
\hline 4 & 2 & 523 & 12 & 5,0 & 77,8 & 11,2 & 9,6 & 1,4 \\
\hline 5 & 3 & 473 & 6 & 4,5 & 91,2 & 3,7 & 4,2 & 0,9 \\
\hline 6 & 3 & 473 & 12 & 2,9 & 92,1 & 3,6 & 3,7 & 0,6 \\
\hline 7 & 3 & 523 & 6 & 15,7 & 80,4 & 15,0 & 2,7 & 1,9 \\
\hline 8 & 3 & 523 & 12 & 10,8 & 82,6 & 13,2 & 2,9 & 1,3 \\
\hline 9 & 1.66 & 498 & 9 & 3,0 & 85,4 & 5,3 & 8,3 & 1,0 \\
\hline 10 & 3.34 & 498 & 9 & 8,3 & 91,1 & 5,4 & 2,6 & 0,9 \\
\hline 11 & 2.5 & 455.96 & 9 & 1,3 & 96,2 & 2,0 & 1,5 & 0,3 \\
\hline 12 & 2.5 & 540.04 & 9 & 12,1 & 76,8 & 12,1 & 9,1 & 2,0 \\
\hline 13 & 2.5 & 498 & 3.95 & 10,0 & 89,7 & 5,1 & 3,6 & 1,6 \\
\hline 14 & 2.5 & 498 & 14.05 & 4,2 & 91,8 & 4,4 & 3,1 & 0,7 \\
\hline 15 & 2.5 & 498 & 9 & 5,4 & 90,9 & 4,7 & 3,4 & 1,0 \\
\hline 16 & 2.5 & 498 & 9 & 5,6 & 90,5 & 5,0 & 3,1 & 1,2 \\
\hline 17 & 2.5 & 498 & 9 & 5,3 & 91,1 & 4,2 & 3,8 & 1,0 \\
\hline
\end{tabular}

Utilizou-se, então, os resultados presentes na matriz experimental tendo a seletividade ao metanol como resposta a ser otimizada. Os efeitos principais causados pela variação no valor de cada variável sobre a seletividade ao metanol bem como os efeitos de interação entre essas variáveis foram calculados e sua significância foi avaliada estatisticamente (BARROS NETO; SCARMINIO; BRUNS, 2010).

Os resultados se encontram na Tabela 26 e foram graficamente expressos por meio do Gráfico de Pareto que se encontra na Figura 30. 
Tabela 26. Efeitos principais causados pela alteração de pressão, temperatura e velocidade espacial sobre a seletividade ao metanol e efeitos de interação entre essas variáveis utilizando o catalisador CuZrIn-cs.

\begin{tabular}{ccccc}
\hline Variáveis & Efeitos & Erro & Efeito Padronizado (t) & Significância* $^{*}$ \\
\hline Pressão (X1) & 3,3370 & 0,1653 & 20,1827 & Sim \\
Temperatura (X2) & $-10,6359$ & 0,1653 & $-64,3284$ & Sim \\
V. Espacial (X3) & 1,1030 & 0,1653 & 6,6712 & Sim \\
X1*X2 & $-0,1500$ & 0,2160 & $-0,6944$ & Não \\
X1*X3 & 0,5500 & 0,2160 & 2,5460 & Não \\
X2*X3 & $-0,4500$ & 0,2160 & 2,0831 & Não \\
\hline
\end{tabular}

* Analisada considerando o efeito crítico igual a 0,93 com valor padronizado (t) de 4,303.

Figura 30. Gráfico de Pareto com a significância do efeito principal causado pela variação dos valores de pressão, temperatura e velocidade espacial sobre a seletividade ao metanol assim como os efeitos de interação entre as elas utilizando o catalisador CuZrIn-cs. A análise foi realizada com $95 \%$ de confiabilidade estatística.

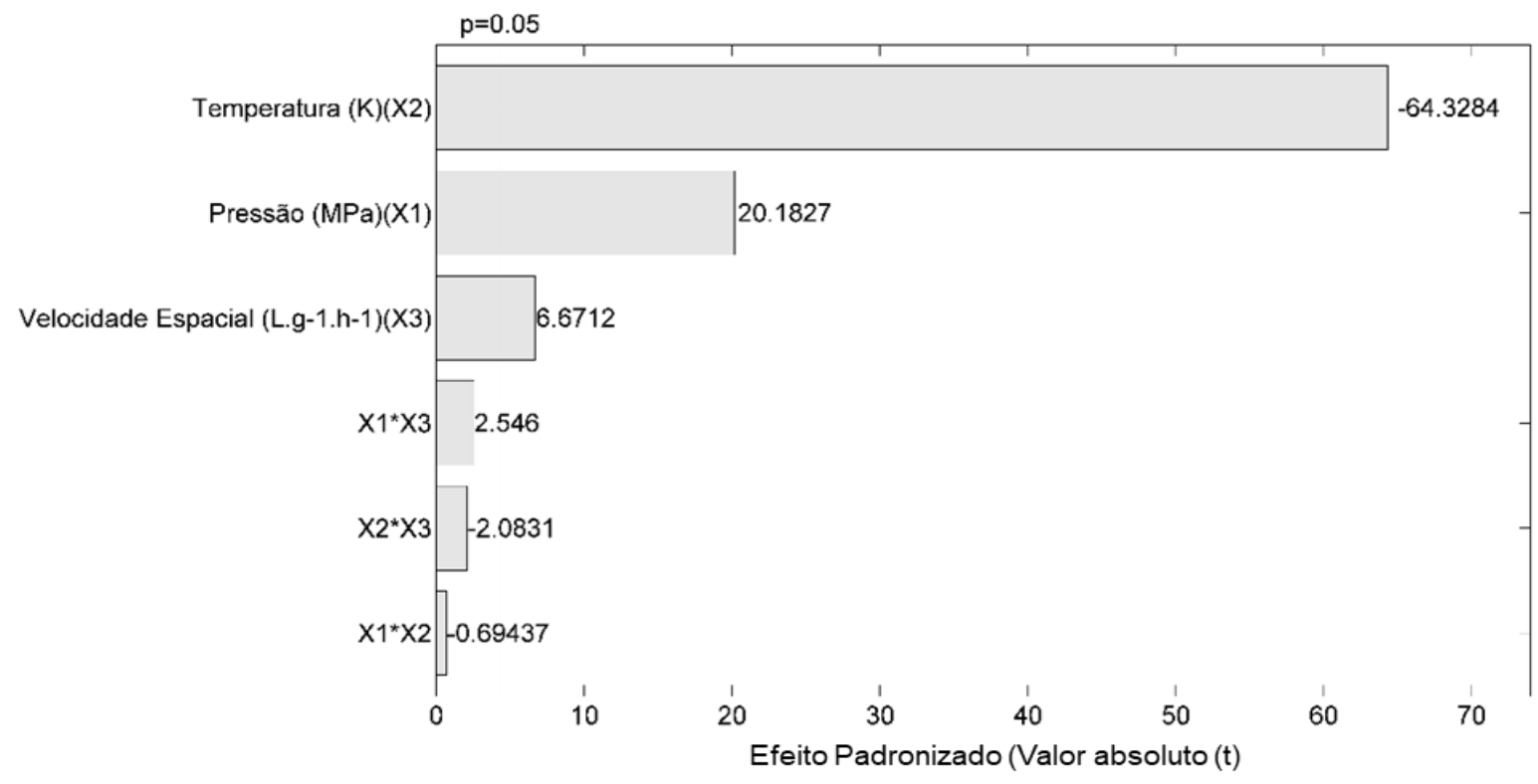

A análise dos efeitos evidencia que as variações nos valores de temperatura, pressão e velocidade espacial levam a alterações estatisticamente significativas nos valores de seletividade ao metanol ao se utilizar o catalisador CuZrIn-cs. 
A variável mais influente sobre o processo foi a temperatura, que apresentou efeito antagônico, seguida pelas variáveis pressão e velocidade espacial, ambas apresentando efeitos sinérgicos.

As razões de cada um dos efeitos das variáveis sobre a produção de metanol são as mesmas já discutidas anteriormente para os materiais $\mathrm{Cu} / \mathrm{ZrO}_{2}-5 \% \mathrm{In}$ e $\mathrm{Cu} / \mathrm{CeO}_{2}-5 \% \mathrm{In}$ na seção que tratou da otimização quimiométrica desses materiais (LARMIER et al., 2017; MARTIN et al., 2016; POROSOFF; YAN; CHEN, 2015; PORTHA et al., 2017; RODRIGUEZ et al., 2015; RUI et al., 2017; WOLF; JESS; KERN, 2016).

Anteriormente, para o material $\mathrm{Cu} / \mathrm{ZrO}_{2}-5 \% \mathrm{In}$, a pressão não havia se mostrado uma variável que levasse a alterações consideráveis na seletividade ao metanol. Para o catalisador $\mathrm{Cu} / \mathrm{ZrIn}$-cs, porém, a pressão passa a exercer influência significativa sobre o processo.

Isso significa que a variação na seletividade ao metanol quando se altera a pressão será maior para o catalisador CuZrIn-cs. No entanto, é muito importante ressaltar que mesmo o menor valor de seletividade ao metanol obtido utilizando-se o catalisador core-shell ainda é consideravelmente superior à seletividade obtida ao se utilizar o material $\mathrm{Cu} / \mathrm{ZrO}_{2}-5 \% \mathrm{In}$.

Portanto, por mais que ao se utilizar o catalisador CuZrIn-cs a seletividade ao metanol varie mais com alterações na pressão, ela sempre permanece em níveis mais altos que os observados para o catalisador $\mathrm{Cu} / \mathrm{ZrO}_{2}-5 \% \mathrm{In}$, especialmente em condições de temperatura elevada.

Sendo assim, as superfícies de resposta foram construídas buscando os valores preditos de seletividade nas condições otimizadas para o catalisador CuZrIn-cs. Para esse catalisador o modelo que apresentou o melhor ajuste entre todos os testados foi polinomial de segundo grau do tipo quadrático. Utilizando esse modelo, a equação de regressão foi construída, a partir da qual as superfícies foram geradas.

Os parâmetros de qualidade de ajuste foram calculados por meio de análise de variância (ANOVA) e os resultados se encontram na Tabela 27. Todos os cálculos foram realizados com confiabilidade estatística de $95 \%$. 
Tabela 27. Análise de variância (ANOVA) para o modelo quadrático utilizando o catalisador CuZrIn-cs e as respostas do planejamento tipo compósito central.

\begin{tabular}{cccccc}
\hline $\begin{array}{c}\text { Fonte de } \\
\text { Variação }\end{array}$ & $\begin{array}{c}\text { Soma } \\
\text { Quadrática }\end{array}$ & $\begin{array}{c}\text { Graus de } \\
\text { Liberdade }\end{array}$ & $\begin{array}{c}\text { Média } \\
\text { Quadrática }\end{array}$ & Valor de F & Valor-p \\
\hline Regressão & $5,01 \times 10^{2}$ & 9 & 55,6958 & 9,2401 & 0,0039 \\
Residual & 42,1934 & 7 & 6,0276 & - & - \\
Falta de Ajuste & 42,0067 & 5 & 8,4013 & 90,0145 & 0,0110 \\
Erro puro & 0,1867 & 2 & 0,0933 & - & - \\
SS $_{\text {Total }}$ & $5,43 \times 10^{2}$ & 16 & & & \\
$\mathrm{R}^{2}$ & 0,9224 & & & & \\
$\mathrm{R}^{2}$ explicável & 0,9997 & & & & \\
\hline
\end{tabular}

A análise de variância permite notar que mais de $90 \%$ de toda a variação na resposta foi explicada adequadamente utilizando a equação de regressão gerada pelo modelo quadrático, o que pode ser confirmado pelo $\mathrm{R}^{2}$ obtido, pelo valor -F $(9,2401)$ superior ao valor- $\mathrm{F}$ tabelado $(3,74)$ e pelo valor-p menor que 0,05 , que atesta a confiabilidade estatística e a qualidade do ajuste do modelo gerado aos dados experimentais (BARROS NETO; SCARMINIO; BRUNS, 2010).

A equação de regressão baseada no modelo quadrático, é apresentada a seguir com as variáveis pressão, temperatura e velocidade espacial expressas como $\mathrm{P}, \mathrm{T}$ e VE, respectivamente.

$$
\begin{array}{r}
\mathrm{S}_{\mathrm{CH} 3 \mathrm{OH}}(\%)=\left[-789,2113+38,1868 \mathrm{P}+3,4855 \mathrm{~T}+2,8029 \mathrm{VE}-6,7024(\mathrm{P})^{2}-, 0037(\mathrm{~T})^{2}\right. \\
\left.-0,0880(\mathrm{VE})^{2}-0,0060(\mathrm{P} . \mathrm{T})+0,1833(\mathrm{P} . \mathrm{VE})-0,0030(\mathrm{~T} . \mathrm{VE})\right]
\end{array}
$$

Por meio da superfície de resposta, valores de seletividade ao metanol foram calculados para as combinações de pressão, temperatura e velocidade espacial não testadas experimentalmente gerando superfícies gráficas chamadas superfícies de resposta apresentadas na Figura 31. 
Figura 31. Superfícies de resposta contendo a seletividade ao metanol para diferentes combinações das variáveis pressão, temperatura e velocidade espacial, utilizando o catalisador CuZrIn-cs.
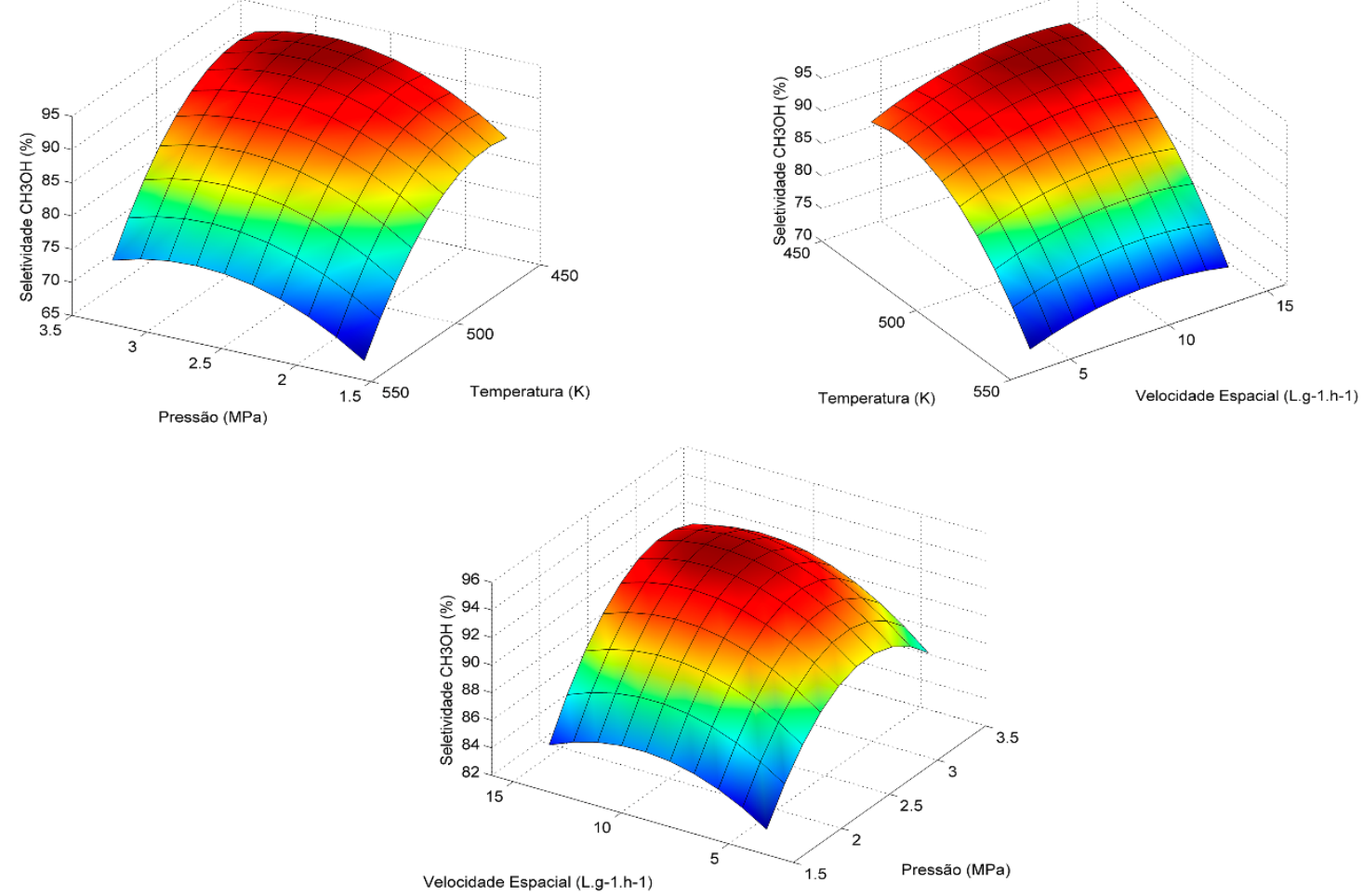

A matriz experimental para a otimização do processo reacional utilizando o catalisador $\mathrm{CuCeIn-cs} \mathrm{com} \mathrm{os} \mathrm{respectivos} \mathrm{resultados} \mathrm{de} \mathrm{conversão} \mathrm{de} \mathrm{CO}_{2}$ e seletividade se encontram na Tabela 28.

Os efeitos principais causados pela variação no valor de cada variável sobre a seletividade ao metanol bem como os efeitos de interação entre essas variáveis foram calculados e sua significância foi avaliada estatisticamente (BARROS NETO; SCARMINIO; BRUNS, 2010).

Os resultados se encontram na Tabela 29 e foram graficamente expressos por meio do Gráfico de Pareto que se encontra na Figura 32. 
Tabela 28. Matriz experimental gerada pelo planejamento estatístico do tipo compósito central com diferentes condições de pressão $(\mathrm{P})$, temperatura $(\mathrm{T})$ e velocidade espacial $\left(\mathrm{L}^{-1} \cdot \mathrm{g}^{-1} \cdot \mathrm{h}^{-1}\right)$ e resultados de conversão $\left(\mathrm{X}_{\mathrm{CO} 2}\right)$ e seletividade $(\mathrm{S})$ utilizando o catalisador CuCeIn-cs.

\begin{tabular}{|c|c|c|c|c|c|c|c|c|}
\hline Assay & $\begin{array}{c}\mathrm{P} \\
(\mathrm{MPa})\end{array}$ & $\begin{array}{c}\mathrm{T} \\
(\mathrm{K})\end{array}$ & $\begin{array}{c}\text { GHSV } \\
\left(\mathrm{L} \cdot \mathrm{g}^{-1} \cdot \mathrm{h}^{-1}\right)\end{array}$ & $\begin{array}{c}\mathrm{X}_{\mathrm{CO} 2} \\
(\%)\end{array}$ & $\begin{array}{c}\mathrm{S}_{\mathrm{CH} 3 \mathrm{OH}} \\
(\%)\end{array}$ & $\begin{array}{l}\mathrm{S}_{\mathrm{CO}} \\
(\%)\end{array}$ & $\begin{array}{l}\mathrm{S}_{\mathrm{CH} 4} \\
(\%)\end{array}$ & $\begin{array}{c}\mathrm{S}_{\mathrm{C} 2 \mathrm{H} 6} \\
(\%)\end{array}$ \\
\hline 1 & 2 & 473 & 6 & 2,0 & 90,9 & 3,2 & 5,7 & 0,2 \\
\hline 2 & 2 & 473 & 12 & 1,0 & 88,5 & 3,6 & 6,5 & 1,4 \\
\hline 3 & 2 & 523 & 6 & 7,8 & 85,4 & 11,6 & 3,0 & 0,0 \\
\hline 4 & 2 & 523 & 12 & 4,1 & 86,0 & 11,0 & 3,0 & 0,0 \\
\hline 5 & 3 & 473 & 6 & 3,4 & 90,2 & 3,8 & 5,3 & 0,7 \\
\hline 6 & 3 & 473 & 12 & 1,9 & 93,5 & 2,0 & 4,4 & 0,1 \\
\hline 7 & 3 & 523 & 6 & 12,2 & 87,3 & 10,4 & 2,3 & 0,0 \\
\hline 8 & 3 & 523 & 12 & 7,8 & 88,9 & 9,0 & 2,1 & 0,0 \\
\hline 9 & 1.66 & 498 & 9 & 2,1 & 89,0 & 7,0 & 4,0 & 0,0 \\
\hline 10 & 3.34 & 498 & 9 & 6,2 & 94,6 & 3,1 & 2,3 & 0,0 \\
\hline 11 & 2.5 & 455.96 & 9 & 0,9 & 93,9 & 1,4 & 2,7 & 2,0 \\
\hline 12 & 2.5 & 540.04 & 9 & 10,2 & 81,5 & 15,5 & 3,0 & 0,0 \\
\hline 13 & 2.5 & 498 & 3.95 & 8,6 & 93,5 & 3,9 & 2,6 & 0,0 \\
\hline 14 & 2.5 & 498 & 14.05 & 3,2 & 93,7 & 3,7 & 2,6 & 0,0 \\
\hline 15 & 2.5 & 498 & 9 & 4,2 & 93,0 & 4,2 & 2,9 & 0,0 \\
\hline 16 & 2.5 & 498 & 9 & 4,0 & 93,4 & 4,2 & 3,0 & 0,0 \\
\hline 17 & 2.5 & 498 & 9 & 4,2 & 94,1 & 3,7 & 3,2 & 0,0 \\
\hline
\end{tabular}


Tabela 29. Efeitos principais causados pela alteração de pressão, temperatura e velocidade espacial sobre a seletividade ao metanol e efeitos de interação entre essas variáveis utilizando o catalisador CuCeIn-cs.

\begin{tabular}{ccccc}
\hline Variáveis & Efeitos & Erro & Efeito Padronizado (t) & Significância* \\
\hline Pressão (X1) & 2,7119 & 0,3013 & 8,9999 & Sim \\
Temperatura (X2) & $-5,3240$ & 0,3013 & $-17,6685$ & Sim \\
V. Espacial (X3) & 0,5032 & 0,3013 & 1,6701 & Não \\
X1*X2 & 0,1250 & 0,3937 & 0,3175 & Não \\
X1*X3 & 1,6750 & 0,3937 & 4,2545 & Não \\
X2*X3 & 0,3250 & 0,3937 & 0,8255 & Não \\
\hline
\end{tabular}

* Analisada considerando o efeito crítico igual a 1,69 com valor padronizado (t) de 4,303.

Figura 32. Gráfico de Pareto com a significância do efeito principal causado pela variação dos valores de pressão, temperatura e velocidade espacial sobre a seletividade ao metanol assim como os efeitos de interação entre as elas utilizando o catalisador CuCeIn-cs. A análise foi realizada com $95 \%$ de confiabilidade estatística.

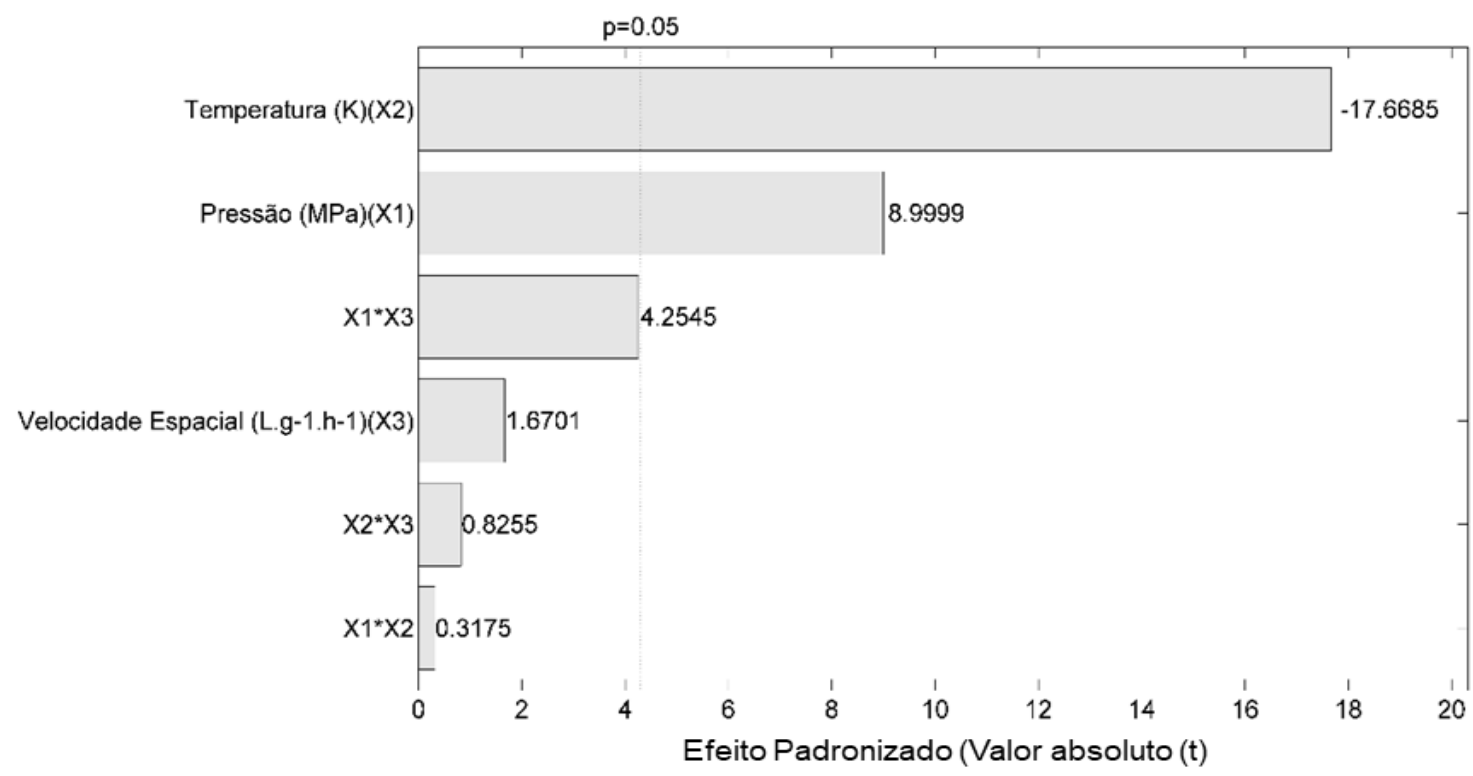


Utilizando-se o catalisador CuCeIn-cs no processo de geração de metanol a partir da hidrogenação do $\mathrm{CO}_{2}$ foi possível observar que alterações na temperatura e na pressão levam a modificações estatisticamente significativas na seletividade ao metanol.

O efeito antagônico da variação da temperatura sobre a produção de metanol foi o mais importante, seguido pelo efeito sinérgico causado por variações na pressão.

As razões para que alterações nessas duas variáveis levem a modificação na seletividade dos produtos obtidos são as mesmas discutidas anteriormente para os catalisadores $\mathrm{Cu} / \mathrm{ZrO}_{2}$ 5\%In e $\mathrm{Cu} / \mathrm{CeO}_{2}-5 \%$ In (LARMIER et al., 2017; MARTIN et al., 2016; POROSOFF; YAN; CHEN, 2015; PORTHA et al., 2017; RODRIGUEZ et al., 2015; RUI et al., 2017; WOLF; JESS; KERN, 2016).

Para o catalisador CuCeIn-cs, diferentemente dos anteriores, a velocidade espacial não se mostrou uma variável que pudesse conduzir a mudanças significativas na seletividade, dentro da faixa de valores analisada.

Essa observação, implica no fato de que, ao se utilizar o catalisador CuCeIn-cs, valores muito altos de seletividade ao metanol serão obtidos mesmo em condições de velocidade espacial que favoreceriam a ocorrência paralela de reações mais lentas como a formação do CO pela rota da reação reversa de deslocamento gás-água discutida anteriormente.

As superfícies de resposta foram construídas buscando os valores preditos de seletividade nas condições otimizadas para o catalisador CuZrIn-cs. Para esse catalisador o modelo que apresentou o melhor ajuste entre todos os testados foi polinomial de segundo grau do tipo quadrático.

Utilizando esse modelo, a equação de regressão foi construída, a partir da qual as superfícies foram geradas. Os parâmetros de qualidade de ajuste foram calculados por meio de análise de variância (ANOVA) e os resultados se encontram na Tabela 30. Todos os cálculos foram realizados com confiabilidade estatística de $95 \%$.

A análise de variância permite notar que um valor próximo a $90 \%$ de toda a variação na resposta foi explicada adequadamente utilizando a equação de regressão gerada pelo modelo quadrático, o que pode ser confirmado pelo $\mathrm{R}^{2}$ obtido, pelo valor - $\mathrm{F}(5,5986)$ superior ao valorF tabelado $(3,74)$ e pelo valor-p menor que 0,05 , que atesta a confiabilidade estatística e a qualidade do ajuste do modelo gerado aos dados experimentais (BARROS NETO; SCARMINIO; BRUNS, 2010). 
Tabela 30. Análise de variância (ANOVA) para o modelo quadrático utilizando o catalisador CuCeIn-cs e as respostas do planejamento tipo compósito central.

\begin{tabular}{cccccc}
\hline $\begin{array}{c}\text { Fonte de } \\
\text { Variação }\end{array}$ & $\begin{array}{c}\text { Soma } \\
\text { Quadrática }\end{array}$ & $\begin{array}{c}\text { Graus de } \\
\text { Liberdade }\end{array}$ & $\begin{array}{c}\text { Média } \\
\text { Quadrática }\end{array}$ & Valor de F & Valor-p \\
\hline Regressão & $2,03 \times 10^{2}$ & 9 & 22,5085 & 5,5986 & 0,0167 \\
Residual & 28,1425 & 7 & 4,0204 & - & - \\
Falta de Ajuste & 27,5225 & 5 & 5,5045 & 17,7565 & 0,0542 \\
Erro puro & 0,62 & 2 & 0,3100 & - & - \\
SS Total & $2,31 \times 10^{2}$ & 16 & & & \\
$\mathrm{R}^{2}$ & 0,8780 & & & & \\
$\mathrm{R}^{2}$ explicável & 0,9973 & & & & \\
\hline
\end{tabular}

A equação de regressão baseada no modelo quadrático, é apresentada a seguir com as variáveis pressão, temperatura e velocidade espacial expressas como $\mathrm{P}, \mathrm{T}$ e VE, respectivamente.

$$
\begin{array}{r}
\mathrm{S}_{\mathrm{CH} 3 \mathrm{OH}}(\%)=\left[-856,4820+16,3031 \mathrm{P}+3,8533 \mathrm{~T}-1,5531 \mathrm{VE}-4,2212(\mathrm{P})^{2}-0,004(\mathrm{~T})^{2}\right. \\
\left.-0,0465(\mathrm{VE})^{2}-0,005(\mathrm{P} . \mathrm{T})+0,5583(\mathrm{P} . \mathrm{VE})+0,0022(\mathrm{~T} . \mathrm{VE})\right]
\end{array}
$$

Por meio da superfície de resposta, valores de seletividade ao metanol foram calculados para as combinações de pressão, temperatura e velocidade espacial não testadas experimentalmente gerando superfícies gráficas chamadas superfícies de resposta representadas na Figura 33.

Uma última observação muito importante a ser feita é que, em geral, os valores dos efeitos de cada variável sobre a seletividade ao metanol para os catalisadores "core-shell" foram consideravelmente menores do que os valores observados anteriormente para os catalisadores $\mathrm{Cu} / \mathrm{ZrO}_{2}-5 \%$ In e $\mathrm{Cu} / \mathrm{CeO}_{2}-5 \%$ In. Tal diferença é notável especialmente para o efeito da temperatura sobre o processo.

Isso implica no fato de que os catalisadores revestidos com sílica se mostram menos sensíveis a variações das condições reacionais, especialmente de temperatura, mantendo valores muito altos de seletividade ao metanol mesmo em condições nas quais os materiais 
$\mathrm{Cu} / \mathrm{ZrO}_{2}-5 \%$ In e $\mathrm{Cu} / \mathrm{CeO}_{2}-5 \%$ In geravam uma quantidade muito mais alta de monóxido de carbono.

Essa comprovação estatística do menor efeito da temperatura sobre a seletividade ao metanol quando se utilizou os catalisadores "core-shell" se mostra totalmente condizente com o que é reportado na literatura acerca do potencial que o revestimento poroso de sílica apresenta de minimizar a agregação das partículas em condições reacionais severas gerando resultados muito promissores em situações nas quais, catalisadores convencionais apresentam considerável queda de desempenho (CHAUDHURI; PARIA, 2012; GAWANDE et al., 2015; ZHANG, Q. et al., 2010).

Figura 33. Superfícies de resposta contendo a seletividade ao metanol para diferentes combinações das variáveis pressão, temperatura e velocidade espacial, utilizando o catalisador CuCeIn-cs.
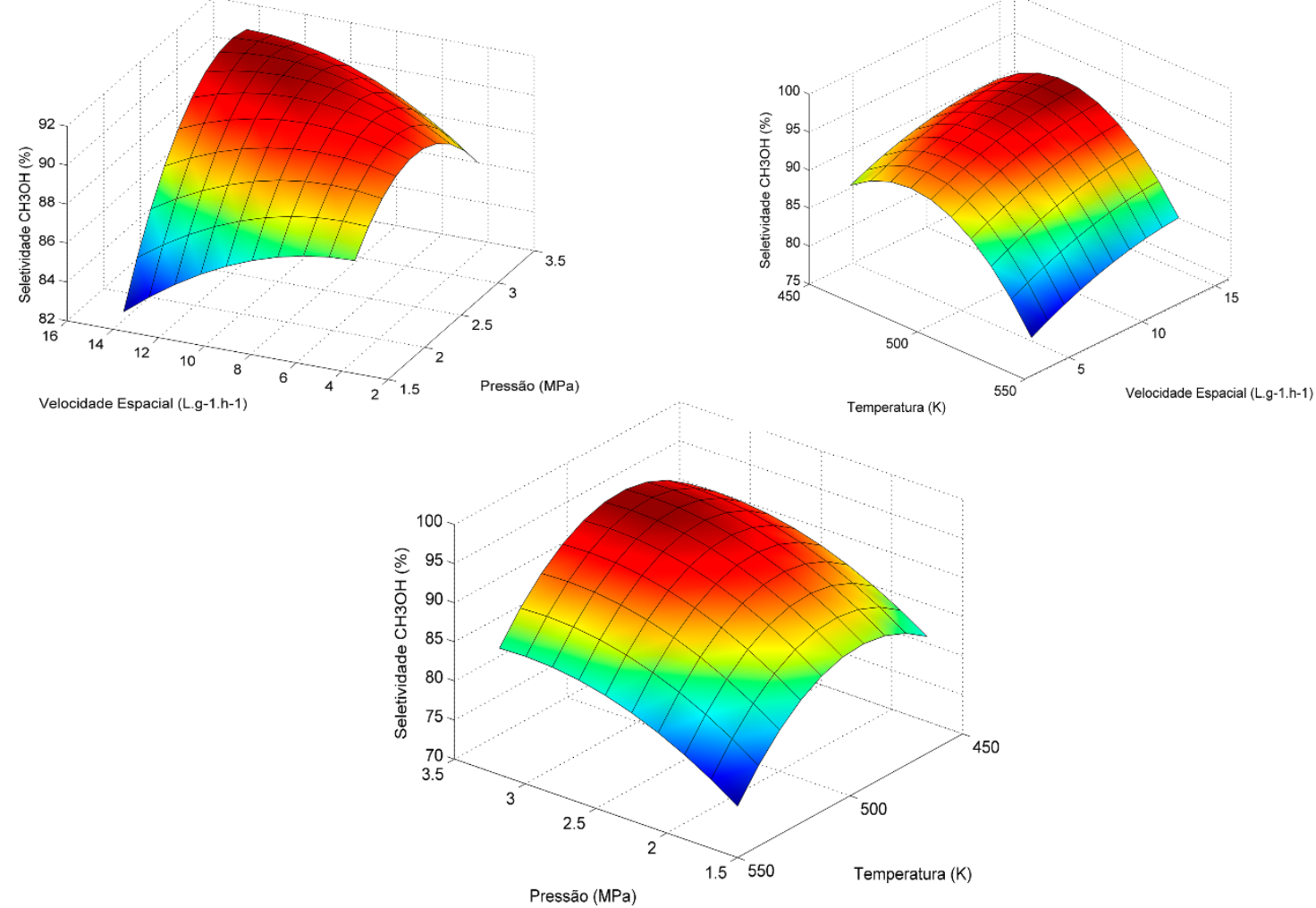

Após a otimização, foram calculadas as energias de ativação aparente para o metanol e monóxido de carbono por meio da equação de Arrhenius a partir da produtividade molar de ambos os produtos utilizando o catalisador CuZrIn-cs e CuCeIn-cs em várias condições de 
temperatura e mantendo-se a pressão e velocidade espacial constantes em $3 \mathrm{MPa}$ e $6 \mathrm{~L} \cdot \mathrm{g}^{-1} \cdot \mathrm{h}^{-1}$ (Chang, 2017). Os resultados se encontram na Figura 34.

\section{Cálculo das Energias de Ativação Aparentes}

Figura 34. Gráficos de Arrhenius para a produção de $\mathrm{CH}_{3} \mathrm{OH}$ e $\mathrm{CO}$ utilizando os catalisadores $\mathrm{Cu} / \mathrm{ZrO}_{2}-5 \% \mathrm{In}, \mathrm{Cu} / \mathrm{CeO}_{2}-5 \% \mathrm{In}, \mathrm{CuZrIn}-\mathrm{cs}$ e CuCeIn-cs.
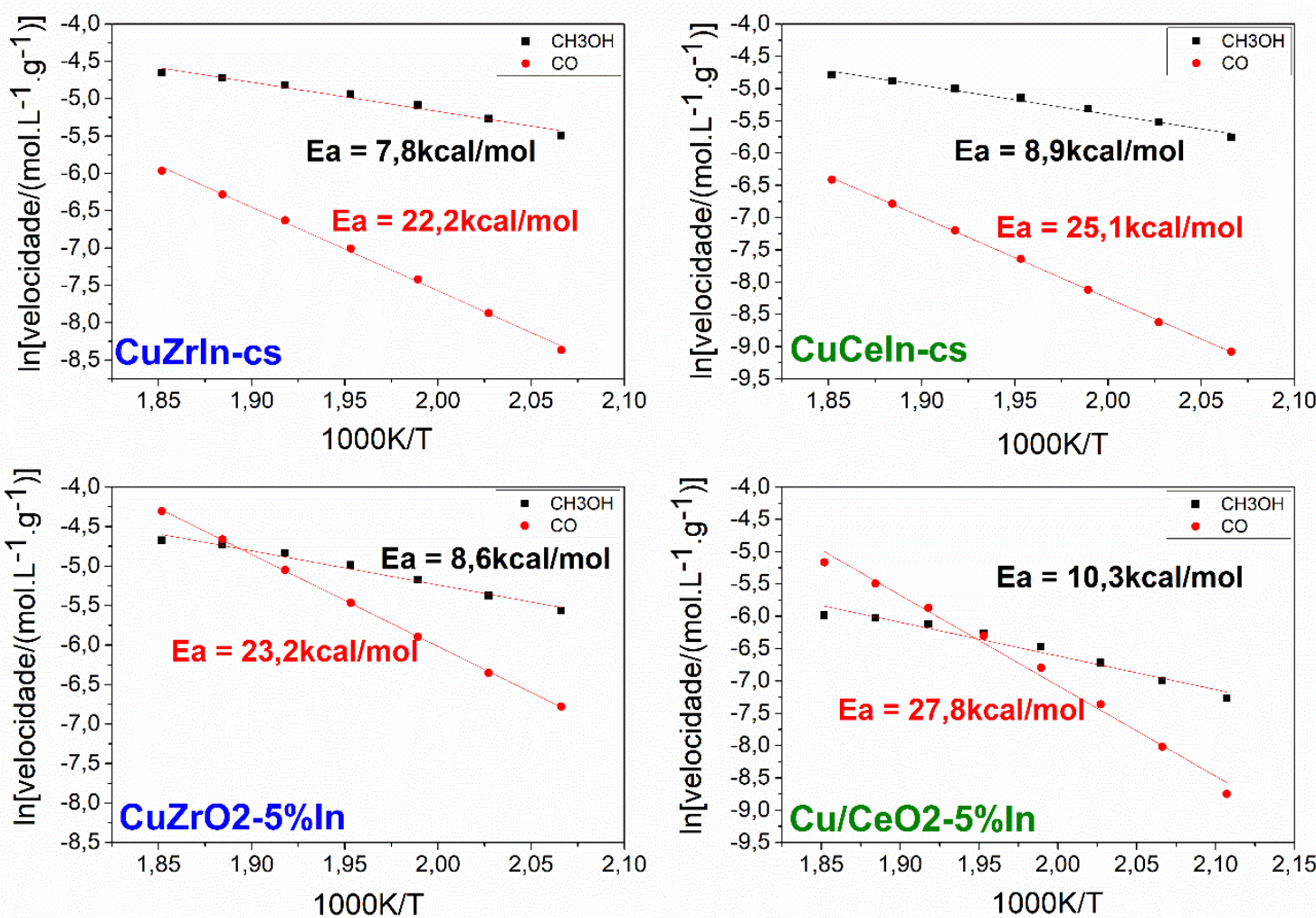

As energias de ativação do metanol produzido na superfície dos catalisadores CuZrIncs e $\mathrm{CuCeIn}$-cs foram ainda menores que as calculadas para os materiais estudados em etapas anteriores desse projeto, como pode ser visto pelos resultados presentes na Figura 34.

Essa observação sugere a maior eficiência catalítica dos materiais revestidos e reforça as evidências de que a arquitetura core-shell trouxe melhorias significativas aos materiais.

É importante destacar que todos os materiais contendo índio em sua composição, sejam revestidos ou não, apresentaram valores de energia de ativação menores para o metanol do que para o monóxido de carbono, algo que só foi verificado na literatura para catalisadores que apresentaram alta seletividade ao metanol (CHANG; WANG; CHEN, 2017). 


\section{CONCLUSÕES}

A primeira etapa deste trabalho foi dedicada a estudar os efeitos causados pela presença de átomos de índio em catalisadores baseados em cobre e zircônia e cobre em céria.

Foi verificado que a presença de índio levou a efeitos significativos de aumento da seletividade ao metanol em virtude de sua capacidade já estabelecida de diminuir os valores de energia de ativação para algumas etapas específicas de hidrogenação que se mostram muito elevadas para a maioria dos catalisadores utilizados, inviabilizando a geração de metanol com alta seletividade.

Além disso, superfícies contendo índio levam a maiores valores de energia de adsorção das moléculas de CO do que é observado para outros materiais, desfavorecendo sua dessorção como um produto indesejado e as mantendo adsorvidas na superfície até que etapas posteriores de hidrogenação realizem sua conversão em metanol.

Além disso, a introdução de índio nesses materiais levou a um aumento da basicidade apresentada em virtude da geração de vacâncias de átomos de oxigênio que surgiram devido tanto aos efeitos de dopagem com cátions de menor valência quanto ao menor tamanho médio de partícula apresentado pelos catalisadores promovidos que levam a uma diminuição na energia necessária para a formação de vacâncias de átomos de oxigênio.

Tais vacâncias, por atuarem como fortes sítios básicos de Lewis, contribuem para melhor interação entre a superfície do catalisador e moléculas ácidas adsorvidas como $\mathrm{CO}_{2} \mathrm{e}$ muitos dos intermediários gerados no processo.

Devido a menor área metálica e menor porcentagem de óxido na superfície, menores valores de conversão foram obtidos. No caso dos materiais contendo zircônia isso levou a menores produtividades molares enquanto para a céria, o aumento na seletividade foi tão significativo que a diminuição na conversão não foi suficiente para prejudicar as produtividades molares, que se mostraram maiores para os catalisadores promovidos com índio. Em todos os materiais promovidos, houve redução significativa da geração de monóxido de carbono.

Já a segunda etapa foi dedicada ao estudo do desempenho de catalisadores com estrutura core-shell comparadas aos catalisadores que apresentaram melhor desempenho na etapa anterior. O objetivo da utilização de catalisadores revestidos por sílica porosa envolvia minimizar a sinterização das partículas durante as etapas de tratamento térmico e testes reacionais em altas temperaturas, de modo que as propriedades como área metálica e tamanho de partícula não sofressem alterações negativas significativas. 
Os resultados evidenciaram um desempenho consideravelmente superior aos catalisadores sem revestimento em praticamente todas as condições testadas, com destaque para aquelas nas quais as temperaturas foram mantidas em seus valores mais altos. Nessa última condição, o desempenho dos catalisadores core-shell foi muito superior aos materiais não revestidos. A presença de índio novamente contribui para altas seletividades.

Além disso, a baixa dimensão das partículas e alta homogeneidade das mesmas levaram a valores expressivos de basicidade devido ao fato de que a energia livre de superfície nessas condições é mais alta, diminuindo a energia necessária para a formação de vacâncias de átomos de oxigênio. Com isso, foram obtidos altos valores de seletividade ao metanol mesmo em condições pouco favoráveis a esse composto, como na temperatura de $543 \mathrm{~K}$.

Para os catalisadores baseados em zircônia, os valores de conversão foram muito próximos aos obtidos pelo material $\mathrm{Cu} / \mathrm{ZrO}_{2}-5 \%$ In uma vez que os valores de área metálica se mostraram muito próximos. De qualquer modo, os maiores valores de seletividade ao metanol obtidos pelo catalisador CuZrIn-cs possibilitaram valores de produtividade molar mais elevados.

Já para os materiais baseados em céria, a área metálica foi muito superior à apresentada pelo material $\mathrm{Cu} / \mathrm{CeO}_{2}-5 \%$ In, o que possibilitou não somente produtividade muito maior que a obtida com o catalisador não revestido como também, pela primeira vez, que valores de produtividade molar próximos aos alcançados com os materiais de zircônia fossem obtidos.

Por fim, foi possível verificar que a utilização de índio como promotor foi muito eficiente no aumento da seletividade ao metanol reduzindo expressivamente os valores de $\mathrm{CO}$ formados.

Além disso, a estratégia de encapsulamento dos catalisadores com revestimentos poroso de sílica foi fundamental para que se obtivesse um desempenho catalítico notavelmente superior, especialmente no que se refere aos catalisadores baseados em céria, para os quais, a melhoria dos resultados foi mais significativa.

Dessa forma, é possível concluir que as estratégias de modificação da natureza química do catalisador, por meio da introdução de átomos de índio, e também aquelas de natureza estrutural, com a aplicação de um revestimento poroso inerte de sílica, contribuíram fortemente para o melhor desempenho dos catalisadores estudados. 


\section{REFERÊNCIAS BIBLIOGRÁFICAS}

ÁGUILA, G. et al. A novel method for preparing high surface area copper zirconia catalysts. Influence of the preparation variables. Applied Catalysis A: General, v. 360, n. 1, p. 98-105, 2009.

AHMADI, M.; MISTRY, H.; ROLDAN CUENYA, B. Tailoring the Catalytic Properties of Metal Nanoparticles via Support Interactions. Journal of Physical Chemistry Letters, v. 7, n. 17, p. 3519-3533, 2016.

AMADINE, O. et al. Effect of calcination temperature on the structure and catalytic performance of copper-ceria mixed oxide catalysts in phenol hydroxylation. $R S C A d v$., v. 7, p. 12586-12597, 2017.

AMOLI, V. et al. Indium oxide nanocluster doped $\mathrm{TiO} 2$ catalyst for activation of molecular O2. RSC Adv., v. 5, p. 67089-67092, 2015.

ANWAR, M.; GHAURI, I. M.; SIDDIQI, S. A. An XPS study of amorphous thin films of mixed oxides In2O3-SnO2 system deposited by co-evaporation. Int. J. Mod. Phys. B, v. 21, p. 1027-1042, 2007.

ARENA, F. et al. Synthesis, characterization and activity pattern of $\mathrm{Cu}-\mathrm{ZnO} / \mathrm{ZrO} 2$ catalysts in the hydrogenation of carbon dioxide to methanol. J. Catal., v. 249, p. 185-194, 2007.

AZDAD, Z. et al. Valence band behaviour of zirconium oxide, Photoelectron and Auger spectroscopy study. Scientific Reports, v. 8, n. 1, p. 1-6, 2018.

BAI, A. et al. Facile synthesis of core-shell structured ZrO2@SiO2 via a modified Stöber method. Ceramics International, v. 42, n. 6, p. 7583-7592, 2016.

BANSODE, A. et al. Impact of $\mathrm{K}$ and $\mathrm{Ba}$ promoters on $\mathrm{CO} 2$ hydrogenation over $\mathrm{Cu} / \mathrm{A} 12 \mathrm{O} 3$ catalyst at high pressure. Catal. Sci. Technol., v. 3, p. 767-778, 2013. 
BARROS NETO, B.; SCARMINIO, I. S.; BRUNS, R. E. Como Fazer Experimentos: Pesquisa e Desenvolvimento na Ciência e na Indústria. 4. ed. [S.1.]: Bookman, 2010.

BÊCHE, E. et al. Ce 3d XPS investigation of cerium oxides and mixed cerium oxide (CexTiyOz ). Surf. Interface Anal., v. 40, p. 264-267, 2008.

BERSANI, M. et al. Combined EXAFS , XRD , DRIFTS , and DFT Study of Nano CopperBased Catalysts for CO2 Hydrogenation. ACS Catal., v. 6, p. 5823-5833, 2016.

BIELZ, T et al. Water-Gas Shift and Formaldehyde Reforming Activity Determined by Defect Chemistry of Polycrystalline In2O3. J. Phys. Chem. C, v. 115, p. 6622-6628, 2011.

BIELZ, THOMAS et al. Hydrogen on in2O3: Reducibility, bonding, defect formation, and reactivity. Journal of Physical Chemistry C, v. 114, n. 19, p. 9022-9029, 2010.

BONURA, G. et al. Role of the ceria promoter and carrier on the functionality of $\mathrm{Cu}$-based catalysts in the CO2-to-methanol hydrogenation reaction. Catalysis Today, v. 171, n. 1, p. 251256, 2011.

CALliSTER JR., W. D.; RETHWISCH, D. G. Materials Science and Engineering - An Introduction. 8. ed. [S.1.]: John Wiley and Sons, Inc., 2009.

CHANG, K.; WANG, T.; CHEN, J. G. Hydrogenation of CO2 to methanol over CuCeTiOx catalysts. Appl. Catal B-Environ., v. 206, p. 704-711, 2017.

CHARY, K. V. R.; SAGAR, G. V.; SRIKANTH, C. S. Characterization and Catalytic Functionalities of Copper Oxide Catalysts Supported on Zirconia. J. Phys. Chem. B, v. 111, p. 543-550, 2007.

CHAUDHURI, R. G.; PARIA, S. Core/Shell Nanoparticles : Classes, Properties, Synthesis Mechanisms, Characterization, and Applications. Chem. Rev., v. 112, p. 2373-2433, 2012.

CHEN, M. et al. Supported indium oxide as novel efficient catalysts for dehydrogenation of 
propane with carbon dioxide. Appl. Catal. A-Gen., v. 377, p. 35-41, 2010.

CHENG, Z.; LO, C. S. Mechanistic and microkinetic analysis of CO2 hydrogenation on ceria. Physical Chemistry Chemical Physics, v. 18, n. 11, p. 7987-7996, 2016.

CHOI, E. J. et al. Hydrogenation of $\mathrm{CO} 2$ to methanol over $\mathrm{Pd}-\mathrm{Cu} / \mathrm{CeO} 2$ catalysts. Mol. Catal., v. 434, p. 146-153, 2017.

CHUAH, G. K. et al. The influence of preparation conditions on the surface area of zirconia. Applied Catalysis A: General, v. 145, n. 1-2, p. 267-284, 1996.

CONTRERAS, J. L. et al. Synthesis of Pt/A12O3 catalyst using mesoporous alumina prepared with a cationic surfactant. Catal. Today, v. 250, p. 72-86, 2015.

CUSHING, B. L.; KOLESNICHENKO, V. L.; O'CONNOR, C. J. Recent advances in the liquid-phase syntheses of inorganic nanoparticles. Chemical Reviews, v. 104, n. 9, p. 38933946, 2004.

DA SILVA, R. J. et al. Synthesis of methanol and dimethyl ether from the CO2 hydrogenation over $\mathrm{Cu} \cdot \mathrm{ZnO}$ supported on Al2 and Nb2. Journal of CO2 Utilization, v. 15, p. 83-88, 2016.

DIMITRIOU, I. et al. Carbon dioxide utilisation for production of transport fuels: Process and economic analysis. Energy and Environmental Science, v. 8, n. 6, p. 1775-1789, 2015.

DONLEY, C. et al. Characterization of Indium-Tin Oxide Interfaces Using X-ray Photoelectron Spectroscopy and Redox Processes of a Chemisorbed Probe Molecule : Effect of Surface Pretreatment Conditions. Langmuir, v. 18, p. 450-457, 2002.

DUYAR, M. S.; TREVIÑO, M. A. A.; FARRAUTO, R. J. Dual function materials for CO2 capture and conversion using renewable H2. Applied Catalysis B: Environmental, v. 168-169, p. $370-376,2015$.

ESPOSITO, S. et al. New insight into the preparation of copper/zirconia catalysts by sol-gel 
method. Applied Catalysis A: General, v. 403, n. 1-2, p. 128-135, 2011.

FIORDALISO, E. M. et al. Intermetallic GaPd2 Nanoparticles on $\mathrm{SiO} 2$ for Low-Pressure CO2 Hydrogenation to Methanol: Catalytic Performance and In Situ Characterization. ACS Catal., v. 5, p. 5827-5836, 2015.

FUJIWARA, K. et al. Influences of particle size and crystallinity of highly loaded $\mathrm{CuO} / \mathrm{ZrO} 2$ on CO2 hydrogenation to methanol. AIChE Journal, v. 65, n. 12, 2019.

$\mathrm{GAO}$, P. et al. Influence of $\mathrm{Zr}$ on the performance of $\mathrm{Cu} / \mathrm{Zn} / \mathrm{Al} / \mathrm{Zr}$ catalysts via hydrotalcitelike precursors for $\mathrm{CO} 2$ hydrogenation to methanol. Journal of Catalysis, v. 298, p. 51-60, 2013.

GAWANDE, M. B. et al. Core-shell nanoparticles: synthesis and applications in catalysis and electrocatalysis. Chem. Soc. Rev., v. 44, n. 21, p. 7540-7590, 2015.

GOEPPERT, A. et al. Recycling of carbon dioxide to methanol and derived products - closing the loop. Chem. Soc. Rev., v. 43, p. 7995-8048, 2014.

GRACIANI, J. et al. Highly active copper-ceria and copper-ceria-titania catalysts for methanol synthesis from CO2. v. 345, p. 546-550, 2014.

GUO, X. et al. The influence of La doping on the catalytic behavior of $\mathrm{Cu} / \mathrm{ZrO} 2$ for methanol synthesis from CO2 hydrogenation. J. Mol. Catal. A-Chem., v. 345, p. 60-68, 2011.

HU, Q. et al. Aluminum-doped zirconia-supported copper nanocatalysts: Surface synergistic catalytic effects in the gas-phase hydrogenation of esters. ChemCatChem, v. 6, n. 12, p. 3501$3510,2014$.

HUNGRÍA, A. B. et al. Structural, Morphological, and Oxygen Handling Properties of Nanosized Cerium-Terbium Mixed Oxides Prepared by Microemulsion. Chemistry of Materials, v. 15, n. 22, p. 4309-4316, 2003. 
JADHAV, S. G. et al. Catalytic carbon dioxide hydrogenation to methanol: A review of recent studies. Chemical Engineering Research and Design, v. 92, n. 11, p. 2557-2567, 2014.

JIANG, H. et al. One-pot synthesis of mesoporous $\mathrm{Cu}-\gamma-\mathrm{Al} 2 \mathrm{O} 3$ as bifunctional catalyst for direct dimethyl ether synthesis. Microporous and Mesoporous Materials, v. 164, p. 3-8, 2012.

JUNG, C. R. et al. Selective oxidation of carbon monoxide over $\mathrm{CuO}-\mathrm{CeO} 2$ catalyst: Effect of hydrothermal treatment. Appl. Catal B-Environ., v. 84, p. 426-432, 2008.

KATTEL, S. et al. Optimizing Binding Energies of Key Intermediates for CO2 Hydrogenation to Methanol over Oxide-Supported Copper. J. Am. Chem. Soc., v. 138, p. 12440-12450, 2016.

KAVVADA, O. et al. Assessing location and scale of urban nonpotable water reuse systems for life-cycle energy consumption and greenhouse gas emissions. Environmental Science and Technology, v. 50, n. 24, p. 13184-13194, 2016.

KOUVA, S. et al. Review: Monoclinic zirconia, its surface sites and their interaction with carbon monoxide. Catalysis Science and Technology, v. 5, n. 7, p. 3473-3490, 2015.

KUMAR, S.; OJHA, A. K. Oxygen vacancy induced photoluminescence properties and enhanced photocatalytic activity of ferromagnetic $\mathrm{ZrO} 2$ nanostructures on methylene blue dye under ultra-violet radiation. Journal of Alloys and Compounds, v. 644, p. 654-662, 2015.

KYNDIAH, A. et al. A Multifunctional Interlayer for Solution Processed High Performance Indium Oxide Transistors. Sci. Rep., v. 8, p. 1-7, 2018.

LARMIER, K. et al. CO2 -to-Methanol Hydrogenation on Zirconia-Supported Copper Nanoparticles : Reaction Intermediates and the Role of the Metal - Support Interface. Angew. Chem. Int. Ed., v. 56, p. 1-7, 2017.

LI, L. et al. Highly selective hydrogenation of $\mathrm{CO} 2$ to methanol over $\mathrm{CuO}$ e $\mathrm{ZnO}$ e $\mathrm{ZrO} 2$ catalysts prepared by a surfactant-assisted co-precipitation method. Journal of Power Sources, v. 279 , p. $394-404,2015$. 
LI, W. et al. Facile synthesis of pure monoclinic and tetragonal zirconia nanoparticles and their phase effects on the behavior of supported molybdena catalysts for methanol-selective oxidation. Langmuir, v. 24, n. 15, p. 8358-8366, 2008.

LI, YAWEI; CHAN, S. H.; SUN, Q. Heterogeneous catalytic conversion of CO2: A comprehensive theoretical review. Nanoscale, v. 7, n. 19, p. 8663-8683, 2015.

LI, YEZHOU et al. Investigation of oxygen vacancy and photoluminescence in calcium tungstate nanophosphors with different particle sizes. Materials Research Bulletin, v. 50, p. 3641, 2014.

LI, YULIN et al. In situ preparation of mesoporous iron titanium catalysts by a CTAB-assisted process for NO reduction with NH3. Applied Catalysis A, General, v. 559, n. 1, p. 146-152, 2018.

LIANG, Q. et al. Oxygen activation on $\mathrm{Cu} / \mathrm{Mn}$-Ce mixed oxides and the role in diesel soot oxidation. Catalysis Today, v. 139, n. 1-2, p. 113-118, 2008.

LIAO, F. et al. Morphology-dependent interactions of $\mathrm{ZnO}$ with $\mathrm{Cu}$ nanoparticles at the materials' interface in selective hydrogenation of $\mathrm{CO} 2$ to $\mathrm{CH} 3 \mathrm{OH}$. Angewandte Chemie International Edition, v. 50, n. 9, p. 2162-2165, 2011.

LIN, X. et al. Evolution of oxygen vacancies in $\mathrm{MnOx}-\mathrm{CeO} 2$ mixed oxides for soot oxidation. Applied Catalysis B: Environmental, v. 223, p. 91-102, 2018.

LIU, C.; CUNDARI, T. R.; WILSON, A. K. CO 2 reduction on transition metal (Fe, Co, Ni, and $\mathrm{Cu}$ ) surfaces: In comparison with homogeneous catalysis. Journal of Physical Chemistry C, v. 116, n. 9, p. 5681-5688, 2012.

LIU, Y.; GOEBL, J.; YIN, Y. Templated synthesis of nanostructured materials. Chem. Soc. Rev., v. 42, p. 2473-3174, 2013. 
LOU, Y. et al. Promoting Effects of In2O3 on Co3O4 for CO Oxidation : Tuning O2 Activation and CO Adsorption Strength Simultaneously. ACS Catal., v. 4, p. 4143-4152, 2014.

$\mathrm{LU}$, X. et al. Initial reduction of $\mathrm{CO} 2$ on perfect and O-defective $\mathrm{CeO} 2$ (111) surfaces: Towards CO or COOH? RSC Advances, v. 5, n. 118, p. 97528-97535, 2015.

MA, L. et al. Indium-doped Co3O4 Nanorods for Catalytic Oxidation of CO and C3H6 towards Diesel Exhaust. Appl. Catal. B-Environ., v. 222, p. 44-58, 2017.

MACIEL, C. G. et al. Effect of nature of ceria support in $\mathrm{CuO} / \mathrm{CeO} 2$ catalyst for PROX-CO reaction. Fuel, v. 97, p. 245-252, 2012.

MARAGKAKI, A. E. et al. Pilot-scale anaerobic co-digestion of sewage sludge with agroindustrial by-products for increased biogas production of existing digesters at wastewater treatment plants. Waste Management, v. 59, p. 362-370, 2017.

MARTIN, O. et al. Indium Oxide as a Superior Catalyst for Methanol Synthesis by CO2 Hydrogenation. Angew. Chem. Int. Ed., v. 55, p. 6261-6265, 2016.

MCFARLAND, E. W.; METIU, H. Catalysis by Doped Oxides. Chem. Rev., v. 113, p. 43914427, 2013.

MEKKI-BERRADA, A. et al. Design of amphoteric mixed oxides of zinc and Group 3 elements (Al, Ga, In): migration effects on basic features. Phys. Chem. Chem. Phys., v. 14, p. 4155-4161, 2012.

MOULDER, J. F. et al. Handbook of X-ray photoelectron spectroscopy: a reference book of standard spectra for identification and interpretation of XPS data. . [S.1: s.n.]. , 1995

MUNNIK, P.; DE JONGH, P. E.; DE JONG, K. P. Recent Developments in the Synthesis of Supported Catalysts. Chemical Reviews, v. 115, n. 14, p. 6687-6718, 2015.

MUSIĆ, S.; FILIPOVIĆ-VINCEKOVIĆ, N.; SEKOVANIĆ, L. Precipitation of amorphous 
$\mathrm{SiO} 2$ particles and their properties. Brazilian Journal of Chemical Engineering, v. 28, n. 1, p. 89-94, 2011.

NAIK, M. Z.; SALKER, A. V. Effect of indium doping on magnetic properties of cerium oxide nanoparticles. Mater. Chem. Phys., v. 212, p. 336-342, 2018.

NUNES, C. A. et al. Chemoface: a Novel Free User-Friendly Interface for Chemometrics. v. 23, n. 11, p. 2003-2010, 2012.

PAN, C. et al. Journal of the Taiwan Institute of Chemical Engineers Tuning / exploiting Strong Metal-Support Interaction ( SMSI ) in Heterogeneous Catalysis. J. Taiwan. Inst. Chem. E., v. 74, p. 154-186, 2017.

POROSOFF, M. D.; YAN, B.; CHEN, J. G. Catalytic reduction of CO2 by $\mathrm{H} 2$ for synthesis of CO, methanol and hydrocarbons: challenges and opportunities. Energ. Environ. Sci., v. 9, p. $62-73,2015$.

PORTHA, J.-F. et al. Kinetics of Methanol Synthesis from Carbon Dioxide Hydrogenation over Copper - Zinc Oxide Catalysts. Ind. Eng. Chem. Res., v. 56, p. 13133-13145, 2017.

PUSHPARAJ, S. S. C. et al. How the Method of Synthesis Governs the Local and Global Structure of Zinc Aluminum Layered Double Hydroxides. Journal of Physical Chemistry C, v. 119, n. 49, p. 27695-27707, 2015.

RODRIGUEZ, J. A. et al. Hydrogenation of CO2 to Methanol : Importance of Metal-Oxide and Metal-Carbide Interfaces in the Activation of $\mathrm{CO} 2$ Hydrogenation of $\mathrm{CO} 2$ to Methanol: Importance of Metal-Oxide and Metal-Carbide Interfaces in the Activation of CO2. ACS Catal., v. 5, p. 6696-6706, 2015.

ROMEO, M.; FALLAH, J. EL; NORMAND, F. LE. XPS Study of the Reduction of Cerium Dioxide. Surf. Interface Anal., v. 20, p. 508-512, 1993.

ROUQUEROL, F. et al. Adsorption by powders and porous solids: Principles, methodology 
and applications. $2^{\circ}$ ed. [S.1.]: Elsevier, 2014.

RUI, N. et al. CO2 hydrogenation to methanol over $\mathrm{Pd} / \mathrm{In} 2 \mathrm{O} 3$ : effects of $\mathrm{Pd}$ and oxygen vacancy. Appl. Catal B-Environ., v. 218, p. 488-497, 2017.

SAGAR, G. V. et al. Dispersion and reactivity of copper catalysts supported on $\mathrm{Al} 2 \mathrm{O} 3-\mathrm{ZrO} 2$. Journal of Physical Chemistry B, v. 110, n. 28, p. 13881-13888, 2006.

SENANAYAKE, S. D. et al. Hydrogenation of $\mathrm{CO} 2$ to Methanol on $\mathrm{CeOx} / \mathrm{Cu}(111)$ and $\mathrm{ZnO} / \mathrm{Cu}(111)$ Catalysts: Role of the Metal-Oxide Interface and Importance of Ce3+ Sites. Journal of Physical Chemistry C, v. 120, n. 3, p. 1778-1784, 2016.

SHI, Z.; TAN, Q.; WU, D. A Novel Core - Shell Structured CuIn@SiO2 Catalyst for CO2 Hydrogenation to Methanol. React. Kinet. Mech. Cat., v. 65, n. 3, p. 1047-1058, 2018.

SIMS, C. M. et al. Approaches for the quantitative analysis of oxidation state in cerium oxide nanomaterials. Nanotechnology, v. 30, p. 1-14, 2019.

STRUNK, J. et al. Au/ZnO as catalyst for methanol synthesis: The role of oxygen vacancies. Applied Catalysis A: General, v. 359, n. 1-2, p. 121-128, 2009.

STUDT, F. et al. Discovery of a Ni-Ga catalyst for carbon dioxide reduction to methanol. Nature Chemistry, v. 6, n. 4, p. 320-324, 2014.

SUN, L.; TIAN, W.-H.; LIU, X.-Q. Magnesia-Incorporated Mesoporous Alumina with Crystalline Frameworks : A Solid Strong Base Derived from Direct Synthesis. J. Phys. Chem. C, v. 113, p. 19172-19178, 2009.

TETERIN, Y. A. et al. The XPS spectra of cerium compounds containing oxygen. J. Electron. Spectrosc., v. 91, p. 275-279, 1998.

THOMAS, J. et al. Synthesis of cobalt ferrite nanoparticles by constant $\mathrm{pH}$ co-precipitation and their high catalytic activity in CO oxidation. New Journal of Chemistry, v. 41, n. 15, p. 7356- 
$7363,2017$.

THOMAS, J. M. Heterogeneous catalysis and the challenges of powering the planet, securing chemicals for civilised life, and clean efficient utilization of renewable feedstocks. ChemSusChem, v. 7, n. 7, p. 1801-1832, 2014.

TILLEY, R. J. D. Understanding Solids: The Science of Materials. 2. ed. [S.1.]: John Wiley and Sons, Inc., 2004.

UD DIN, I. et al. Synthesis, characterization and activity pattern of carbon nanofibers based copper/zirconia catalysts for carbon dioxide hydrogenation to methanol: Influence of calcination temperature. Journal of Power Sources, v. 274, p. 619-628, 2015.

WANG, L. C. et al. Structural evolution and catalytic properties of nanostructured $\mathrm{Cu} / \mathrm{ZrO} 2$ catalysts prepared by oxalate gel-coprecipitation technique. Journal of Physical Chemistry C, v. 111, n. 44, p. 16549-16557, 2007.

WANG, WEI et al. Recent advances in catalytic hydrogenation of carbon dioxide. Chem. Soc. Rev., v. 40, p. 3703-3727, 2011.

WANG, WEIWEI et al. $\mathrm{CO} 2$ hydrogenation to methanol over $\mathrm{Cu} / \mathrm{CeO} 2$ and $\mathrm{Cu} / \mathrm{ZrO} 2$ catalysts: Tuning methanol selectivity via metal-support interaction. Journal of Energy Chemistry, v. 40, p. $22-30,2020$.

WANG, X. M.; LORIMER, G.; XIAO, P. Solvothermal synthesis and processing of yttriastabilized zirconia nanopowder. Journal of the American Ceramic Society, v. 88, n. 4, p. 809$816,2005$.

WOLF, A.; JESS, A.; KERN, C. Syngas Production via Reverse Water-Gas Shift Reaction over a Ni-A12O3 Catalyst: Catalyst Stability, Reaction Kinetics, and Modeling. Chem. Eng. Technol., v. 39, p. 1040-1048, 2016.

XIE, R. et al. Controlled Preparation of Co3O4@porous -SiO2 Nanocomposites for Fischer - 
Tropsch Synthesis. Catal. Lett., v. 144, p. 516-523, 2014.

YANG, H. et al. Core-shell structured $\mathrm{Cu} @ \mathrm{~m}-\mathrm{SiO} 2$ and $\mathrm{Cu} / \mathrm{ZnO} @ \mathrm{~m}-\mathrm{SiO} 2$ catalysts for methanol synthesis from CO2 hydrogenation. Catal. Commun., v. 84, p. 56-60, 2016.

YE, J. et al. Active Oxygen Vacancy Site for Methanol Synthesis from CO2 Hydrogenation on In2O3 ( 110 ): A DFT Study. ACS Catal., v. 3, p. 1296-1306, 2013.

YE, J.; LIU, C.; GE, Q. DFT Study of CO2 Adsorption and Hydrogenation on the In2O3 Surface. J. Phys. Chem. C, v. 116, p. 7817-7825, 2012.

ZABILSKIY, M. et al. Nanoshaped $\mathrm{CuO} / \mathrm{CeO} 2$ Materials : Effect of the Exposed Ceria Surfaces on Catalytic Activity in N2O Decomposition Reaction. ACS Catal., v. 5, p. 5357$5365,2015$.

ZHANG, Q. et al. Surface-protected etching of mesoporous oxide shells for the stabilization of metal nanocatalysts. Advanced Functional Materials, v. 20, n. 14, p. 2201-2214, 2010.

ZHANG, R. et al. Gold supported on ceria nanotubes for CO oxidation. Appl. Surf. Sci., v. 416, p. 183-190, 2017.

ZHU, H. et al. Be12 O12 nano-cage as a promising catalyst for $\mathrm{CO} 2$ hydrogenation. Scientific Reports, v. 7, n. September 2016, p. 1-7, 2017. 